Florida International University FIU Digital Commons

\title{
The Individual and Interactive Effects of Nitrogen and Phosphorus Enrichment on Coral Reefs
}

Andrew A. Shantz

shantz.a@gmail.com

DOI: $10.25148 /$ etd.FIDC000262

Follow this and additional works at: https://digitalcommons.fiu.edu/etd

Part of the Comparative and Evolutionary Physiology Commons, Ecology and Evolutionary Biology Commons, and the Marine Biology Commons

\section{Recommended Citation}

Shantz, Andrew A., "The Individual and Interactive Effects of Nitrogen and Phosphorus Enrichment on Coral Reefs" (2016). FIU Electronic Theses and Dissertations. 2462.

https://digitalcommons.fiu.edu/etd/2462 


\title{
FLORIDA INTERNATIONAL UNIVERSITY
}

Miami, Florida

\section{THE INDIVIDUAL AND INTERACTIVE EFFECTS OF NITROGEN AND PHOSPHORUS ENRICHMENT ON CORAL REEFS}

\author{
A dissertation submitted in partial fulfillment of \\ the requirements for the degree of \\ DOCTOR OF PHILOSOPHY \\ in \\ BIOLOGY \\ by
}

Andrew A. Shantz 
To: Dean Michael R. Heithaus

College of Arts, Sciences and Education

This dissertation, written by Andrew A. Shantz, and entitled The Individual and Interactive Effects of Nitrogen and Phosphorus Enrichment on Coral Reefs, having been approved in respect to style and intellectual content, is referred to you for judgment.

We have read this dissertation and recommend that it be approved.

Elizabeth P. Anderson

Craig A. Layman

James W. Fourqurean

Randi D. Rotjan

Deron E. Burkepile, Major Professor

Date of Defense: March 24, 2016

The dissertation of Andrew A. Shantz is approved.

Dean Michael R. Heithaus

College of Arts, Sciences and Education

Andrés G. Gil

Vice President of Research and Economic Development and Dean of the University Graduate School

Florida International University, 2016 


\section{COPYRIGHT PAGE}

The chapters listed below have been published in peer-reviewed journals. The journals "Ecology", and "Ecological Applications" published by the Ecological Society of America allow use of published articles for educational use at the home institution, Florida International University. Blackwell Publishing allows authors to use articles published in "Ecology Letters" in future works and publications so long as the original work is properly cited. Chapters II, IV, and VI have been formatted for publication in their respective journals. Chapter III is currently in review in the "Journal of Experimental Marine Biology and Ecology" and Chapter IV is currently in review in the journal "Coral Reefs". Both chapters have been formatted according to the publication guidelines of the respective journals.

\section{CHAPTER II}

Shantz AA and Burkepile DE (2014) Context-dependent effects of nutrient loading on the coral-algal mutualism. Ecology 95: 1995-2005.

CHAPTER III

Shantz AA, Ladd MC, Burkepile DE. Species-specific differences in the growth and photobiology of three Caribbean corals under nitrate, ammonium, and phosphorus enrichment. In Review, Journal of Experimental Marine Biology and Ecology.

\section{CHAPTER IV}

Shantz AA, Ladd MC, Burkepile DE. Enrichment-induced changes in algal nitrogen and phosphorus content modify herbivore grazing. In Review, Coral Reefs.

\section{CHAPTER V}

Shantz AA, Ladd MC, Schrack E, Burkepile DE (2015) Fish-derived nutrient hotspots shape coral reef benthic communities. Ecological Applications 25: 2142-2152.

\section{CHAPTER VI}

Shantz AA, Lemoine NP, Burkepile DE (2016) Nutrient-loading alters the performance of key nutrient exchange mutualisms. Ecology Letters 19: 20-28.

All other materials $($ C Copyright 2016 by Andrew A. Shantz

All rights reserved. 


\section{DEDICATION}

For my family, friends, and loved ones, and everyone who helped me become who I am today. 


\section{ACKNOWLEDGMENTS}

Becoming a doctor is apparently not an easy task. All told, this dissertation consumed six years of my life and completing it entailed endeavors that ranged from seemingly monumental to trivially mundane, and everything in between. Through it all, I relied on more people than I can count for help and support. To each every one of you, I am grateful. That said, there are a few people who deserve special mention.

First and foremost are my family - who have been unwavering in their support, encouragement, and belief in me. Perhaps most importantly, they have been amazingly tolerant of all the stupid crap I've done over the years. I could not have done it without all of you.

I'd also like to thank my advisor, Deron Burkepile. He naively hired me as a field tech and for reasons I'll never know, kept me around for a PhD. He provided me with guidance, knowledge, funding, and the occasional gin and tonic. Most importantly, he gave me six years to develop my ideas, grow as a person and a scientist, and meet so many amazing people. Thanks D. Sorry I broke the boat. Twice.

I'd also like to say thank you to a few of those amazing people, in particular my lab-family - both past and present, who helped me with so much of this. Cate Pritchard has been a tremendous crutch for me since our first days working together as techs (at least since whenever she stopped hating me). She listens to my rants, calls me on my bullshit, makes things right when I need them to be, and occasionally beats me up. Thank you Cate. Mark Ladd, a.k.a. Fragile Mark, a.k.a... helped me in more ways than he has nicknames. He was there for the early morning dives, the late night lab work, and every other torturous project that sounded so good on paper. My liver is a small price to pay for your friendship Mark, you'll always be family. Sabrina, although not officially in the lab, you also deserve a special thanks here (and probably a few apologies as well). Thanks for putting up with us. I'm also immensely grateful to my one-time office mate and life-long friend, Nate "The Alley Cat" Lemoine. It's hard not to get choked up when I think of all the good times we had. Whether he was teaching me stats in our office, clogging his regulator with cheese-vomit during a dive, or smuggling me into a federal facility in 
the trunk of his car, he made me a better scientist and my PhD immensely more entertaining. I'm looking forward to our next adventure Nate. Alain Duran is probably the most hard working, generous person I've ever met and one hell of a salsa dancer. Thank you Alain for your friendship and all of the help with everything, I'm honored you named your son after me. Tom Adam, although the weak drinks you poured were not always be appreciated, the advice and insight you gave always was. Thank you. Mallory Rice brought tremendous energy and fun to the lab. Plus, she usually had good beer. She taught me that pine has no place in an apartment and tried to help me understand youths. I still have no idea what half of your text messages mean. Kelly Speare instantly earned my friendship by not just being a fellow coral-nerd, but also a fellow wino. She survived the Schnitzel House, Magnums, and the Sand Bar, and even managed to "acquire" a pair of sunglasses for me along the way. Thanks Kelly, that's good looking out. Cory Fuchs was usually the most reliable part of the Pile, but that may just be because she hadn't developed the proclivity for G\&T's that the rest of us have. Thanks for the years of help with field work Cory. James Stroud deserves a special mention in this group as well. He has been a great friend and a surprisingly talented ecologist to talk science with, something you would never suspect it if you bumped into him at noon with no pants on in a hotel hot tub. James, you made me a better ecologist and an only marginally worse human being, so I guess that's a win. I lift a plate to all of you and will always remember, Pile sticks together.

In addition, l'd also like to thank the following people: Becky, Rory, Adrienne \& the MM-95 Crew - a better field team has never been assembled. Adrienne, I forgive you for Steve and the Strawberry Vodka. Cach-alsa and MM-95's will flow next time we all meet. In a similar vein, thanks Gary for letting us turn the Gross Compound into a gross field lab. Many great memories were made there. Goose - I don't care what you have done for me lately, you're the best wingman I could ask for. M.R.B., R.J.W. \& J.S. - thanks for the good times, the science talk and everything else. Sorry I exposed myself to you J.S., I didn't realize anyone was in the kitchen. Also, sorry I exposed myself to J.S., M.R.B., I didn't realize anyone was in the kitchen. Microeye, I'll miss all the long drives up US 1, the Circle K pitstops and your amazing eye for cloud shapes. 
Keep the orange spray paint handy. Bree - you've been a great friend and saturation buddy. Thanks Green Diver. Also Roger, Otter and Ryan - thanks to each of you for helping me check one of my life goals off the bucket list, twice. Speaking of which, C.L., thanks for the first go around - bar that one time you left me at 110' with almost no air, you were a fantastic sat buddy. El Lobo, we went through some of the highest of highs in Bocas and lowest of lows in El Pit. There is no one l'd rather go four-wheeling through Panama in a rented Chevy Spark with than you. ¡Gracias mi amigo! S.T.G. you're the most lecherous human being l've ever met, thanks for all the good times and the Freddie Mercury koozie. Maggie, thank you for opening up your home to all us wayward souls and for the amazing Thanksgiving dinners. I look forward to the day when jai alai and thrift stores are once again an annual tradition. Vic - when the R/V Gilby was out of commision your boats often sucked and barely ran, but they were cheap and got the job done. JLo, thank you for showing me the ropes and Sal, thanks for taking a gamble on a doorman from the Pourhouse with a not-so-great GPA, you changed my life. M.A.S., thanks for starting this train rolling - I'll always be grateful. To everyone else who I don't have space to thank properly, please know that I appreciate everything you've done for me.

Finally, this is the part of the dissertation where I have to acknowledge my funders. A good portion of this research was supported by National Science Foundation grant OCE-1130786 to DEB \& RVT. The PADI Foundation, Explorer's Club, and Sigma Xi Society all gave me money along the way. A Dissertation Evidence Acquisition Fellowship from FIU allowed me to spend a semester in the field collecting data while an FIU Dissertation Year Fellowship let me write in peace to get this thing done. 
ABSTRACT OF THE DISSERTATION

THE INDIVIDUAL AND INTERACTIVE EFFECTS OF NITROGEN AND PHOSPHORUS ON CORAL REEFS

by

\author{
Andrew A. Shantz \\ Florida International University, 2016 \\ Miami, Florida \\ Professor Deron E. Burkepile, Major Professor
}

Human domination of global nutrient cycles is profoundly altering our planet. Yet on coral reefs, the effects of changing nutrient regimes have likely been over-simplified. This dissertation investigates the complexity of animal-nutrient interactions at the organismal level and explores how the outcomes of these interactions cascade through levels of biological organization. To do so, I examined the effects of nitrogen $(\mathrm{N})$ and phosphorus $(\mathrm{P})$ on corals and macroalgae, and how these effects in turn influenced reef communities and entire ecosystems. I show that $P$ consistently increases coral growth rates while $\mathrm{N}$ has variable, often negative, effects on coral growth. The majority of this variability was explained by the contrasting responses of corals to ammonium, which had negligible effects on coral growth, versus nitrate, which consistently had negative effects on corals. Experimental manipulations of nutrient regimes revealed that these effects could be attributed, in part, to increased damage to the photosynthetic components of the corals' endosymbionts. Nitrogen and P-enrichment also impacted macroalgae, increasing the nutrient content of algal tissue and in turn, consumption patterns of herbivorous fishes. Initial phase parrotfishes and juvenile surgeonfishes increased their feeding rates on algae rich in $\mathrm{N}$ and $\mathrm{P}$ respectively. However, adults from both species were irresponsive to algal nutrient content. At the community level, the effects of $\mathrm{N}$ and $\mathrm{P}$ on corals, algae and herbivory were linked to the development of distinct benthic communities. Algae cover was lower and coral growth rates higher around reef structures that were consistently enriched with $\mathrm{N}$ and $\mathrm{P}$ excreted by sheltering fishes. At the ecosystem level, I found that the responses of corals to $\mathrm{N}$ and $\mathrm{P}$ enrichment were 
similar to those of other nutrient-sharing mutualists. Across terrestrial and marine environments, I show that $\mathrm{N}$ and $\mathrm{P}$ enrichment consistently decouples mutualism performance, benefiting one partner at the expense of the other. Thus, collectively this dissertation demonstrates that the impacts of global nutrient loading resonate from single organisms through whole ecosystems. 


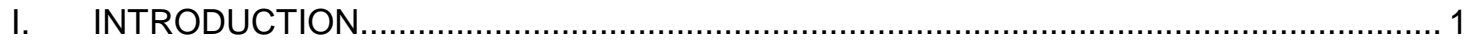

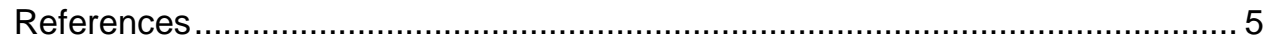

II. CONTEXT-DEPENDENT EFFECTS OF NUTRIENT LOADING ON THE CORAL-ALGAL

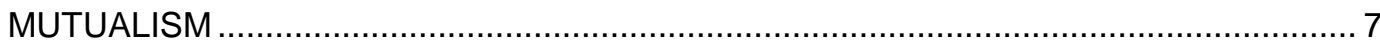

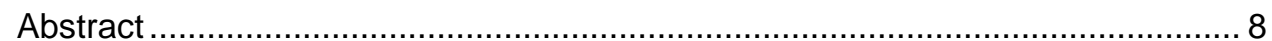

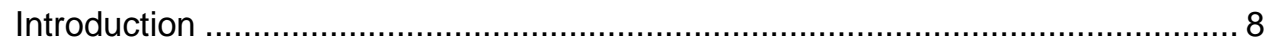

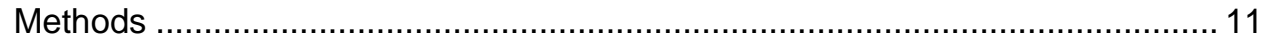

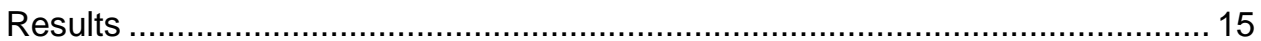

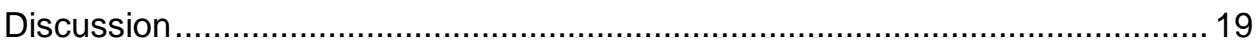

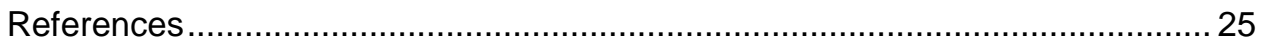

III. SPECIES-SPECIFIC DIFFERENCES IN THE GROWTH AND PHOTOBIOLOGY OF THREE CARIBBEAN CORALS UNDER NITRATE, AMMONIUM AND PHOSPHATE ENRICHMENT.

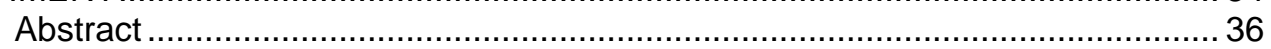

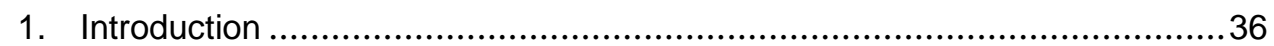

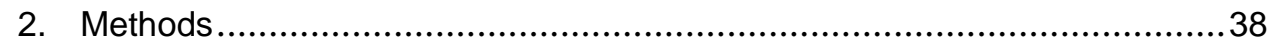

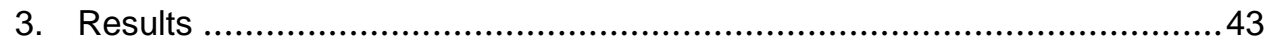

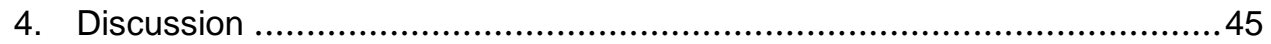

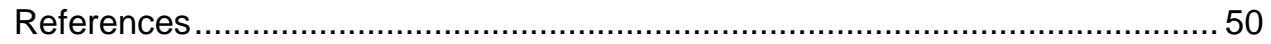

IV. ENRICHMENT-INDUCED CHANGES IN ALGAL NITROGEN AND PHOSPHORUS

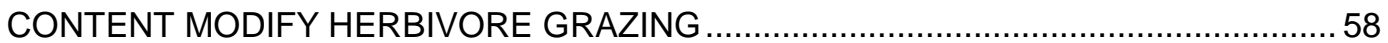

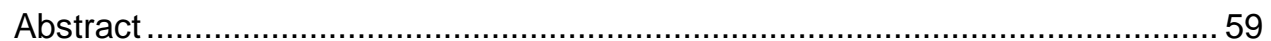

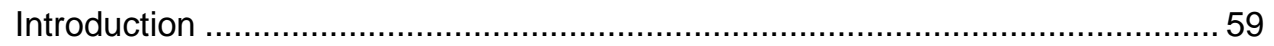

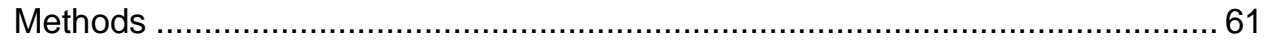

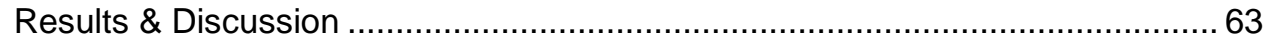

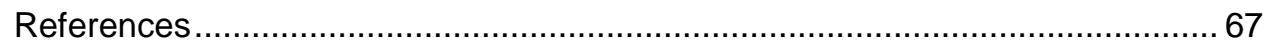

V. FISH-DERIVED NUTRIENT HOTSPOTS SHAPE CORAL REEF BENTHIC

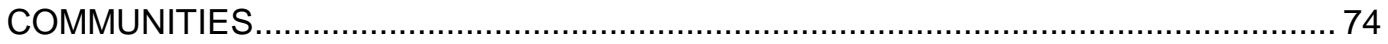

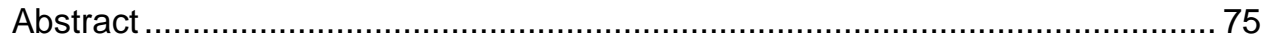

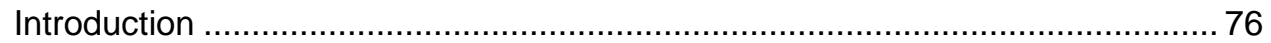

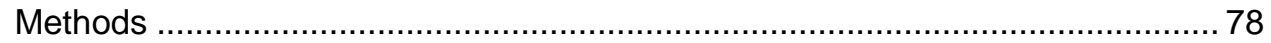

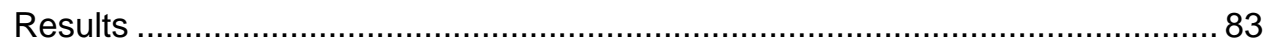

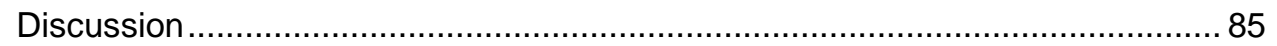

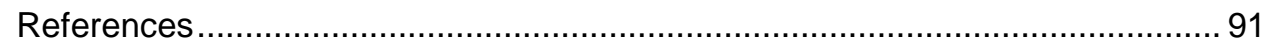

VI. NUTRIENT LOADING ALTERS THE PERFORMANCE OF KEY NUTRIENT

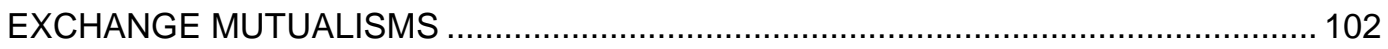

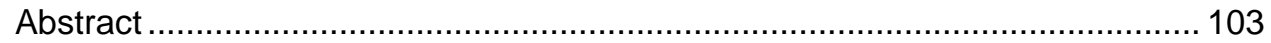

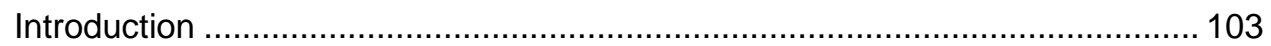

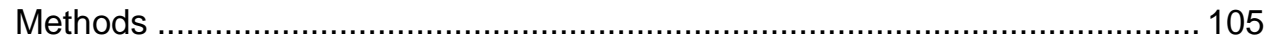

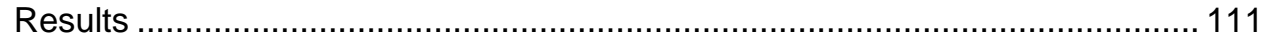

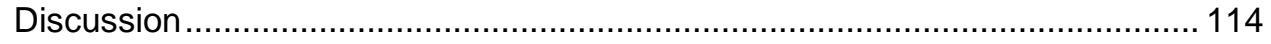

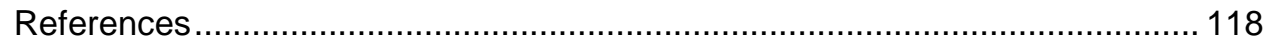

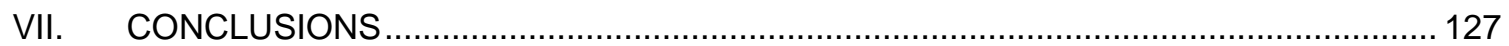

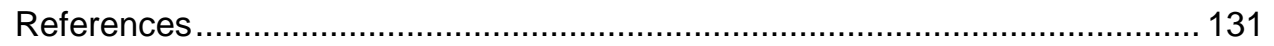


APPENDICES .......

134

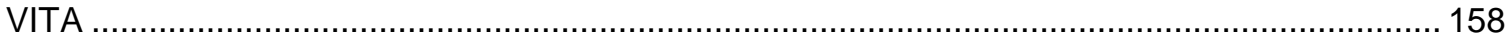




\section{LIST OF TABLES}

TABLE

PAGE

CHAPTER III

3.1 Parameters and values for the three best performing models, based on AICc, of coral growth in response to changes in the measured metrics of PSII health and performance for each coral species. P-values for each term as well as the marginal and conditional $\mathrm{R}^{2}$ values for the model are listed. Marginal $\mathrm{R}^{2}$ values represent the variance explained by the fixed effects, conditional $R^{2}$ values represent the variance explained by the full model

\section{CHAPTER VI}

6.1 The mean log response ratio (RR) and upper and lower 95\% Bayesian credible intervals for phototroph and heterotroph partners from each mutualism type overall and to each enrichment type. Data are provided for both the unweighted and weighted models for comparison

\section{APPENDIX A}

A1 Summary of studies used for analyses of the effects of nutrients on coral growth. Categories are: Study: the author(s) and year published for each study. Letters in superscript, when present, indicate additional notes provided below. Species: list of coral species used in each study. Metric: Growth metric used in our analyses. Cal = Calcification rate, Den $=$ Skeletal Density, Ext $=$ Extension Rate. Multiple metrics listed under a single study indicates use in each analysis. Nutrient: Type of enrichment used in the study. $\mathrm{N}=$ mixed/unspecified nitrogen, $\mathrm{NH}_{4}=$ ammonium, $\mathrm{NO}_{3}=$ Nitrate, $\mathrm{P}=$ Phosphate. Nutrients separated by ',' indicate separate enrichments with each, nutrients separated by ' + ' indicate joint enrichment. Source: Nutrient source used in each study. ANTH=enrichment from anthropogenic pollution, MAN=enrichment from manipulative nutrient additions, $\mathrm{FISH}=$ enrichment resulted from fish excretion. Control N/P: Background level or range of levels for $N$ and $P$ in micromoles recorded in control treatments. Enriched N/P: The level or range of levels for $\mathrm{N}$ and $\mathrm{P}$ in micromoles recorded in enriched treatments.

A2 Summary of studies used for analyses of the effects of nutrients on coral photobiology. Categories are: Study: the author(s) and year published for each study. Letters in superscript, when present, indicate additional notes provided below. Species: list of coral species used in each study. Metric: Photobiology metric used in our analyses. Chl.a = Chlorophyll a concentration obtained from an area of coral tissue, Chl. per Symbio = Chlorophyll a within individual Symbiodinium, SymDensity = Density of Symbiodinium within an area of coral tissue, Photosynth $=$ Gross photosynthetic rate. Multiple metrics listed under a single study indicates use in each analysis. Nutrient: Type of enrichment used in the study. $\mathrm{NH}_{4}=$ ammonium, $\mathrm{NO}_{3}=$ Nitrate, $\mathrm{P}=$ Phosphorus. Nutrients separated by ',' indicate separate enrichments with each, nutrients separated by '+' indicate joint enrichment. Source: Nutrient source used in each study. ANTH=enrichment resulted from anthropogenic pollution, MAN=enrichment resulted from manipulative nutrient additions, FISH=enrichment resulted from fish excretion. $N$ Level/P Level: The level or range of levels provided for $\mathrm{N}$ and $\mathrm{P}$ 
A3 Results of linear regression analysis examining the relationship between effect sizes and the background nitrogen $(\mathrm{N})$ and phosphorus $(\mathrm{P})$ levels for each metric of coral growth and photobiology under $\mathrm{N}, \mathrm{P}$ and $\mathrm{N}+\mathrm{P}$ enrichment.

A4 Results from model selection for linear or quadratic models and the corresponding regression analysis for the relationship between effect sizes and enrichment level for calcification and each metric of photobiology. Best fit was determined via Akaike Information Criteria corrected for small sample sizes (AICc). For each metric, the best model type is listed along with the AICc score, the AICc difference between the two model types, and the regression statistics. NA = not sufficient data to conduct the analysis

A5 Results from model selection using Akaike Information Criteria corrected for small sample sizes $(\mathrm{AICc}$ ) to select between linear and quadratic models of the effect of $\mathrm{N}: \mathrm{P}$ ratio of different metrics of coral growth. For each metric, the best model type is listed along with the corresponding fit, AICc score and difference between the two model types.....

\section{APPENDIX B}

B1 Results of repeated measures ANOVA to assess the biomass of grunts sheltering around study colonies throughout the duration of the study.

B2 Results from SIMPER analysis for the contribution of dissimilarity between High Biomass vs. Low Biomass sites for each benthic group. Contribution is the mean percent dissimilarity contribution from each benthic category. Cumulative contribution represents the total dissimilarity contribution from multiple groups

\section{APPENDIX C}

C1 List of studies used in our analyses. "Type" indicates the mutualism group. "Site" denotes whether the study was conducted in an outdoor field setting (Field) or in a lab or glasshouse (Lab). "Location" provides the country or ocean region where the study took place. "Treat" denotes the type of nutrients provided with multiple nutrients listed if a study contained independent treatments of different nutrients. "N" provides the enrichment level and units for $\mathrm{N}$-enrichments while "P" provides the enrichment level and units for $\mathrm{P}$ enrichments. "Duration" provides the length of the study in days. "Metric $(\mathrm{P} / \mathrm{H})$ " indicates the response metric used to measure the performance for the phototroph partner / the heterotroph partner. "Wtd. Anl." Provides a Yes/No indication of whether or not the study was included in our weighted analysis.

C2 Calculated slopes and the probability that slopes differ from zero for Bayesian Type II regressions of phototroph versus heterotroph response ratios for weighted and unweighted analyses. $\mathrm{N}$ indicates the number of experiments available for the regressions.

C3 The mean log response ration (RR) and upper and lower 95\% Bayesian credible intervals for phototroph and heterotroph partners in the Plant-Fungi and Plant-Bacteria mutualisms calculated from studies in natural field settings versus controlled lab or glass-house environments. $\mathrm{N}$ indicates the number of experiments available for the calculations. 


\section{LIST OF FIGURES}

FIGURE

PAGE

\section{CHAPTER II}

2.1 Cumulative effect sizes for coral calcification rates in response to enrichment with nitrogen $(N)$, phosphorus $(P)$ or joint nitrogen and phosphorus $(N+P)$. Responses are shown for: (a) all corals, (b) branching corals, (c) mounding corals, (d) Acropora spp., and (e) Porites spp. Data are means $\pm 95 \%$ confidence intervals. Numbers in parenthesis indicate the number of experiments used to calculate effect sizes.

2.2 Cumulative effect sizes of nutrient enrichment on different metrics of photobiology of corals: (a) the density of chlorophyll a within individual Symbiodinium, (b) the density of Symbiodinium within corals, (c) the density of chlorophyll a per area of coral, and (d) gross photosynthesis. Statistics as in Fig. 2.1

2.3 Cumulative effect sizes of fish-derived (naturally occurring), manipulative, or anthropogenic nutrient enrichment on the calcification rates of corals. Nutrients provided for manipulative studies are indicated in parentheses on the X-axis. Statistics as in Fig. 1

2.4 Cumulative effect sizes for the impact of ammonium or nitrate on: (a) the calcification rates of corals, (b) the concentration of chlorophyll a within Symbiodinium, and (c) the density of Symbiodinium in coral tissue. Statistics as in Fig. 1

\section{CHAPTER III}

3.1 Schematic of the growth platforms used for our coral experiments. Each platform was $75 \times 50 \mathrm{~cm}$ and contained six elevated posts to hold coral fragments. Nutrient diffusers, represented as the hashed cylinder, were filled with the respective nutrient treatment and secured to a post in the center of the platform

3.2 The impact of chronic nutrient loading with nitrate $\left(\mathrm{NO}_{3}^{-}\right)$, ammonium $\left(\mathrm{NH}_{4}{ }^{+}\right)$, nitrate and phosphate (NP) or phosphate (P) on A. cervicornis, M. cavernosa, and S. siderea. (a) Maximum dark adapted quantum yield of photosystem II taken before sunrise, (b) Maximum excitation pressure on photosystem II (Qm) at solar noon, and (c) Photoinhibition of photosystem II (q $\left.q_{1}\right)$. N.S. indicates no significant differences while letters represent significant differences at $\alpha=0.05$. Data are means $\pm 1 \mathrm{~S}$.E

3.3 Growth rates of $A$. cervicornis, $M$. cavernosa, and S. siderea subjected to enrichment with either: nitrate $\left(\mathrm{NO}_{3}{ }^{-}\right)$, ammonium $\left(\mathrm{NH}_{4}{ }^{+}\right)$, nitrate and phosphate (NP) or phosphate $(\mathrm{P})$. N.S. indicates no significant differences while letters represent significant differences at $\alpha=0.05$. Data are means $\pm 1 \mathrm{~S}$.E.

\section{CHAPTER IV}

4.1 Biomass of herbivorous fishes $\left(\mathrm{g} \mathrm{m}^{-2}\right)$ recorded at our study site prior to the beginning of the study. Data are means \pm 1 S.E. 
4.2 (a) The average molar ratios ( $C: N$ - circles, $C: P$ - triangles) measured from $S$. polyceratium feeding assays. (b) Average consumption of feeding assays after two hour deployments. Data are means \pm 1 S.E. Capital letters above each treatment denote significant differences in C:N based on Tukey's HSD following one-factor ANOVA. C:P showed no differences across treatments.

4.3 Average grazing rates in bites minute ${ }^{-1}$ on $S$. polyceratium assays for $S p$. aurofrenatum, Sp. chrysopterum, and Sp. rubripinne combined (a) or A. coeruleus and A. tractus (b). Number of feeding forays hour ${ }^{-1}$ for the above parrotfish species (c) and surgeonfish species (d). Data are means \pm 1 S.E. P-values for nitrogen enrichment (N), phosphorus enrichment $(\mathrm{P})$ and the interaction $\left(\mathrm{N}^{*} \mathrm{P}\right)$ are from two-factor ANOVA.

4.4 Average bites minute-1 for Sp. aurofrenatum, Sp. chrysopterum, and Sp. rubripinne from each assay regressed against (a) the $C: N$ and (b) $C: P$ of $S$. polyceratium assays. Initial phase parrotfish in blue and terminal phase parrotfish in grey. Average bites minute $^{-1} \quad$ for $A$. coeruleus and $A$. tractus are presented in panels (c) and (d). Juvenile surgeonfishes are shown in dark green, adults in light green. P-values for significant model terms or interactions are provided. N.S. indicates that no terms were significant. 73

\section{CHAPTER V}

5.1 (a) Results from agglomerative cluster analysis categorizing the 20 study colonies as either High Biomass or Low Biomass sites based on the biomass of grunts at each site during weekly surveys. (b) Biomass of grunts calculated from weekly surveys at High vs. Low Biomass sites throughout the study. P-values from repeated-measures ANOVA. Data are means \pm SE

5.2 (a) Daily excretion rates, as calculated by bioenergetics modeling, of nitrogen and phosphorus from grunts around High Biomass and Low Biomass sites. (b) Percent nitrogen and phosphorus content in the tissue of the alga Dictyota menstrualis collected from High Biomass vs. Low Biomass sites. P-values from mixed effects ANOVA. Data are means \pm SE.

5.3 Results of nonmetric multidimensional scaling (nMDS) depicting algal community structure around High Biomass vs. Low Biomass sites. Benthic categories depict the distance relationships between colonies based on the percent cover of the category. Pvalue from ANOSIM.

5.4 Percent cover of different benthic groups at High Biomass vs. Low Biomass sites. Pvalues from mixed effects ANOVA. Data are means $\pm \mathrm{SE}$.

5.5 Skeletal extension rates, as a percent of total linear extension per day, for Acropora cervicornis transplants located at High Biomass vs. Low Biomass sites. P-value from mixed effects ANOVA. Data are means \pm SE.

5.6 Grazing rates of herbivorous fishes at High Biomass vs. Low Biomass colonies.

$P$-value from mixed effects ANOVA. Data are means \pm SE. 101 


\section{CHAPTER VI}

6.1 Map of the locations and countries where marine (blue dots) and terrestrial (green shading) experiments used in our analyses were conducted.

6.2 Estimated effect sizes based on log response ratios for phototrophs and heterotrophs from each mutualism type (blue=marine, green=terrestrial) and overall median response across all studies from the unweighted model as $(A)$ pooled across all nutrients or under (B) nitrogen, (C) phosphorus, (D) nitrogen+phosphorus enrichment. Thin and thick lines depict the $95 \%$ and $80 \%$ Bayesian credible intervals respectively. Numbers in parentheses denote the number of experiments used in each calculation. 125

6.3 Results of Bayesian Type II regression of heterotroph log response ratios against phototroph log response ratios for the different mutualism types: (A) Algae-Clam, (B) Algae-Coral, (C) Algae/Cyanobacteria-Fungi, (D) Plant-AM Fungi, (E) Plant-EM Fungi, and $(F)$ Plant-Bacteria. Shaded area represents the 95\% Bayesian credible interval of the regression.

\section{APPENDIX A}

A1 Cumulative effect sizes for (a) skeletal extension rates for all corals and (b) skeletal density for all corals, in response to enrichment with $\mathrm{N}, \mathrm{P}$, or $\mathrm{N}+\mathrm{P}$. Data are means \pm $95 \%$ confidence intervals. Numbers in parenthesis indicate the number of experiments used to calculate effect sizes.

A2 Regression analysis using best fitting quadratic models of the effect of N:P ratio on effect sizes for coral calcification (left), and skeletal extension rates (right).

\section{APPENDIX B}

D1 Google Earth image of the study location. Numbers indicate location of each of the 20 study colonies, as determined by a diver towing a GPS attached to a dive float. Red numbers are High Biomass sites and white numbers are Low Biomass sites.

\section{APPENDIX C}

C1 Estimated effect sizes based on log response ratios from the subset of data used in our weighted analysis for comparison with the unweighted analysis (Figure 2 in the main text). The phototroph and heterotroph for each mutualism type (blue=marine, green=terrestrial) and the overall median response across all studies as (A) pooled across nutrients or under (B) nitrogen, (C) phosphorus, or (D) nitrogen+phosphorus enrichment. Thin and thick lines depict the $95 \%$ and $80 \%$ Bayesian credible intervals respectively. Numbers in parentheses denote the number of experiments used in each calculation.

C2 Results from our weighted Bayesian Type II regression of heterotroph log response ratios against phototroph log response ratios for comparison with the unweighted model (Figure 3 in the main text). Panels are (A) Algae-Clams, (B) Algae-Coral, (C) Algae/Cyanobacteria-Fungi, (D) Plant-AM Fungi, (E) Plant-EM Fungi, and (F) PlantBacteria. Shaded area represents the $95 \%$ Bayesian credible interval of the regression. 
C3 Effect sizes plotted against total nitrogen and phosphorus enrichment magnitude. For each group, enrichment metrics are: (A) Algae-Clams: $\mu \mathrm{M}$; (B) Algae-Coral: $\mu \mathrm{M}$; (C) Algae/Cyanobacteria-Fungi: $\mathrm{mg} \mathrm{m}^{-2}$; (D) Plant-AM Fungi: $\mathrm{mg} \mathrm{kg}^{-1}$; (E) Plant-EM Fungi: $\mathrm{mg} \mathrm{kg}^{-1}(\mathrm{~F})$ Plant-Bacteria: $\mathrm{mg} \mathrm{m}^{-2}$. Note that no measurements were available to examine the effect of daily phosphorus enrichment on lichen.

C4 Effect sizes plotted against average daily nitrogen and phosphorus enrichment levels. For each group, enrichment metrics are: (A) Algae-Clams: $\mu \mathrm{M}_{\text {day }}{ }^{-1}$; (B) Algae-Coral: $\mu \mathrm{M}$ day-1; (C) Algae/Cyanobacteria-Fungi: $\mathrm{mg} \mathrm{m}^{-2}$ day $^{-1}$; (D) Plant-AM Fungi: $\mathrm{mg} \mathrm{kg}^{-1}$ day $^{-1}$; (E) Plant-EM Fungi: $\mathrm{mg} \mathrm{kg}^{-1}$ day $^{-1}$ (F) Plant-Bacteria: $\mathrm{mg} \mathrm{m}^{-2}$ day ${ }^{-1}$. Note that no measurements were available to examine the effect of daily phosphorus enrichment on lichen. 
CHAPTER I

INTRODUCTION 
Since the latter half of the last century human activity has played a greater role in the biogeochemical cycling of limiting nutrients, such as nitrogen $(N)$ and phosphorus $(P)$ than all biological processes combined (Vitousek et al. 1997; Elser et al. 2007). This pervasive nutrient enrichment has repercussions that resonate across ecosystems worldwide. The supply rates of $\mathrm{N}$ and $\mathrm{P}$ shape the dynamics and productivity of terrestrial and marine environments and often dictate the structure of ecological communities (e.g., Lindeman 1942; Chapin et al. 1997; Smith et al. 1999; Smith and Schindler 2009). Nutrient levels may be particularly important on coral reefs, where anthropogenic nutrient enrichment is often associated with the collapse of coral communities and phase shifts to algae dominated reefs. However, nutrients have traditionally been considered to be of secondary importance in shaping reef communities when compared with top-down processes (e.g., Ogden and Lobel 1978; McCook 1999; Szmant 2002; Bellwood et al. 2004; Burkepile and Hay 2006). As a result, the impacts of nutrient enrichiment on coral reefs remain regularly under-studied.

In this dissertation, I examine the impact of nutrients across levels of biological complexity to expand on our limited understanding of the pathways through which nutrients affect reefs. In Chapter II, I compile the available literature assessing the responses of reef building corals to enrichment with nitrate $\left(\mathrm{NO}_{3}^{-}\right)$, ammonium $\left(\mathrm{NH}_{4}{ }^{+}\right)$, phosphate, or combinations of these nutrients. Using meta-analyses, I show that $\mathrm{N}$ and $\mathrm{P}$ impact corals through two different pathways. Nitrogen affects corals via direct effects on the endosymbionts within corals, Symbiodinium, but the responses further depend on the identity of $\mathrm{N}$ provided. Nitrate tends to impair coral growth and increase the chlorophyll content in Symbiodinium while $\mathrm{NH}_{4}{ }^{+}$has negligible effects on coral growth but still benefits the Symbiodinium within corals. In contrast, Penrichment has no measurable impact on Symbiodinium populations but alters coral growth, most likely via direct effects on the calcification process.

To explore the mechanisms that mediate these responses, in Chapter III I experimentally manipulate coral exposure to different nutrient regimes. Using polymer coated slow-release fertilizers, I expose three species of important reef building corals to either $\mathrm{NO}_{3}{ }^{-}, \mathrm{NH}_{4}{ }^{+}, \mathrm{P}$, or a 
combination of $\mathrm{NO}_{3}{ }^{-}$and $\mathrm{P}(\mathrm{NP})$. I track the growth rates of each coral and use pulse amplitude modulated (PAM) fluorometry to assess the health and performance of photosystem II (PSII) in corals subjected to each nutrient regime. I show that coral responses to enrichment are speciesspecific. Neither N nor P-enrichment impact the photobiology of the staghorn coral, Acropora cervicornis, or the round starlet coral, Siderastrea siderea. However, P-enrichment increases $A$. cervicornis growth rates. In contrast, $\mathrm{NO}_{3^{-}}, \mathrm{P}$, and NP significantly increase the excitation pressure on PSII in the massive star coral Montastraea cavernosa, with $\mathrm{NO}_{3}{ }^{-}$enrichment resulting in the accumulation of photodamge to PSII. Furthermore, impaired PSII performance in M. cavernosa significantly reduced the growth rates of these corals. Thus, Chapter III improves our understanding of the mechanisms through which nutrients impact coral growth and suggests new avenues of investigation in coral-nutrient research.

In Chapter IV I shift focus from the impact of nutrients on corals, to herbivores and herbivory. Ecological stoichiometry predicts that animals should target resources that best match their elemental body composition (Sterner and Elser 2002). Dietary matching presents a particular challenge for herbivores because elements like nitrogen $(\mathrm{N})$ and phosphorus $(\mathrm{P})$ are typically far more prevalent in animal tissue than plant tissue. As a result, animals are often $\mathrm{N}$ and P-limited and selectively forage on resources rich in these nutrients (Mattson 1980; Barboza et al. 2009; Lemoine et al. 2013). Indeed, experiments comparing the consumption of nutrient enriched algae to controls often document higher rates of grazing and biomass removal of algae enriched with N and P (e.g., Boyer et al. 2004; Chan et al. 2012). However, as of yet no studies have differentiated the effects of $\mathrm{N}$ versus $\mathrm{P}$ on reef fish foraging, nor clarified the responses of different fish taxa to these enrichments. Chapter IV shows that grazing rates of initial, but not terminal phase sparisomid parrotfishes increase with algal $\mathrm{N}$-content while grazing rates of juvenile, but not adult acanthurid surgeonfishes increase with algal P-content. Consequently, juvenile and initial phase fishes likely fill functional roles that distinctly differ from those of adult fishes. My results show that both the $\mathrm{N}$ and $\mathrm{P}$ content of algae can influence herbivore feeding 
decisions and that the nutritional content of resources may play a role in partitioning herbivory on coral reefs.

Chapter V scales upwards to examine how the effects of nutrients on coral, algae, and herbivores can impact reefs at the community level. Aggregations of animals within a landscape often cause spatial or temporal variation in nutrient delivery, potentially creating nutrient "hotspots" (McClaine et al. 2003). I examine the potential for sheltering schools of grunts to create biogeochemical hotspots on a reef in the upper Florida Keys and the impact these hotspots have on benthic communities. I show that $\mathrm{N}$ and $\mathrm{P}$ delivery is respectively 10 and 7 times greater at grunt shelter sites than at structurally similar sites that lack schools of these fishes. As a result, coral growth is roughly 1.5 times greater and herbivore grazing rates approximately 3 times greater at grunt-derived hotspots. These differences in nutrient delivery, coral growth and grazing result in the development of distinct benthic communities with increased cover of crustose coralline algae and reduced total algal abundance at grunt aggregation sites. Thus, schooling reef fish and their nutrient subsidies can play an important role mediating community structure on coral reefs and overfishing may have critical negative consequences on ecosystem functions.

With a better understanding of the impact of nutrients on organisms and the importance this can have on community structure, Chapter VI again scales upwards to explore the effects of $\mathrm{N}$ and $\mathrm{P}$ on ecosystems across the globe. Nutrient-exchange symbioses are reciprocal partnerships in which a heterotroph provides limiting nutrients, primarily $\mathrm{N}$ or $\mathrm{P}$, to a phototrophic partner in exchange for photosynthetically-fixed carbon (C). While these relationships form the foundation of coral reefs, over $80 \%$ of plant species also partake in nutrient exchange symbioses with mycorrhizal fungi (van der Heijden et al. 2015). In Chapter VI, I show that nutrient loading can destabilize these mutualisms across ecosystems by altering the costs and benefits each partner incurs from interacting. Using meta-analyses, I show a near ubiquitous decoupling in mutualism performance in which phototrophs benefit from enrichment at the expense of their heterotrophic partners. These nutrient-driven changes in mutualism performance may alter community organization and ecosystem processes and increase costs of food production, with 
potentially severe consequences for human populations. Consequently, the decoupling of nutrient-exchange mutualisms via alterations of the world's nitrogen and phosphorus cycles represents an emerging threat of global change.

In conclusion, this dissertation advances our knowledge with respect to the effects of nutrient enrichment across levels of biological complexity. I show that nutrient enrichment effects the growth rates and photobiology of corals, alters the nutritional content of algae, and influences herbivore feeding decisions. In turn, these changes cascade upwards to shape entire reef communities and impact foundation species of ecosystems worldwide.

\section{References}

Barboza PS, Parker KL, Hume ID (2009) Integrative wildlife nutrition. Springer-Verlag, Heidelberg, Germany

Bellwood DR, Hughes TP, Folke C, Nyström M (2004). Confronting the coral reef crisis. Nature 429: 827-833

Boyer KE, Forrester A, Armitage AR, Cohen RA (2004) Elevated nutrient content of tropical macroalgae increases rates of herbivory in coral, seagrass, and mangrove habitats. Coral Reefs 23:530-538

Burkepile DE, Hay ME (2006) Herbivore vs. nutrient control of primary producers: Contextdependent effects. Ecology 87:3128-3139

Chapin FS, Walker BH, Hobbs RJ, Hooper DU, Lawton JH, et al (1997) Biotic control over the functioning of ecosystems. Science 227:500-504

Chan A, Lubarsky K, Judy K, Fong P (2012) Nutrient addition increases consumption rates of tropical algae with different initial palatabilities. Mar Ecol Prog Ser 465:25-31

Elser JJ, Bracken MES, Cleland EE, Gruner DS, Harpole WS, Hillebrand H, Ngai JT, et al (2007) Global analysis of nitrogen and phosphorus limitation of primary producers in freshwater, marine and terrestrial ecosystems. Ecol Lett 10:1135-1142

Lemoine NP, Giery ST, Burkepile DE (2013) Differing nutritional constraints of consumers across ecosystems. Oecologia 174:1367-1376

Lindeman, RL (1942) The trophic-dynamic aspect of ecology. Ecology 23:399-418

Mattson WJ, (1980) Herbivory in relation to plant nitrogen content. Ann Rev Ecol Syst 11:119-161

McClaine ME, Boyer EW, Dent CL, Gergel SE, Grimm NB, et al (2003) Biogeochemical hot spots and hot moments at the interface of terrestrial and aquatic ecosystems. Ecosystems 6:301-312 
McCook LJ (1999) Macroalgae, nutrients and phase shifts on coral reefs: scientific issues and management consequences for the Great Barrier Reef. Coral Reefs 18:357-367

Ogden JC, Lobel PS, (1978) The role of herbivorous fishes and urchins in coral reef communities. Environ Biol Fishes 3:49-63

Smith VH, Tilman GD, Nekola JC (1999) Eutrophication: impacts of excess nutrient inputs on freshwater, marine, and terrestrial ecosystems. Environ. Pollut. 100:179-196

Smith VH, Schindler DW (2009) Eutrophication science: where do we go from here? Trends Ecol. Evol. 24:201-207

Sterner RW, Elser JJ (2002) Ecological Stoichiometry: The biology of elements from molecules to the biosphere. Princeton University Press, Princeton, New Jersey

Szmant AM (2002) Nutrient enrichment on coral reefs: is it a major cause of coral reef decline? Estuaries and Coasts 25:743-766

van der Heijden MGA, Martin F, Selosse M-A, Sanders IR (2015) Mycorrhizal ecology and evolution: the past, the present, and the future. New Phytol. 205:1406-1423 


\section{CHAPTER II}

CONTEXT-DEPENDENT EFFECTS OF NUTRIENT LOADING ON THE CORAL-ALGAL

MUTUALISM 


\section{Abstract}

Human-mediated increases in nutrient availability alter patterns of primary production, alter species diversity, and threaten ecosystem function. Nutrients can also alter community structure by disrupting the relationships between nutrient-sharing mutualists that form the foundation of communities. Given their oligotrophic nature and the dependence of reef building corals on symbiotic relationships, coral reefs may be particularly vulnerable to excess nutrients. However, individual studies suggest complex, even contradictory, relationships among nutrient availability, coral physiology, and coral growth. Here, we used meta-analysis to establish general patterns of the impact of nitrogen $(\mathrm{N})$ and phosphorus $(\mathrm{P})$ on coral growth and photobiology. Overall, we found that over a wide range of concentrations, $\mathrm{N}$ reduced coral calcification on average $11 \%$ but enhanced metrics of coral photobiology, such as photosynthetic rate. In contrast, $\mathrm{P}$ enrichment increased average calcification rates by $9 \%$, likely through direct impacts on the calcification process, but minimally impacted coral photobiology. There were few synergistic impacts of combined $\mathrm{N}$ and $\mathrm{P}$ on corals, as the nutrients impact corals via different pathways. Additionally, the response of corals to increasing nutrient availability was contextdependent, varying with coral taxa and morphology, enrichment source, and nutrient identity. For

example, naturally occurring enrichment from fish excretion increased coral growth while humanmediated enrichment tended to decrease coral growth. Understanding the nuances of the relationship between nutrients and corals may allow for more targeted remediation strategies and suggest how other global change drivers such as overfishing and climate change will shape how nutrient availability impacts corals.

\section{Introduction}

In most ecosystems, nitrogen $(\mathrm{N})$ or phosphorus $(\mathrm{P})$ limits primary production (Elser et al. 2007), but humans have increased the supply of these nutrients to well above the natural levels found in many systems (Vitousek et al. 1997a, b; Elser et al. 2007). Increases in nutrient loading can have severe consequences on the environment, often resulting in the dominance of species best suited to monopolize these new nutrient regimes, and the competitive exclusion of 
subordinate species (Tilman 1988; Smith et al. 1999). These changes result in declines in biological diversity, greater susceptibility to disturbances, and the loss of ecosystem services (Vitousek 1997a; Smith et al. 1999; Harpole and Tilman 2007). Aquatic systems may be particularly vulnerable to nutrient loading due to downstream transport of nutrients, making increasing nutrient delivery a primary threat to coastal ecosystems (Vitousek et al. 1997b).

Although anthropogenic enrichment often delivers both $\mathrm{N}$ and $\mathrm{P}$, the concentration of each nutrient will differ with the source of enrichment. For example, regions with intense agricultural activity or urban development often experience greater delivery of $\mathrm{N}$ to coastal waters (Howarth et al 1996; Carpenter et al. 1998). In contrast, municipal and industrial wastewater, as well as run-off from regions with intense livestock production, often deliver substantial P to coastal systems (Conley et al. 2009). Geomorphology can also play a large role in shaping the identity of nutrient loads as soil type, age, and $\mathrm{pH}$ affect sorption of $\mathrm{P}$ and its downstream availability (Schachtman et al. 1998). Additionally, different $\mathrm{N}$ species (nitrate or ammonium) are often found in different anthropogenic or natural nutrient sources and primary producers often have significant preferences for one versus the other (Raven 1992). Given that different nutrient sources frequently deliver different ratios or types of $\mathrm{N}$ and $\mathrm{P}$, it is imperative to understand how altering the magnitude and identity of nutrients delivered to coastal systems will impact them.

On coral reefs, increasing nutrient availability may be a critical driver of degradation as it often promotes fast-growing algae that can hinder coral growth and survivorship (Mumby and Steneck 2008). The effects of these nutrients on algal communities of coral reefs have received considerable attention (McCook 1999; Szmant 2002; Burkepile and Hay 2006). Yet, there has been no quantitative synthesis of the impacts of nutrient availability on corals, the foundation species of these ecosystems. Although the negative impacts of nutrients are widely assumed (reviewed by Fabricius 2005), the direct effects of nutrients on corals are likely complex as enrichment may affect both the coral host and their symbiotic dinoflagellates, Symbiodinium spp.

Understanding the individual impacts of $\mathrm{N}$ or $\mathrm{P}$ loading is important, as both nutrients may impact coral growth rates through a host of possible mechanisms. For example, $\mathrm{N}$ 
enrichment may inhibit coral growth by increasing the density of Symbiodinium within corals (Muscatine et al. 1989; Hoegh-Guldberg and Smith 1989). As a result, greater densities of Symbiodinium may monopolize dissolved inorganic carbon (DIC) for photosynthesis, limiting the DIC available for calcification and reducing coral growth rates (Muscatine et al. 1998). In contrast, P enrichment may have negligible effects on Symbiodinium (Muscatine et al. 1989; Godinot et al. 2011) but may impair coral growth by inhibiting the formation of calcium carbonate crystals thereby hindering skeletal formation (Simkiss 1964; Dunn et al. 2012). However, some studies have documented positive effects of both $\mathrm{N}$ and $\mathrm{P}$ on coral growth (e.g. Meyer and Schultz 1985a; Holbrook et al. 2008; Godinot et al. 2011). These positive effects may be driven by physiological changes in the coral such as increased photosynthetic output providing more energy to the coral or $\mathrm{pH}$ shifts within the coral tissue that facilitate calcification (Tambutte et al. 2011). Ultimately, the conflicting reports of negative and positive effects of nutrients on coral growth suggest that the effects of nutrient enrichment on the coral-algal mutualism may be context dependent.

Because symbiotic relationships such as the coral-algal mutualism typically incur both costs and benefits to each participant (Herre et al. 1999), any factors that shift the cost-benefit ratio of the interaction for one or both participants have the potential to alter the dynamics of the symbiosis. For example, plant-mycorrhizae interactions, one of the best-studied nutrient-sharing mutualisms, are frequently vulnerable to increases in nutrient loading (Hoeksema et al. 2010). In these mutualisms, plants provide more energy to mycorrhizal fungi when nutrients are limiting but reduce energy delivery to mycorrhizae as nutrient levels increase, causing fungal populations to decline and plant growth to suffer (Johnson et al. 2008). Nutrient enrichment may ultimately reorganize plant communities by allowing species that are less dependent on mycorrhizae to become competitively dominant when nutrient loading slows the growth mycorrhizae-dependent species (Tilman 1988; Treseder 2004, Johnson et al. 2008). Whether enrichment-driven breakdowns in nutrient-sharing symbioses are ubiquitous or exclusive to plants and their 
mutualists is currently unclear. But, the coral-algal mutualism may be similarly vulnerable to increases in nutrient availability.

Here, we used meta-analysis of 208 independent experiments from 47 studies to quantify the impact of $\mathrm{N}$ and $\mathrm{P}$ loading on coral growth and photobiology. With our data set, we were able to assess: (1) how N vs. P impact corals differently, (2) how coral morphology and taxonomy influence responses to nutrients, and (3) how the source of nutrient enrichment determines the effect on corals. Our analyses reveal contrasting effects of $\mathrm{N}$ and $\mathrm{P}$, illustrate the importance of nutrient source for coral growth, and suggest that there are common patterns across ecosystems in how altered nutrient supply affects the dynamics of nutrient-sharing mutualisms.

\section{Methods}

Coral growth is variously measured through calcification rates, skeletal extension rates, and changes in skeletal density. However nutrient enrichment can affect each metric differently, making quantitative comparisons among them difficult. For example, Dunn et al. (2012) showed that in Acropora muricata, $\mathrm{P}$ enrichment caused increased extension rates but reduced skeletal density. To account for these differences in our analyses, we divided coral growth responses into metrics of: (1) calcification rates, (2) extension rates, and (3) skeletal density. Similarly, nutrients can affect the density of chlorophyll within Symbiodinium, the density of Symbiodinium within corals, or both. Therefore, photobiology measurements were grouped as responses in: (1) chlorophyll a within Symbiodinium cells, (2) Symbiodinium cell density within coral hosts, (3) chlorophyll a density per unit area of coral (a product of Symbiodinium cell density and chlorophyll a per Symbiodinium), and (4) maximum gross photosynthesis of corals.

We compiled studies assessing the impact of $\mathrm{N}$ and $\mathrm{P}$ on any of the above metrics of coral growth and photobiology using ISI Web of Science (1978 - 2012). Search terms included key words such as 'nutr^ and coral', 'coral growth', 'nutr^ and Symbiodinium', etc. We identified additional studies by searching the references of studies identified in our Web of Science searches. For inclusion, studies were required to compare the effect of $\mathrm{N}$ and/or $\mathrm{P}$ between 
control and treatment corals on at least one of our metrics of coral growth or photobiology. To minimize confounding factors, studies that obtained measurements from corals growing on reefs rather than controlled lab settings, were only included when the environments around control and treatment corals (e.g. depth, temperature, etc.) were controlled for as much as possible. As a result, studies that examined the response of corals to factors such as upwelling were not included due to co-occurring differences in temperature, which also impacts coral growth (e.g. Leichter and Genovese 2006). Similarly, measurements from studies that manipulated factors in addition to $\mathrm{N}$ or $\mathrm{P}$ that could impact coral growth, such as the presence of competitors or coral predators (e.g. Burkepile and Hay 2009), were excluded from our data set as it was often difficult to decouple the effects of nutrients from other confounding factors. We restricted our analyses of photobiology to include only studies that assessed the impact of nutrient enrichment on Symbiodinium within the coral host rather than responses in culture.

We obtained data from the text of the studies, directly from the authors, or extracted measurements from digital PDFs using DataThief III V1.6 (Tummers 2006). When studies reported growth rates throughout a time series we averaged the measurements to calculate a mean effect for the whole study duration. For studies that provided measurements from multiple nutrient treatments (i.e. $\mathrm{N}$ and $\mathrm{P}$ independently) or across several enrichment levels, each treatment level was counted as an independent experiment. The exceptions to this were three studies that exposed the same corals to multiple enrichment levels through time (Appendix A1). In these instances, we calculated the average growth rate through the entirety of the experiment to test the effect of nutrient identity but excluded these results from tests of enrichment level.

We found 26 studies with 101 separate experiments from 17 species of coral that met all of our criteria for the analyses of nutrient loading on coral growth. Studies which reported the change in mass per unit volume of whole colonies through time were used in our analysis as measurements of both calcification rates and skeletal density. As a result we were able to obtain 59 independent measurements of calcification from 21 studies, 37 measurements of skeletal extension rates from 14 studies, and 19 measurements of skeletal density from 5 studies (Table 
A1). To assess the impact of nutrient enrichment on Symbiodinium and photosynthesis, we identified 21 studies with 107 separate experiments from 13 species of corals. We found 27 experiments from 8 studies that assessed how nutrient input alters chlorophyll a density within Symbiodinium, 38 experiments from 15 studies examining Symbiodinium density, 27 experiments from 11 studies examining chlorophyll a density per unit area of coral, and 15 experiments from 6 studies examining the gross photosynthetic rates of corals (Table A2).

Analysis

To standardize the effect of nutrient enrichment on different metrics of coral growth and photobiology we used a log response ratio in which effect sizes for each study were calculated as $L R R=\ln \left(\frac{X_{E}}{X_{C}}\right)$ where $X_{E}$ is the mean response to nutrient enrichment and $X_{C}$ is the mean control response. This metric estimates the effect size as a proportionate change between the response and control groups such that values equal to zero signify no effect of enrichment, values less than zero indicate a negative effect of nutrient enrichment, and positive values indicate a positive response to nutrients. Log response ratios are often a useful metric when replication is low and Type II error can prevent the detection of biologically meaningful responses (Rosenberg et al. 1999; Harpole et al. 2011). Weighting effect sizes can account for inequality in study variance as well as increase the power and precision of tests by as much as $50-100 \%$ (Stewart 2010). Thus, we calculated weighted effect sizes using the inverse of the sampling variance, in which the variance for each effect size was

$$
V_{l n R}=\frac{\left(s_{E}\right)^{2}}{n_{E}\left(X_{E}\right)^{2}}+\frac{\left(s_{C}\right)^{2}}{n_{C}\left(X_{C}\right)^{2}}
$$

where $s_{E}$ and $s_{C}$ are the variance of treatment and control groups respectively and $N_{E}$ and $N_{C}$ are the replication of each group. For all our analyses we plotted standardized effect sizes against a standard normal distribution and calculated fail-safe numbers using Rosenthal's method to confirm the absence of publication bias.

Because responses may vary with experimental conditions among studies (e.g. temperature, light, etc), we used mixed-effect models in MetaWin V2.0 that considered the treatment variable of interest as a fixed factor and study as a random factor (Rosenberg et al. 
1999). We calculated weighted cumulative effect sizes and assessed significance by constructing standard 95\% confidence intervals around the weighted mean effect size for each response variable examined. We tested the effect of nutrient enrichment on each metric of growth and photobiology for each nutrient type across all coral species. To determine if growth form had an impact on the response of corals to nutrients, we grouped corals by morphology (branching versus mounding) and examined their response to each metric. We addressed taxonomic variation in responses to nutrients by repeating our analyses with Acropora spp. and Porites spp., the only two genera with enough replication for meaningful tests.

To test whether enrichment source affected coral growth we divided studies into groups based on whether enrichment was the result of naturally occurring fish excretion, anthropogenic pollution, or experimental manipulations of nutrient levels. We used Welch's T-tests to determine whether enrichment levels differed between $\mathrm{N}$ species (i.e. ammonium versus nitrate) and tested whether $\mathrm{N}$ species had differential effects on coral growth and photobiology. To account for the effect of background $\mathrm{N}$ and $\mathrm{P}$ levels on responses we used multiple regressions that included an interaction term for $\mathrm{N}$ and $\mathrm{P}$ to test for changes in the magnitude of effect size with control $\mathrm{N}$ and $\mathrm{P}$ levels for each of our metrics of growth and photobiology. For most organisms, there is a general expectation that performance peaks at an optimal level of nutrient supply, beyond which increases in nutrients have no impact or may even become toxic (Barboza et al. 2009). Therefore, using the MuMIn package in R (Barton 2012) we used AICc to select the best fit from linear and quadratic models to examine how the enrichment level and the ratio of $\mathrm{N}: \mathrm{P}$ provided impacted the effect sizes for each metric of growth and photobiology.

Although coral size and experimental duration could also affect the magnitude of coral responses to nutrients, there was not a wide enough range of either coral size or experimental duration for meaningful statistical analyses. Age of coral tissue can also influence growth rates (Elahi \& Edmunds 2007) but was not reported in any of the studies that we used. Therefore, we cannot exclude the possibility that age played a role in the reported growth differences. However, 
most studies used in our analysis used similar sized coral fragments cut from the distal portions of adult colonies, suggesting that the tissue age was similar among the corals in each study.

\section{Results}

Studies used for our analyses of coral growth came from both manipulative experiments in the lab and field as well as measurements taken along existing nutrient gradients. $\mathrm{N}$ and $\mathrm{P}$ enrichment ranged from 0.5-26 $\mu \mathrm{M}$ and 0.11-26 $\mu \mathrm{M}$ respectively (Table A1), which equated to levels that were $0.15-25.5 \mu \mathrm{M}$ higher than controls for $\mathrm{N}$ and $0.05-25.5 \mu \mathrm{M}$ higher for phosphorus. All of the studies used to explore the effects of nutrient availability on Symbiodinium and photosynthesis were tank-based except for four field-based experiments (Table A2). Nitrogen enrichment ranged from $1-50 \mu \mathrm{M}$ while $\mathrm{P}$ enrichment trials spanned $0.5-4 \mu \mathrm{M}$. This equated to nutrient levels $0.8-50$ and $0.4-4 \mu \mathrm{M}$ above control levels for $\mathrm{N}$ and $\mathrm{P}$ respectively. For studies that enriched in $\mathrm{N}+\mathrm{P}$ the range for $\mathrm{P}$ was similar to the single nutrient studies, $0.3-4 \mu \mathrm{M}(0.28-4$ higher than controls), while $\mathrm{N}$ levels were slightly more restricted than $\mathrm{N}$-only trials, 5 - $20 \mu \mathrm{M}$, (4$18 \mu \mathrm{M}$ higher than control levels).

\section{Coral Growth}

Nitrogen enrichment resulted in significant declines in coral calcification (mean $=-0.278$, $95 \% \mathrm{Cl}=-0.376 /-0.181$ ), which equated to $11 \%$ lower calcification rates on average (Fig. 2.1a). In contrast, $\mathrm{P}$ enrichment caused a significant increase in calcification, on average $9 \%$ greater than controls $($ mean $=0.136,95 \% \mathrm{Cl}=0.011 / 0.262)$. When provided in concert, $\mathrm{N}+\mathrm{P}$ had no effect on calcification (Fig. 2.1a). Branching corals made up $>70 \%$ of the replicates for all enrichment treatments. Therefore, the effect of nutrients on calcification in branching corals was nearly identical to the effect on all corals (Fig. 2.1b). For mounding corals, $\mathrm{N}$ enrichment caused a greater inhibition of calcification than was seen in branching morphologies (Fig. 2.1c). Calcification in Acropora spp. was not inhibited by $\mathrm{N}$ or $\mathrm{N}+\mathrm{P}$, but was enhanced in the presence of $\mathrm{P}$ alone (mean $=0.149,95 \% \mathrm{Cl}=0.039 / 0.259)($ Fig. 2.1d). For Porites spp., N enrichment caused a significant decline in calcification (mean $=-0.371,95 \% \mathrm{Cl}=-0.518 /-0.224)($ Fig. 2.1e). 
Although Porites spp. included both mounding and branching species, this reduction remained significant even when only branching Porites spp. were included (mean $=-0.378,95 \% \mathrm{Cl}=$ $0.523 /-0.233$ ) suggesting the effect was not solely driven by morphology. $N+P$ had no effect on calcification of Porites spp., and no studies documented the impact of $\mathrm{P}$ in isolation on calcification.

For coral extension rates, both $\mathrm{N}$ and $\mathrm{N}+\mathrm{P}$ had significant negative effects (mean = $0.414,95 \% \mathrm{Cl}=-0.740 /-0.089$ and $-0.231,95 \% \mathrm{Cl}=-0.393 /-0.069$ respectively; Fig. A1a). $\mathrm{P}$ enrichments increased extension rates by $35.4 \%$ over control corals but this effect was not significant (mean $=0.248,95 \% \mathrm{Cl}=-0.257 / 0.752)$, possibly due to high variability and low replication $(n=5)$. Enrichment had no significant effects on skeletal density. However, replication was low and there were trending negative effects of $\mathrm{P}$ and $\mathrm{N}+\mathrm{P}$ enrichment, which caused a nearly $9 \%$ and $10 \%$ decline in skeletal density respectively (Fig. A1b).

When we assessed how background nutrient levels impacted the effect of enrichment, the only significant pattern was a decline in effect size as control nutrient levels rose for the effect of phosphorus on coral calcification rates (Table A3), suggesting that initial differences in nutrient limitation minimally influenced patterns in effect sizes. Similarly, enrichment level had little impact on effect sizes. In every case, linear models best described the relationship between enrichment level and effect size, but these best fit models yielded no significant relationships (Table A4). When we assessed how the ratio of $\mathrm{N}: \mathrm{P}$ impacted corals, replication was only sufficient to examine studies that utilized ammonium and phosphorus for enrichment. For these studies, the relationship between effect size and N:P ratio was best explained by a quadratic model for calcification and skeletal extension and a linear model for skeletal density (Table A5). The ratio of $\mathrm{N}: \mathrm{P}$ provided had a marginally significant effect on calcification and a significant effect on skeletal extension ( $d f=2,8, F=4.26, p=0.055$ and $d f=2,9, F=4.64, p=0.041$ respectively; Fig. A2). In both cases, effect sizes peaked near the Redfield Ratio of $16: 1, N: P$, however our results should be interpreted with caution as the replication across the range of ratios provided was low and N:P ratios were confounded with enrichment level. 


\section{Coral Photobiology}

Nitrogen enrichment caused significant increases in the amount of chlorophyll a within the Symbiodinium of corals (Fig. 2.2a; mean $=0.204,95 \% \mathrm{Cl}=0.072 / 0.338$ ) while enrichment with P caused a nearly $20 \%$ decline but the $95 \%$ confidence intervals crossed zero slightly (mean $=-0.269,95 \% \mathrm{Cl}=-0.582 / 0.045)$, likely due to low replication $(n=6)$. When provided together, both nutrients resulted in an average $15 \%$ increase in chlorophyll $a$ and a similar mean effect to $\mathrm{N}$ alone although the effect of $\mathrm{N}+\mathrm{P}$ was not significant (mean $=0.185,95 \% \mathrm{Cl}=-0.186 / 0.556)$.

$\mathrm{N}$ enrichment resulted in higher Symbiodinium densities than in control corals (mean = $0.260,95 \% \mathrm{Cl}=0.150 / 0.370$ ), and when $\mathrm{N}$ and $\mathrm{P}$ were provided together the effect size more than doubled $($ mean $=0.549,95 \% \mathrm{Cl}=0.292 / 0.806)($ Fig. 2.2b). There was no effect of $\mathrm{P}$ on Symbiodinium density. Accordingly, because both $\mathrm{N}$ and $\mathrm{N}+\mathrm{P}$ enrichments increased the chlorophyll a in Symbiodinium and the Symbiodinium density in corals, the effects of these enrichments on chlorophyll a per unit of coral tissue were even more pronounced. Both $\mathrm{N}$ and $\mathrm{N}+\mathrm{P}$ significantly increased the density of chlorophyll $\mathrm{a}$ in corals (mean $=0.824,95 \% \mathrm{Cl}=$ $0.516 / 1.133$ and mean $=0.978,95 \% \mathrm{Cl}=0.494 / 1.146$ respectively) (Fig. 2.2c) whereas $\mathrm{P}$ again had no effect. Our analysis of gross photosynthetic rates revealed that $\mathrm{N}$ enrichment elicited higher rates of photosynthesis (mean $=0.232,95 \% \mathrm{Cl}=0.032$ to 0.432 ) while the effect of $\mathrm{P}$ was non-significant and highly variable and N+P lacked sufficient replication for analysis (Fig. 2.2d). Because $\sim 80 \%$ of the studies that examined nutrients and coral photobiology were conducted on branching corals, we did not attempt comparisons between functional groups or genera. There were no significant effects of enrichment level or $\mathrm{N}: \mathrm{P}$ ratio on any of our metrics of photobiology for which we had sufficient data to analyze (Tables A3 \& A4).

\section{Enrichment Source}

Enrichment source was analyzed to determine whether naturally-occurring enrichment processes impacted coral growth differently than did anthropogenic pollution or manipulative enrichment. We found six experiments from five studies examining the effect of natural, fishderived enrichment (fish excretion) on coral calcification rates. Two experiments from two studies 
reported the effect of this type of enrichment on extension rates of corals and one experiment reported the effect on skeletal density. In all cases the effect of natural enrichment on corals was positive, although due to low replication, only significant for calcification (mean $=0.353,95 \% \mathrm{Cl}=$ 0.109/0.598) (Fig. 2.3). In contrast, when enrichment was the result of anthropogenic pollution, such as wastewater delivery or high levels of agricultural runoff, nutrients resulted in a $5 \%$ decline in average calcification rates (mean $=-0.120,95 \% \mathrm{Cl}=-0.289 / 0.050$ ), although the $95 \%$ confidence intervals slightly crossed zero. In manipulative experiments, $\mathrm{N}$ enrichment resulted in significant declines in calcification (mean $=-0.278,95 \% \mathrm{Cl}=-0.375 /-0.181$ ) and extension rates (mean $=-0.476,95 \% \mathrm{Cl}=-0.870 /-0.081)$ while $\mathrm{P}$ enrichment caused increased calcification (mean $=0.136,95 \% \mathrm{Cl}=0.012 / 0.261)$ but had no effect on other growth metrics. $\mathrm{N}+\mathrm{P}$ enrichment caused significant reductions in extension rates (mean $=-0.508,95 \% \mathrm{Cl}=-0.751 /-$ 0.264) but had no effect on calcification or skeletal density. We were unable to explore the impact of enrichment source on coral photobiology because all but two studies were from manipulative experiments.

Differences between ammonium and nitrate enrichment were analyzed only for studies of calcification, chlorophyll a within Symbiodinium, and Symbiodinium density due to lack of replication for other metrics. For coral growth studies, when ammonium was the sole source of Nenrichment, $\mathrm{N}$ concentrations were over 1.5 times higher than when nitrate used for enrichment $(13.59 \mu \mathrm{M}$ vs. $8.07 \mu \mathrm{M}$ respectively; $\mathrm{t}=2.11, \mathrm{df}=18.07, \mathrm{p}=0.05)$. Similarly, for studies of photobiology ammonium was provided at nearly 3 times higher concentrations than nitrate in single $\mathrm{N}$ enrichment studies $(20.62 \mu \mathrm{M}$ vs. $7.66 \mu \mathrm{M} ; \mathrm{t}=4.13, \mathrm{df}=59.17, \mathrm{p}=0.001)$. Nitrate caused a significant reduction in calcification (Mean $=-0.476,95 \% \mathrm{Cl}=-0.583 /-0.369$ ) while there was no effect of ammonium (mean $=-0.037,95 \% \mathrm{Cl}=-0.150 / 0.075)$ (Fig. 2.4a). Nitrate also caused a significant increase in chlorophyll a density within Symbiodinium (mean $0.278,95 \% \mathrm{Cl}=0.017 / 0.538)$ but again ammonium had no effect (Fig. 2.4b). In contrast, only ammonium caused a significant increase in the Symbiodinium density within coral tissue (mean = 
0.508, 95\% $\mathrm{Cl}=0.334 / 0.683$ ) (Fig. 2.4c) while nitrate had a trending positive, but non-significant, effect $($ mean $=0.106,95 \% \mathrm{Cl}=-0.036 / 0.249)$.

\section{Discussion}

Nutrient loading represents one of the greatest threats to the function of coastal ecosystems (Vitousek et al. 1997b). Our analyses of the effects of nutrient loading on coral the coral-algal mutualism both supports and challenges some commonly held beliefs concerning the impact of nutrients on corals. In general, our data support the broadly held notion that nitrogen inhibits coral growth (reviewed by Fabricius 2005). However, we show that these effects are context-dependent and vary with coral taxa, $\mathrm{N}$ identity (ammonium vs. nitrate), enrichment source (fish excretion vs. anthropogenic nutrients), and the presence or absence of P. Furthermore, rather than suppressing growth as has been commonly assumed, $\mathrm{P}$ enrichment enhances calcification in corals but may compromise skeletal integrity. Nitrogen drives the effects of nutrient loading on coral photobiology but acts synergistically with $\mathrm{P}$ in co-enrichments to further increase Symbiodinium populations. Ultimately, our analyses suggest that changing nutrient loading patterns in coastal oceans will impact the dynamics of the coral-algal mutualism and may alter their susceptibility to stressors associated with global climate change.

Nitrogen enrichment decreased coral growth (Fig. 2.1) while increasing all metrics of coral photobiology (Fig. 2.3). These patterns are consistent with proposed $\mathrm{N}$-induced inhibition of growth via DIC limitation whereby abundant Symbiodinium fix carbon so rapidly that it becomes limiting for calcification in the coral (Muscatine et al. 1989). Unexpectedly, this is dependent on nitrogen identity with nitrate causing strong reductions in calcification but ammonium having no effect (Fig. 2.4). Significantly, higher concentrations of ammonium vs. nitrate could have contributed to this pattern. However, if the magnitude of enrichment were the primary driver of patterns in coral growth, then coral growth rates should have been lower in ammonium enrichment studies than in nitrate enrichment experiments. Yet, we showed that nitrate strongly inhibited coral growth while ammonium had no effect. 
Instead, the different effects of $\mathrm{N}$ identity may be driven by differential utility of ammonium and nitrate by Symbiodinium and subsequent changes in the delivery of photosynthate to coral hosts. Coral calcification is enhanced during periods of photosynthesis (Gattuso et al. 1999), presumably through internal changes in $\mathrm{pH}$ or the delivery of surplus oxygen or photosynthetic products to the coral host (Tambutte et al. 2011). However, unlike ammonium, nitrate utilization by photoautotrophs requires an energetically costly reduction (Patterson et al. 2010), potentially reducing the benefits that Symbiodinium provide to the coral by decreasing the surplus energy available for transfer to the host when nitrate is the dominant $\mathrm{N}$ source. This may also explain increases in Symbiodinium density under ammonium but not nitrate enrichment, as marine microalgae often have higher specific growth rates when using ammonium versus nitrate due to the differential costs of utilization (Raven 1992).

The density and species composition of mutualists may also shape the response of symbioses to altered abiotic conditions. For example, species-specific plant traits shape the diversity and abundance of their mycorrhizal associates (Eom et al. 2000), consequentially impacting the response of plants to enrichment (Johnson et al. 2008). Here, taxa specific differences in Symbiodinium density may have shaped the response of different coral taxa to nutrient enrichment, with $\mathrm{N}$ inhibiting calcification more strongly in mounding morphologies and Poritids than in branching morphologies or Acroporids (Fig 2.1). Symbiodinium densities are typically lower in branching versus mounding corals (Li et al. 2008), and Poritids had twice the Symbiodinium density of Acroporids (mean $=2.608 * 10^{6}$ versus $1.133 * 10^{6}$ respectively) in our dataset. These differences may result in lower rates of DIC use, and consequently less DIC limitation, in Acroporids and branching corals. Additionally, mass transfer rates are faster in branching corals, allowing replenishment of DIC from the water column more rapidly than in mounding corals and further mitigating carbon limitation associated with higher Symbiodinium densities under nutrient enrichment (van Woesik et al. 2012). This taxonomic variation in responses to nutrients means that coral species composition could influence the vulnerability of reefs to nutrient loading. For example, in the Caribbean almost half of reef-building corals are 
Poritids or mounding species, possibly making these reefs more susceptible to the negative effects of excess nutrients than reefs in regions such as the Indo-Pacific with more Acroporids and branching corals.

In contrast to the negative effects of nitrogen, $\mathrm{P}$ enrichment increased calcification rates of corals (Fig 2.1) but had no effect on extension rates or skeletal density. This pattern was surprising given that phosphorus inhibits calcium carbonate precipitation (Lin and Singer 2006). However coral calcification involves active biomineralization, rather than passive precipitation of $\mathrm{CaCO}_{3}$ (Tambutte et al. 2011). Dunn et al. (2012) proposed that corals incorporate $\mathrm{CaHPO}_{4}$ into the skeleton when phosphate is abundant, allowing calcification to proceed at high phosphorus levels but distorting the skeletal lattice and creating a more porous coral skeleton. While we found no significant evidence of reduced skeletal density to support this hypothesis, five of six measurements in our analysis reported decreased skeletal density under $\mathrm{P}$ enrichment. Decreased skeletal density but increased rates of calcification seem to be at odds with one another. However, because calcification was often measured via changes in coral mass, rates of calcification may not have changed significantly. Rather, corals may have incorporated a greater amount of heavy $\mathrm{CaHPO}_{4}$ into their skeletons, instead of $\mathrm{CaCO}_{3}$, resulting in heavier but more porous skeletons as Dunn et al. (2012) suggested. Increased porosity leads to greater susceptibility of corals to boring organisms and breakage (Caroselli et al. 2011), potentially making them more vulnerable to disturbances under $\mathrm{P}$ enrichment.

Synergistic effects of $\mathrm{N}$ and $\mathrm{P}$ on primary production are common across a variety of ecosystems (Elser et al. 2007). However, the coral-Symbiodinium mutualism adds complexity with nutrients directly affecting both the coral and their mutualists. The only synergistic effect of $\mathrm{N}$ and $\mathrm{P}$ in our analyses was on Symbiodinium density with $\mathrm{N}+\mathrm{P}$ enrichment having more than twice the effect of $\mathrm{N}$ alone and 15 times more than $\mathrm{P}$ alone (Fig 2.2b). Despite super-additive responses in Symbiodinium and the apparent increase in photosynthesis, the effects of N+P on coral growth were largely additive (Fig. 2.1). Thus for Symbiodinium growth, enrichment with N+P over the range of levels provided appears to shift nutrient limitation to whichever of the two is 
least abundant yielding synergistic effects. Yet for calcification, $\mathrm{N}$ enrichment appears to shift limitation to DIC, regardless of $\mathrm{P}$ level. Furthermore, $\mathrm{P}$ may actually alleviate DIC limitation in part by replacing carbonate in the skeletal lattice with $\mathrm{HPO}_{4}$ (Dunn et al. 2012), effectively cancelling out the negative effect of $\mathrm{N}$ and explaining the absence of effects of $\mathrm{N}+\mathrm{P}$ in our analyses. Ultimately, $\mathrm{N}$ and $\mathrm{P}$ appear to impact the coral-Symbiodinium mutualism in fundamentally different ways.

One surprising pattern in our analyses was the differential effect of enrichment source on corals. Natural enrichment via fish excretion always enhanced coral growth (Fig. 2.3). In contrast, human-derived nutrients, whether from manipulative experiments or anthropogenic pollution, tended to have negative effects on corals. Differences in nutrient identity, concentration, and consistency between fish excretion and human-derived nutrients as well physical parameters like the flow rates around corals may drive these differential effects. For example, fish excretion delivers primarily ammonium and $\mathrm{P}$ (Meyer and Schultz 1985b), while anthropogenic enrichment tended to deliver more nitrate, which easily leaches from soils relative to phosphorus (Appendix 1). Our analyses show that nitrate tends to slow coral growth while ammonium has little effect (Fig. 2.4). Further, the combined ammonium and $\mathrm{P}$ delivered by fishes may benefit corals more than $\mathrm{N}$-dominated anthropogenic sources as $\mathrm{N}$-only enrichment drove decreases in coral calcification (Fig. 2.1). Fishes may also be a source of particulate organic matter which corals could ingest, further enhancing their growth rates (Meyer and Schultz 1985b).

Fishes could also alter rates of nutrient uptake by increasing mixing in the water column via their movement around corals and facilitate mass transfer. Additionally, water flow may influence the impact of different nutrient sources. For example, downstream plumes from river discharge on the Great Barrier Reef range from $0.26 \mu \mathrm{M}$ to $16.1 \mu \mathrm{M} \mathrm{N}$, depending on distance from shore and the water currents at each site (Schaffelke and Klumpp 1998). Similarly, when nutrients are delivered in discrete pulses, such as via fish excretion or upwelling events, currents and tidal flushing can quickly dissipate nutrients from an area and modify either their positive or negative impact (Hatcher \& Larkum 1983). As a result, water flow can act as either a dissipater or 
deliver of nutrients depending on the origin of enrichment, potentially modifying the differential effects of nutrients.

Animals are often important sources of limiting nutrients across many disparate ecosystems. For example, large ungulates can facilitate primary production in terrestrial systems via urine and dung deposits (Burkepile 2013). Likewise, fishes often deliver important limiting nutrients in oligotrophic ecosystems (Allgeier et al. 2013) and can be important sources of nutrients on coral reefs (Burkepile et al. 2013). Thus, overfishing on coral reefs, an important driver of change in these ecosystems (Hughes et al. 2007), could disrupt the critical link between fish excretion and corals and dramatically alter production and coral growth (Layman et al. 2011). Given that increasing human populations along coastlines result in both overfishing and increased input of anthropogenic nutrients to coastal waters (Halpern et al. 2008), the trajectory of current global change may mean that corals suffer from a reduction of beneficial nutrient sources and an increase in detrimental ones.

Excess nutrients may also increase coral susceptibility to the effects of climate change such as coral bleaching, due to the effects of nutrient availability on Symbiodinium. Wooldridge and Done (2009) suggested that nutrient-induced increases in Symbiodinium density drove correlations between water-column nitrogen and bleaching on the Great Barrier Reef. Additionally, Cunning and Baker (2012) found that elevated Symbiodinium densities in corals increased their susceptibility to bleaching due to increased production of reactive oxygen species during periods of thermal/light stress. Thus, the nutrient-induced increases in Symbiodinium from both $\mathrm{N}$ and $\mathrm{N}+\mathrm{P}$ enrichment that we show (Fig. 2.2) may make corals more vulnerable as bleaching conditions become more common. Furthermore, $\mathrm{N}$ enrichment in the absence of increased P can lead to P starvation of Symbiodinium, further increasing bleaching susceptibility (Wiedenmann et al. 2012). As a result, the simultaneous loading with $N$ and $P$, such as from fish excretion, may actually be less harmful to, or even benefit, corals under bleaching conditions.

Nutrients also interact with other important drivers of coral reef decline that warrant consideration. For example, disease is a strong driver of coral decline on reefs worldwide (Bruno 
et al. 2007), and although nutrients influence the pathology of coral diseases (Vega Thurber et al. 2013), the role of specific nutrients in coral epidemiology remains unknown. Similarly, interactions between nutrient loading and ocean acidification require critical analysis. Increased atmospheric $\mathrm{CO}_{2}$ lowers oceanic $\mathrm{CO}_{3}{ }^{2-}$ concentrations and impairs calcification (Hoegh-Guldberg et al. 2007). How DIC-limited photosystems of enriched corals will respond to these changes remains unclear, but preferential use of $\mathrm{CO}_{3}{ }^{2-}$ by Symbiodinium could exacerbate the negative effects of nutrients as $\mathrm{CO}_{2}$ levels rise (Marubini et al. 2008). Our analysis also highlights several gaps in our understanding of the effects of nutrient loading on reefs. In particular, experiments assessing a wider range of enrichment levels are needed to assess non-linear responses to enrichment. For example, Gil (2013) documented a unimodal growth curve for Porites spp. across a gradient of enrichment in which peak growth occurred between $1-3 \mu \mathrm{M} \mathrm{N}$ and declined above this level. In our analyses, almost $75 \%$ of the studies we found used enrichment levels higher than these peak values, potentially explaining the linear decline in coral growth with increasing enrichment levels that we found and the absence of expected unimodal responses to nutrient enrichment. Ultimately, our work emphasizes the importance of nutrient availability to the health of coral reefs and that a more nuanced understanding of impact of nutrients on corals is sorely needed.

At a more fundamental level, our analyses provide insight into the effects of nutrient loading on symbiotic interactions. Cost-benefit tradeoffs in symbioses are often state-dependent and exogenous factors, such as nutrient availability, may dictate where such interactions fall along the continuum of mutualism and parasitism (Leung and Poulin 2008). For example, Wooldridge (2010) proposed that the coral host maintains active control of $\mathrm{N}$ delivery to Symbiodinium in order to regulate symbiont populations. In this case, $\mathrm{N}$ loading may alter the cost-benefit tradeoff for Symbiodinium by alleviating dependence on host-derived N. In turn this disrupts the coral's control over Symbiodinium populations, leading to increased competition between the host and symbiont for DIC and photosynthate, which may be monopolized by the now N-replete Symbiodinium for population growth. Increased Symbiodinium populations and slower coral growth under $\mathrm{N}$ enrichment documented here support these hypotheses that nutrient 
enrichment can potentially decouple this mutualism. In analogous plant-mycorrhizae (Hoeksema et al. 2010) and legume-Rhizobium (Zahran 1999) symbioses, increased nutrient availability from nutrient loading can reduce the benefits provided by symbionts to plant hosts and push these interactions from mutualism to parasitism. Our study reveals similar patterns in the responses of foundational marine species and suggests that there may be general patterns in how nutrientsharing mutualists respond to nutrification. Understanding patterns such as these are a fundamental goal of ecology and provide insight into how global change will impact community structure and function.

\section{References}

Allgeier, J. E., L. Yeager, and C. Layman. (2013). Consumers regulate nutrient limitation regimes and primary production in seagrass ecosystems. Ecology, 94, 521-529.

Barton, K. (2012). Package 'MuMIn'. Model selection and model averaging based on information criteria. $\mathrm{R}$ package version 1.7.11.

Barboza, P. S., K. L. Parker, and I. D. Hume. (2009). Integrative wildlife nutrition. Springer-Verlag, Berlin, Germany.

Bruno, J. F., E. R. Selig, K. S. Casey, C. A. Page, B. L. Willis, C. D. Harvell, H. Sweatman, and A. M. Melendy. 2007. Thermal stress and coral cover as drivers of coral disease outbreaks. PLoS Biology,5, e124.

Burkepile, D. E., and M. E. Hay. (2006). Herbivore vs. nutrient control of marine primary producers: context-dependent effects. Ecology, 87, 3128-3139.

Burkepile, D. E., and M. E. Hay. (2009). Nutrient versus herbivore control of macroalgal community development and coral growth on a Caribbean reef. Marine Ecology Progress Series, 389, 71-84.

Burkepile, D. E. (2013). Comparing aquatic and terrestrial grazing ecosystems: Is the grass really greener? Oikos, 122, 306-312.

Burkepile, D. E., J. E. Allgeier, A. A. Shantz, C. E. Pritchard, N. P. Lemoine, L. H. Bhatti, and C. A. Layman. (2013). Nutrient supply from fishes facilitates macroalgae and suppresses corals in a Caribbean coral reef ecosystem. Scientific Reports, 3, 1493.

DOI:10.1038/srep01493

Caroselli, E., F. Prada, L. Pasquini, F. N. Marzano, F. Zaccanti, G. Falini, Z. Dubinsky, and S. Goffredo. (2011). Environmental implications on skeletal micro-density and porosity variation in two scleractinian corals. Zoology, 114, 255-264. 
Carpenter, S. R., N. F. Caraco, D. L. Correll, R. W. Howarth, A. N. Sharpley, and V. H. Smith. (1998). Nonpoint pollution of surface waters with phosphorus and nitrogen. Ecological Applications, 8, 559-568.

Conley, D. J., H. W. Pearl, R. W. Howarth, D. F. Boesch, S. P. Seitzinger, K. E. Havens, C. Lancelon, G. E. Likens. (2009). Controlling eutrophication: Nitrogen and Phosphorus. Science, 323, 1014-1015.

Cunning, R. and A. C, Baker. (2012). Excess algal symbionts increase the susceptibility of reef corals to bleaching. Nature Climate Change, 3, 259-262.

Dunn, J. G., P. W. Sammarco, and G. LaFleur. (2012). Effects of phosphate on growth and skeletal density in the scleractinian coral Acropora muricata: A controlled experimental approach. Journal of Experimental Marine Biology and Ecology, 411, 34-44.

Elahi, R. and P. J. Edmunds. (2007). Tissue age affects calcification in the scleractinian coral Madracis mirabilis. The Biological Bulletin, 212, 20-28.

Elser, J. J., M. E. S. Bracken, E. E. Cleland, D. S. Gruner, W. S. Harpole, H. Hillebrand, J. T. Ngai, E. W. Seabloom, J. B. Shurin, and J. E. Smith. (2007). Global analysis of nitrogen and phosphorus limitation of primary producers in freshwater, marine and terrestrial ecosystems. Ecology letters, 10, 1135-42.

Eom, A-H, D. C. Hartness, and G. W. T. Wilson. (2000). Host plant species effects on arbuscular mycorrhizal fungal communities in tallgrass prairie. Oecologia, 122, 435-444.

Fabricius, K. E. (2005). Effects of terrestrial runoff on the ecology of corals and coral reefs: review and synthesis. Marine pollution bulletin, 50(2), 125-46.

Gattuso, J.-P., D. Allemand, and M. Frankingnoulle. (1999). Photosynthesis and calcification at cellular, organismal and community levels in coral reefs: A review of interactions and control by carbonate chemistry. American Zoologist, 39, 160-183

Godinot, C., C. Ferrièr-Pages, P. Montagna, and R. Grover. (2011). Tissue and skeletal changes in the scleractinian coral Stylophora pistillata Esper 1797 under phosphate enrichment. Journal of Experimental Marine Biology and Ecology, 409, 200-207.

Gil, M. A. (2013). Unity through nonlinearity: A unimodal coral-nutrient interaction. Ecology, 94, 1871-1877.

Halpern, B. S., S. Walbridge, K. A. Selkoe, C. V. Kappel, F. Micheli, C. D’Agrosa, J. F. Bruno, K. S. Casey, C. Ebert, H. E. Fox, R. Fujita, D. Heinemann, H. S. Lenihan, E. M. P. Madin, M. T. Perry, E. R. Selig, M. Spalding, R. Steneck, and R. Watson. (2008). A global map of human impact on marine ecosystems. Science, 319, 948-52.

Harpole, W.S. and D. Tilman. (2007). Grassland species loss resulting from reduced niche dimension. Nature, 446, 791-793.

Harpole, W. S., J. T. Ngai, E. E. Cleland, E. W. Seabloom, E. T. Borer, M. E. S. Bracken, J. J. Elser, D. S. Gruner, H. Hillebrand, J. B. Shurin, and J. E. Smith. (2011). Nutrient colimitation of primary producer communities. Ecology letters, 14(9), 852-62. 
Hatcher, B. G. and A. W. D. Larkum. (1983). An experimental analysis of factors controlling the standing crop of the eplithic algal community on a coral reef. Journal of Experimental Marine Biology and Ecology, 69, 61-84.

Herre, E., N. Knowlton, U. Mueller, and S. Rehner. (1999). The evolution of mutualisms: exploring the paths between conflict and cooperation. Trends in ecology and evolution, 14(2), 49-53.

Hoegh-Guldberg, O. and G. J. Smith. (1989). Influence of the population density of zooxanthellae and supply of ammonium on the biomass and metabolic characteristics of the reef corals Seriatopora hystrix and Stylophora pistillata. Marine Ecology Progress Series, 57, 173-186.

Hoegh-Guldberg, O., P. J. Mumby, A. J. Hooten, R. S. Steneck, P. Greenfield, E. Gomez, C. D. Harvell, P. F. Sale, A. J. Edwards, K. Caldeira, N. Knowlton, C. M. Eakin, R. Iglesias-Prieto, N. Muthiga, R. H. Bradbury, A. Bubi, and M. E. Hatziolos. (2007). Coral reefs under rapid climate change and ocean acidification. Science, 318(5857), 1737-42.

Hoeksema, J.D., V.B. Chaudhary, C. A. Gehring, N. C. Johnson, J. Karst, R. T. Koide, A. Pringle, C. Zabinski, J. D. Bever, J. C. Moore, G. W. Wilson, J.N. Klironomos, and J. Unbanhowar. (2010). A meta-analysis of context-dependency in plant responses to inoculation with mycorrhizal fungi. Ecology Letters, 13, 394-407.

Holbrook, S.J., A. J. Brooks, R. J. Schmitt, and H. L. Stewart. (2008). Effects of sheltering fish on growth of their host corals. Marine Biology, 155, 521-530.

Howarth, R. W., G. Billen, D. Swaney, A. Townsend, N. Jaworski, K. Lahtha, J. A. Downing, R. Elmgren, N. Caraco, T. Jordan, F. Berendse, J. Freney, V. Kudeyarov, P. Murdoch and Z. Zhao-liang. (1996). Regional nitrogen budgets and riverine N \& P fluxes for the drainages to the North Atlantic Ocean: Natural and human influences. Biogeochemistry, 35, 75-139.

Hughes, T. P., D. R. Bellwood, C. S. Folke, L. J. McCook, and J. M. Pandolfi. (2007). No-take areas, herbivory and coral reef resilience. Trends in ecology and evolution, 22(1), 1-3.

Johnson, N. C., J. H Graham, and F. A. Smith. (1997). Functioning of mycorrhizal associations along the mutualism-parasitism continuum. New Phytologist, 135, 575-585.

Johnson, N. C., D. L. Rowland, L. Corkidi, and E. B. Allen. (2008). Plant winners and losers during grassland $\mathrm{N}$-eutrophication differ in biomass allocation and mycorrhizas. Ecology, 89, 2868-2878.

Layman, C. A., J. E. Allgeier, A. D. Rosemond, C. P. Dahlgren, and L. A. Yeager. (2011). Marine fisheries declines viewed upside down: human impacts on consumer-driven nutrient recycling. Ecological Applications, 21(2), 343-349.

Leichter, J. J. and S. J. Genovese. (2006). Intermittent upwelling and subsidized growth of the scleractinian coral Madracis mirabilis on the deep fore-reef slope of Discovery Bay, Jamaica. Marine Ecology Progress Series, 316, 95-103.

Li, S., K. F. Yu, Q. Shi, T. R. Chen, M. X. Zhao, and J. X. Zhao. (2008) Interspecies and spatial diversity in the symbiotic zooxanthellae density in corals from the northern South China Sea and its relationship to coral reef bleaching. Chinese Science Bulletin, 53, 295-303.

Lin, Y.-P., and P. C. Singer. (2006). Inhibition of calcite precipitation by orthophosphate: Speciation and thermodynamic considerations. Geochemica et Cosmochimica Acta, 70, 2530-2539. 
Leung, T., and R. Poulin. (2008). Parasitism, commensalism, and mutualism: exploring the many shades of symbioses. Vie et Milieu - Life and Environment, 58(2), 107-115.

Marubini, F., C. Ferrier-Pages, P. Furla, and D. Allemand. (2008). Coral calcification responds to seawater acidification: a working hypothesis towards a physiological mechanism. Coral Reefs, 27, 491-499.

McCook, L. J. (1999). Macroalgae, nutrients and phase shifts on coral reefs: scientific issues and management consequences for the Great Barrier Reef. Coral Reefs, 18(4), 357-367.

Meyer, J. L., and E. T. Schultz. (1985a). Tissue condition and growth rate of corals associated with schooling fish. Limnology and Oceanography, 30(1), 157-166.

Meyer, J. L., and E. T. Schultz. (1985b). Migrating haemulid fishes as a source of nutrients and organic matter on coral reefs. Limnology and Oceanography, 30(1), 146-156.

Mumby, P. J., and R. S. Steneck. (2008). Coral reef management and conservation in light of rapidly evolving ecological paradigms. Trends in ecology and evolution, 23(10), 555-563.

Muscatine, L., W. Porter, and I. R. Kaplan. (1989). Resource partitioning by reef corals as determined from stable isotope composition ${ }^{1} . \delta^{13} \mathrm{C}$ of zooxanthellae and animal tissue vs depth. Marine Biology, 100, 185-193.

Muscatine, L., C. Ferrier-Pagès, A. Blackburn, R. D. Gates, G. Baghdasarian, and D. Allemand. $(1998)$. Cell-specific density of symbiotic dinoflagellates in tropical anthozoans. Coral Reefs, 17, 329-337.

Patterson, K., T. Cakmak, A. Cooper, I. Lager, A. G. Rasmusson, and M. A. Escobar. (2010). Distinct signaling pathways and transcriptome response signatures differentiate ammoniumand nitrate-supplied plants. Plant, Cell and Environment, 33, 1486-1501.

Raven, J. A., B. Wollenweber, and L. L. Handley. (1992). A comparison of ammonium and nitrate as nitrogen sources for photolithorophs. New Phytologist, 121, 19-32.

Rosenberg, M. S., D. C. Adams, and J. Gurevitch. (1999). MetaWin: Statistical Software for MetaAnalysis. Version 2.0. Sinauer Associates, Sunderland, MA.

Schachtman, D. P., R. J. Reid, S. M. Ayling. (1998). Phosphorus uptake by plants: From soil to cell. Plant Physiology, 116, 447-453.

Schaffelke, B and D. W. Klump. (1998). Short-term nutrient pulses enhance growth and photosynthesis of the coral reef macroalga Sargassum baccularia. Marine Ecology Progress Series, 170, 95-105.

Smith, V. H., G. D. Tilman, J. C. Nekola. (1999). Eutrophication: Impacts of excess nutrient input on freshwater, marine, and terrestrial ecosystems. Environmental Pollution, 100, 179-196.

Stewart, G. (2010). Meta-analysis in applied ecology. Biology letters, 6(1), 78-81.

Szmant, A. M. (2002). Nutrient enrichment on coral reefs: is it a major cause of coral reef decline? Estuaries and Coasts, 25(4), 743-766. 
Tambutte, S., M. Holcomb, C. Ferrier-Pagès, S. Reynaud, É. Tambuttè, D. Zoccola, and D. Allemand. (2011). Coral biomineralization: From the gene to the environment. Journal of Experimental Marine Biology and Ecology, 408, 58-78.

Tilman, D. (1988). Plant strategies and the dynamics and structure of plant communities. Princeton University Press, Princeton, NJ.

Treseder, K. K. (2004). A meta-analysis of mycorrhizal responses to nitrogen, phosphorus, and atmospheric $\mathrm{CO}_{2}$ in field studies. New Phytologist, 164, 347-355.

Tummers, B. DataThief III. 2006. (http://datathief.org/).

van Woesik, R., A. Irikawa, R. Anzai, and T. Nakamura. (2012). Effects of coral colony morphologies on mass transfer and susceptibility to thermal stress. Coral Reefs, 31, 633639.

Vega-Thurber, R. L., D. E. Burkepile, C. Fuchs, A. A. Shantz, R. McMinds and J. R. Zaneveld. (2013). Chronic nutrient enrichment increases prevalence and severity of coral disease and bleaching. Global Change Biology, DOI: 10.111/gcb.12450.

Vitousek, P. M., H. A. Mooney, J. Lubchenco, and J. M. Melillo. (1997a). Human Domination of Earth's Ecosystems. Science, 277(5325), 494-499. doi:10.1126/science.277.5325.494

Vitousek, P. M., J. Aber, R. W. Howarth, G. E. Likens, P. A. Matson, D. W. Schindler, W. H. Schlesinger, and D. G. Tilman. (1997b). Human alteration of the global nitrogen cycle: sources and consequences. Ecological Applications, 7, 737-750.

Wiedenmann, J., C. D’Angelo, E. G. Smith, A. N. Hunt, F-E Legiret, A. D. Postle, and E. P. Achterberg. (2012). Nutrient enrichment can increase the susceptibility of reef corals to bleaching. Nature Climate Change, 3(2), 160-164.

Wooldridge, S. A. (2010). Is the coral-algae symbiosis really "mutually beneficial" for the partners? BioEssays, 32(7), 615-25.

Wooldridge, S. A. and T. J. Done. (2009). Improved water quality can ameliorate effects of climate change on corals. Ecological Applications, 19, 1492-1499.

Zahran, H. H. (1999). Rhizobium-Legume symbiosis and nitrogen fixation under sever conditions and in an arid climate. Microbiology and molecular biology reviews, 63, 968-989. 
Figure 2.1 - Cumulative effect sizes for coral calcification rates in response to enrichment with nitrogen $(N)$, phosphorus $(P)$ or joint nitrogen and phosphorus $(N+P)$. Responses are shown for: (a) all corals, (b) branching corals, (c) mounding corals, (d) Acropora spp., and (e) Porites spp. Data are means $\pm 95 \%$ confidence intervals. Numbers in parenthesis indicate the number of experiments used to calculate effect sizes.

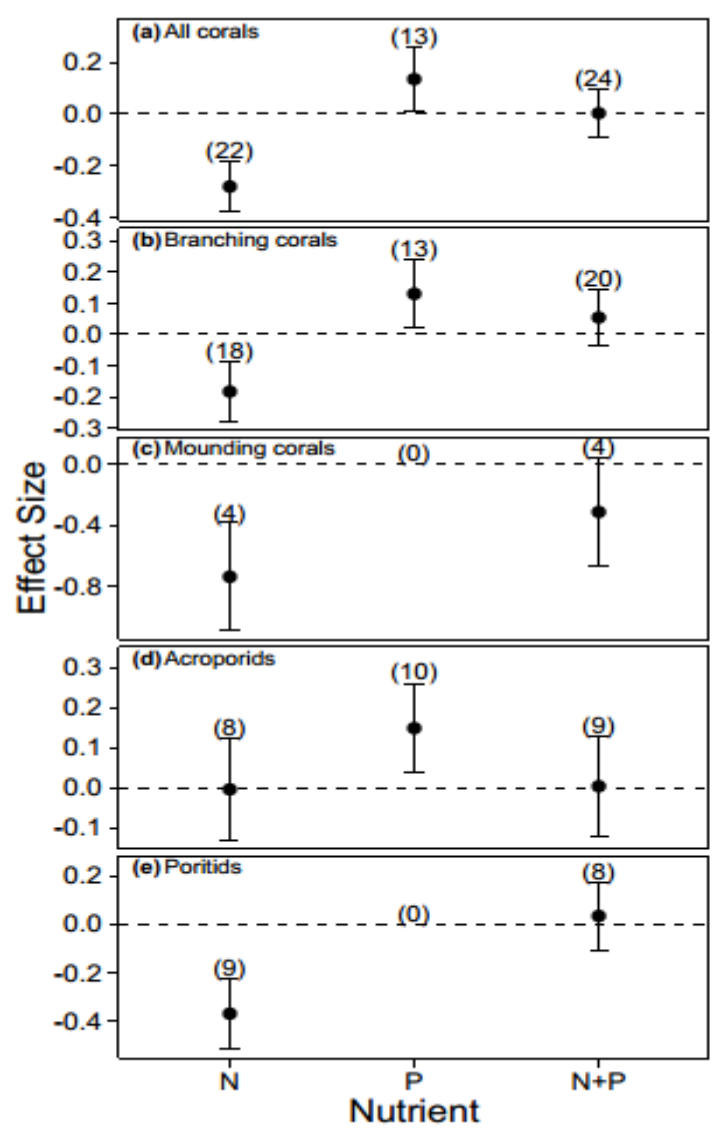


Figure 2.2 - Cumulative effect sizes of nutrient enrichment on different metrics of photobiology of corals: (a) the density of chlorophyll a within individual Symbiodinium, (b) the density of Symbiodinium within corals, (c) the density of chlorophyll a per area of coral, and (d) gross photosynthesis. Statistics as in Fig. 2.1

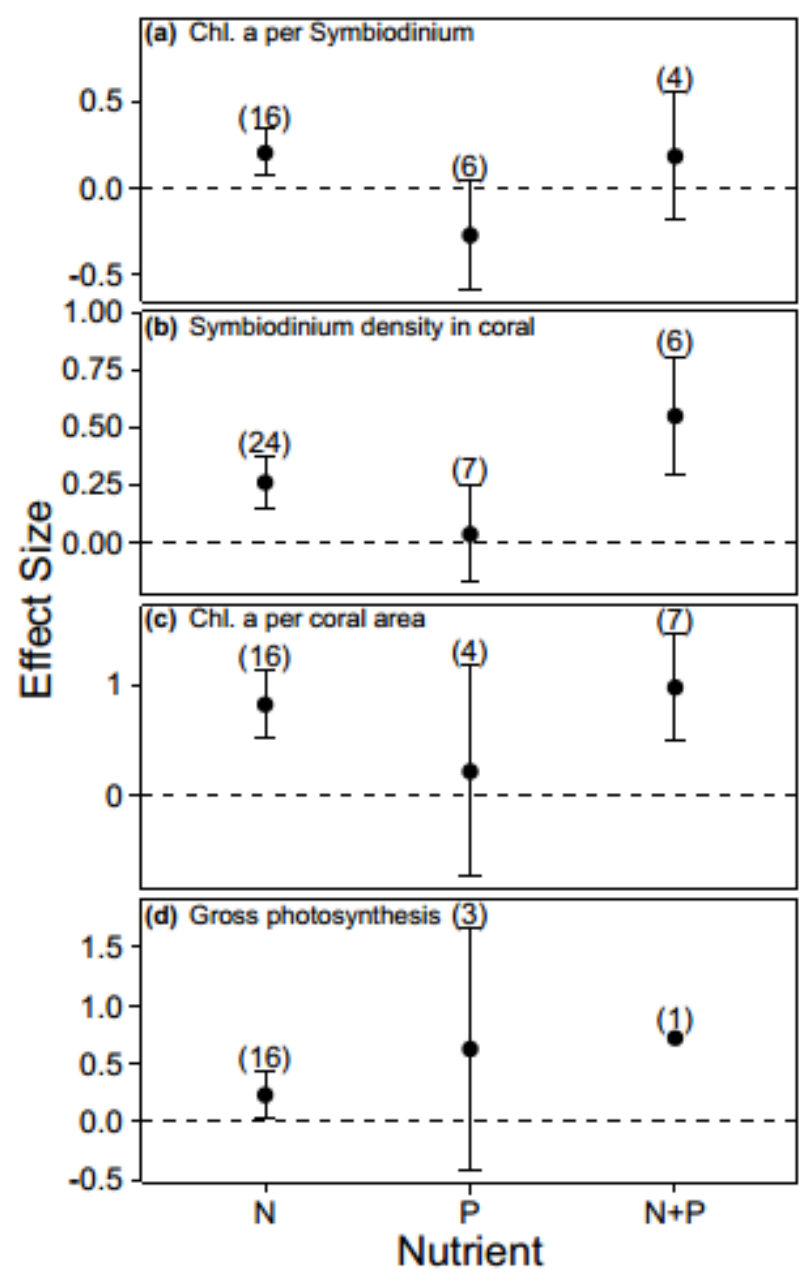


Figure 2.3 - Cumulative effect sizes of fish-derived (naturally occurring), manipulative, or anthropogenic nutrient enrichment on the calcification rates of corals. Nutrients provided for manipulative studies are indicated in parentheses on the X-axis. Statistics as in Fig. 1

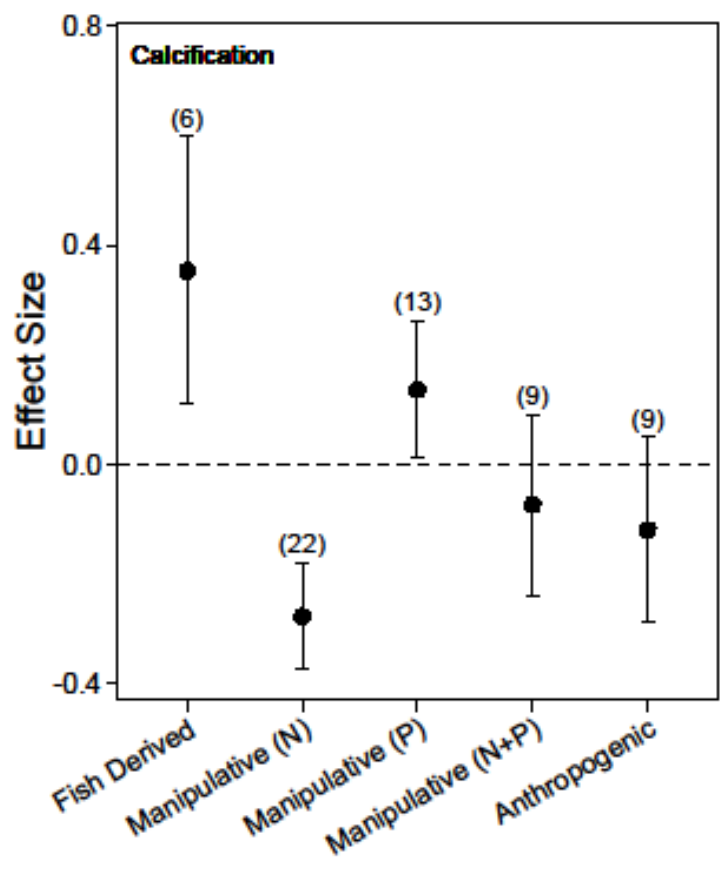


Figure 2.4 - Cumulative effect sizes for the impact of ammonium or nitrate on: (a) the calcification rates of corals, (b) the concentration of chlorophyll a within Symbiodinium, and (c) the density of Symbiodinium in coral tissue. Statistics as in Fig. 1

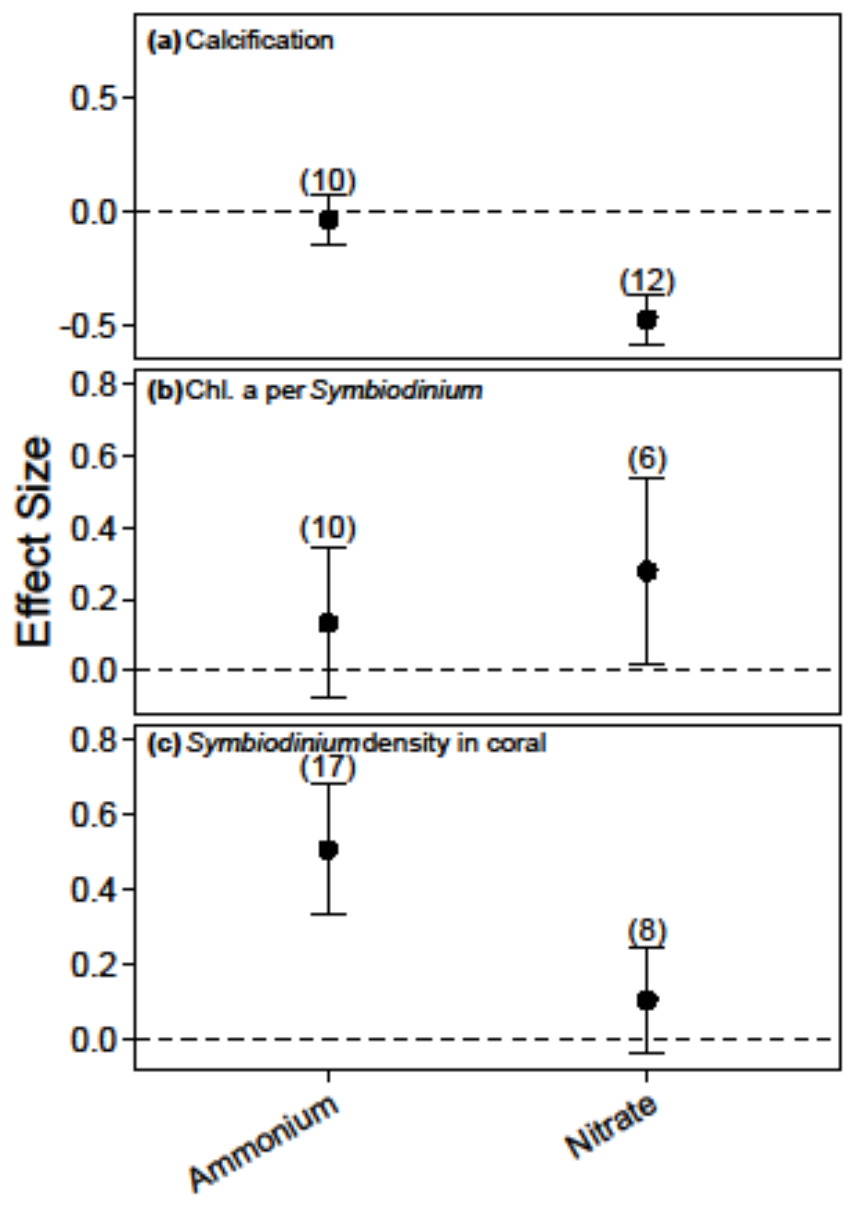




\section{CHAPTER III}

SPECIES-SPECIFIC DIFFERENCES IN THE GROWTH AND PHOTOBIOLOGY OF THREE CARIBBEAN CORALS UNDER NITRATE, AMMONIUM, AND PHOSPHATE ENRICHMENT 
Abstract

Chronic nutrient enrichment is an increasingly prevalent problem on coral reefs, yet there is still a great deal of uncertainty regarding how nutrient enrichment may impact coral physiology and performance. Here, we examined the impacts of prolonged nutrient enrichment on two important performance metrics: the photobiology and growth of three Caribbean corals. Over six weeks we tracked changes in the growth rates and functioning of photosystem II (PSII) in three reef building corals on a reef in the Florida Keys, USA. We enriched fragments of Acropora cervicornis, Montastraea cavernosa, and Siderastrea siderea with either nitrate $\left(\mathrm{NO}_{3}^{-}\right)$, ammonium $\left(\mathrm{NH}_{4}{ }^{+}\right)$, phosphorus $(\mathrm{P})$, or a combination of $\mathrm{NO}_{3}{ }^{-}$and $\mathrm{P}(\mathrm{NP})$ to compare with corals maintained at ambient nutrient levels. Using fluorometry, every week we measured the impact of each treatment regime on: (1) the maximum dark-adapted quantum yield of PSII ( $\left.F_{v} / F_{M}\right)$ before sunrise, (2) the excitation pressure on PSII under peak irradiance $\left(Q_{m}\right)$ and (3) the accumulation of photodamage at the end of the day $\left(q_{1}\right)$. At the culmination of the experiment we calculated the growth rates of each fragment to explore the relationship between growth and PSII performance. For A. cervicornis, we found no effects of any of the enrichment treatments on PSII performance, yet coral growth rates increased under $\mathrm{P}$ enrichment and declined in nitrogen treatments. For $M$. cavernosa, excitation pressure on PSII (Qm) was significantly elevated by treatments containing nitrate, phosphorus, or a combination of the two, and q। was significantly higher in nitrateenriched corals. Coral growth rate was negatively correlated with $\mathrm{Q}_{\mathrm{m}}$ in $M$. cavernosa. In contrast to the other species, Siderastrea siderea showed no changes in growth or PSII performance under any of the nutrient regimes. Our study indicates that chronic nutrient enrichment can impair PSII function and thereby reduce coral growth, but both nutrient identity and the species-specific responses of corals mediate the severity of these effects. On chronically polluted reefs, speciesspecific coral responses to enrichment like those we report here could shape the depth distribution of different species within reefs and provide insight into the vulnerability of different coral species to bleaching events. Thus, our data join a small but growing collection of literature 
showing that the identity and ratio of nutrients on reefs must be taken into consideration when considering how nutrient pollution will impact coral reefs.

Introduction

\section{Introduction}

Coral reefs are historically resilient ecosystems capable of enduring both acute and chronic disturbances (Connell 1997). However, in recent years, human activity has increased the frequency with which reefs are subjected to multiple stressors, jeopardizing the integrity of these ecosystems (Polidoro and Carpenter 2013). Perhaps one of the most ubiquitous and persistent sources of chronic stress is coastal nutrient loading (Fabricius 2005; Halpern et al. 2007). Although nutrient loading can often disrupt the performance of nutrient-exchange mutualisms, such as the coral-Symbiodinium partnership (Shantz et al. 2016, nutrient loading on reefs has predominantly been studied in conjunction with other stressors (e.g. overfishing - Burkepile and Hay 2009; Rasher et al. 2012; or thermal anomalies - Wooldridge 2009; Wiedenmann et al. 2012; Tanaka et al. 2014). As a result, we still have only a rudimentary understanding of how nutrients affect coral biology. Our lack of knowledge is particularly true of assessments of nutrient effects on corals over ecologically relevant time frames and under natural environmental conditions. Because the future of many reefs will depend on corals' ability to survive and grow under nutrient stress, a better understanding of how nutrient loading directly impacts corals is urgently needed.

Nutrients are believed to impact coral growth primarily via direct effects on Symbiodinium - the endosymbiotic dinoflagellates within corals. Reef building corals rely on photosyntheticallyderived carbohydrates from their endosymbionts for the majority of their energetic requirements (Houlbréque and Ferrier-Pagés 2009). Phosphorus (P) is vital for ATP production and energy transfer while nitrogen $(\mathrm{N})$ is an essential nutrient for protein synthesis, chlorophyll production, and photosynthesis (Shelly et al. 2010). Accordingly, both nutrients are essential for the energy production that sustains the coral-algal holobiont. Yet human-mediated increases in levels of these nutrients often impair coral growth (Fabricious 2005, Shantz and Burkepile 2014; Shantz et al. 2015). 
Various mechanisms may explain the different impacts of nutrient enrichment on corals. For example, P-enrichment increases coral growth (Shantz and Burkepile 2014) but this is likely the result of incorporation of calcium phosphate into the coral skeleton. Consequentially, Penriched corals grow faster but may be more susceptible to breakage (Dunn et al. 2012). Similarly, the increased photosynthesis that occurs under N-enrichment may monopolize dissolved inorganic carbon and make this resource limiting for calcification (Muscatine et al. 1998), reducing coral growth rates. However, in a recent meta-analysis Shantz and Burkepile (2014) found that only nitrate $\left(\mathrm{NO}_{3}{ }^{-}\right)$regularly impaired coral growth, despite ammonium $\left(\mathrm{NH}_{4}{ }^{+}\right)$ consistently benefitting Symbiodinium populations. Similarly, Ezzat et al. (2015) reported that $\mathrm{NH}_{4}{ }^{+}$enrichment increases photosynthesis in the coral Stylophora pistillata but found that $\mathrm{NO}_{3}$ - enrichment depressed photosynthesis. Thus, while there has been considerable progress resolving the complexity of coral nutrient interactions, substantial gaps in our understanding of how nutrients impact corals still remain.

One mechanism through which nutrients could affect corals is by influencing the production of reactive oxygen species (ROS). Oxygenic photosynthesis routinely produces ROS that damage organic tissue (Vass 2012), particularly the D1 protein in the reaction center of photosystem II (PSII) (Aro et al. 1993). Nitrogen enrichment may fuel ROS production by increasing Symbiodinium populations in corals and directly increasing ROS production (Wooldridge and Done 2009; Wooldridge 2013; Cunning and Baker 2012). Furthermore, rapidly proliferating Symbiodinium can monopolize $\mathrm{P}$, leading to $\mathrm{P}$-starvation. Because $\mathrm{P}$ is an important component of the thylakoid membrane, which actively sequesters and scavenges ROS, Pstarvation can alter the membrane's ionic character and increase oxidative damage (Lesser 2006; Shelly et al. 2010; Wiedenmann et al. 2012). D1 protein damage in PSII is a considerable burden for primary producers, both in terms of energy spent on PSII repair, and the photosynthetic production that cannot occur until the damaged D1 protein has been replaced. For example, normal daily rates of oxidative damage to PSII in plankton may reduce daily net photosynthesis by $20 \%$, monopolize $\sim 5 \%$ of protein budgets, and $\sim 15 \%$ phosphorus budgets (Raven 2011). 
Given this energetic cost of PSII damage, even minor nutrient-induced increases in ROS production could substantially reduce the energy transferred from Symbiodinium to their coral hosts and result in lowered coral growth rates.

Here, we examine changes in the growth and photobiology of three Caribbean corals subjected to five different nutrient regimes. Over six weeks, we maintained fragments of Acropora cervicornis, Montastraea cavernosa, and Siderastrea siderea under either ambient conditions, or enriched with $\mathrm{NO}_{3}{ }^{-}, \mathrm{NH}_{4}{ }^{+}, \mathrm{P}$, or a combination of $\mathrm{NO}_{3}{ }^{-}$and $\mathrm{P}$ at a $\sim 3: 1$ molar ratio (NP). We used pulse amplitude modulated (PAM) fluorometery to track changes in PSII performance and assessed the influence of these changes on the growth rates of each coral species. We predicted that chronic $\mathrm{NO}_{3}{ }^{-}, \mathrm{NH}_{4}{ }^{+}$, and NP enrichment would increase ROS production and elevate excitation pressure on PSII but this effect would be absent in P-enriched corals. For $\mathrm{NO}_{3}$ enrichments, we predicted that this would result in the accumulation of photodamage throughout the day. In contrast, due to the greater utilization efficiency of $\mathrm{NH}_{4}{ }^{+}$for photosynthesis (Ezzat et al. 2015), we predicted that $\mathrm{D} 1$ protein turnover rates would be enhanced under $\mathrm{NH}_{4}{ }^{+}$ enrichment, allowing for the complete recovery of PSII and negligible effects on photochemical efficiency. Similarly, we predicted that despite increased pressure on PSII in NP enrichments the additional $\mathrm{P}$ would alleviate P-starvation, helping to maintain the integrity of the thylakoid membranes and minimizing oxidative damage to PSII. Cumulatively, we expected these patterns to lead to reduced coral growth rates under $\mathrm{NO}_{3}$ - treatments but that this effect would be ameliorated under the other enrichment regimes.

\section{Materials \& Methods}

\subsection{Experimental Setup}

In July 2014 we deployed 20 experimental growth platforms at 8-9 m depth on a sand flat near Pickles Reef in the Florida Keys National Marine Sanctuary, USA $\left(24.99^{\circ} \mathrm{N} 80.40^{\circ} \mathrm{W}\right)$. Each platform consisted of a $75 \times 50 \times 4 \mathrm{~cm}$ (length $\mathrm{x}$ width $\mathrm{x}$ height) concrete base supporting a ring of six, $25 \mathrm{~cm}$ tall PVC stands with flat caps (Fig. 3.1). Growth platforms were deployed at least $3 \mathrm{~m}$ 
apart from each other. We epoxied a single coral fragment to the cap on each stand so that each platform contained two A. cervicornis, two M. cavernosa, and two S. siderea fragments haphazardly arranged on the PVC stands. For $A$. cervicornis, we cut $10 \mathrm{~cm}$ fragments with a single apical tip from parent colonies of the same genotype provided by the Coral Restoration Foundation. For M. cavernosa and S. siderea two colonies of each, provided by the NOAA Nursery in Key West, FL, USA, were cut into $10 \mathrm{~cm} \times 10 \mathrm{~cm}$ fragments. Corals were epoxied to the growth platforms in early July and given two weeks to acclimate to conditions at the field site. After two weeks, we collected all 120 coral fragments and transported them to shore in fresh seawater. We then measured the buoyant weight for each fragment and calculated the surface area of live tissue using a standard foil technique (Marsh 1970). We then returned all of the fragments to the field on the same day and allowed the corals an additional 5 day recovery period before beginning the nutrient enrichment portion of the study.

On July $31,2014^{t}$ we began nutrient enrichment treatments. Each growth platform was randomly assigned to one of five treatments (control, $\mathrm{NO}_{3}{ }^{-}, \mathrm{NH}_{4}{ }^{+}, \mathrm{P}$, or $\mathrm{NP} ; n=4$ platforms per treatment with each platform holding 2 fragments of each coral species). Enrichment was achieved by adding enough slow release fertilizer of the appropriate type (Floricote ${ }^{\mathrm{TM}}$ Slow Release Nitrate, Ammonium, Phosphate, or a combination of Nitrate and Phosphate) to provide $25 \mathrm{~g}$ of the desired nutrient. Fertilizer pellets were poured into $15 \times 6.5 \mathrm{~cm}$ (length $\mathrm{x}$ diameter) PVC tubes with six $1.5 \mathrm{~cm}$ holes drilled in the sides to facilitate water flow, and then wrapped in window screen. One PVC tube containing the desired nutrient treatment was secured to the center of each growth platform. This method has been successfully used in the past and shown to successfully enrich $\sim 1 \mathrm{~m}$ radius around the nutrient diffusers up to 6 weeks (e.g. Burkepile and Hay 2009; Vega Thurber et al., 2014). Nonetheless, to ensure our enrichments were working, we collected water samples from $25 \mathrm{~cm}$ above the base of growth platform from each treatment 14 days after placing the fertilizer tubes at the start of the experiment. Water samples were slowly drawn into $60 \mathrm{ml}$ acid-washed syringes, GF/F filtered into acid washed bottles and frozen until analysis. For analysis, ammonium, nitrate, and soluble reactive phosphorus (SRP) concentrations 
were determined via autoanalyzer. At the end of the experiment, we collected all of the corals to obtain final buoyant weights and calculate growth rates.

\subsection{Photobiology Measurements}

We used PAM fluorometry to quantify the performance of PSII. Measurements were taken once a week from approximately the same spot on each coral fragment, using markings on each PVC stand as a guideline. We deployed two Odyssey cosine light loggers (Dataflow Systems, Christchurch, NZ) at opposite ends of the experimental area to record relative downwelling irradiance. Using a diving PAM we measured the maximum dark adapted quantum yield of PSII both before and after sunset and the effective light dependent reduction in quantum yield at solar noon. These data allowed us to quantify three parameters of PSII health:

(i) Maximum dark adapted quantum yield before sunrise (hereafter $F_{v} / F_{m}$ ). These values range from $0-1$ and are the ratio of photons absorbed by PSII that are directed towards photochemistry versus those emitted as fluorescence (See Maxwell and Johnson 2000 for a review on chlorophyll fluorescence). Numbers closer to 1 indicate a greater portion of absorbed light is directed towards photochemistry. Although values are species dependent (Suggett et al. 2009), lower $F_{v} / F_{m}$ values within a species are often an early indicator of stress (Maxwell and Johnson 2000).

(ii) Maximum excitation pressure on PSII $\left(Q_{m}\right)$. We used measurements of the effective light dependent reduction in quantum yield of each fragment at solar noon ( $\Delta \mathrm{F} / \mathrm{Fm}$ ') and the dark adapted quantum yield before sunrise to calculate $Q_{m}$ as 1- $\left[\left(\Delta F / F_{m}{ }^{\prime}\right) /\left(F_{v} / F_{m}\right)\right]$ (Iglesias-Prieto et al. 2004). Qm values range from 0-1. Values near zero occur when there is little pressure on PSII and can indicate light limitation. Increasing values occur as the reaction centers within PSII are closed, which occurs through the normal process of photochemistry or when the D1 protein within the reaction center is damaged. Thus increasing values of $Q_{m}$ can be indicative of photodamage (Warner et al. 2010).

(iii) Photoinhibition at the end of the day $\left(q_{1}\right)$. Because PSII repair is energetically expensive, the vast majority of D1 repair can only occur during the day, thus differences 
in the maximum dark adapted yield in the morning before sunrise and the dark adapted yield immediately after sunset are indicative of accumulated photodamage throughout the day (Aro et al. 1993; Hill et al. 2005). We calculated $q_{1}$ as $\left[1-\left(\left(F_{v} / F_{m}\right.\right.\right.$ in the evening)/ $\left(F_{v} / F_{m}\right.$ in the morning $\left.\left.)\right)\right]$ such that values ranged from -1 to 1 with values significantly greater than zero indicative accumulated photodamage to PSII.

\subsection{Analysis}

Understanding the effects of chronic enrichment on PSII requires incorporating natural environmental variability over an ecologically relevant time period. Symbiodinium can photoacclimate by changing their macromolecular composition to maximize performance under different environmental regimes as well as photoadapt over time as some symbiont genotypes outperform others within host corals (Huot and Babin 2010). In addition, environmental conditions (e.g., cloud cover, temperature, salinity, water flow; Maxwell and Johnson 2000) and the interactions between them can influence PSII performance. For example, rates of water flow mediate the effect of temperature on PSII performance (Carpenter and Patterson 2007). Furthermore, PSII performance is also dependent on the recent environmental history corals experience. For example severe photodamage one day would depress the maximum dark adapted quantum yield the next morning, potentially impacting measurements of $Q_{m}$ and $q_{1}$ made later that day. As a result, measurements from one week to the next are highly variable and the data needed for more meaningful assessment of temporal changes in PSII performance (i.e., daily measurements) were beyond the logistic capabilities of our study. Instead, we calculated the average values of each metric of photobiology $\left(F_{v} / F_{m}, Q_{m}\right.$ and $\left.q_{I}\right)$ for each coral fragment to assess the cumulative effects of enrichment over time. Although less preferable to more dataintensive repeated measures designs, this allowed us to capture the biologically relevant responses of corals through time while reducing the possibility of making spurious conclusions based on anomalous environmental conditions from individual days.

We used these averaged values for each coral as a response variable in a nested mixed effects models to analyze the cumulative impact of nutrient enrichment on each metric of PSII 
performance and the size-corrected growth rates of each coral. In each model, corals were nested within their respective platforms. Treatment was considered a fixed effect with 5 levels (C, $\mathrm{NO}_{3}{ }^{-}, \mathrm{NH}_{4}+, \mathrm{P}$, and $\mathrm{NP}$ ) and we included a random effect for potential variability between platforms. When significant differences were detected, we used Tukey's HSD to determine differences between the treatment levels. Throughout the study, corals were periodically broken, likely by turtles (pers. obs.), and preyed on by parrotfish (see Results). Preliminary analyses of the photobiology data revealed that as long as the tissue was not damaged near the sight of fluorescence measurements, there was no impact on our measurements of quantum yield. Therefore, for our analyses of photobiology, we only excluded corals in which damage occurred within $2 \mathrm{~cm}$ of the original measurement site or breakage made measuring the same location impossible.

For our analyses of coral growth however, corallivory and breakage resulted in substantial losses in skeletal mass. Therefore, all of the broken and predated corals were excluded from our growth analyses. For $A$. cervicornis this resulted in the exclusion of all but one of the control fragments. Therefore, to test the effect of nutrients on A. cervicornis growth we excluded the control coral and tested for differences between the four enrichment types only. Our analysis revealed significant differences in growth between $A$. cervicornis enriched with $\mathrm{P}$ versus those subjected to other enrichment regimes (see Results). Based on these differences we treated these corals as two different populations and used a modified $t$-test for single samples to test the probability that the growth rate of the single remaining control coral was equal to either of the populations (Sokal and Rohlf 1995). While this approach is not ideal, it was the only way to quantitatively test our hypotheses given the loss of the control corals.

To assess whether PSII performance influenced coral growth rates, we used mixed effects models similar to those described above, with growth rates as the response variable and including the average $F_{v} / F_{m}, Q_{m}, q_{1}$, scores as predictors rather than nutrient treatment. We once again included a random effect for platform, which encompassed both potential random environmental variability between platforms as well as any nutrient effects on corals not 
represented in our metrics of photobiology. For each coral species, the optimal model was selected by fitting multiple models with all combinations of the predictors and comparing the Akaike Information Criterion corrected for small sample sizes (AICC) (Anderson 2008). For the three best models we calculated marginal and conditional $R^{2}$ values to examine the percentage of variation explained by each model (Nakagawa and Schielzeth 2013). Marginal $\mathrm{R}^{2}$ values represent the variance explained by the fixed effects and were calculated as:

$$
R_{(m)}^{2}=\frac{\sigma_{f}^{2}}{\sigma_{f}^{2}+\sum\left(\sigma_{l}^{2}\right)}+\sigma_{e}^{2}+\sigma_{d}^{2}
$$

where $\sigma_{f}^{2}$ is the variance of the fixed effects and $\sum\left(\sigma_{l}^{2}\right)$ is the sum of all variance components and $\sigma_{d}^{2}$ is variance due to additive dispersion. Conditional $\mathrm{R}^{2}$ values are the variance explained by the full model and were calculated as:

$$
R_{(c)}^{2}=\frac{\left(\sigma_{f}^{2}+\sum\left(\sigma_{l}^{2}\right)\right)}{\sigma_{f}^{2}+\sum\left(\sigma_{l}^{2}\right)}+\sigma_{e}^{2}+\sigma_{d}^{2}
$$

Thus, comparing the marginal vs. conditional $R^{2}$ values allows us to determine the variance in growth explained by the fixed effects (i.e. parameters of PSII performance) versus variance in growth explained by the random effect (i.e. additional effects of nutrients beyond PSII performance and random variation by platform).

All analyses were conducted in R (R Core Team 2012) using the nlme and MuMIn packages (Barton 2014; Pinheiro et al. 2015). Assumptions of normality and equal variances were verified via Shapiro-Wilk and Levine's Tests and visual examination of QQ plots.

\section{Results}

\subsection{Nutrient Measurements}

For $\mathrm{NO}_{3}{ }^{-}, \mathrm{NH}_{4}{ }^{+}$, and $\mathrm{P}$ enrichments water column nutrient samples suggested our enrichments were substantially increasing levels of the desired nutrients. Nitrate enrichment resulted in $3.18 \mu \mathrm{M} \mathrm{NO}_{3}{ }^{-}$compared to $0.71 \mathrm{MM} \mathrm{NO}_{3}{ }^{-}$at the control platform. Similarly $\mathrm{NH}_{4}{ }^{+}$ enrichment $(1.71 \mu \mathrm{M})$ and $\mathrm{P}$ enrichment $(3.51 \mu \mathrm{M})$ were both substantially higher than the control 
levels of these nutrients ( 0.47 and $0.14 \mu \mathrm{M}$ respectively). In the NP enrichment levels were still 2$3 x$ greater than control levels $\left(1.07 \mathrm{MM} \mathrm{NO}_{3}{ }^{-}\right.$and $\left.0.47 \mu \mathrm{M} \mathrm{P}\right)$ however, they were lower than the levels recorded in the individual $\mathrm{NO}_{3}-$ and $\mathrm{P}$ enrichment. This difference was likely because by alleviating $\mathrm{NO}_{3}-$ and $\mathrm{P}$ limitation, both nutrients were utilized until another nutrient became limiting (Sterner and Elser 2002).

\subsection{Coral Photobiology}

Because of breakage and corallivory, we excluded 7 measurements from our analyses of PSIl performance (A. cervicornis: $1 \mathrm{NO}_{3}{ }^{-}, 1 \mathrm{NH}_{4}{ }^{+}, 1 \mathrm{NP}, 1 \mathrm{P}$; M. cavernosa: $1 \mathrm{NP} ; \mathrm{S}$. siderea: $1 \mathrm{C}$ and $1 \mathrm{NH}_{4}^{+}$). Dark adapted quantum yield was highest for $A$. cervicornis, intermediate for $S$. siderea and lowest for $M$. cavernosa, but there were no effects of enrichment on any of the three species (Fig. 3.2a). In contrast, $Q_{m}$, the excitation pressure exerted on PSII during peak irradiance, was lowest for $A$. cervicornis, highest for $M$. cavernosa, and again intermediate for $S$. siderea. Enrichment had no effect on $\mathrm{Q}_{\mathrm{m}}$ values for $A$. cervicornis or S. siderea but significantly affected $Q_{m}$ for $M$. cavernosa $\left(F_{4,15}=5.04, p<0.01\right.$; Fig 3.2b). For these corals, average $Q_{m}$ was $\sim 40 \%$ higher than controls in $\mathrm{NO}_{3}^{-}, \mathrm{NP}$, and $\mathrm{P}$ enriched corals but statistically indistinguishable from controls in $\mathrm{NH}_{4}{ }^{+}$enrichments. Similarly, nutrient enrichment had no effect on q, for $A$. cervicornis or $\mathrm{S}$. siderea but significantly increased the average photoinhibition in $\mathrm{NO}_{3}{ }^{-}$enriched M. cavernosa $\left(F_{4,15}=5.25, p<0.01\right.$; Fig. 3.2c).

\subsection{Coral Growth}

Breakage and corallivory forced us to exclude 35 measurements of coral growth from our analyses (A. cervicornis: $7 \mathrm{C}, 1 \mathrm{NO}_{3}{ }^{-}, 4 \mathrm{NH}_{4}{ }^{+}, 4 \mathrm{NP}, 4 \mathrm{P}$; M. cavernosa: $1 \mathrm{NO}_{3}^{-}, 1 \mathrm{NH}_{4}{ }^{+}, 1 \mathrm{NP}, 1$ P; and S. siderea: $3 \mathrm{C}, 3 \mathrm{NO}_{3}{ }^{-}, 4 \mathrm{NH}_{4}{ }^{+}, 1 \mathrm{NP}$ ). Despite the loss of replication, we found speciesspecific effects of enrichment on coral growth. On average, P-enriched A. cervicornis grew $2.51 \pm$ $0.04 \mathrm{mg} \cdot \mathrm{cm}^{-2} \cdot$ day $^{-1}$ (mean $\pm \mathrm{SE}$ ), significantly faster than those enriched with any type of nitrogen $\left(1.93 \pm 0.14,1.72 \pm 0.19\right.$ and $1.84 \pm 0.17$ for $\mathrm{NO}_{3}{ }^{-}, \mathrm{NH}_{3 / 4}$, and NP respectively; $\mathrm{F}_{3,9}=3.97$, $p=0.047$; Fig. 3.3). Furthermore, the lone control coral grew at an intermediate rate of $2.14 \mathrm{mg}$. $\mathrm{cm}^{-2}$. day ${ }^{-1}$ which differed from both the P-enriched population $\left(\mathrm{t}_{(4)}=-136.35, \mathrm{p}<0.01\right)$ and the 
$\mathrm{N}$-enriched population $\left(t_{(15)}=2.63 p=0.019\right)$. Due to large variance between replicates, we found no significant effect of enrichment on $M$. cavernosa growth rates $\left(F_{4,15}=2.22 p=0.12\right)$. However, there appeared to be a trend towards $\mathrm{P}$ and particularly $\mathrm{NH}_{4}{ }^{+}$increasing $M$. cavernosa growth relative to controls (Fig. 3.3). Siderastrea siderea growth rates were the most variable of the three corals. Growth patterns were qualitatively similar to A. cervicornis, (i.e., control and P-enriched corals growing fastest, $\mathrm{NO}_{3}{ }^{-}, \mathrm{NH}_{4}{ }^{+}$, and NP enriched corals growing more slowly) but differences between the treatments groups were statistically indistinguishable $\left(F_{4,12}=0.51, p=0.72\right)$.

\subsection{Model Selection}

For all three coral species, the single best explanatory model of coral growth included $\mathrm{Q}_{\mathrm{m}}, \mathrm{q}_{\mathrm{I}}$, and the interaction between the two factors (Table 3.1). For A. cervicornis this model explained $75 \%$ of the variation in coral growth, although $64 \%$ of the variation resulted from the random platform effect (which included different enrichment types) and only 11\% could be attributed to differences in photobiology. For M. cavernosa, the best model explained $64 \%$ of the variation in coral growth rates, nearly $30 \%$ of which was explained by the metrics of PSII performance. Finally, the best fitting model for S. siderea accounted for only $10 \%$ of the variation in growth, all of which could be attributed to the metrics of PSII performance.

\section{Discussion}

Nutrient loading presents a significant threat to coral reefs. Understanding how nutrients influence coral photobiology, and consequentially coral performance, will help predict how reefs respond to ongoing changes water quality associated with global change. Our study revealed species-specific variations in the responses of three corals to different types of nutrient enrichment. For $A$. cervicornis the responses in three common metrics of PSII health and performance were surprisingly consistent across all four types of enrichment and explained little variation in coral growth. However, the growth rates of these corals were significantly elevated under phosphorus enrichment (Fig. 3.3). In contrast, for M. cavernosa none of the enrichment treatments affected coral growth, but $\mathrm{N}$ enrichment did significantly increase excitation pressure 
and photoinhibition of PSII. Furthermore, changes in these metrics of photobiology explained nearly one third of the observed differences in $M$. cavernosa growth rates. Siderastrea siderea appeared to be the most tolerant species to nutrient enrichment, displaying no significant changes in growth or photobiology under any of the enrichment regimes. Thus, our study highlights the varied responses of corals to nutrient loading depend on coral species identity and the type of nutrient.

Nutrient enrichment is well known to impact the growth rates of corals. Yet, it is often unclear if these effects are associated with impacts on the coral endosymbionts, their photobiology, or the calcification process itself. Our study suggests that nutrients influence all three and that these effects are likely dependent on the coral species in question and their environment. For A. cervicornis we found no significant effects of nutrients on any of our metrics of photobiology, but still found significant differences in coral growth between treatments. Acropora cervicornis subjected to P-enrichment grew faster than any other corals while those subjected to any of the various $\mathrm{N}$ containing enrichments grew more slowly (Fig. 3.3). Whether this was due to increased growth under P-enrichment or decreased growth under $\mathrm{N}$-enrichments is less certain, as all but one replicate of the controls were broken. Higher growth rates under Penrichment may occur if $\mathrm{P}$ is incorporated directly into the $\mathrm{CaCO}_{3}$ lattice of the coral skeleton (Dunn et al. 2012). The optimal model of the effects of PSII performance on coral growth supports this as metrics of $A$. cervicornis photobiology explained only $11 \%$ of the variation in coral growth rates. Yet, the overall effects of nutrients, irrespective of their impacts on photobiology, explained over five times as much of the observed variation in growth rates (Table 3.1).

In contrast, we found that nutrients had significant effects on $\mathrm{Q}_{\mathrm{m}}$ and $\mathrm{q}_{1}$ in $M$. cavernosa and these explained the most variation in observed coral growth rates. Average excitation pressure on PSII was significantly elevated by $\mathrm{NO}_{3}{ }^{-}, \mathrm{P}$, and NP enrichments (Fig. 3.2b), indicating a greater potential for the accumulation of photodamage in these corals. Although $\mathrm{N}$ enrichment can increase Symbiodinium density, which may increase ROS production and damage to PSII (Cunning and Baker 2012), we found no effect of $\mathrm{NH}_{4}{ }^{+}$enrichment on $\mathrm{Q}_{\mathrm{m}}$. 
Previous studies have shown that $\mathrm{NH}_{4}{ }^{+}$enrichment results in greater levels carbohydrate production during photosynthesis and higher protein content in Symbiodinium (Ezzat 2015). Therefore, it is possible that higher turnover rates of damaged D1 proteins in $\mathrm{NH}_{4}{ }^{+}$enriched corals drove the differences in PSII performance between $\mathrm{NO}_{3}{ }^{-}$and $\mathrm{NH}_{4}{ }^{+}$enrichments. Because photosynthesis is often correlated with the quantum yield of PSII, this could lead to greater rates of net photosynthesis in $\mathrm{NH}_{4}{ }^{+}$enriched corals and consequentially account for the significant relationship between $\mathrm{Q}_{\mathrm{m}}$ and $M$. cavernosa growth. Additionally, despite comparable levels of $\mathrm{Qm}_{\mathrm{m}}$ under $\mathrm{NO}_{3}{ }^{-}, \mathrm{NP}$ and $\mathrm{P}$ enrichments, q was significantly elevated only in $\mathrm{NO}_{3}{ }^{-}$enriched corals (Fig. 3.2c). Phosphorus-starvation jeopardizes the integrity of the thylakoid membrane (Wiedenmann et al. 2012), which plays an important role in containing and scavenging ROS to prevent damage to chloroplasts (Asada 2006). Therefore, the additional P in NP and P enrichments may have alleviated P-starvation and thereby reduce the accumulation of photodamage throughout the day. Thus, $\mathrm{NO}_{3}$-appears to increase photodamage in corals while $\mathrm{NH}_{4}{ }^{+}$and $\mathrm{P}$ could actually help repair and alleviate photodamage.

In contrast to both A. cervicornis and M. cavernosa, we found no effects of nutrients on S. siderea growth or any of the three metrics of PSII performance. For these corals the overall patterns in PSII performance were similar to those recorded in $M$. cavernosa but the values were generally lower and more variable. Our inability to detect any significant effects of nutrients or photobiology on growth may have been due to lower replication, as there were more S. siderea replicates that were excluded due to corallivory as compared to M. cavernosa. However this would still not explain why we did not detect any effects of enrichment on PSIl performance. Instead these corals may simply be more physiologically tolerant to different nutrient regimes. Coral species vary in their stress responses, such as the production Heat Shock Proteins, and these differences can mediate their tolerance to environmental stress (Fitt et al. 2009). The apparent tolerance for a wide array of nutrient regimes may explain the distribution and success of Siderastrea spp. across a variety of habitats, including heavily human impacted ones (Muthiga and Szmant 1987; Lirman and Manzello 2009). 
Numerous additional factors likely contributed to the species-specific responses to nutrient loading documented here. Acropora cervicornis is a shallow water species that is adapted for high light levels (Torres et al. 2007), and the low $Q_{m}$ values we recorded here suggest that the ambient light at our experimental site put very little pressure on PSII in these corals. Had we conducted this study at shallower depths it is possible that we may have observed stronger responses in A. cervicornis photobiology. Differences in morphology were likely important as well, as growth form (i.e. plating vs. mounding vs. branching), tissue thickness, and skeletal architecture all influence the realized light levels that corals experience (Enríquez et al. 2005; Hoogenboom et al. 2008; Wangpraseurt et al. 2012). Thus branching A. cervicornis likely experienced very different realized light levels than the mounding M. cavernosa and S. siderea. Furthermore, at equivalent levels of water flow branching corals typically experience greater rates of mass transfer than mounding species (van Woesik et al. 2012). As a result, $A$. cervicornis may be more capable of reducing pressure on PSII by dissipating excess absorbed energy as heat (i.e. non-radiative quenching; Cosgrove and Borowitzka 2010) than the two mounding morphologies. Additionally, some clades of Symbiodinium are more resistant to heat and light stress than others (Robinson and Warner 2006). Unfortunately we were unable to assess Symbiodinium clade. However, the differences in photobiology responses between the morphologically similar $M$. cavernosa and S. siderea could be a result of differences in symbiont identity, as S. siderea often hosts a greater diversity of Symbiodinium clades than does $M$. cavernosa (Finney et al. 2010). The overall importance of each of these factors is likely to be context dependent and future research exploring how these factors interact with nutrient availability to explain the resilience of corals may be fruitful.

Our results suggest that both the identity of nutrients and their stoichiometric ratio have important effects on coral photobiology. The low values of $\mathrm{Q}_{\mathrm{m}}$ we recorded in $M$. cavernosa under $\mathrm{NH}_{4}{ }^{+}$enrichment and lower $\mathrm{q}_{1}$ values under $\mathrm{NH}_{4}{ }^{+}, \mathrm{NP}$, and $\mathrm{P}$ enrichments suggest that these nutrients may not be as harmful as $\mathrm{NO}_{3}{ }^{-}$. Of particular interest for future researchers may be the potential for $\mathrm{P}$ to alleviate some of the harmful effects of $\mathrm{NO}_{3}{ }^{-}$loading on $\mathrm{PSII}$, as the average 
level of D1 protein damage in M. cavernosa under NP enrichments was nearly $60 \%$ lower than under similar levels of $\mathrm{NO}_{3}{ }^{-}$enrichment alone (Fig. 3.2c). Furthermore, preserving natural nutrient pathways on reefs may help to alleviate harmful nutrient pollution. For example, fish excretion is predominantly comprised of $\mathrm{NH}_{4}{ }^{+}$and $\mathrm{P}$, typically at low $\mathrm{N}: \mathrm{P}$ ratios (Shantz et al. 2015), and thus may reduce or alleviate damage to PSII. The combined roles of $\mathrm{NH}_{4}{ }^{+}$and $\mathrm{P}$ from fishes may be one reason why fish-derived nutrients often benefit coral growth (Shantz and Burkepile 2014). Unfortunately, because $\mathrm{P}$ is readily bound by calcareous sediments (Jensen et al. 1998) and nitrification rapidly converts $\mathrm{NH}_{4}{ }^{+}$to $\mathrm{NO}_{3}{ }^{-}$(Peterson et al. 2001), nutrients in ground water and terrestrial run-off are predominantly elevated in $\mathrm{NO}_{3}{ }^{-}$(Heisler et al. 2008). Thus, attempts to manage high-nutrient levels on impacted reefs should consider the identity and ratios of the nutrients present.

Species-specific responses to nutrient loading may affect the competitive abilities of corals and ultimately influence their abundance and distribution on chronically enriched reefs. For example, the depth distribution of some corals can be explained by measurements of excitation pressure on PSII (Iglesias-Prieto et al. 2004). By elevating $Q_{m}$, chronic enrichment, particularly with $\mathrm{NO}_{3}{ }^{-}$, could drive more vulnerable corals from their upper depth distributions and influence the coral species composition on reefs across a depth gradient. The interaction between $\mathrm{Q}_{\mathrm{m}}$ and depth may also be particularly important when bleaching events occur. While nutrient loading can increase the frequency and severity of bleaching (Wooldridge and Done 2009; Vega Thurber et al. 2014), there is often a depth refuge where temperature and light levels are lower and corals do not bleach (Smith et al. 2014). By increasing pressure on PSII, enrichment may extend bleaching to deeper portions of the reef. This could be particularly problematic for reefs where the maximum depth is limited or for coral species whose growth is restricted to shallow waters. Thus understanding how coral species respond to nutrient enrichment may be a critical component of predicting the future of coral reefs in a rapidly changing world. 


\section{References}

Anderson, D. R., 2008. Model based inferences in the life science: a primer in evidence. Springer Science, New York.

Aro, E. M., McCaffery, S., \& Anderson, J. M. (1993). Photoinhibition and D1 Protein Degradation in Peas Acclimated to Different Growth Irradiances. Plant Physiol. 103, 835-843.

Asada, K., 2006. Production and scavegning of reactive oxygen species in chloroplasts and their functions. Plant Physiol. 141, 391-396.

Barton, K., 2014. MuMIn: Multi-model inference. Version 1.15.1

Burkepile, D.E., Hay, M.E., 2009. Nutrient versus herbivore control of macroalgal community development and coral growth on a Caribbean reef. Mar. Ecol. Prog. Ser. 389, 71-84.

Carpenter, L.W., Patterson, M.R., 2007. Waterflow influences the distribution of photosynthetic efficiency within the scleractinian Montastraea annularis(Ellis and Solander, 1786). Can water flow modulate coral reef bleaching? J. Exp. Mar. Bio. Ecol. 351, 10-26.

Connell, J.H., 1997. Disturbance and recovery of coral assemblages. Coral Reefs 16, 101-113.

Cosgrove, J., Borowitzka, M.A., 2010. Chlorophyll fluorescence terminology: an introduction. In D.J. Sugget, O. Prášil \& M.A. Borowitzka (eds.). Chlorophyll-a fluorescence in aquatic sciences: methods and applications. Springer-Verlag, Heidelberg, pp. 1-17.

Cunning, R., Baker, A.C., 2012. Excess algal symbionts increase the susceptibility of reef corals to bleaching. Nat. Clim. Chang. 3 259-262.

Dunn, J.G., Sammarco, P.W., LaFleur, G. 2012. Effects of phosphate on growth and skeletal density in the scleractinian coral Acropora muricata: A controlled experimental approach. J. Exp. Mar. Bio. Ecol. 411:34-44.

Enríquez, S., Méndez, E.R., Iglesias-Prieto, R., 2005. Multiple scattering on coral skeletons enhances light absorption by symbiotic algae. Limnol. Oceanogr. 50, 1025-1032.

Ezzat, L., Maguer, J-F., Grover, R., Ferrier-Pagès, C., 2015. New insights into carbon acquisition and exchanges within the coral-dinoflagellate symbiosis under $\mathrm{NH}_{4}{ }^{+}$and $\mathrm{NO}_{3}$ - supply.

Proc. R. Soc. B. 282, 20150610.

Fabricius, K.E., 2005. Effects of terrestrial runoff on the ecology of corals and coral reefs: Review and synthesis. Mar. Pollut. Bull. 50, 125-146.

Finney, J.C., Pettay, D.T., Sampayo, E.M., Warner, M.E., Oxenford, H.A., LaJeunesse, T.C., 2010. The relative significance of host-habitat, depth, and geography on the ecology, endemism and speciation of coral endosymbionts in the genus Symbiodinium. Mircob. Ecol. 60, 250-263.

Fitt, W.K., Gates, R.D., Hoegh-Guldberg, O., Bythell, J.C., Jatkar, A., Grottoli, A.G., Gomez, et. al., 2009. Response of two species of Indo-Pacific corals, Porites cylindrical and Stylophora pistillata, to short-term thermal stress: The host does matter in determining the tolerance of corals to bleaching. J. Exp. Mar. Biol. Ecol. 373, 102-110 
Halpern, B.S., Selkoe, K.A., Micheli, F., Kappel, C.V., 2007. Evaluating and ranking the vulnerability of global marine ecosystems to anthropogenic threats. Conserv. Biol. 21, 1301-15.

Heisler, J., Gilbert, P.M., Burkholder, J.M., Anderson, D.M., Cochlan, W., 2008. Eutrophication and harmful algal blooms: A scientific consensus. Harmful Algae 8, 3-13.

Hill, R., Frankart, C., Ralph, P.J., 2005. Impact of bleaching conditions on the components of nonphotochemical quenching in the zooxanthellae of a coral. J. Exp. Mar. Biol. Ecol. 322, 8392.

Hoogenboom, M.O., Connolly, S.R., Anthony, K.R.N., 2008. Interactions between morphological and physiological plasticity optimize energy acquisition in corals. Ecology, 89, 1144-1154.

Houlbrèque, F., Ferrier-Pagès, C., 2009. Heterotrophy in tropical scleractinian corals. Biol Rev. 84, 1-17.

Huot, Y, Babin, M., 2010. Overview of fluorescence protocols: Theory, basic concepts, and practice. In D.J. Sugget, O. Prášil \& M.A. Borowitzka (eds.). Chlorophyll-a fluorescence in aquatic sciences: methods and applications. Springer-Verlag, Heidelberg, pp. 31-74.

Iglesias-Prieto, R., Beltrán, V.H., LaJuenesse, T.C., Reyes-Bonilla, H., Thomé, P.E., 2004. Different algal symbionts explain the vertical distribution of dominant reef corals in the eastern Pacific. Proc. Roy. Sot. Lond. B. 271, 1757-1763.

Jensen, H.S., McGlathery, K.J., Marinow, R., Howarth, R.W., 1998. Forms and availability of sediment phosphorus in carbonate sand of Bermuda seagrass beds. Limnol. Oceanogr. 43, 799-810.

Lesser, M.P., 2006. Oxidative stress in marine environments: biochemistry and physiological ecology. Annl. Rev. Physiol. 68, 253-278.

Lirman, D., Manzello, D., 2009. Patterns of resistance and resilience of the stress-tolerant coral Siderastrea radians (Pallas) to sub-optimal salinity and sediment burial. J. Exp. Mar. Biol. Ecol. 369, 72-77.

Marsh, J.A., 1970. Primary productivity of reef building calcareous red algae. Ecology 51, 255263.

Maxwell, K., Johnson, G.N., 2000. Chlorophyll fluorescence - a practical guide. J. Exp. Bot. 51, 659-668.

Muscatine, L., Ferrier-Pagès, C., Blackburn, A., Gates, R.D., Baghdasarian, G., Allemand, D., 1998. Cell-specific density of symbiotic dinoflagellates in tropical anthozoans. Coral Reefs 17, 329-337.

Muthiga, N.A., Szmant, A.M., 1987. The effects of salinity stress on the rates of aerobic respiration and photosynthesis in the hermatypic coral Siderastrea siderea. Biol. Bull. $173,339-351$.

Nakagawa, S., Schielzeth, H., 2013. A general and simple method for obtaining $\mathrm{R}^{2}$ from generalized linear mixed-effects models. Methods in Ecol. Evol. 4, 133-142. 
Peterson, B.J., Wollheim, W.M., Mulholland, P.J., Webster, J.R., Meyer, J.L., et al. 2001. Control of nitrogen export from watersheds by headwater streams. Science $292,86-90$.

Pinheiro J, Bates D, DebRoy S, Sarkar D and R Core Team (2015). nlme: Linear and Nonlinear Mixed Effects Models. R package version 3.1-122, http://CRAN.Rproject.org/package=nlme.

Polidoro, B., Carpenter, K., 2013. Dynamics of coral reef recovery. Science 340, 34-35.

R Core Team (2012). R: A language and environment for statistical computing. R Foundation for Statistical Computing, Vienna, Austria. ISBN 3-900051-07-0, URL http://www.Rproject.orgl

Rasher, D.B., Engel, S., Bonito, V., Fraser, G.J., Montoya, J.P., Hay, M.E., 2012. Effects of herbivory, nutrients, and reef protection on algal proliferation and coral growth on a tropical reef. Oecologia 169, 187-198.

Raven, J.A., 2011. The costs of photoinhibition. Physiologia Plantarum 142, 87-104.

Robinson, J.D., Warner, M.E., 2006. Differential impacts of photoacclimation and thermal stress on the photobiology of four different phylotypes of Symbiodinium (Pyrrhophyta). J. Phycol. 42, 568-579.

Shantz, A.A., Burkepile, D.E., 2014. Context-dependent effects of nutrient loading on the coralalgal mutualisms. Ecology 95, 1995-2005.

Shantz, A.A., Ladd, M.C., Schrack, E., Burkepile, D.E., 2015. Fish-derived nutrient hotspots shape coral reef benthic communities. Ecol. Appl. 25, 2142-2152.

Shantz, A.A., Lemoine, N.P., Burkepile, D.E. 2016. Nutrient loading alters the performance of key nutrient exchange mutualisms. Ecol. Lett. 19, 20-28.

Shelly, K., Holland, D., Beardall, J., 2010. Assessing nutrient status of microalgae using chlorophyll a Fluorescence. In D.J. Sugget, O. Prášil \& M.A. Borowitzka (eds.). Chlorophyll-a fluorescence in aquatic sciences: methods and applications. SpringerVerlag, Heidelberg, pp. 223-235.

Smith, T.B., Glynn, P.W., Maté, J.L., Toth, L.T., Gyory, J., 2014. A depth refugium from catastrophic coral bleaching prevents regional extinction. Ecology 95, 1663-1673.

Sokal, R.R., Rohlf, F.J., 1995. Biometry: the principles and practice of statistics in biological research. $4^{\text {th }}$ Edition. W.H. Freeman and Co. New York.

Sterner, R.W., Elser, J.J., 2002. Ecological stoichiometry: The biology of elements from molecules to the biosphere. Princeton University Press. New Jersey, USA.

Suggett, D.J., Moore, C.M., Hickman, A.E., Geider, R.J., 2009. Interpretation of fast repetition rate (FFR) fluorescence: signatures of phytoplankton community structure versus physiological state. Mar. Ecol. Prog. Ser. 376, 1-19.

Tanaka, Y., Inoue, M., Nakamura, T., Suzuki, A., Sakai, K., 2014. Loss of zooxanthellae in a coral under high seawater temperature and nutrient enrichment. J. Exp. Mar. Biol. Ecol. 457, 220-225 
Torres, J.L., Armstrong, R.A., Corredor, J.E., Gilbes, F. 2007. Physiological responses of Acropora cervicornis to increased solar irradiance. Photochem. Photobiol. 83, 839-850.

van Woesik, R., Irikawa, A., Anzai, R., Nakamura, T., 2012. Effects of coral morphologies on mass transfer and susceptibility to thermal stress. Coral Reefs 31, 633-639.

Vass, I. (2012). Molecular mechanisms of photodamage in the Photosystem II complex. Biochimica et Biophysica Acta 1817, 209-217.

Vega Thurber, R.L., Burkepile, D.E., Fuchs, C., Shantz, A.A., McMinds, R., Zaneveld, J.R., 2014. Chronic nutrient enrichment increases the prevalence and severity of coral disease and bleaching. Glob. Chang. Biol. 20, 544-554.

Wangpraseurt, D., Larkum, A.W., Ralph, P.J., Kühl, M., 2012. Light gradients and optical microniches in coral tissues. Front. Microbiol. 3, doi: 10.3389/fmicb.2012.00316

Warner, M.E., Lesser, M.P., Ralph, P.J., 2010. Chlorophyll fluorescence in reef building corals. In D.J. Sugget, O. Prášil \& M.A. Borowitzka (eds.). Chlorophyll-a fluorescence in aquatic sciences: methods and applications. Springer-Verlag, Heidelberg, pp. 209-222

Wiedenmann, J., D'angelo, C., Smith, E.G., Hunt, A.N., Legiret, F-E., Postle, A.D., Achterberg, E.P., 2012. Nutrient enrichment can increase the susceptibility of reef corals to bleaching. Nat. Clim. Chang. 3, 160-164.

Wooldridge, S.A., 2009. Water quality and coral bleaching thresholds: Formalizing the linkage for the inshore reefs of the Great Barrier Reef, Australia. Mar. Pollut. Bull. 58, 745-751.

Wooldridge, S. A., 2013. Breakdown of the coral-algae symbiosis: towards formalising a linkage between warm-water bleaching thresholds and the growth rate of the intracellular zooxanthellae. Biogeosciences, 10, 1647-1658. 
Table 3.1 - Parameters and values for the three best performing models, based on AICc, of coral growth in response to changes in the measured metrics of PSII health and performance for each coral species. P-values for each term as well as the marginal and conditional $\mathrm{R}^{2}$ values for the model are listed. Marginal $\mathrm{R}^{2}$ values represent the variance explained by the fixed effects, conditional $\mathrm{R}^{2}$ values represent the variance explained by the full model.

\begin{tabular}{|c|c|c|c|c|c|c|}
\hline \multicolumn{7}{|c|}{ Optimal models for photobiology on coral growth } \\
\hline & Model & $\underset{c}{\mathrm{AIC}}$ & $\triangle \mathrm{AICC}$ & $\boldsymbol{p}$ & $\mathbf{R}_{\substack{\text { Margin } \\
\text { al }}}$ & $\mathbf{R}^{2}$ Condition \\
\hline \multirow[t]{3}{*}{$\begin{array}{l}\text { Acropora } \\
\text { cervicornis }\end{array}$} & $\begin{array}{c}Q_{m} \times q_{I}+ \\
\text { random }_{(\text {platform })}\end{array}$ & 17.1 & 0 & $\begin{array}{c}Q_{m}-0.14 \\
q_{I}-0.43 \\
Q_{m} \times q_{I}-0.33 \\
\end{array}$ & 0.11 & 0.75 \\
\hline & $q_{I}+$ random $_{\text {(platform) }}$ & 22.5 & 5.4 & $q_{I}-0.44$ & 0.02 & 0.79 \\
\hline & $\begin{array}{c}Q_{m}+q_{I}+ \\
\text { random }_{(\text {platform })}\end{array}$ & 24.4 & 7.3 & $\begin{array}{c}Q_{m}-0.72 \\
q_{I}-0.41\end{array}$ & 0.03 & 0.73 \\
\hline \multirow[t]{3}{*}{$\begin{array}{l}\text { Montastraea } \\
\text { cavernosa }\end{array}$} & $\begin{array}{c}Q_{m} * q_{I} * \\
\text { random } \\
\text { (platform) }\end{array}$ & 37.2 & 0 & $\begin{array}{c}Q_{m}<0.01 ; \\
q_{I}-0.39 ; \\
Q_{m} \times q_{I}-0.38\end{array}$ & 0.27 & 0.64 \\
\hline & $\begin{array}{c}Q_{m}+q_{I}+ \\
\operatorname{random}_{\text {(platform) }}\end{array}$ & 44.2 & 7 & $\begin{array}{c}Q_{m}<0.01 \\
q_{I}-0.41\end{array}$ & 0.24 & 0.65 \\
\hline & $\begin{array}{c}Q_{m}+ \\
\text { random }{ }_{(\text {platform })}\end{array}$ & 45.0 & 7.8 & $Q_{m}<0.01$ & 0.24 & 0.68 \\
\hline$\frac{\text { Siderastrea }}{\text { siderea }}$ & $\begin{array}{c}Q_{m} * q_{I} * \\
\text { random }_{(\text {platform })}\end{array}$ & 61.0 & 0 & $\begin{array}{c}Q_{m}-0.28 \\
q_{I}-0.47 \\
Q_{m} \times q_{I}-0.32\end{array}$ & 0.10 & 0.10 \\
\hline & $\begin{array}{c}Q_{m}+q_{I}+ \\
\text { random }_{(\text {platform })}\end{array}$ & 68.0 & 7 & $\begin{array}{c}Q_{m}-0.27 \\
q_{I}-0.47\end{array}$ & 0.06 & 0.06 \\
\hline & $q_{I}+$ random $_{\text {(platform) }}$ & 69.2 & 8.2 & $q_{I}-0.31$ & 0.04 & 0.04 \\
\hline
\end{tabular}


Figure 3.1 - Schematic of the growth platforms used for our coral experiments. Each platform was $75 \times 50 \mathrm{~cm}$ and contained six elevated posts to hold coral fragments. Nutrient diffusers, represented as the hashed cylinder, were filled with the respective nutrient treatment and secured to a post in the center of the platform.

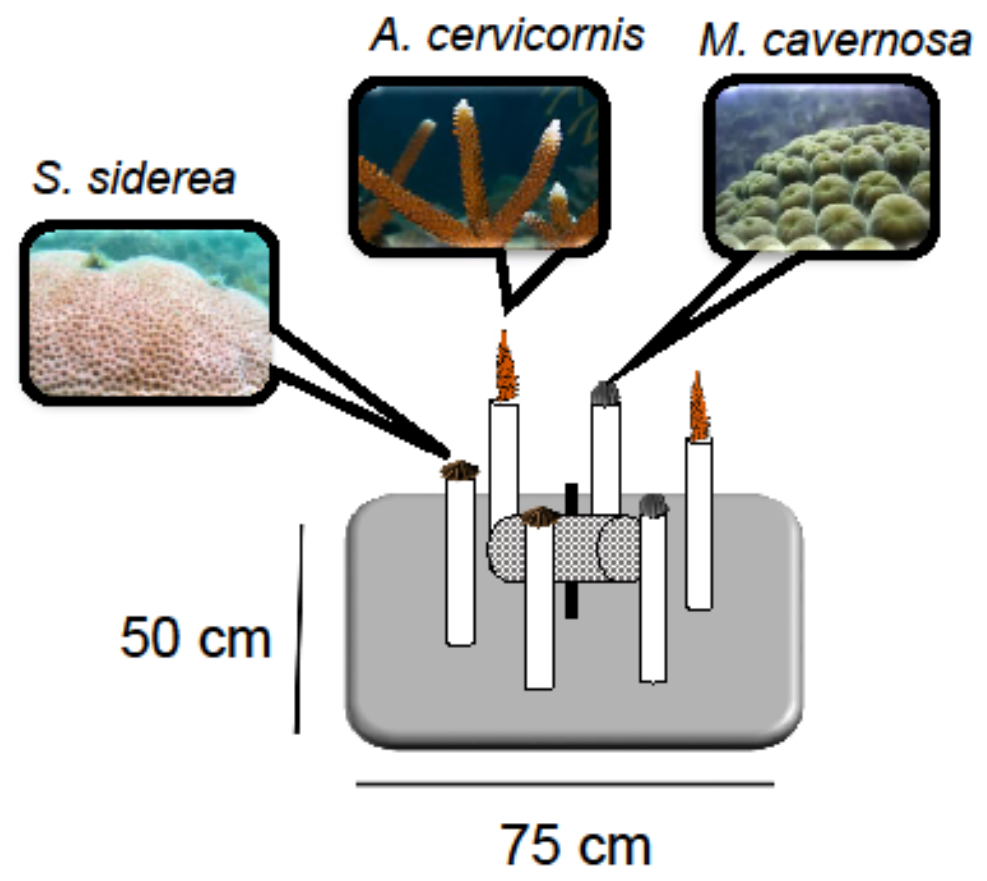


Figure 3.2 - The impact of chronic nutrient loading with nitrate $\left(\mathrm{NO}_{3}^{-}\right)$, ammonium $\left(\mathrm{NH}_{4}^{+}\right)$, nitrate and phosphate (NP) or phosphate (P) on A. cervicornis, M. cavernosa, and S. siderea. (a) Maximum dark adapted quantum yield of photosystem II taken before sunrise, (b) Maximum excitation pressure on photosystem II $\left(\mathrm{Q}_{\mathrm{m}}\right)$ at solar noon, and (c) Photoinhibition of photosystem II $\left(q_{I}\right)$. N.S. indicates no significant differences while letters represent significant differences at $\alpha=$ 0.05. Data are means \pm 1 S.E.
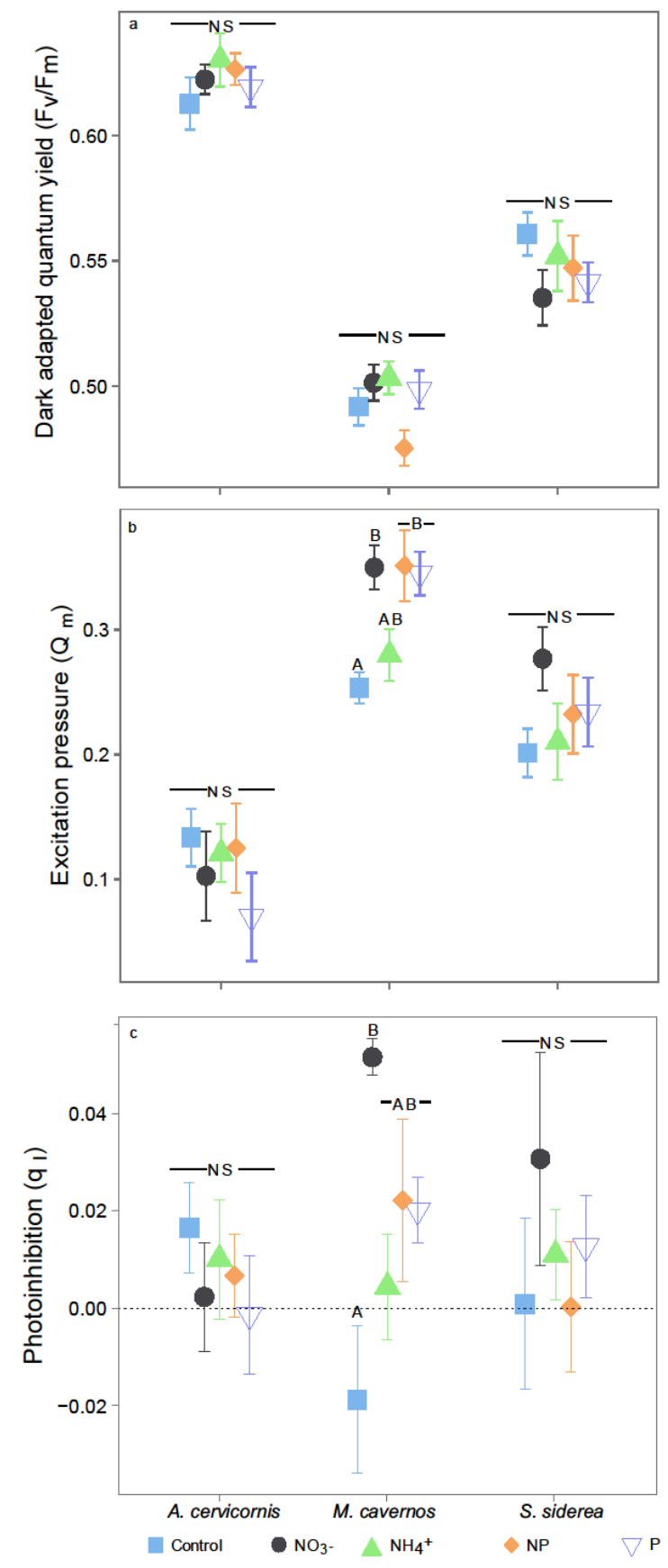
Figure 3.3 - Growth rates of $A$. cervicornis, M. cavernosa, and S. siderea subjected to enrichment with either: nitrate $\left(\mathrm{NO}_{3}{ }^{-}\right)$, ammonium $\left(\mathrm{NH}_{4}{ }^{+}\right)$, nitrate and phosphate (NP) or phosphate (P). N.S. indicates no significant differences while letters represent significant differences at $\alpha=0.05$. Data are means \pm 1 S.E.

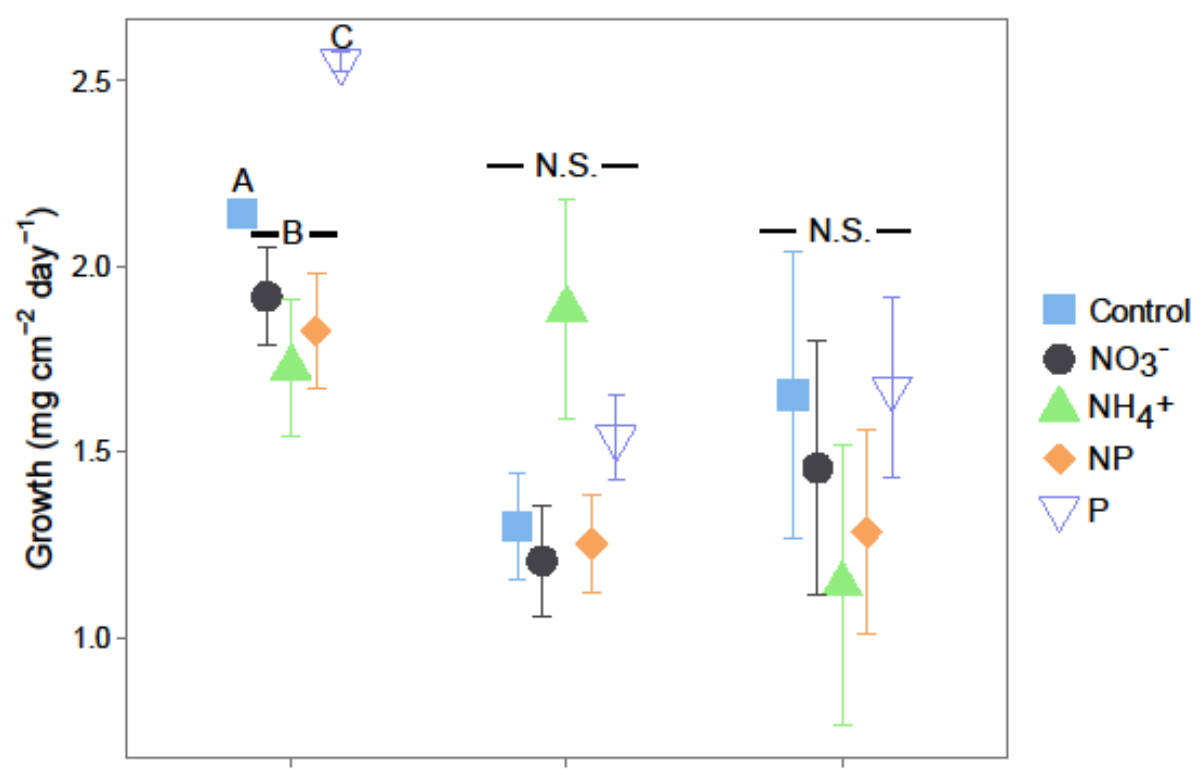
A. cervicornis
M. cavernosa
S. siderea 


\section{CHAPTER IV}

ENRICHMENT-INDUCED CHANGES IN ALGAL NITROGEN AND PHOSPHORUS CONTENT MODIFY HERBIVORE GRAZING 


\begin{abstract}
The majority of coral reefs around the world are subjected to nitrogen $(\mathrm{N})$ and phosphorus $(\mathrm{P})$ pollution. Nutrient pollution can alter the concentration of these nutrients in algal tissue, and in turn may influence herbivore feeding. To explore the impacts of enrichment on herbivory, we conducted feeding assays on a coral reef using Sargassum polyceratium grown under $\mathrm{N}, \mathrm{P}$, or a combination of $\mathrm{N}+\mathrm{P}$ enrichment. We found that grazing rates of initial, but not terminal, phase Sparisoma spp. parrotfishes increased with algal N-content. Similarly, grazing rates of juvenile, but not adult, surgeonfishes increased with algal P-content. As a result, consumption of $\mathrm{N}$ and NP-enriched algae was $\sim 20 \%$ greater than control algae. Our data suggest that nutrient content of resources plays a role in partitioning herbivory among coral reef taxa. Importantly, juvenile and initial phase fishes likely fill functional roles that distinctly differ than those of adult fishes.
\end{abstract}

\title{
Introduction
}

On coral reefs, herbivores consume algae that compete with corals (Bellwood et al. 2004; Hughes et al. 2007). Herbivory is particularly important for reef health, as algae can poison coral tissue (Rasher and Hay 2010), reduce coral growth rates (Vega Thurber et al. 2012), vector coral diseases (Smith et al. 2006), and impede the settlement and survival of coral larvae (Vermeij et al. 2009; Dixon et al. 2010). Thus, herbivores are vital for coral reef resilience (Adam et al. 2011) and understanding the factors that influence patterns of herbivore feeding is essential for coral reef management.

Ecological stoichiometry predicts that animals should target resources that best match their elemental body composition (Sterner and Elser 2002). Stoichiometric mismatch presents a particular challenge for herbivores because elements like nitrogen $(N)$ and phosphorus $(P)$ are typically far more prevalent in animal tissue than plant tissue. As a result, animals are often $\mathrm{N}$ and P-limited and may selectively forage on resources rich in these nutrients (Mattson 1980; Barboza et al. 2009; Lemoine et al. 2013). However, a variety of physiological and morphological characteristics can influence consumer's need for $\mathrm{N}$ versus $\mathrm{P}$. For instance, $\mathrm{P}$ is an important 
nutrient for lipid and carbohydrate metabolism in all animals but because of its essential role in bone mineralization and scale formation, is one of the most important mineral nutrients for teleost fishes (Sales \& Janssens 2003). Similarly, N is essential for protein production, which may be more important in juvenile animals that need to support rapid muscle growth (Barboza et al. 2009). Such differences in the stoichiometric needs of consumers suggests that the $N$ and $P$ content of macroalgae could be important for mediating species-specific foraging decisions of herbivorous fishes on coral reefs (e.g., Bellwood et al. 2006; Rasher et al. 2013; Adam et al. 2015). Indeed, consumption rates of $\mathrm{N}$ and $\mathrm{P}$ enriched algae are often greater than those of algae that has not experienced nutrient enrichment (e.g. Boyer et al. 2004; Chan et al. 2012). However, it remains unclear how $\mathrm{N}$ vs. $\mathrm{P}$ may affect the intensity of herbivory, or whether different herbivore species respond differently to these nutrients.

Understanding how $\mathrm{N}$ and $\mathrm{P}$ impact herbivore feeding patterns may be particularly important given the rapid rates that humans are increasing the delivery of these nutrients to coastal ecosystems (Wear and Vega Thurber 2015). Nutrient-induced changes in algal palatability may occur because in some algae, excess $\mathrm{N}$ and $\mathrm{P}$ results in luxury consumption in which excess nutrients are incorporated into the algae tissue for storage (Droop 1973), potentially increasing their value to herbivores. Here, we explore the impact of algae $\mathrm{N}$ and $\mathrm{P}$ content on herbivore feeding decisions and the overall consumption of the palatable Caribbean alga Sargassum polyceratium. We grew S. polyceratium in aquaria under either ambient nutrient conditions or enriched with $\mathrm{N}, \mathrm{P}$, or a combination of $\mathrm{N}+\mathrm{P}$. Each week we transplanted feeding assays of nutrient-enriched algae to the reef and filmed fishes feeding on the algae. We measured both overall mass of algae removed and consumption rates of different herbivore species in response to the treatments. We predicted that fishes would consume algae enriched with $\mathrm{N}, \mathrm{P}$ and $\mathrm{N}+\mathrm{P}$ faster than algae grown in ambient conditions. For $\mathrm{N}$ and $\mathrm{N}+\mathrm{P}$ assays we predicted this would be the result of higher feeding rates amongst all herbivorous fishes. For Penriched assays however, we predicted that only surgeonfishes (Acanthuridae), which have roughly two-times more $\mathrm{P}$ in their tissue than parrotfishes (Sidwell et al. 1977), would increase 
their consumption rates. Finally, we predicted that, within fish families, younger individuals would forage more intensely on enriched algae than adults because of their higher $\mathrm{N}$ and $\mathrm{P}$ demands to support rapid growth.

\section{Methods}

From June through August of 2013 we deployed feeding assays of S. polyceratium enriched with either $\mathrm{N}, \mathrm{P}, \mathrm{N}+\mathrm{P}$, or maintained as controls on a shallow forereef site near Conch Reef in the Florida Keys, USA $\left(24.9614^{\circ} \mathrm{N}\right.$ and $\left.80.4539^{\circ} \mathrm{W}\right)$. Prior to deploying the first round of assays, we swam ten $25 \times 2 \mathrm{~m}$ transects around the site to characterize the fish community. For each transect, a diver slowly swam the length of transect, recording the species and size of all herbivorous fishes present within the area.

To create assays of varying nutritional content, each week we collected $\sim 200 \mathrm{~g}$ of $\mathrm{S}$. polyceratium from an offshore patch reef for nutrient enrichment. We transported the $S$. polyceratium to shore in fresh seawater, where we cleaned off any epiphytic growth using a razor blade and tweezers, and divided the cleaned algae evenly into four, $50 \mathrm{I}$ aquaria. We maintained the aquaria outdoors under shade cloth in a seawater bath chilled to $26^{\circ} \mathrm{C}$. Each tank was supplied with a continuous drip of fresh seawater at $\sim 500 \mathrm{ml}$ hour. To enrich the S. polyceratium, we spiked the seawater supply of three of the tanks with commercial aquarium supplements (Flourish $^{\mathrm{TM}}$ Nitrogen and Phosphorus, Seachem Laboratories, Madison, GA. USA) to increase N and P levels by $10 \mu \mathrm{m} \mathrm{N}, 1 \mu \mathrm{m} P$, or $10 \mu \mathrm{m} \mathrm{N}+1 \mu \mathrm{m} P$ for the respective $\mathrm{N}, \mathrm{P}$, and $\mathrm{N}+\mathrm{P}$ enrichments.

For each assay, we allowed the sections of $S$. polyceratium to grow for one week in their respective aquaria. After one week, we collected a $\sim 5 \mathrm{~g}$ portion of algae from each tank for nutrient analysis. The remainder of each clump was spun dry in a salad spinner for $1 \mathrm{~min}$, weighed to $\sim 40 \mathrm{~g}$, and transported to the reef in a bag containing water from the appropriate treatment tank for deployment. For each assay, we secured one pre-weighed S. polyceratium section from a single treatment to an array of 5 clothes pegs. We used arrays of 5 pegs to ensure 
that the sections of S. polyceratium did not float away when bitten. Review of preliminary assay footage revealed that all algae loss from the pegs was due to herbivory, therefore we did not deploy any cage controls to test for autogenic changes in mass in the algae.

Each week for nine weeks, we deployed four assays (1 Control, $1 \mathrm{~N}, 1 \mathrm{P}, 1 \mathrm{~N}+\mathrm{P}$ ) separated by at least $10 \mathrm{~m}$ at $6-8 \mathrm{~m}$ depth ( $\mathrm{n}=9$ for each treatment over the study duration). Assays were deployed between 10:00 and 11:00 AM and left undisturbed for a two hour feeding period. We filmed each assay by placing a GoPro digital camera $1 \mathrm{~m}$ away from the algae to record any grazing activity. After two hours, we collected all of the assays and returned them to shore to obtain a final weight as described above. We scored videos to record the species, size, and phase of any fish observed feeding during the assay. Fish size was estimated from a marker of known length included in each video. In addition, we recorded the total number of bites taken throughout the assay by each herbivore and the number of bites per foray. We counted bites as any time the fishes' mouth was seen to make clear contact with the algae. We considered a foray to begin with the first bite and to end after any pause longer than necessary for the fish to reapply its jaws to the algae (Bellwood and Choat 1990). To determine bite rates, we divided the number of bites observed by the total assay duration in minutes.

Analysis

To ensure that our treatments increased the assay nutrient content, we measured the carbon (C), N, and P content of S. polyceratium from each assay. For $\mathrm{C}$ and $\mathrm{N}$ analysis, samples from each assay were dried at $60^{\circ} \mathrm{C}$ to a constant weight, ground to a fine powder, and analyzed via a carbon-nitrogen elemental analyzer (Thermo Fisher Scientific, Waltham MA. USA). Phosphorus content was measured using dry oxidation-acid hydrolysis extraction followed by colorimetric analysis. We tested for differences in the C:N and C:P content of S. polyceratium assays grown under the different nutrient enrichments via one-way ANOVA. We tested for differences in total algal consumption based on differences in initial and final weights with a oneway ANOVA that included a random effect for deployment date to account for any differences in herbivory among days. 
Videos of the assays revealed that over $95 \%$ of the bites taken could be attributed to 5 species of fish (2 species of surgeonfish; Acanthurus tractus and $A$. coeruleus, and 3 species of parrotfish; Sparisoma aurofrenatum, Sp. chrysopterum, and Sp. rubripinne). Because all species did not feed on every assay and we expected fishes within the same family to be stoichiometrically similar, we pooled the data for the surgeonfishes and parrotfishes by family to increase our replication. For both fish families, we tested for differences in the average feeding rates and number of forays among treatments using two-way ANOVA with $\mathrm{N}$ and $\mathrm{P}$ treatments as interacting factors and a random effect for the assay date. For both analyses, data were log transformed to meet assumptions of normality.

Finally, we used linear regression to determine whether ontogeny influenced nutritional demands. We regressed the average number of bites taken by each species of parrotfish or surgeonfish against the $\mathrm{C}: \mathrm{N}$ and $\mathrm{C}: \mathrm{P}$ ratios of the assay, including a factor for phase (parrotfishes) or class (juvenile vs adult surgeonfishes). Regression data were square root transformed to meet assumptions of normality. Data for both regressions were square root transformed to meet assumptions of normality. All analyses were conducted in R using the package nmle (R Core Team; Pinhiero et al. 2015).

\section{Results \& Discussion}

Herbivorous fish biomass at our site averaged $7.0 \mathrm{~g} \mathrm{~m}^{-2}$ and was comprised of 10 species of common Caribbean herbivores (3 surgeonfish species: Acanthurus coeruleus, A. chirurgus, and $A$. tractus; and seven parrotfish species: Scarus coelestinus, Sc. guacamaia, Sc. iserti, Sc. taeniopterus, Sparisoma aurofrenatum, Sp. chrysopterum, and Sp. rubripinne) (Fig. 1). From this group, we primarily observed the Acanthurus spp. and Sparisoma spp. feeding on the assays. Although Acanthurus spp. are not often considered important grazers on reefs (Lewis 1985; Burkepile and Hay 2008), the assays were cleaned of epiphytes and it was clear that these fishes were feeding on the S. polyceratium tissue. Because $>95 \%$ of the bites captured on video were 
taken by A. coeruleus, A. tractus, Sp. aurofrenatum, Sp. chrysopterum, and Sp. rubripinne our analyses focuses on these five species.

Nitrogen addition increased the $\mathrm{N}$ the content in S. polyceratium, $\sim 25 \%$, decreasing the molar C: $\mathrm{N}$ by $\sim 22.5 \%$ in $\mathrm{N}$-enrichments and $19.5 \%$ in NP-enrichments $\left(F_{3,31}=3.21, p=0.04\right.$; Fig 2a). Phosphorus addition also lowered C:P by an average of $17.2 \%$ in P-enrichments and $14.4 \%$ in NP-enrichments, although these differences were not statistically significant $\left(F_{3,31}=0.58, p=\right.$ $0.63)$. Average $\mathrm{N}: \mathrm{P}$ ratios were $17.6: 1$ in both the control and NP assays, $20.5: 1$ in the N-enriched assays and 14.6 in P-enriched assays but did not statistically differ from each other.

On average, fish consumed $98.1 \% \pm 0.10$ (mean \pm S.E.) of the biomass from $\mathrm{N}$-enriched assays and $97.4 \% \pm 0.02$ of biomass from NP-enriched assays. In contrast, consumption of Control $(73.8 \% \pm 10)$ and P-enriched assays $(78.8 \pm 0.09 \%)$ were significantly lower $\left(F_{3,23}=\right.$ 3.34, $\mathrm{p}=0.04$; Fig. 2b). For the Sparisoma spp. we found that $\mathrm{N}$-enrichment significantly increased the feeding rates $\left(F_{1,23}=6.93, p=0.01\right.$ Fig. $\left.3 a\right)$ and number of forays $\left(F_{1,23}=6.19, p=\right.$ 0.02; Fig. 3c) but there was no effect of $P$ or interaction between $N$ and $P$ on either metric of grazing. For surgeonfishes, neither the bite rates nor the number of forays differed between any of the nutrient treatments (Figs $3 b \& 3 d$ ). Regressing the number of bites taken from each assay by surgeonfishes against the number of bites taken by parrotfishes fishes revealed no pattern between the two families $\left(T_{23}=0.70, p=0.49\right)$. Therefore feeding by one family did not appear to influence feeding by the other.

Selective removal of enriched resources has been documented in numerous studies (e.g., Boyer et al. 2004; Burkepile and Hay 2009; Chan et al. 2012; Shantz et al. 2015) but to this point it has remained unclear whether $\mathrm{N}$ versus $\mathrm{P}$ drives this pattern. We found that $\mathrm{N}$-enriched algae is preferentially consumed by parrotfishes but that P-enrichment had little effect on parrotfish foraging. Because parrotfish are responsible for the majority of algal biomass removal on Caribbean coral reefs (Mumby 2006), this equated to increased biomass removal of algae enriched with $\mathrm{N}$. While herbivory is generally considered to be more important than nutrients in structuring coral reef communities (Burkepile and Hay 2006, 2009; Jackson et al. 2014), selective 
feeding on enriched resources suggests the relative importance of top-down and bottom-up forcing on coral reefs may vary with the spatial scale of enrichment.

Nutrients also influenced the number of bites taken per feeding foray. For parrotfish, this manifested as a significant interaction between C:N content of the assay and the fish phase. Initial phase parrotfish on average took fewer bites per foray with declining $\mathrm{N}$-content but this pattern was not present for terminal phase adults ( $t_{59}=2.74, p<0.01, r^{2}=0.45$; Fig. $\left.4 a\right)$. Analysis of parrotfish foraging versus the C:P of S. polyceratium revealed that initial phase fishes took more bites per foray across all treatments $\left(t_{59}=3.04, p<0.01\right)$ but there was no impact of enrichment on the average bite rates (Fig. 4b). For surgeonfish, S. polyceratium C:N had no impact on the number of bites taken per foray for any sized fish (Fig. 4c). Instead, bite rates for juvenile fishes increased with algal P-content, whereas bite rates by adult surgeonfish were similar across the range of algal C:P $\left(t_{23}=2.42, p=0.02\right.$, Fig. $\left.4 d\right)$.

Thus, herbivorous reef fishes preferentially consume resources enriched in N, and to some extent $\mathrm{P}$, but these responses differ with both species identity and ontogeny. Specifically, initial phase parrotfish targeted S. polyceratium that was high in $\mathrm{N}$, whereas younger surgeonfish appeared to prefer algae rich in P. For adults of both species, differences in algal nutrient content are less important than in juvenile feeding decisions. Differences in nutrient selection between size and age classes likely results from changes in physiology with life history. Protein requirements to sustain maximum growth rates decline throughout the lifespan for several fish species (Dabrowski 1986). Additionally, parrotfish are protogynous hermaphrodites, meaning that most initial phase fishes are female and terminal phase fishes are always male (Robertson and Warner 1978). Eggs are more nutritionally demanding than sperm to produce and increasing dietary protein yields greater egg production (Brooks et al. 1997). Thus, initial phase female parrotfishes may also consume more $\mathrm{N}$ in their diets to increase reproductive output. Taken together, these factors could explain why initial phase parrotfish targeted $\mathrm{N}$-enriched algae but terminal phase males did not. 
In contrast, morphology may drive P-demand in surgeonfish. Phosphorus is a primary constituent of bone and scales (Lall and Lewis-McCrea 2007), and on a per gram basis, surgeonfish contain almost two times more $\mathrm{P}$ in their tissue than parrotfish $(3.24 \pm 0.90 \mathrm{mg} \mathrm{P} \mathrm{g}$ ${ }^{1}$ in surgeonfish versus $1.67 \pm 0.23 \mathrm{mg} \mathrm{P} \mathrm{g}^{-1}$ in parrotfish; Sidwell et al. 1977). Because fish obtain the majority of their P from their diet, this higher P-requirement likely necessitates that young surgeonfishes forage on P-rich foods to grow. In contrast, slower growing adult fishes may not have this dietary constraint.

The functional diversity of herbivores on coral reefs is vital for maintaining healthy reefs (Burkepile and Hay 2008, Rasher et al. 2013) and promoting recovery after disturbances (Bellwood et al. 2006). Many different traits influence the functional diversity of herbivores including feeding morphology (Bellwood and Choat 1990), body size (Lokrantz et al. 2008), tolerance of chemical defenses (Rasher et al. 2012), foraging range and habitat use (Adam et al. 2015), and microhabitat use (Brandl and Bellwood 2014). Here, we show that algal nutrient content may be an important axis of niche diversification and influence complementarity and redundancy patterns among and within herbivore species. For example, parrotfishes clearly targeted N-rich foods while P content more strongly influenced surgeonfish feeding. Moreover, the quality of resources targeted appears to differ with size and age, with juvenile surgeonfishes and initial phase parrotfishes targeting nutrient-rich foods relative to larger fishes. Thus, body size may be an important factor shaping not only the types of bites that fishes take from resources (e.g., Bonaldo and Bellwood 2008) but also the type and quality of resources these fishes choose. Importantly, this suggests that the loss of large herbivores due to overfishing not only reduces overall grazing intensity but also may be vacating functional niches that are not filled by smaller juvenile fishes, even within the same species.

Ultimately, our study suggests herbivorous fishes selectively target resources rich in specific nutrients and that ecological stoichiometry can effectively predict the importance of particular nutrients to different consumers. In turn, discerning the relative importance of different nutritional currencies to consumers may aid in predicting the optimal foraging strategies of 
herbivorous fishes and help better understand the functional roles of different species on coral reefs. Such knowledge will be important for understanding the function of an intact guild of herbivorous fishes and how these herbivores influence the resilience of coral reefs.

References

Adam TC, Schmitt RJ, Holbrook SJ, Brooks AJ, Edmunds PJ, Carpenter RC, Bernardi G (2011) Herbivory, connectivity, and ecosystem resilience: response of a coral reef to a largescale perturbation. PLoS ONE 6: e23717. Doi:10.1371/journal.pone.0023717

Adam TC, Kelley M, Ruttenberg BI, Burkepile DE (2015) Resource partitioning along multiple niche axes drives functional diversity in parrotfishes on Caribbean coral reefs. Oecologia 179:1173-1185

Barboza PS, Parker KL, Hume ID (2009) Integrative wildlife nutrition. Springer-Verlag, Heidelberg, Germany.

Bellwood DR, Choat JH (1990) A functional analysis of grazing in parrotfishes (family Scaridae): the ecological implications. Environ Biol Fishes 28:189-214

Bellwood DR (2003). Origins and escalation of herbivory in fishes: a functional perspective. Paleobiol 29:71-83

Bellwood DR, Hughes TP, Folke C, Nyström M (2004) Confronting the coral reef crisis. Nature 429:827-833

Bellwood DR, Wainwright CJ, Fulton CJ, Hoey AS (2006) Functional versatility supports coral reef biodiversity. Proc. R. Soc. B 273: DOI: 10.1098/rspb.2005.3276

Bonaldo RM, Bellwood DR (2008) Size-dependent variation in the functional role of the parrotfish Scarus rivulatus on the Great Barrier Reef, Australia. Mar Ecol Prog Ser 360:237-244

Boyer KE, Forrester A, Armitage AR, Cohen RA (2004) Elevated nutrient content of tropical macroalgae increases rates of herbivory in coral, seagrass, and mangrove habitats. Coral Reefs 23:530-538

Brandl SJ, Bellwood DR (2014) Individual-based analyses reveal limited functional overlap in a coral reef fish community. J Animal Ecol 83:661-670

Brooks S, Tyler CR, Sumpter JP (1997) Egg quality in fish: what makes a good egg? Rev. Fish Biol and Fisher 7:387-416

Burkepile DE, Hay ME (2006) Herbivore vs. nutrient control of marine primary producers: contextdependent effects. Ecology 87:3128-3139

Burkepile DE, Hay ME (2008) Herbivore species richness and feeding complementarity affect community structure and function on a coral reef. Proc Natl Acad Sci 105:16201-6.

Burkepile DE, Hay ME (2009) Nutrient versus herbivore control of macroalgal community development and coral growth on a Caribbean reef. Mar Ecol Prog Ser 389:71-84 
Chan A, Lubarsky K, Judy K, Fong P (2012) Nutrient addition increases consumption rates of tropical algae with different initial palatabilities. Mar Ecol Prog Ser 465:25-31

Dabrowski KR (1986) Ontogenetical aspects of nutritional requirements in fish. Comp Biochem Physiol 85:639-655.

Droop MR (1973) Some thoughts on nutrient limitation in algae. J. Phycol. 9:264-272

Hughes TP, Rodrigues MJ, Bellwood DR, Ceccarelli D, Hoegh-Guldberg O, McCook L, Moltschaniwskyj N, Pratchett MS, Steneck RS, Willis B (2007) Phase shifts, herbivory, and the resilience of coral reefs to climate change. Current Biol 17:360-365.

Jackson JBC, Donovan MK, Cramer KL, Lam Y (2014) Status and trends of Caribbean coral reefs: 1970-2012. Gland, Switzerland, Global Coral Reef Monitoring Network, IUCN.

Lall SP, Lewis-McCrea LM (2007) Role of nutrient in skeletal metabolism and pathology in fish An overview. Aquaculture 267:3-19.

Lemoine NP, Giery ST, Burkepile DE (2013) Differing nutritional constraints of consumers across ecosystems. Oecologia 174:1367-1376.

Lewis SM (1985) Herbivory on coral reefs: algal susceptibility to herbivorous fishes. Oecologia 65:370-375

Lokrantz J, Nystrom M, Thyresson M, Johansson C (2008) The non-linear relationship between body size and function in parrotfishes. Coral Reefs 27:967-974

Mattson WJ (1980) Herbivory in relation to plant nitrogen content. Ann Rev Ecol Syst 11:119-161

Mumby PJ (2006) The impact of exploiting grazers (Scaridae) on the dynamics of Caribbean coral reefs. Ecol Appl 2006:747-769

Pinheiro J, Bates D, DebRoy S, Sarkar D and R Core Team (2015) nlme: Linear and Nonlinear Mixed Effects Models. R package version 3.1-122, http://CRAN.Rproject.org/package=nlme.

R Core Team (2012). R: A language and environment for statistical computing. R Foundation for Statistical Computing, Vienna, Austria. ISBN 3-900051-07-0, URL http://www.Rproject.org/

Rasher DB, Hay, ME (2010) Chemically rich seaweeds poison corals when not controlled by herbivores. Proc. Natl Acad Sci. 107:9683-9688.

Rasher DB, Hoey AS, Hay ME (2013) Consumer diversity interacts with prey defenses to drive ecosystem function. Ecology 94:1347-1358

Robertson DR, Warner RR, (1978) Sexual patterns in the labroid fishes of the Western Caribbean, II: The Parrotfishes (Scaridae). Smithson. C. Zool. 255:1-26.

Sales J, Janssens GP, (2003) Nutrient requirements of ornamental fish. Aquat. Living Resour. 16:533-540. 
Shantz AA, Ladd MC, Schrack E, Burkepile DE (2015) Fish derived nutrient hotspots shape coral reef benthic communities. Ecol Appl 25:2142-2152.

Sidwell RD, Buzzell DH, Foncannon PR, Smith AL (1977) Composition of the edible portion of raw (fresh or frozen) crustaceans, finfish and mollusks. II. Macroelements: Sodium, potassium, chlorine, calcium, phosphorus, and magnesium. Mar. Fisher Rev 39:1-11.

Smith JE, Shaw M, Edwards RA, Obura D, Pantos O, Sala E, Sandin SA, Smriga S, Hatay M, Rohwer FL, (2006) Indirect effects of algae on coral: algae-mediated, microbe-induced coral mortality. Ecol. Lett. 9:835-45.

Sterner RW, Elser JJ (2002) Ecological Stoichiometry: The biology of elements from molecules to the biosphere. Princeton University Press, Princeton, New Jersey.

Vega Thurber R, Burkepile DE, Correa AMS, Thurber AR, Shantz AA, Welsh R, Pritchard C, Rosales S (2012) Macroalgae decrease growth and alter microbial community structure of the reef-building coral, Porites astreoides. PLoS ONE 7: e44246.

Doi:10.1371/journal.pone.0044246.

Wear SL, Vega Thurber R (2015) The year in ecology and conservation biology. Ann N Y Acad Sci 1355:15-30

Vermeij MJA, Smith JE, Smith CM, Vega Thurber R, Sandin SA (2009) Survival and settlement success of coral planulae: independent and synergistic effects of macroalgae and microbes. Oecologia 159:325-336. 
Figure 4.1 - The biomass of herbivorous fishes $\left(\mathrm{g} \mathrm{m}^{-2}\right)$ recorded at our study site prior to the beginning of the study. Data are means \pm 1 S.E.

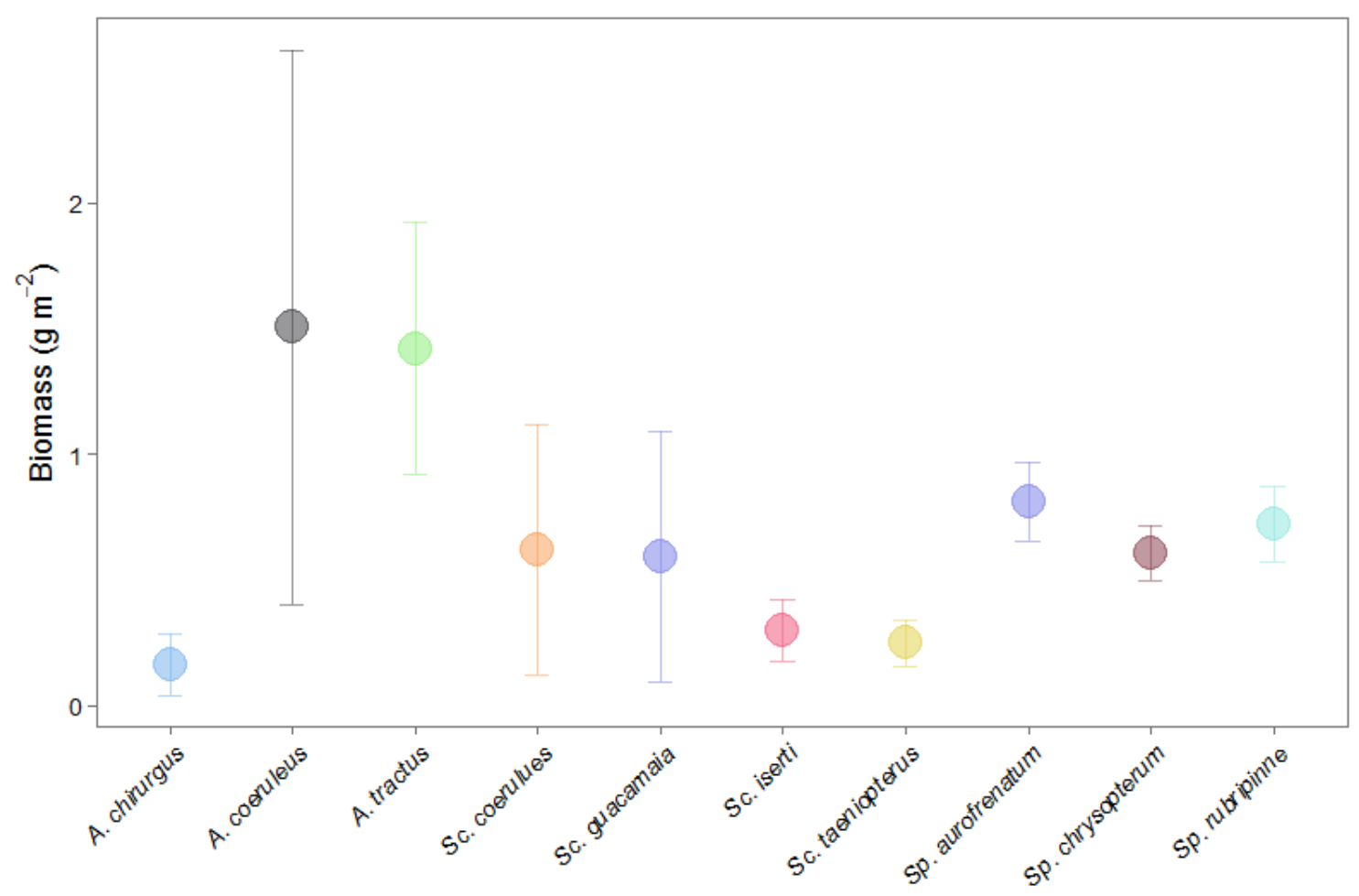


Figure 4.2 - ((a) The average molar ratios (C:N - circles, C:P - triangles) measured from $\mathrm{S}$. polyceratium feeding assays. (b) Average consumption of feeding assays after two hour deployments. Data are means \pm 1 S.E. Capital letters above each treatment denote significant differences in C:N based on Tukey's HSD following one-factor ANOVA. C:P showed no differences across treatments.
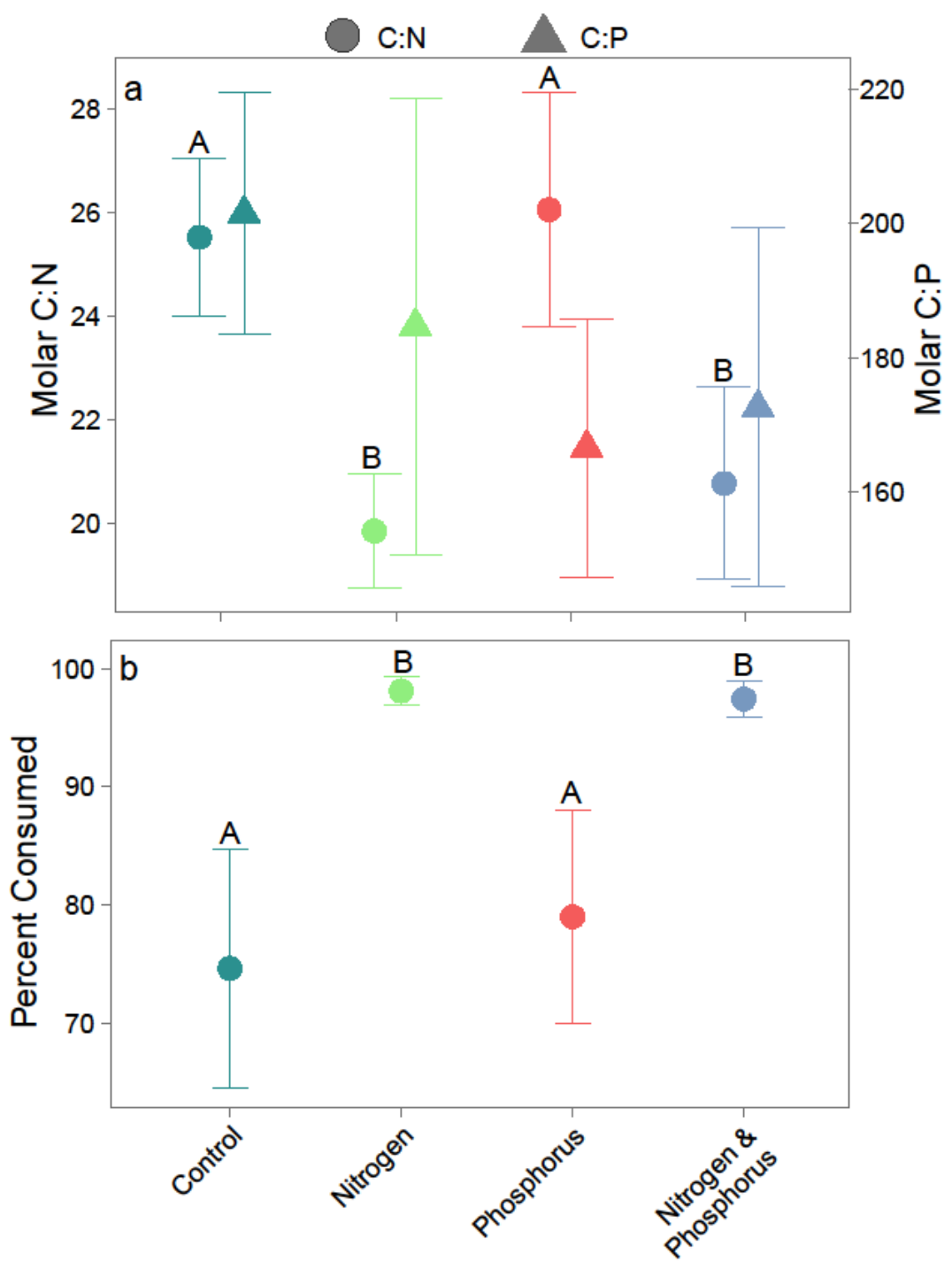
Figure 4.3 - Average grazing rates in bites minute ${ }^{-1}$ on $S$. polyceratium assays for $S p$. aurofrenatum, Sp. chrysopterum, and Sp. rubripinne combined (a) or A. coeruleus and A. tractus (b). Number of feeding forays hour ${ }^{-1}$ for the above parrotfish species (c) and surgeonfish species (d). Data are means \pm 1 S.E. P-values for nitrogen enrichment $(N)$, phosphorus enrichment $(P)$ and the interaction $\left(\mathrm{N}^{*} \mathrm{P}\right)$ are from two-factor ANOVA.
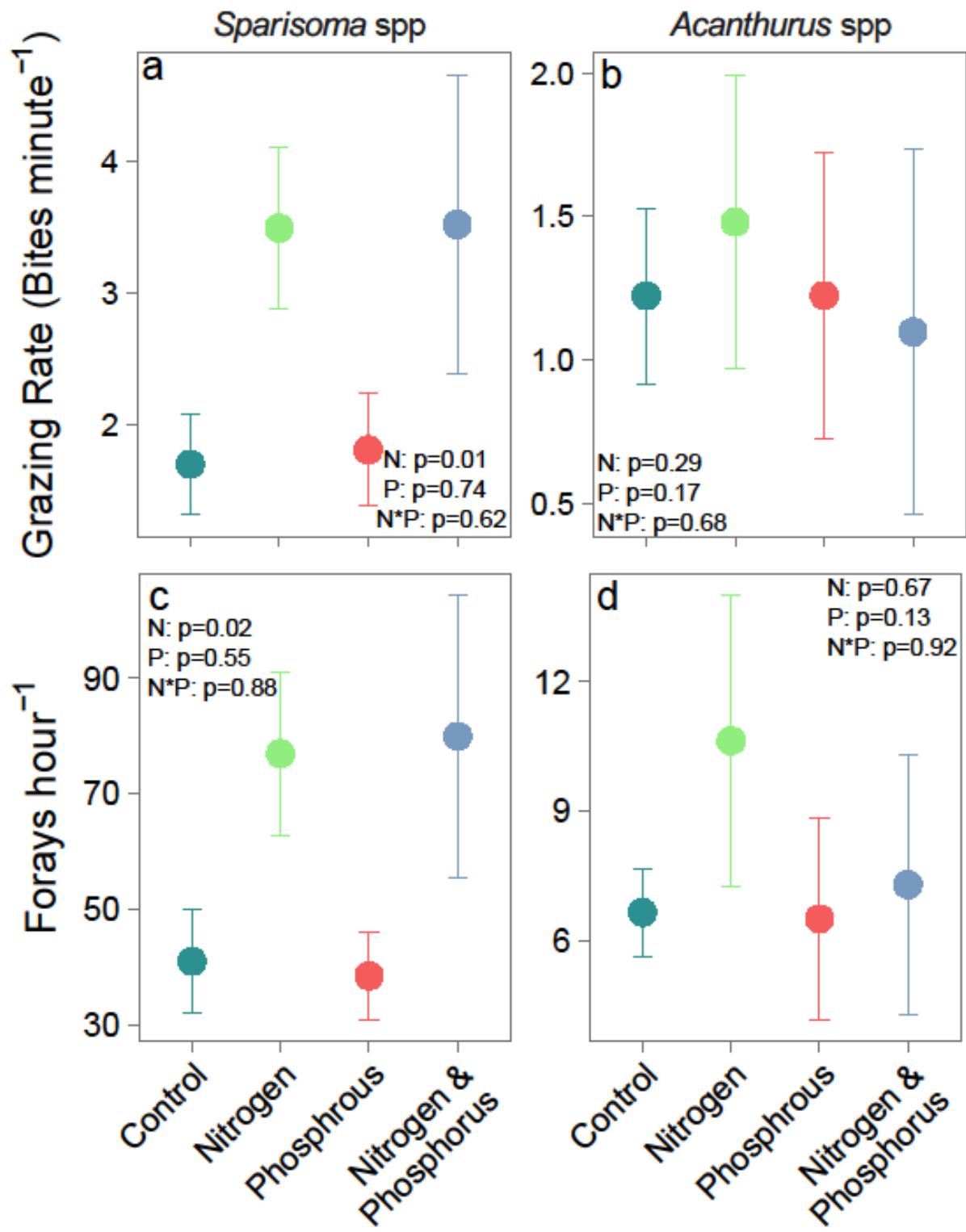
Figure 4.4 - Average bites minute ${ }^{-1}$ for $S p$. aurofrenatum, Sp. chrysopterum, and Sp. rubripinne from each assay regressed against (a) the $\mathrm{C}: \mathrm{N}$ and (b) C:P of $S$. polyceratium assays. Initial phase parrotfish are in blue and terminal phase parrotfish in grey. Average bites minute ${ }^{-1}$ for $A$. coeruleus and $A$. tractus are presented in panels (c) and (d). Juvenile surgeonfishes are shown in dark green, adults in light green. P-values for significant model terms or interactions are provided. N.S. indicates that no terms were significant.

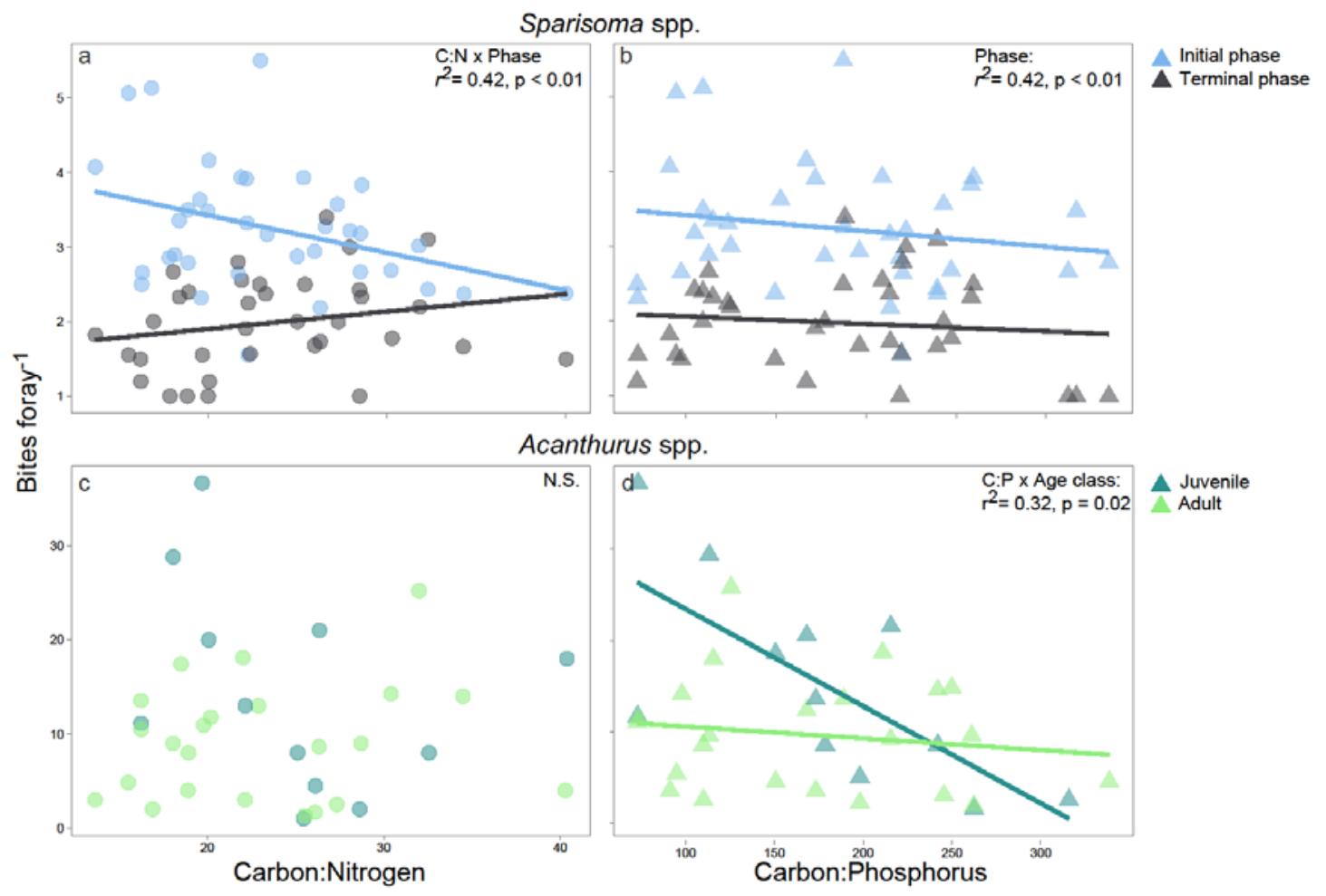


CHAPTER V

FISH-DERIVED NUTRIENT HOTSPOTS SHAPE CORAL REEF BENTHIC COMMUNITIES 


\section{Abstract}

Animal-derived nutrients play an important role in structuring nutrient regimes within and between ecosystems. When animals undergo repetitive, aggregating behavior through time, they can create nutrient hotspots where rates of biogeochemical activity are higher than those found in the surrounding environment. In turn, these hotspots can influence ecosystem processes and community structure. We examined the potential for reef fishes from the family Haemulidae (grunts) to create nutrient hotspots and the potential impact of these hotspots on reef communities. To do so, we tracked the schooling locations of diurnally migrating grunts, which shelter at reef sites during the day but forage off reef each night, and measured the impact of these fish schools on benthic communities. We found that grunt schools showed a high degree of site fidelity, repeatedly returning to the same coral heads. These aggregations created nutrient hotspots around coral heads where nitrogen and phosphorus delivery was roughly 10 and 7 times the respective rates of delivery to structurally similar sites that lacked schools of these fishes. In turn, grazing rates of herbivorous fishes at grunt-derived hotspots were approximately 3 times those of sites where grunts were rare. These differences in nutrient delivery and grazing led to distinct benthic communities with higher cover of crustose coralline algae and less total algal abundance at grunt aggregation sites. Importantly, coral growth was roughly 1.5 times greater at grunt hotspots, likely due to the important nutrient subsidy. Our results suggest that schooling reef fish and their nutrient subsidies play an important role in mediating community structure on coral reefs and that overfishing may have important negative consequences on ecosystem functions. As such, management strategies must consider mesopredatory fishes in addition to current protection often offered to herbivores and top-tier predators. Furthermore, our results suggest that restoration strategies may benefit from focusing on providing structure for aggregating fishes on reefs with low topographic complexity or focusing the restoration of nursery raised corals around existing nutrient hotspots. 


\section{Introduction}

Mobile animals can influence the availability of limiting nutrients across landscapes through the consumption and excretion of resources (Vanni 2002; Estes et al. 2011). Ungulates (McNaughton et al. 1997), seabirds (Croll et al. 2005) and fishes (Burkepile et al. 2013) are just a few examples of animals that accelerate nutrient cycling and enhance nitrogen $(\mathrm{N})$ and phosphorus $(P)$ availability within their habitats. Animals that move between systems also transport nutrients, serving as nutrient sinks in the systems in which they feed and nutrient sources in the systems where waste is excreted. For example, seabirds move nutrients from marine to terrestrial systems, alleviating nutrient limitation in plants and changing plant community structure and ecosystem processes (Croll et al. 2005). Such animals act as mobile links between systems and can provide recipient systems with nutrient subsidies that often exceed abiotic sources of nutrients, ultimately altering nutrient storage and rates of primary productivity in the recipient systems (Lundberg \& Moberg 2003; Vanni 2002; Vanni et al. 2013).

Aggregations of animals within a landscape can lead to spatial or temporal variation in nutrient delivery, potentially creating nutrient "hotspots" (McClaine et al. 2003). These spatially heterogeneous patches of nutrients can influence the abundance and distribution of primary producers by altering species performance and competitive interactions (Chesson 2000; John et al. 2007). Nutrient hotspots may also attract herbivores and intensify grazing pressure as herbivores seek out high quality resources (Steinauer \& Collins 2001; Anderson et al. 2010). Despite the well-recognized importance of animal-derived nutrients in both terrestrial (e.g. McNaughton et al. 1997; Hilderbrand et al. 1999; Croll et al. 2005) and freshwater systems (e.g. Larkin \& Slaney 1997; Moore 2006; McIntyre et al. 2008), the potential influence of animalmediated nutrient hotspots in structuring marine communities have rarely been demonstrated (but see Layman et al. 2013).

In marine systems, the majority of studies investigating nutrient subsidies focus on nutrients derived from nitrogen fixation, physical processes such as upwelling or run-off, or anthropogenic sources (e.g. Welsh 2000; Leichter et al.2003; Schaffelke et al. 2005). However, 
fishes can be important sources of nutrients, particularly in oligotrophic systems such as tropical seagrass beds and coral reefs (Layman et al. 2011; Burkepile et al. 2013). For example, in the Florida Keys, fishes are one of the most important sources of $\mathrm{N}$ on reefs and can impact algal and coral abundance on a reef-wide scale (Burkepile et al. 2013). Many species of carnivorous fishes, particularly grunts (family Haemulidae), shelter on reefs during the day but forage in adjacent seagrass, sand-flat, and mangrove habitats at night, thereby vectoring nutrients to reefs when they return daily. Because these fishes show high fidelity towards specific shelter sites, often returning to the same coral heads (Ogden \& Quinn 1989; Heck et al. 2008), they may create consistent nutrient hotspots that could alter primary production and benthic community composition. Furthermore, fish-derived nutrients affect corals in fundamentally different ways than anthropogenic sources, with nutrients from fishes often facilitating coral growth and anthropogenic nutrients often slowing coral growth (Shantz \& Burkepile 2014). Given the high biomass of fishes on pristine coral reefs (e.g. Friedlander et al. 2010), the rates and patterns of fish excretion may strongly influence the dynamics of reef communities and be important components of healthy reef systems. Yet, we know very little about how the distribution of fishes and their nutrients within the reef landscape impacts ecological processes or community structure.

Here, we examined the role of fishes as generators of nutrient hotspots on an Atlantic coral reef and explored how these hotspots influenced benthic community structure. Over three months, we monitored the biomass of fishes sheltering across twenty structurally similar coral heads on a shallow forereef. We estimated the rates of nutrient delivery from fishes and assessed the impact of these nutrients on coral growth, algal community structure, and herbivorous fish grazing at each site. We predicted that aggregations of fishes would create nutrient hotspots around the coral heads where they sheltered and that these fish-derived hotspots would increase coral growth and alter the composition of primary producer communities. Additionally, we predicted that by creating hotspots of important limiting nutrients, fish aggregations would concentrate herbivore grazing on nutrient-enriched algae growing in these hotspots. Herbivory is 
a fundamentally important process for structuring coral reefs, with high levels of herbivory keeping reefs free of excess harmful algae and facilitating coral recruitment, survivorship, and growth (Hughes et al. 2007; Burkepile \& Hay 2008). Accordingly, we expected the cumulative effects of fish-derived nutrients to create distinct benthic communities around hotspots.

\section{Methods}

\section{Study Species and Site}

We conducted our research on a shallow forereef (5-7 m deep) in the Florida Keys National Marine Sanctuary, USA $\left(24.992^{\circ} \mathrm{N} 80.408^{\circ} \mathrm{W}\right)$ from May through August of 2013 . This site is dominated by primarily dead colonies of the massive, digitate coral Dendrogyra cylindrus. During the day, large schools of grunts consistently shelter around some of these $D$. cylindrus colonies, while remaining consistently absent at other colonies.

\section{Experimental Setup}

In April 2013 we tagged every D. cylindrus colony in a 60 × 20 m section of the reef. Over the ensuing month we conducted weekly surveys between 10:00 AM and 3:00 PM to record the number, size, and species of fishes within a $0.5 \mathrm{~m}$ perimeter of each tagged colony. From these preliminary surveys we selected twenty study colonies with live tissue, haphazardly distributed across the reef, that consistently sheltered either high or low biomass of fishes and were separated by at least $2 \mathrm{~m}(n=10$ each; Appendix A). Colonies were interspersed throughout the site to ensure that any large scale abiotic factors such as nutrient delivery from internal waves, which rarely reach these depths in the Florida Keys (Leichter et al. 2003), or land-based sources of pollution, which are negligible at these sites $>10 \mathrm{~km}$ offshore (Briceño \& Boyer 2012), would affect both high and low biomass colonies equally.

Study colonies ranged in size from $1 \times 1 \times 0.75 \mathrm{~m}$ to $2 \times 2 \times 2.25 \mathrm{~m}$ (length $\mathrm{x}$ width $\mathrm{x}$ height), with fish tending to shelter at taller colonies. To determine the consistency of fish residency we conducted five-minute surveys between 10:00 AM and 3:00 PM at each study colony every 7 - 9 days from May to mid-August ( $n=11$ surveys) and recorded the number, size, 
and species of fishes at each colony. Fish were considered residents of the colony if they spent the entirety of the survey within $0.5 \mathrm{~m}$ of the colony's perimeter. Each week we began our surveys at a randomly selected colony and surveyed colonies from nearest to the start location to furthest away in order to prevent any artifacts that may have occurred from surveying colonies in the same order. For our analyses, we converted estimates of fish length to biomass using published length-weight relationships (Bohnsack and Harper 1988; Marks and Klomp 2003).

\section{Estimates of Nutrient Delivery}

Fishes excrete nitrogenous waste as ammonia, and to some extent urea, while $\mathrm{P}$ is excreted in both soluble and fecal forms (Dosdat et al. 1995). As a result, fish-derived nutrients are quickly diluted in the water column and rapidly utilized by benthic organisms, making it difficult to capture the signal of fish-derived nutrients in water samples. Therefore, we used bioenergetics models from Burkepile et al. (2013) to estimate nutrient excretion rates from sheltering fishes at each colony. Bioenergetics models use a mass balance approach given a priori knowledge of a fishes' diet, physiology, and the environmental conditions to provide accurate estimates of excretion via linear models (e.g. Vanni 2002; Allgeier et al. 2013; Burkepile et al. 2013). We used these linear models to estimate excretion rates (mg nutrient fish-wet-weight ${ }^{-1}$ day $^{-1}$ ) of nitrogen and phosphorus based on the biomass of all Haemulid fishes sheltering around $D$. cylindrus colonies. We focused solely on Haemulid fishes as they represented $99 \%$ of the biomass of resident fishes across all study colonies.

We complemented our bioenergetics models to evaluate nutrient output by assessing the nutrient content of macroalgae at the different study colonies, as it reflects ambient nutrient conditions over a relatively long time frame (i.e., weeks to months) (Atkinson \& Smith 1983). Thus, algae in consistently enriched environments typically show higher tissue nutrients (e.g. Burkepile and Hay 2009, Vega Thurber et al. 2014). During Weeks 7 and 14 samples of the macroalga Dictyota menstrualis were collected from within the survey areas at each colony for analysis of $\mathrm{N}$ and $\mathrm{P}$ content. Samples were immediately placed on ice, transported to the lab, and frozen until processed. Samples were rinsed with deionized water and scraped free of epiphytes 
before being dried at $50^{\circ} \mathrm{C}$ to a constant weight and ground to powder. Total carbon and $\mathrm{N}$ content was determined via elemental analysis using a CHN analyzer (FlashEA 1112 Series, Thermo Electron Corporation). We measured P content through a standard oxidation-acid hydrolysis extraction followed by a colorimetric analysis.

\section{Community Structure}

To determine how differences in fish-derived nutrients impacted community structure, we established $0.5 \mathrm{~m} \times 0.5 \mathrm{~m}$ permanent quadrats adjacent to the southwestern side of each study colony. These areas fell within the radius of our fish surveys, and their position was selected to standardize for differences in water motion and light availability that could have occurred based on their position relative to the study colony. To estimate the percent cover of benthic organisms, we took digital photos of each permanent quadrat during the final week of the study. We overlaid a one hundred-point grid on each photo and identified the organism below each point to the lowest taxonomic level possible. After identification, each point was categorized as either: 1) brown macroalgae (>90\% Dictyota spp.), 2) red macroalgae (primarily articulated corallines from the genera Amphiroa and Galaxaura), 3) green macroalgae (Halimeda spp.), 4) filamentous turf algae, 5) crustose coralline algae (CCA), 6) turf algae mixed with sediment mats (TAS), 7) cyanobacteria, 8) soft corals, or 9) stony corals. In addition, we pooled all upright algae (brown algae, red algae, green algae, and both turf groups) into a "Total Algae" group, as members from these groups can impair coral recruitment and growth (Birrell et al. 2008).

Fish excretion can increase the growth of the corals in which they shelter (Meyer et al. 1983, Shantz \& Burkepile 2014). However, it is unclear how fish schools impact corals that they are not directly sheltering in. Therefore, in Week 2 of the study we transplanted four Acropora cervicornis fragments (10 cm each) around each study colony to investigate the effect of fishderived nutrients on corals around shelter sites. We transplanted two fragments into each permanent benthic quadrat. To examine if potential differences in abiotic forces (e.g. flow rate, shading, sedimentation) could account for variation in coral growth, we transplanted the other two A. cervicornis fragments to the top of dead $D$. cylindrus pillars on the southwestern edge of each 
study colony. These corals were within $1 \mathrm{~m}$ of those placed in our permanent benthic quadrats, but could have experienced different flow, light, and sedimentation regimes than the corals at the base of the colonies. All corals were tagged, measured, and photographed at the time of outplanting. During Weeks 7 and 14 each coral was re-measured and photographed to calculate the total linear extension. Differences between final and initial sizes were used to calculate the percent growth day ${ }^{-1}$.

To assess how fish aggregations impacted herbivore foraging, in Weeks 10 and 11 we filmed each study colony for two hours and documented the species, size, and total number of bites taken by herbivorous fishes within each permanent quadrat. All colonies were filmed between 10:00 AM and 1:00 PM over the course of two days. When the videos were scored, only bites taken within the permanent quadrats were counted towards the total number of bites taken. To ensure that differences in grazing resulted from nutrient delivery from grunts and the ensuing enrichment of algae on the benthos rather than some other intrinsic factors of the colony, we also transplanted pre-weighed sections of a palatable alga, Laurencia sp., into each permanent quadrat to measure algal biomass removal rates. All Laruencia sp. was collected from a $\sim 3 \mathrm{~m}^{2}$ area in a nearby backreef location to ensure similar nutrient quality. Prior to deployment, Laurencia sp. was spun dry in a salad spinner and divided into 20 individually weighed portions (initial weight $15.0-20.0 \mathrm{~g}$ ). Pre-weighed algae were kept in aerated seawater overnight and randomly assigned to a study colony the following day for assays. At each colony, algae were secured to clothespins, attached to the substrate and left for two hours. After two hours, assays were collected in individual bags, returned to the lab, spun dry, and re-weighed to determine mass lost during deployment. Half of the assays were filmed using GoPro digital cameras to confirm that the mass lost was due to herbivory.

Statistical Analyses

Because fish biomass tended to cluster at either low or high levels rather than along a continuum of occupation (see Results), we used agglomerative hierarchical clustering to categorize study colonies as "High Biomass" or "Low Biomass" sites. Biomass status was 
assigned using the biomass of grunts around each colony throughout the study based on Wards method using Euclidean distances and the Cluster library in $R$ (Maechler et al. 2013). Differences in fish biomass based on cluster (High Biomass vs. Low Biomass) and time were assessed by mixed effects repeated measures ANOVA with the nlme package in $R$ (Pinheiro et al. 2007). To conform to assumptions of ANOVA biomass data were log transformed. Because biomass was significantly and consistently higher at High Biomass versus Low Biomass sites throughout the entirety of the experiment (see Results), we used these groups as a treatment variable for all subsequent analyses.

We used mixed-model ANOVAs that considered biomass status (High vs. Low) a treatment factor and included a random effect for colony to test for differences in the mean $\mathrm{N}$ and P delivery from fishes (as calculated from bioenergetics models), and the algal mass lost from feeding assays. Because grazing rates on the benthos were filmed over separate days, we included an additional treatment factor for day to test for differences in grazing between colonies. Both excretion rates and algal mass loss from feeding assay data were log transformed, while grazing rate data were square root transformed to meet assumptions of ANOVA. Differences in the $\mathrm{N}$ and $\mathrm{P}$ content of $D$. menstrualis were tested via mixed effects repeated measures ANOVA.

We tested for differences in the growth rates of $A$. cervicornis transplants via a nested two-way ANOVA that considered biomass status and position (elevated vs. colony base) as predictors and included an interaction between the two. Transplants suffered high rates of breakage, likely due to the many careless recreational divers visiting the site (pers. obs). Therefore, we restricted our analysis to transplants that showed no signs of breakage at the time of measurement. This limited our analysis to 46 of the 80 transplants, 18 from High biomass colonies ( 8 elevated and 10 at the base of colonies) and 28 from Low biomass colonies (15 elevated and 13 base).

We used mixed-effects ANOVA to test for differences in the percent cover of each benthic category as well as the overall cover of Total algae at High vs. Low Biomass colonies. For groups that were rare (i.e. $<5 \%$ of benthic cover) we used Fishers Exact Tests to test for 
differences in their presence or absence between colonies. We also used ANOSIM and SIMPER analyses to test for similarity in the benthic algal community. We visualized differences in the benthic algal communities via nonmetric multidimensional scaling (nMDS) using a random starting configuration and Bray-Curtis distance based on the percent cover of each benthic category at each colony. ANOSIM and nMDS analyses were conducted using the Vegan package in $R$ (Oksanen et al. 2013). All data are reported as means \pm S.E.

\section{Results}

Grunts accounted for the majority of biomass observed at $D$. cylindrus colonies and nearly $99 \%$ of the variation between High and Low Biomass colonies. The biomass of resident grunts sheltering among corals varied from 0 to $830 \mathrm{~g} \mathrm{~m}^{-2}$, and agglomerative clustering indicated that colonies could be classified as either High Biomass or Low Biomass sites (Fig. 5.1a). Biomass was relatively consistent at colonies identified as Low Biomass but showed significant variation through time at High Biomass sites (Biomass $x$ Time effect: $F_{10,180}=3.81, p<0.001$; Table B1). Despite this variability, grunt biomass remained consistently higher at sites designated as High Biomass versus those designated as Low Biomass for the entirety of the study (Biomass effect: $F_{1,18}=67.83, p<0.001 ;$ Fig. 5.1b).

From our bioenergetics models, the average modeled grunt excretion rates of $\mathrm{N}$ and $\mathrm{P}$ around High Biomass sites were $\sim 10$ times greater than at Low Biomass sites $\left(F_{1,16}=91.07, p<\right.$ 0.001 and $F_{1,16}=25.07, p<0.001$ respectively; Fig 5.2a). Modeled mean N excretion around High Biomass sites was $50.07 \pm 9.43 \mathrm{mg} \mathrm{m}^{-2}$ day $^{-1}$ while $\mathrm{P}$ excretion was $5.32 \pm 1.01 \mathrm{mg} \mathrm{m}^{-2}$ day $^{-1}$. Calculated excretion rates around Low Biomass sites also represented a sizable contribution of $\mathrm{N}$ and $P$ to the area $\left(5.72 \pm 0.72 \mathrm{mg} \mathrm{N} \mathrm{m}^{-2}\right.$ day $^{-1}$ and $0.53 \pm 0.08 \mathrm{mg} \mathrm{P} \mathrm{m}^{-2}$ day $\left.^{-1}\right)$, but were approximately an order of magnitude lower than at High Biomass sites. Additionally, nitrogen content of $D$. menstrualis was roughly $15 \%$ higher near High Biomass than Low Biomass sites $\left(F_{1,18}=4.64, p=0.045 ;\right.$ Fig. $\left.5.2 b\right)$, but we found no difference in $P$ content $\left(F_{1,18}<0.001, p=\right.$ $0.98)$. 
ANOSIM showed a significant difference in the benthic algal communities between High and Low Biomass sites $(R=0.31, p=0.007)$. Dissimilarity between sites was driven primarily by TAS (26.7\% of dissimilarity), CCA (24.5\%), and brown macroalgae (24.0\%) (Table B2). These results were supported by our nMDS analysis, which suggested that High and Low Biomass sites were similar in turf cover, and to some extent red macroalgae, but diverged in percent cover of most other benthic groups (Fig. 5.3).

Colonies that sheltered large schools of grunts tended to have lower overall cover of Total Algae and TAS ( $p=0.01$ and 0.001 respectively; Fig. 5.4) than colonies without large schools of grunts. The percent cover of CCA was also $~ 70 \%$ higher around High Biomass colonies than Low Biomass colonies ( $p=0.013$ Fig. 5.4). There were no significant differences in the percent cover of brown or red macroalgae individually. Green macroalgae cover was low across sites. However, these algae were present at 7 of 10 High Biomass sites but completely absent at all Low Biomass sites ( $p=0.003$, two-tailed Fisher's exact test). Other rare benthic groups (e.g. stony coral, soft coral, cyanobacteria) did not differ between sites either in percent cover or presence/absence (Fig. 5.4).

A. cervicornis transplanted around High Biomass sites grew nearly $75 \%$ faster than transplants at Low Biomass sites $\left(F_{1,16}=6.63, p=0.02\right.$; Fig. 5.5). We found no difference in growth rates between elevated coral transplants and those at the base of colonies $\left(F_{1,12}=0.22, p\right.$ $=0.65)$ and no interaction between biomass and position $\left(F_{1,12}=0.39, p=0.55\right)$.

No herbivorous fishes (e.g. Acanthurids or Scarids) spent enough time around any colony to be considered resident fish. Nonetheless, grazing rates by these herbivores were roughly three times greater at the High Biomass sites than at the Low Biomass sites $(1.52 \pm 0.36$ versus $0.50 \pm$ 0.10 bites per minute respectively; $F_{1,17}=8.56, p=0.009 ;$ Fig. 5.6$)$ and day had no effect $\left(F_{1,17}=\right.$ $2.57, p=0.127)$. Grazing rates were roughly $1.5-2$ times higher for all herbivorous fishes except the ocean surgeonfish (Acanthurus tractus) and the yellowtail parrotfish (Sparisoma rubripinne), which increased grazing roughly 9 and 15 fold in High Biomass sites, respectively, and the queen parrotfish, Scarus vetula, which showed no change in grazing rates between sites. In contrast to 
grazing patterns on the benthos, herbivores consumed similar amounts of Laurencia from feeding assays at both High and Low Biomass sites ( $46.6 \pm 10 \%$ mass consumed versus $35.9 \pm 8 \%$ consumed respectively, $\left.F_{1,18}=0.71, p=0.41\right)$.

\section{Discussion}

On coral reefs consumer-mediated nutrient cycling is rarely appreciated as an important driver of community structure. However, we show that fish-derived nutrients from common mesopredators that occupy the middle of food chains can play an important role in dictating community structure. Our bioenergetics models show that the high site fidelity of sheltering Haemulid fishes increased the delivery of both $\mathrm{N}$ and $\mathrm{P}$ around their shelter sites by an order of magnitude. These nutrient hotspots had higher coral growth rates, less harmful algae, and more crustose coralline algae compared to areas where fishes rarely sheltered. Interestingly, the increased input of limiting nutrients at hotspots led to increased feeding by herbivorous fishes, which likely drove much of the difference in benthic community structure at the High Biomass sites. Our data are some of the first to indicate that fish aggregations and their nutrient subsidies can be important determinants of ecosystem processes and community structure on coral reefs.

High rates of nutrient delivery often influence the species composition and dominance of primary producer communities, as well as impact overall rates of production, elemental storage and ecosystem function (Chapin et al. 1997). For example, Burkepile et al. (2013) documented a positive relationship between fish excretion rates and the percent cover of macroalgae across multiple reefs in the Florida Keys, including the site used in this study. However, the spatial distribution of nutrients may be as important as total delivery rates for determining ecological processes. Heterogeneity in resource supply can have profound effects on ecosystems by creating gradients in species-performance within the landscape (Chesson 2000) or altering the feeding patterns of consumers (Barboza et al. 2009). At our site, the majority of fish-derived nutrients were not distributed evenly across the reef. Instead, bioenergetics models indicated that large schools of grunts provided on average roughly ten times more $\mathrm{N}$ and $\mathrm{P}$ to discrete sites 
where they consistently sheltered. Importantly, our study site had the lowest reef-wide rates of $\mathrm{N}$ and $\mathrm{P}$ excretion among reefs in the upper Florida Keys, but the consistent aggregation of fishes at specific sites within our study reef created nutrient hotspots where nutrient excretion rates exceeded those of most other reefs in the region (Burkepile et al. 2013). Thus, fish aggregations appear to be important for determining both within and among reef patterns in nutrient distribution.

High Biomass sites also possessed distinctly different algal communities than structurally similar sites that lacked large schools of grunts (Fig. 5.3). Low rates of nutrient supply typically favor slow-growing algae that are effective in nutrient acquisition, storage, and use, while high nutrient levels often promote rapidly growing, ephemeral species such as filamentous turf (Herbert \& Fourqurean 2008). Surprisingly, we found no difference in the percent cover of turf or macroalgae between sites. Instead, the lower cover of TAS and higher cover of CCA at High Biomass sites accounted for over $50 \%$ of the differences between High and Low Biomass sites (Fig. 5.4; Table B2). Given that fast growing algae are typically favored by excess nutrients, one might expect the opposite pattern. However, previous experiments manipulating nutrients on reefs have reported that both shorter filamentous turf algae and TAS are mediated by grazing rather than nutrients, while CCA responds positively to nutrient enrichment in the presence of grazers (Burkepile \& Hay 2009; Walsh 2011). Our findings are consistent with these patterns and suggest that the nutrient-induced concentration in grazing around nutrient hotspots had more influence on benthic algal communities than did the direct effects of nutrients on algal growth and competition.

Given that herbivores are often nutrient limited, they should focus their foraging on high quality primary producers (Barboza et al. 2009; Lemoine et al. 2014). We found that herbivorous fishes fed at roughly three times greater rates around High Biomass sites than Low Biomass sites (Fig. 5.6). This is similar to large herbivores in terrestrial systems such as bison in tall-grass prairies (Steinauer \& Collins 2001) and large ungulates in African savannahs (Anderson et al. 2010) that exhibit higher grazing rates around nutrient hotspots. Accordingly, the increased 
grazing at High Biomass sites likely explains the absence of higher macroalgal cover associated with high levels of fish-derived nutrients on a reef-wide scale (Burkepile et al. 2013), as more intense herbivory likely compensates for increased algal production at the scale of individual coral heads.

We also found that the high levels of fish-derived nutrients at High Biomass sites promoted coral growth, with extension rates of $A$. cervicornis approximately 1.5 times greater at these sites than at sites where grunt biomass was low (Fig. 5.5). This pattern has been documented for corals that shelter fishes directly within their branches. For example, growth of Porites furcata was approximately 1.4 times greater when colonies sheltered schools of grunts (Meyer \& Schultz 1985). While this value is similar to the increased growth rates recorded here, our study shows that corals receive benefits from fishes by merely growing in the proximity $(\leq 1 \mathrm{~m})$ of large schools of fishes. Given the high fish biomass on reefs with low fishing pressure (Sandin et al. 2008, Friedlander et al. 2010), corals may be adapted to thrive in areas with high rates of nutrient recycling by fishes, so long as macroalgal cover remains low. Indeed, Allgeier et al. (2014) suggested that fish may deliver nutrients to corals at an optimum N:P ratio for coral growth of around 20:1, a level almost identical to the 20.3:1 calculated in our study. Thus, fish-derived nutrients and nutrient hotspots may be an important positive feedback on coral success that could facilitate coral dominated communities.

As a result, nutrient hotspots may serve as important nodes for the recovery of degraded reefs. On coral depauperate reefs, diffuse grazing by fishes may be insufficient to consistently suppress macroalgae and facilitate coral recovery (Mumby et al. 2007; Sandin \& McNamara 2012). However, we show that nutrient hotspots can focus grazing from herbivorous fishes on discrete patches, leading to decreased cover of upright algae, which can inhibit coral settlement and growth (Birrell et al. 2008), and increased cover of CCA, which can promote the settlement and survival of coral larvae (Harrington et al. 2004). Furthermore, higher coral growth rates around fish-derived hotspots may reduce the time corals spend in smaller size classes, when they are weaker competitors and suffer greater levels of size-dependent mortality (Bak \& Meester 
1999). Thus, fish-derived nutrient hotspots may not only improve coral settlement but also increase survival rates.

These positive feedbacks are likely important for the recovery of degraded reefs and may be important when considering restoration efforts. For example, reefs with low topographic complexity may benefit from artificial structure to provide aggregation points for fishes. Likewise, on coral depauperate reefs, planting nursery-raised corals around existing fish aggregation sites may improve the growth, survival, and potential reproductive output of transplanted corals. In turn, the increased topographic complexity afforded by restored corals may provide more sheltering habitat for fishes, encouraging a positive feedback that promotes reef recovery (e.g. Mumby \& Steneck 2008). Accordingly, the significant positive effects of fish-derived nutrient hotspots on grazing and coral growth rates demonstrated in this study may be an important consideration for coral restoration strategies.

One potential concern with our study is that the sites where grunts aggregated could have coincided with some unique location effects such as different wave exposure, currents, or abiotic nutrient delivery that attracted herbivorous fishes and resulted in different benthic communities but was unrelated to fish-derived nutrients. However, both High and Low Biomass sites were well interspersed over a $20 \mathrm{~m} \times 60 \mathrm{~m}$ area of reef (Appendix A). This interspersion minimized the chances of any physical forces such as wave exposure or currents affecting only High or Low Biomass sites. Further, in the Florida Keys, the major sources of abiotic nutrients are typically internal waves (e.g. Leichter et al. 2003) or delivery of nutrients from land-based sources. However, internal waves rarely reach the shallow depths where we were working and are extremely variable in space and time when they do reach these shallow depths (Leichter et al. 2003), which would make them an unlikely explanatory factor for generating very consistent spatial and temporal differences in fish and benthic communities. Further, land-based sources of pollution are quite rare on these outer forereefs that are $>10 \mathrm{~km}$ offshore (Briceño \& Boyer 2012). Even if these abiotic sources were important deliverers of nutrients to our field site, the 
interspersion of our High and Low Biomass sites would have made it very unlikely that these nutrient sources would have biased our data set in a significant way.

Another potential explanation of differences in increased herbivore foraging around High Biomass sites could be that these sites just attract more types of all fishes regardless of fishderived nutrients. However, while grunts spend the entire day in shelter sites (Ogden \& Quinn 1989), both parrotfish and surgeonfish are roving herbivores with average territory sizes ranging from $100 \mathrm{~m}^{2}$ to over $1,000 \mathrm{~m}^{2}$ (Mumby \& Wabnitz 2002, Catano et al. 2015). Due to the small size of our study site $(20 \mathrm{~m} \times 60 \mathrm{~m})$, individual parrotfish and surgeonfish would likely range over the majority of our site, including both High and Low Biomass colonies. The fact that we found a threefold increase in foraging on the benthos only around High Biomass colonies strongly suggests that these fishes consistently choose to forage in these areas. In contrast to benthic grazing rates on the existing algal community, there was no difference in consumption of Laurencia sp. during feeding assays between High and Low Biomass sites. If grazing at these coral colonies were based on attraction of herbivores to these sites via mechanisms unrelated to fish-derived nutrients, than we would have expected consumption of algae in the feeding assays to follow the same pattern as we saw in grazing on the benthos. However, these data suggest that increased grazing around High Biomass sites was a direct result of nutrient delivery from fishes and the subsequent increase in nutritional quality in naturally occurring algae rather than herbivorous fishes being attracted to High Biomass sites for reasons unrelated to fish-derived nutrients.

Ideally, we would have been able to conduct a fish removal/addition experiment that would conclusively show that fish aggregations impacted herbivore foraging and benthic dynamics. But, these experiments were not possible at this popular dive site within a national marine sanctuary. However, recent experimental studies have shown that the creation of artificial reefs in oligotrophic seagrass beds promote fish aggregations (especially grunts and snappers) that, in turn, lead to increased delivery of fish-derived nutrients, increased primary production and biomass accumulation (e.g. Dewsbury \& Fourqurean 2010; Layman et al. 2013; Allgeier et al. 
2013). Thus, in experiments that have directly altered fish aggregations, the impacts on nutrient cycling and benthic dynamics that they show support our hypotheses about the impact of fishderived nutrients in this reef system.

Finally, the level of increase in the $\mathrm{N}$ content of algae around the High Biomass sites that we recorded requires a large and consistent amount of $\mathrm{N}$ input to generate. For example, in a recent experiment (Vega Thurber et al. 2014), we enriched plots of reef with $\sim 600 \mathrm{~g} \mathrm{~m}^{-2}$ of slow release $\mathrm{N}+\mathrm{P}$ fertilizer, replaced monthly, for three years. This enrichment increased $\mathrm{N}$ and $\mathrm{P}$ in the water column $\sim 6-8$ times above ambient levels, although the actual delivery rate was likely higher as some of the $\mathrm{N}$ and $\mathrm{P}$ was diffused and absorbed before we could measure it. This enrichment experiment resulted in a $20 \%$ increase in the $\mathrm{N}$ content of $D$. menstrualis, which is very similar to the $15 \%$ increase that we documented at High biomass sites in this study. This indicates that the differences in algal tissue $\mathrm{N}$ we report here, between study colonies often separated by just a few meters, requires an extremely substantial, localized, and consistent input of $\mathrm{N}$ to achieve. It seems extremely unlikely that differences in physical forcing could generate these differences in algal $\mathrm{N}$ content at such small scales given both the interspersion of our sites within the reef and the lack of other physical mechanisms (e.g. internal waves or land-based pollution) that could drive such large differences in nutrient delivery. Thus, the concentration of fish-derived nutrients at High Biomass sites are the mostly likely explanation driving increases in algal $\mathrm{N}$ content, alterations to herbivore foraging, differences in benthic communities, and increases in coral growth.

Human activity is likely to continue to cause biodiversity loss and habitat fragmentation capable of disrupting consumer-mediated nutrient regimes. Accordingly, studies are needed to quantify the importance of animal-derived nutrients on community structure and ecosystem function before important consumer-mediated nutrient-pathways are inadvertently broken and valuable ecological processes lost. Our understanding of the impact of fish-derived nutrients on coral reefs is sorely incomplete. This study demonstrates that by creating nutrient hotspots, coral reef mesopredators play an important, yet previously unrecognized, role in shaping coral reef 
communities. As a result, overfishing of mesopredators may undermine coral reef health by disrupting the natural delivery and distribution of nutrients on reefs. This is noteworthy because management strategies often focus protection on herbivores and apex predators but overlook these mid-level predators. Furthermore, this pattern is likely not unique to reefs and may represent a less recognized threat of overfishing to marine systems. For example, Layman et al. (2011) documented an approximately 500\% decline in nutrient delivery in fished versus unfished tidal creeks in the Bahamas and subsequent declines in primary production with the removal of fishes. Because many mobile-link organisms, including the grunts in this study, cross system boundaries to forage or shelter (Lundberg \& Moberg 2003, Heck et al. 2008), conservation must focus not only on the organisms themselves but also on both the donor and recipient ecosystems for the nutrients that they translocate. Our study suggests that whole-system management plans, such as no-take reserves, or targeted protection for these mobile-link species may be needed to retain these important nutrient pathways.

\section{References}

Allgeier, J. E., L. Yeager \& C. A. Layman. 2013. Consumers regulate nutrient limitation regimes and primary production in seagrass ecosystems. Ecology, 94(2), 521-529.

Allgeier, J. E., C. A. Layman, P. J. Mumby \& A. D. Rosemond. 2014. Consistent nutrient storage and supply mediated by diverse fish communities in coral reef ecosystems. Global Change Biology, doi:10.1111/gcb.12566

Atkinson, M. J. \& S. Smith. 1983. C: N: P ratios of benthic marine plants. Limnology and Oceanography, 28(3), 568-574.

Anderson, M. T., J. G. C. Hopcraft, S. Eby, M. Ritchie, J. B. Grace \& H. Olff. 2010. Landscapescale analyses suggest both nutrient and antipredator advantages to Serengeti herbivore hotspots. Ecology, 9, 1519-1529.

Bak, R. P. M. \& E. H. Meester. 1999. Population structure as a response of coral communities to global change. American Zoologist, 39, 56-65.

Barboza, P. S., K. L. Parker \& I. D. Hume. 2009. Integrative wildlife nutrition. Springer-Verlag, Berlin, Heidelberg, Germany.

Birrell, C. L., L. J. McCook, B. L. Willis \& A. Diaz-Pulido. 2008. Effects of benthic algae on the replenishment of corals and the implications for the resilience of coral reefs. Oceanography and Marine Biology: An Annual Review, 46, 25-63. 
Bohnsack, J. A. \& D. E. Harper. 1988. Length-weight relationships of selected marine reef fishes from the southeastern United States and the Caribbean. Technical memorandum 215. National Oceanic and Atmospheric Administration, Miami, Florida.

Briceño, H. O. \& J. N. Boyer. 2012. Annual report of the water quality monitoring project for the water quality protection program of the Florida Keys National Marine Sanctuary. Southeast Environmental Research Center, Florida International University:82 http://serc.fiu.edu/wamnetwork/

Burkepile, D. E. \& M. E. Hay. 2008. Herbivore species richness and feeding complementarity affect community structure and function on a coral reef. Proceedings of the National Academy of Sciences, USA, 105, 16201-16206.

Burkepile, D. E. \& M. E. Hay. 2009. Nutrient versus herbivore control of macroalgal community development and coral growth on a Caribbean reef. Marine Ecology Progress Series, 389, 71-84.

Burkepile, D. E., J. E. Allgeier, A. A. Shantz, C. E. Pritchard, N. P. Lemoine, L. H. Bhatti \& C. A. Layman. 2013. Nutrient supply from fishes facilitates macroalgae and suppresses corals in a Caribbean coral reef ecosystem. Scientific Reports, 3, 1493. doi:10.1038/srep01493

Catano, L.B., B. K. Gunn, M. Kelley \& D. E. Burkepile. 2015. Predation risk, resource quality, and reef structural complexity shape territoriality in a coral reef herbivore. PLoS One. 10(2): e0118764. Doi: 10.1371/journal.pone.0118764

Chapin F. S., B. H. Walker, R. J. Hobbs, D. U. Hooper, J. H. Lawton et al. 1997. Biotic control over the functioning of ecosystems. Science, 227, 500-504.

Chesson, P. 2000. Mechanisms of maintenance of species diversity. Annual Review of Ecology and Systematics, 31, 343-366.

Croll, D. A., J. L. Maron, J. A. Estes, E. M. Danner \& G. V. Byrd. 2005. Introduced predators transform subarctic islands from grassland to tundra. Science, 307, 1959-1961.

Dewsbury, B. M. \& J. F. Fourqurean. 2010. Artificial reefs concentrate nutrients and alter benthic community structure in an oligotrophic, subtropical estuary. Bulletin of Marine Science 86,813-829.

Dosdat, A., F. Gaumet \& H. Chartois. 1995. Marine aquaculture effluent monitoring: Methodological approaches to the evaluation of nitrogen and phosphorus excretion by fish. Aquaculture Engineering, 14, 59-84.

Estes, J. A., J. Terborgh, J. S. Brashares, M. E. Power, J. Berger, et al. 2011. Trophic downgrading of planet earth. Science, 333, 301-306.

Friedlander, A. M., S. A. Sandin, E. E. Demartini \& E. Sala. 2010. Spatial patterns of the structure of reef fish assemblages at a pristine atoll in the central Pacific. Marine Ecology Progress Series, 410, 219-231.

Harrington, L., K. Fabricius, G. De'ath \& A. Negri. 2004. Recognition and selection of settlement substrata determine post-settlement survival in corals. Ecology, 85, 3428-3437. 
Heck, K. L., T. J. B. Carruthers, C. M. Duarte, A. R. Hughes, G. Kendrick, et al. 2008. Trophic transfers from seagrass meadows subsidize diverse marine and terrestrial consumers. Ecosystems, 11, 1198-1210.

Herbert, D. A. \& J. W. Fourqurean. 2008. Ecosystem Structure and Function Still Altered Two Decades After Short-Term Fertilization of a Seagrass Meadow. Ecosystems, 11, 688-700.

Hilderbrand, G. V., T. A. Hanley, C. T. Robbins \& C. C. Schwartz. 1999. Role of brown bears (Ursus arctos) in the flow of marine nitrogen into a terrestrial ecosystem. Oecologia, 121, 546-550.

Hughes, T. P., M. J. Rodrigues, D. R. Bellwood, D. Ceccarelli, O. Hoegh-Guldberg, et al. 2007. Phase shifts, herbivory, and the resilience of coral reefs to climate change. Current Biology, 17, 360-365.

John, R. J., J. W. Dalling, K. E. Harms, J. B. Yavitt, R. F. Stallard, et al. 2007. Soil nutrients influence spatial distributions of tropical tree species. Proceedings of the National Academy of Science, USA, 104, 864-869.

Larkin, G. A. \& P. A. Slaney. 1997. Implications of trends in marine-derived nutrient influx to south coastal British Columbia salmonid production. Fisheries, 22, 16-24.

Layman, C. A., J. E. Allgeier, A. D. Rosemond, C. P. Dahlgren, \& L. A. Yeager. 2011. Marine fisheries declines viewed upside down: human impacts on consumer-driven nutrient recycling. Ecological Applications, 21, 343-349.

Layman, C. A., J. E. Allgeier, L. A. Yeager \& E. Stoner. 2013. Thresholds of ecosystem response to nutrient enrichment from fish aggregations. Ecology, 94, 530-536.

Leichter, J. J., H. L. Stewart \& S. L. Miller. 2003. Episodic nutrient transport to Florida coral reefs. Limnology and Oceanography, 48, 1394-1407.

Lemoine, N. P., S. T. Geary \& D. E. Burkepile. 2014. Differing consumer stoichiometric constraints across ecosystems. Oecologia, 174, 1367-1376.

Lundberg, J. \& F. Moberg. 2003. Mobile link organisms and ecosystem functioning: implications for ecosystem resilience and management. Ecosystems, 6, 87-98.

Maechler, M., A. Struyf, M. Hubert, \& K. Hornick. 2013. Cluster: Cluster Analysis Extended Rousseeuw et al. R Library.

Marks, K. W. \& K. D. Klomp. 2003. Appendix Two: Fish biomass equations. Pp. 625-628 in J.C. Land (ed.), Status of Coral Reefs in the Western Atlantic: Results of Initial Surveys, Atlantic and Gulf Rapid Reef Assessment (AGRAA) Program. Smithsonian Atoll Research Bulletin 496.

McClaine, M. E., E. W. Boyer, C. L. Dent, S. E. Gergel, N. B. Grimm, et al. 2003. Biogeochemical hot spots and hot moments at the interface of terrestrial and aquatic ecosystems. Ecosystems, 6, 301-312.

McIntyre, P. B., A. S. Flecker, M. J. Vanni, J. M. Hood, B. W. Taylor \& S. A. Thomas. 2008. Fish distributions and nutrient cycling in streams: can fish create biogeochemical hotspots? Ecology, 89, 2335-46. 
McNaughton, S. J., F. F. Banyikwa \& M. M. McNaughton. 1997. Promotion of the cycling of dietenhancing nutrients by African grazers. Science, 278, 1798-1800.

Meyer, J. L., E. Schultz \& G. S. Helfman. 1983. Fish schools: an asset to corals. Science, 220, 1047-1049.

Meyer, J. L. \& E. T. Schultz. 1985. Migrating haemulid fishes as a source of nutrients and organic matter on coral reefs. Limnology and Oceanography, 30, 146-156.

Moore, J. W. 2006. Animal ecosystem engineers in streams. Bioscience, 56, 237-246.

Mumby P. J. \& C. C. Wabnitz. 2002. Spatial patterns of aggression, territory size, and harem size in five sympatric Caribbean parrotfish species. Environmental Biology of Fishes 63, 265-279.

Mumby, P. J., A. Hastings \& H. Edwards. 2007. Thresholds and the resilience of Caribbean coral reefs. Nature, 450, 98-101.

Mumby, P. J. \& R. S. Steneck. 2008. Coral reef management and conservation in light of rapidly evolving ecological paradigms. Trends in Ecology and Evolution, 23, 555-563.

Ogden, J. C., \& T. P. Quinn. 1989. Migration in coral reef fishes: ecological significance and orientation mechanisms. In Mechanisms of Migration in Fishes, ed. J.D. Mcleave, G.P. Arnold, J.J. Dodson, and W.H. Neil, 293-308. New York: Plenum Press.

Oksanen, J., F. Blanchet, R. Kindt, P. Legendre, P. R. Minchin, et al. 2013. Vegan. http://cran.rproject.org/package=vegan

Pinheiro, J., D. Bates, S. DebRoy, D. Sarkar, \& the R Core team. 2007. NIme: linear and nonlinear mixed models. $\mathrm{R}$ package version 3.1-86

Sandin, S. A., J. E. Smith, E. E. Demartini, E. A. Dinsdale, S. D. Donner, et al. 2008. Baselines and degradation of coral reefs in the Northern Line Islands. PloS One, 3(2), e1548. doi:10.1371/journal.pone.0001548

Sandin, S. A. \& D. E. McNamara. 2012. Spatial dynamics of benthic competition on coral reefs. Oecologia, 168, 1079-1090.

Schaffelke, B., J. Mellors \& N. C. Duke. 2005. Water quality in the Great Barrier Reef region: responses of mangrove, seagrass and macroalgal communities. Marine Pollution Bulletin, 51, 279-296.

Shantz, A. A. \& D. E. Burkepile. 2014. Context-dependent effects of nutrient loading on the coralalgal mutualism. Ecology, 95, 1995-2005.

Steinauer, E. M. \& S. L. Collins. 2001. Spatial cascades in community structure following urine deposition in tallgrass prairie. Ecology, 82, 1319-1329.

Vanni, M. J. 2002. Nutrient cycling by animals in freshwater ecosystems. Annual Review of Ecology and Systematics, 33, 341-370.

Vanni, M. J., G. Boros \& P. B. McIntyre. 2013. When are fish sources vs. sinks of nutrients in lake ecosystems? Ecology, 94, 2195-2206. 
Vega-Thurber, R.L., D. E. Burkepile, C. Fuchs, A. A. Shantz, R. McMinds \& J. R. Zaneveld. 2014. Chronic nutrient enrichment increases the prevalence and severity of coral disease and bleaching. Global Change Biology, 20, 544-554.

Walsh, S. 2011. Ecosystem-scale effects of nutrients and fishing on coral reefs. Journal of Marine Biology doi: 10.1155/2011/187248

Welsh, D. T. 2000. Nitrogen fixation in seagrass meadows: regulation, plant-bacteria interactions and significance to primary productivity. Ecology Letters, 3, 58-71. 
Figure 5.1 - (a) Results from agglomerative cluster analysis categorizing the 20 study colonies as either High Biomass or Low Biomass sites based on the biomass of grunts sheltering at each site during weekly surveys. (b) Biomass of grunts calculated from weekly surveys at High vs. Low Biomass sites throughout the study. P-values from repeated-measures ANOVA. Data are means $\pm \mathrm{SE}$.
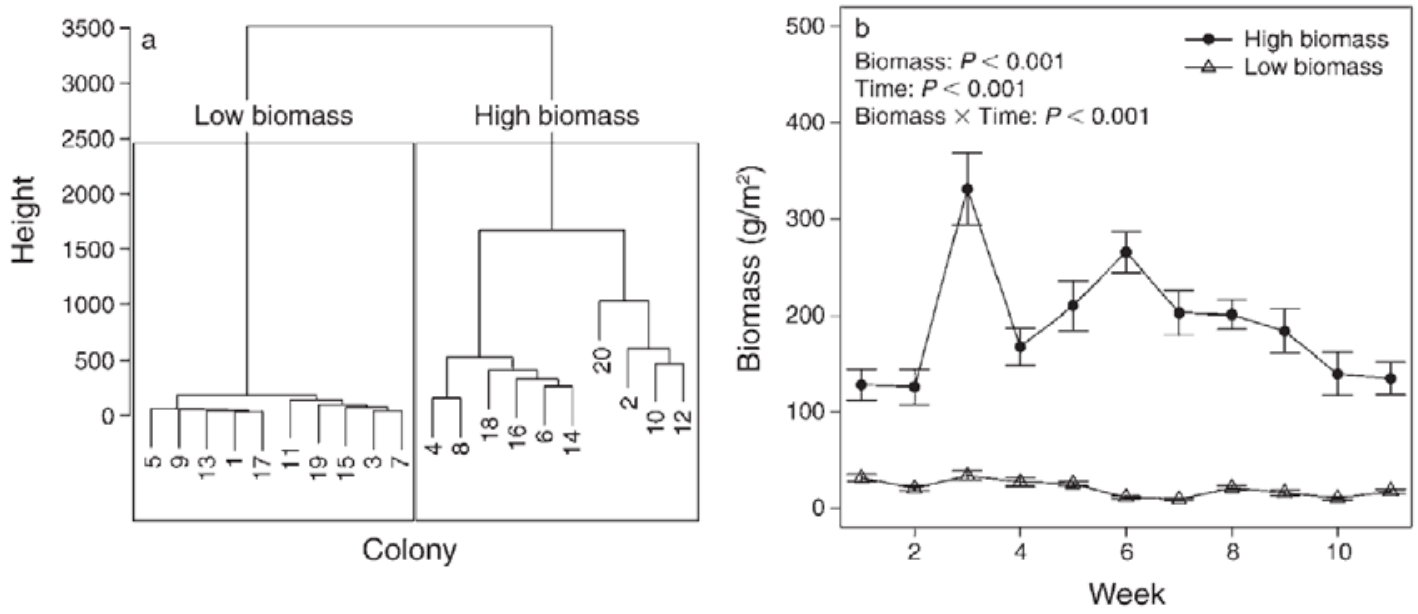
Figure $5.2-$ a) Daily excretion rates, as calculated by bioenergetics modeling, of nitrogen and phosphorus from grunts around High Biomass and Low Biomass sites. (b) Percent nitrogen and phosphorus content in the tissue of the alga Dictyota menstrualis collected from High Biomass vs. Low Biomass sites. P-values from mixed effects ANOVA. Data are means $\pm \mathrm{SE}$.
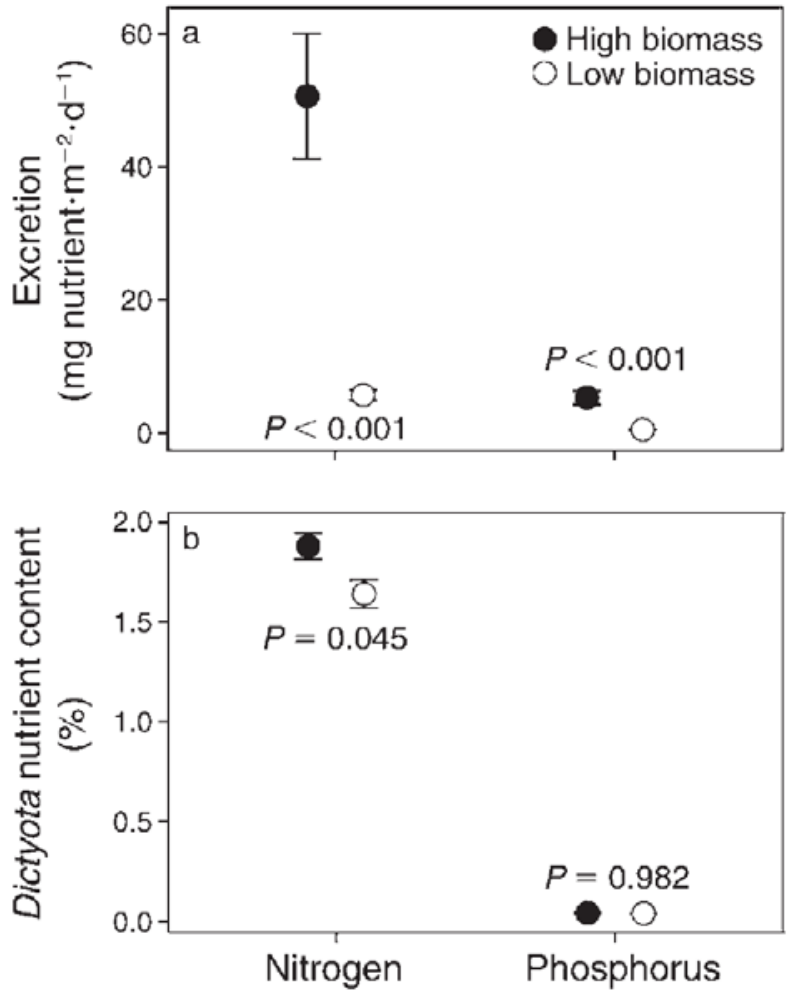
Figure 5.3 - Results of nonmetric multidimensional scaling (nMDS) depicting algal community structure around High Biomass vs. Low Biomass sites. Benthic categories depict the distance relationships between colonies based on the percent cover of the category. P-value from ANOSIM.

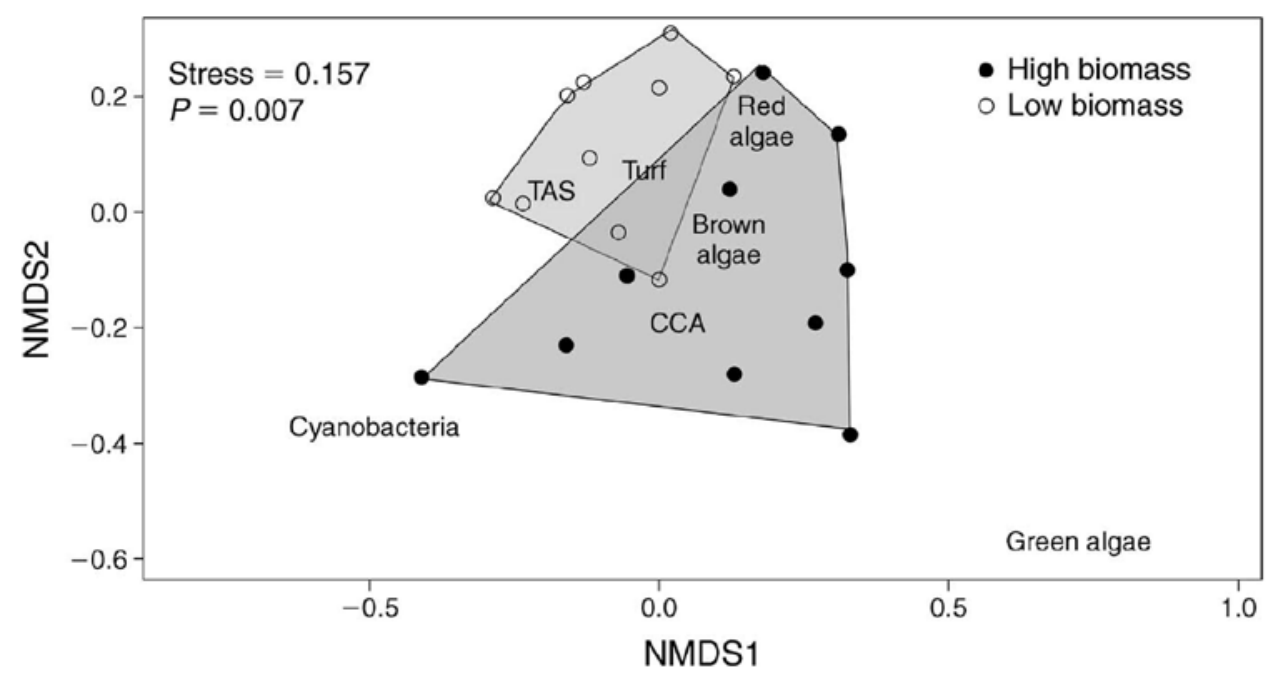


Figure 5.4 - Percent cover of different benthic groups at High Biomass vs. Low Biomass sites. Pvalues from mixed effects ANOVA. Data are means $\pm \mathrm{SE}$.
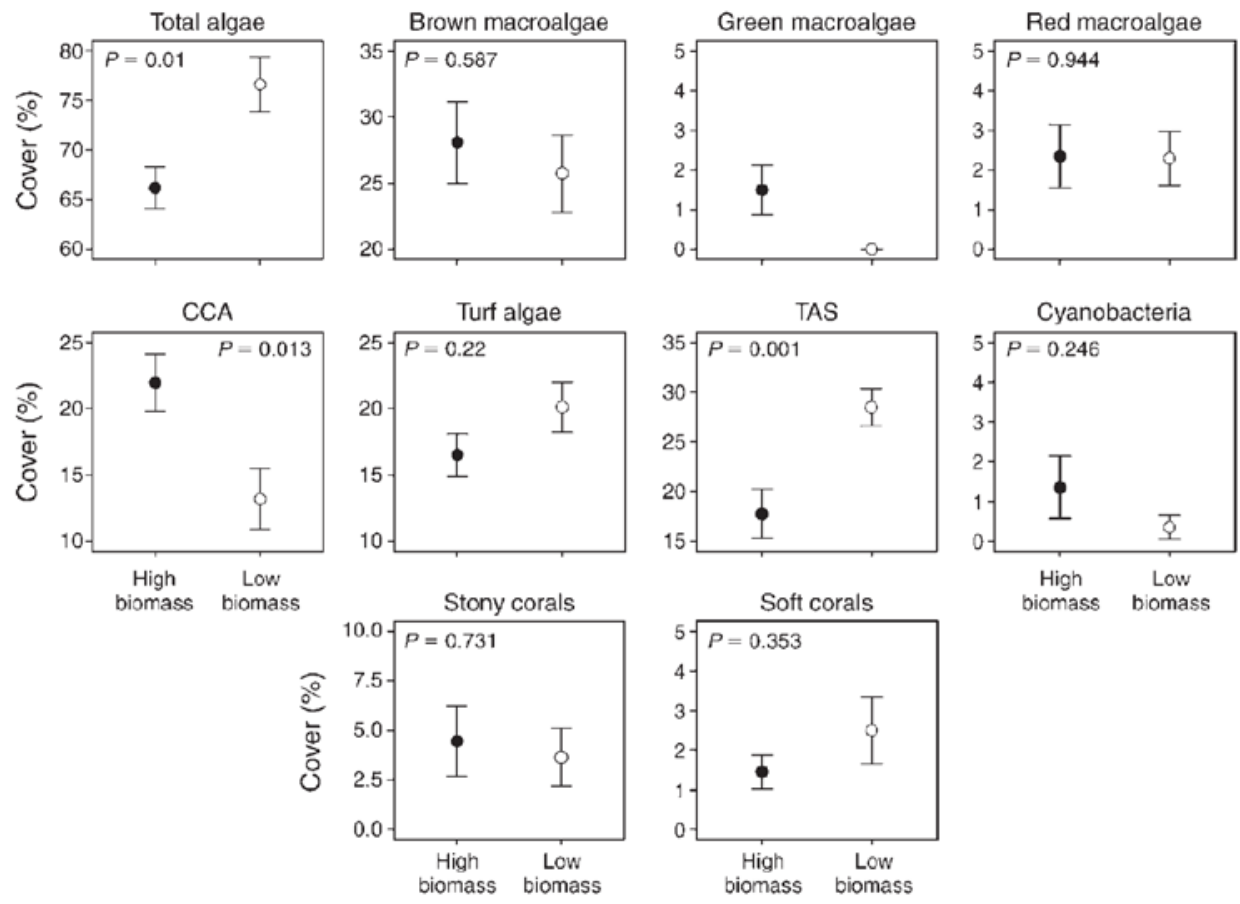

biomass biomass 
Figure 5.5 - Skeletal extension rates, as a percent of total linear extension per day, for Acropora cervicornis transplants located at High Biomass vs. Low Biomass sites. P-value from mixed effects ANOVA. Data are means \pm SE.

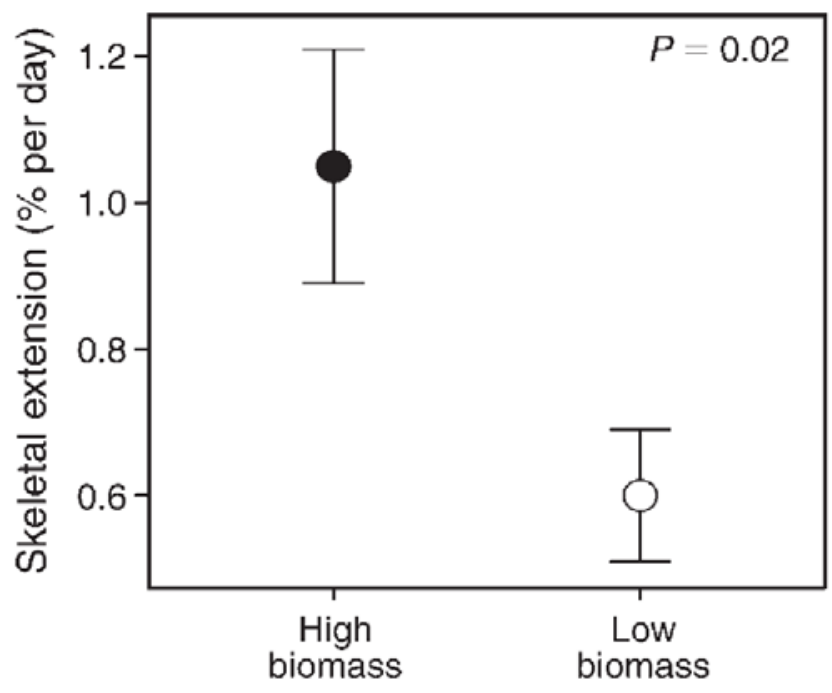


Figure 5.6 - Grazing rates of herbivorous fishes at High Biomass vs. Low Biomass colonies. Pvalue from mixed effects ANOVA. Data are means \pm SE.

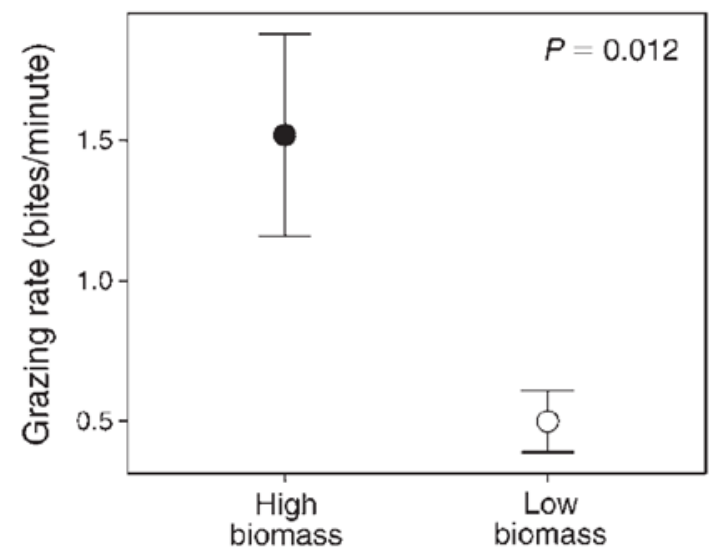




\section{CHAPTER VI}

NUTRIENT LOADING ALTERS THE PERFORMANCE OF KEY NUTRIENT EXCHANGE MUTUALISMS 


\begin{abstract}
Nutrient exchange mutualisms between phototrophs and heterotrophs, such as plants and mycorrhizal fungi or symbiotic algae and corals, underpin the functioning of many ecosystems. These relationships structure communities, promote biodiversity, and help maintain food security. Nutrient loading may destabilize these mutualisms by altering the costs and benefits each partner incurs from interacting. Using meta-analyses, we show a near ubiquitous decoupling in mutualism performance across terrestrial and marine environments in which phototrophs benefit from enrichment at the expense of their heterotrophic partners. Importantly, heterotroph identity, their dependence on phototroph-derived $C$ and the type of nutrient enrichment (e.g. nitrogen vs. phosphorus) mediated the responses of different mutualisms to enrichment. Nutrient-driven changes in mutualism performance may alter community organization and ecosystem processes and increase costs of food production. Consequently, the decoupling of nutrient exchange mutualisms via alterations of the world's nitrogen and phosphorus cycles may represent an emerging threat of global change.
\end{abstract}

\title{
Introduction
}

Nutrient exchange symbioses are reciprocal partnerships in which a heterotroph provides limiting nutrients, primarily nitrogen $(\mathrm{N})$ or phosphorus $(\mathrm{P})$, to a phototrophic partner in exchange for photosynthetically-fixed carbon. Over $80 \%$ of plant species partake in nutrient exchange symbioses (van der Heijden et al. 2015) while in marine environments these mutualisms sustain foundation species such as corals and sponges (Muscatine \& Porter 1977; Cardini et al. 2014). In many natural systems, nutrient exchange mutualisms are essential for maintaining diversity and ecosystem function, while in managed systems they support agriculture by improving crop production and reducing fertilizer expenditures (Stachowicz 2001; Kiers et al. 2002). Furthermore, these partnerships can provide participants with benefits beyond direct nutrient exchange, such as improved tolerance to toxins, disease, drought, and herbivory (Littman et al. 2010; van der 
Heijden et al. 2015). Thus, nutrient exchange symbioses are critical components of ecosystems worldwide.

However, cooperation is rarely favored in nature and theory suggests mutualisms can best be viewed as reciprocal exploitations that provide a net benefit to each partner (Herre TREE). Thus nutrient exchange symbioses are not fixed as positive-positive interactions, but instead exist along a continuum from mutualism to parasitism depending on whether the benefits of interacting outweigh the costs for each partner (Johnson et al. 1997; Sachs \& Simms 2006; Johnson \& Graham 2013). Accordingly, changes in biotic and abiotic conditions can alter the costs and benefits for each partner and may jeopardize the performance and stability of the mutualism (Johnson 1993; Johnson et al. 1997; Akçay \& Simms 2011). These trade-offs variously predict linear, non-linear, and threshold relationships in partner performance, with the outcome often dependent on how the symbiosis is maintained (e.g. Doebeli \& Knowlton 1998; Neuhauser \& Fargione 2002; Wyatt et al. 2014). Given the importance of these mutualisms and the scale at which humans are altering the planet, it is critical to examine how global change will influence the performance of these partnerships.

Human activity now dominates global $\mathrm{N}$ and $\mathrm{P}$ cycles. Over the last century, anthropogenic nutrient delivery has increased to such an extent that anthropogenically-derived nutrients dwarf natural nutrient sources (Vitousek et al. 1997; Bennett et al. 2001). Empirical evidence suggests that this pervasive addition of limiting nutrients may disrupt important nutrient exchange mutualisms (Treseder 2004; Shantz \& Burkepile 2014). Nutrient loading can alleviate phototroph dependence on heterotrophically-derived $\mathrm{N}$ and $\mathrm{P}$, decreasing the net benefit of associating with heterotrophic symbionts and causing phototrophs to reduce the amount of $\mathrm{C}$ allocated to their partners (e.g. Dennison 2000; Kiers et al. 2003; 2011). Yet the mechanisms that mediate nutritional symbioses are diverse. For example, plants and mycorrhizal fungi use a system of reciprocal trade that provides both partners a degree of control over the symbiosis (Kiers et al. 2011). In contrast, plant-rhizobia relationships can be maintained via resource sanctions in which plants reduce the amount of carbon delivered to under-performing symbionts 
(Kiers et al. 2003; Akçay \& Simms 2011). Corals may display yet another strategy by keeping phototrophic algal symbionts nutrient limited to maximize carbon return (Falkowski et al. 1984; Wooldridge 2010). As a result, nutrient loading may have fundamentally different effects on different types of nutrient exchange mutualisms.

Several studies have synthesized the responses of single partners (e.g. phototrophs or heterotrophs only) to enrichment in some of the better-studied mutualisms such as mycorrhizae (Treseder 2004; Karst et al. 2008; Hoeksema et al. 2010) and corals (Shantz \& Burkepile 2014). However, no study to date has tested how nutrient enrichment may impact the predicted fundamental trade-offs in partner performance (e.g. Johnson et. al. 1997; West et al. 2002; Kiers \& van Der Heijden 2006). Furthermore, we still lack a general understanding of how global increases in nutrient availability may affect the integrity of different types of nutrient exchange mutualisms.

To address this gap, we used meta-analyses to assess the extent and consistency to which anthropogenic nutrient pollution disrupts a diverse array of nutrient exchange mutualisms. We identified 306 experiments from 76 studies, spanning three ocean regions and every habitable continent, which recorded the performance of both phototroph and heterotroph partners to control and nutrient enriched conditions (Fig. 1; see Table S1 for details). For each experiment, we examined the simultaneous responses of both heterotroph and phototroph partners to nutrient enrichment. Our results reveal a nearly ubiquitous response to enrichment across mutualism types, in which phototroph performance improves at the expense of their heterotrophic partners. These trade-offs were context dependent and mediated by the identity of the heterotrophic partner and the identity of the enriched nutrient. Together, these data show that nutrient enrichment affects a wide array of nutrient exchange mutualisms by altering the costs and benefits of interacting. 


\section{Methods}

Study selection \& performance criteria

To identify studies for our analyses, we conducted an extensive literature search using ISI's Web of Science (1977 - 2014). We used multiple search terms that included "mutualism" and nutr* or enrich*, and multiple mutualism types crossed with these terms (e.g., "coral" and (enrich* or nutr*)) and identified additional studies from the references of papers from these searches. We identified 6 mutualism types with sufficient data available to be used in our analysis: 1) Symbiodinium exchanging $\mathrm{C}$ for $\mathrm{N}$ from Tridacnid clams (Algae-Clam). 2) Symbiodinium exchanging $\mathrm{C}$ for $\mathrm{N}$ from corals (Algae-Coral). 3) Algae or cyanobacteria exchanging $\mathrm{C}$ for $\mathrm{N}$ from fungi to form lichen (Algae/Cyanobacteria-Fungi). 4) Plants exchanging $C$ for $N$ and/or $P$ from arbuscular mycorrhizal fungi (Plant-AM Fungi), 5) Plants exchanging $C$ for $N$ and/or $P$ from ectomycorrhizal fungi (Plant-EM Fungi), which unlike AM Fungi do not form intracellular connections with host plants and may possess saprotrophic capabilities (Read et al. 2004), and 6) Plants exchanging $\mathrm{C}$ for $\mathrm{N}$ from root-nodulating rhizobia (Plant-Bacteria).

To be included, studies needed to report at least one performance metric for both heterotroph and phototroph partners under control and nutrient-enriched conditions. Phototroph performance was measured as increases in above ground biomass for plants. For algae, performance was measured as areal cell density, cells per clam (two studies), or chlorophyll a $\mathrm{cm}^{-2}$ in one instance, which was used as a proxy for cell density. Heterotroph performance was measured as growth as determined by changes in mass or extension rates (corals, clams, and lichen), chitin (a proxy for fungal mass in lichen), hyphae mass or percent of root colonization calculated from equal sized root samples (mycorrhizal fungi), or nodule biomass or number (rhizobia). Response metrics were standardized for area (e.g. equal sized root samples in plants, symbiont cells $\mathrm{cm}^{-2}$ in corals) to minimize correlation between phototroph and heterotroph responses. When multiple metrics were available, we used measurements of mass rather than other metrics to avoid including multiple response metrics within analyses that could be differentially sensitive to nutrient enrichment. Although these metrics are often not ideal 
measurements of performance, they are the most commonly used measurements of performance available in the published literature for these groups and provide a strong indicator of an organisms' ability to flourish, grow, and occupy their available habitat.

We identified 76 studies containing 306 experiments (5 studies, 19 experiments for Algae-Clam mutualisms; 13 studies, 31 experiments for Algae-Coral mutualisms; 3 studies, 19 experiments for Algae/Cyanobacteria-Fungi mutualisms; 24 studies, 84 experiments for Plant-AM Fungi mutualisms; 5 studies, 38 experiments for Plant-EM experiments; and 26 studies, 115 experiments for Plant-Bacteria mutualisms; Table S1). Data were taken from the text or extracted from digital PDFs using DataThief III V1.6 (Tummers 2006). When studies included multiple independent experiments at different nutrient levels or with different species, each experiment was treated as an individual replicate. For marine studies, enrichment magnitudes ranged from 1$109 \mu \mathrm{M} \mathrm{N}$ and 0.2-18.6 $\mu \mathrm{M}$ P. In terrestrial systems the units of enrichment were variable but ranged from 2-20 times greater than control conditions for $\mathrm{N}$ and 1.5-220 times greater for $\mathrm{P}$. These values represent a gradient from low anthropogenic impact to severe pollution (see Table S1 for details).

To examine the impact of nutrient addition on nutrient exchange mutualisms, we calculated the log response ratios (RR) for both phototroph and heterotroph partners from each study. We used Bayesian meta-analyses to calculate effect sizes with $80 \%$ and $95 \%$ Bayesian credible intervals to examine the overall effect of enrichment and of different enrichment types (e.g. N vs. P) on both partners for each mutualism type and an overall effect across all mutualism types (see Analysis for details). Measuring the simultaneous response of both partners rather than single partner responses limited the number of studies available but allowed us to capture tradeoffs between partner performance that have not been examined in other meta-analyses (e.g. Treseder 2004; Hoeksema 2010; Shantz \& Burkepile 2014). We tested for tradeoffs in performance between partners using hierarchical Bayesian regressions for each mutualism type. Models \& Analysis 
A frequent problem for meta-analyses in ecology is poor reporting of ecological data. Approximately $40 \%$ of the studies failed to properly report sample sizes or variances. Therefore, we first conducted an unweighted Bayesian meta-analysis that allowed us to make use of the entire data set, regardless of deficiencies in reporting, followed by a weighted Bayesian model for comparison (see below for model details). Weighting can improve the power and precision of tests but may sacrifice replication by excluding studies where data are poorly reported (Gurevitch \& Hedges 1999; Stewart 2010). Although weighted analyses are preferred, unweighted tests are encouraged when potentially large amounts of data would otherwise be lost (Gurevitch \& Hedges 1999). Weighting reduced our data set by $\sim 40 \%$ to a subset of 191 experiments from 51 studies (Table S1), but yielded nearly identical results as our unweighted model (see Table 1). Funnel plots revealed no evidence of publication bias in either model. Given the substantially larger dataset and the fact that both analyses showed quantitatively similar patterns, we focus on the unweighted model here and present results from the weighted analyses in the supplemental material.

We used a hierarchical Bayesian model to conduct both unweighted fixed-effects and weighted random-effects meta-analyses. This Bayesian method is similar to frequentist methods used in traditional meta-analyses, allowing for group-level predictors and random effects while providing the flexibility to conduct Type II hierarchical regressions (Sutton \& Abrams 2001). Furthermore, Bayesian methods allowed us to calculate exact posterior probabilities of effects, improving the interpretation of results when compared with traditional significance levels.

We calculated the log response ratio (RR) for each experiment as $\ln \left(\mu_{t r t} / \mu_{\text {cont }}\right)$ where $\mu_{t r t}$ is the mean of the nutrient-enriched treatment group and $\mu_{\text {cont }}$ the mean of the control group. A positive RR means that nutrient enrichment increased performance while a negative RR means that nutrient enrichment caused a decline in performance. When sample size and variances were appropriately reported, the standard error of the RR for each partner in each experiment was calculated using an unpooled variance estimate: 


$$
S . E .=\sqrt{\frac{\sigma_{\text {cont }}^{2}}{n_{\text {cont }} \mu_{\text {cont }}^{2}}+\frac{\sigma_{t r t}^{2}}{n_{\text {trt }} \mu_{\text {trt }}^{2}}}=s_{i}
$$

where, $\sigma_{\text {cont }}^{2}$ and $\sigma_{\text {trt }}^{2}$ are the respective control and treatment group variances and $n_{\text {cont }}$ and $n_{\text {trt }}$ are sample sizes of each group. Thus, each experiment produced a log response ratio $R R_{i}$, and $\sim 60 \%$ of experiments (Table S1) also produced known standard deviation of the response $s_{i}$ for use in weighted analyses.

We first conducted our unweighted model including only a single error term for between study variance so we could incorporate experiments that did not report estimates of variance. This model assumes that the response ratio for each study varied around the group-level means directly. That is, the $i^{\text {th }}$ study in the $j^{\text {th }}$ mutualism type was normally distributed around the mutualism mean $\left(\widehat{y_{J}}\right)$ with a between-study variance $\left(\tau_{j}\right)$ :

$$
R R_{i j} \sim N\left(\widehat{y}_{j}, \tau_{j}\right)
$$

Thus, there was no assumption of homogeneity of variances among mutualism types. The mean for each type was a linear function of the overall mean $(\mu)$ and a deflection from the overall mean for each mutualism type $\left(\delta_{j}\right)$ :

$$
\widehat{y_{J}}=\mu+\delta_{j}
$$

In this model, mutualism types were fixed-effects. We imposed sum-to-zero constraints on the deflections $\delta_{j}$.

The weighted, random effects model considered the RR of each study as randomly varying around the 'true' study value $\theta_{i j}$ with response-ratio variance calculated for the study $s_{i j}^{2}$ :

$$
R R_{i j} \sim N\left(\theta_{i j}, s_{i j}^{2}\right)
$$

'True' study values were assumed to be normally distributed around the mean for each mutualism type $(\hat{y})$ with a between-study variance specific to that mutualism type $(\tau)$ as described in the fixed effects model:

$$
\theta_{i j} \sim N\left(\widehat{y}_{J}, \tau_{j}\right)
$$


The mean for each mutualism type was a linear function of the overall mean and a deflection from the overall mean as described above. This model allowed each study to have its own true response, where true responses of each mutualism type varied around the mutualism type mean.

To test for performance trade-offs, we used Bayesian hierarchical regression that modeled the heterotroph RR as a linear function of phototroph RR in each mutualism type. This was a standard hierarchical regression for the full dataset. For the restricted dataset, both heterotroph and phototroph response ratios were assumed to be subject to sampling error with a known variance calculated as described above. Thus, for the $i^{\text {th }}$ experiment, both phototroph and heterotroph RR were assumed to be normally distributed around some 'true' value and a hierarchical linear regression was carried out that allowed model parameters to vary among the $j$ groups. The 'true' heterotroph and phototroph values for each experiment in the $j^{\text {th }}$ group were normally distributed around some predicted value with a variance specific to the group:

$$
\begin{gathered}
\theta_{\text {hetero } i j} \sim N\left(\hat{y}_{H i j}, \tau_{H j}\right) \\
\theta_{\text {photoij }} \sim N\left(\hat{y}_{P i j}, \tau_{P j}\right)
\end{gathered}
$$

The 'true' heterotroph value was a linear function of the phototroph 'true' value:

$$
\theta_{\text {hetero } i j}=a_{j}+b_{j} \theta_{\text {photo } i j}
$$

such that each group $j$ was allowed a different intercept and slope. The parameters $a$ and $b$ for each group were drawn from a normal distribution with means $\mu_{a}$ and $\mu_{b}$ and variances $\omega_{a}^{2}$ and $\omega_{b}^{2}$, respectively. The only difference between the models for the full dataset and the restricted dataset was that response ratios for the full dataset did not vary around a 'true' value.

We calculated pseudo- $R^{2}$ values, which differ from $R^{2}$ in that they are calculated for each mutualism type within a hierarchical model for each posterior sample, following the standard formula for $R^{2}$ from linear regression. For each posterior sample of parameters, we calculated the sum-of-squared errors $\left(S S_{R}\right)$ between observed and fitted data as a measure of residual variation and the sum-of-squared errors between observed data and the mean $\left(S S_{T}\right)$. Pseudo- $R^{2}$ is then $1-S S_{R} / S S_{T}$. We then took the median posterior value as the $R^{2}$ for each mutualism type. 
Performance may also be expected to change with the level of enrichment or study duration. However, studies differed widely in the amounts of nutrients provided, duration, and rate of nutrient addition (Table S1). To account for these differences, we assessed the effect of overall enrichment magnitude on performance and converted the reported enrichment levels into average enrichment per day by dividing the total amount of nutrients added by the experimental duration. Numerous studies reported enrichment in non-comparable units (e.g. mg nutrient $\mathrm{kg}^{-1}$ of soil versus mg nutrient $\mathrm{m}^{-2}$; Table S1). Therefore, rather than examining each metric and increasing the probability of committing a Type I error, we used whichever units of measurement provided the greatest replication. This reduced our available data by $\sim 30 \%$ for Algae-Coral mutualisms, $\sim 50 \%$ for Algae-Clam, Plant-AM Fungi, and Plant-Bacteria mutualisms and $100 \%$ for Plant-EM Fungi mutualisms, which all used different enrichment metrics. We visually examined the impact of enrichment magnitude and enrichment per day on the response of each partner under both $\mathrm{N}$ and $\mathrm{P}$ enrichment by plotting effect sizes against enrichment. Quantitative regressions of these relationships were not possible due to poor replication across treatment levels.

Additionally, we examined potential differences in effect sizes between lab and glasshouse-based experiments versus those conducted in natural outdoor environments. As virtually all of the experiments involving clams, corals, and lichen were conducted in highly controlled environments, we were only able to conduct these analyses on Plant-Bacteria and Plant-Fungi mutualisms.

Bayesian models were run in STAN, accessed via PyStan in Python v2.7. In all models, coefficients were given weakly informative priors of $N(0,4)$ and variance parameters given uninformative priors of $U(0,10)$. We ran four MCMC chains simultaneously, each with 25,000 burn-in iterations followed by 25,000 sampling iterations, resulting in 100,000 posterior samples for each parameter. We verified chain convergence by ensuring that $\widehat{R}=1$ for all parameters and by examining posterior density plots. 


\section{Results}

Nutrient enrichment increased the performance of nearly all phototroph groups (Fig. 2A;

Table 1). Although the median response across all studies was a nearly $65 \%$ increase in performance, there was significant heterogeneity among group responses. The weakest response occurred in the algae/cyanobacteria in lichen (Fig. 2A, Table 1) with a 15\% greater performance under enrichment (Probability of an effect: $\operatorname{Pr}(\operatorname{RR}>0)=0.92)$. Phototrophs from all other mutualism types showed improved performance, ranging from $\sim 45 \%$ greater performance in the Plant-Bacteria mutualism to $\sim 110 \%$ increase in performance of Symbiodinium in the AlgaeClam relationship $(\operatorname{Pr}(\mathrm{RR}>0)=1.00$ for all other groups $)$.

Similarly, there was an overall $10 \%$ decline in heterotroph performance with enrichment that varied substantially among different mutualism types (Fig. 2A). Coral, lichen, AM fungi and rhizobia displayed declines in performance ranging from $13 \%$ (lichen) to $31 \%$ (coral; Table 1). In contrast, EM fungi showed only minimal signs of impairment (average $8 \%$ decline, $\operatorname{Pr}(\operatorname{RR}<0)=$ 0.80 ) while clams showed an $85 \%$ increase in growth with nutrient enrichment (Table 1; $\operatorname{Pr}(R R>0)$ $=$ 1.00). This pattern was nearly identical in the weighted model (Fig. S1A, Table 1). However, differences were present for lichens where heterotrophs were less consistently impaired by nutrient enrichment in the weighted $(\operatorname{Pr}(\operatorname{RR}<0)=0.90)$ versus unweighted analysis $(\operatorname{Pr}(\operatorname{RR}<0)=$ 0.98) and for Plant-EM relationships where EM Fungi showed greater and more consistent declines in the weighted model $(\operatorname{Pr}(\operatorname{RR}<0)=1.00 ;$ Table 1$)$.

The responses of different mutualism types to enrichment varied considerably with the identity of nutrients provided by the heterotroph (i.e. N versus $\mathrm{P}$ ). In the unweighted model, phototroph and heterotroph responses to $\mathrm{N}$-enrichment were nearly identical to those observed under all enrichment types, except EM fungi, which benefitted from $N$ addition $(\operatorname{Pr}(R R)>0=0.98$; Fig 2B). Phosphorus-enrichment regularly improved phototroph performance in Algae-Clam, Plant-AM Fungi, Plant-EM Fungi and Plant-Bacteria mutualisms but impaired heterotroph performance for $\mathrm{AM}$ and, to a lesser extent, EM fungi $(\operatorname{Pr}(\mathrm{RR}<0)=1.00 \& 0.92$ respectively; Fig. 2C). When experiments co-enriched with $\mathrm{N}+\mathrm{P}$, phototroph performance improved in all mutualism 
types. For heterotrophs however, N+P enrichment resulted in a 95\% increase in clam performance, reduced but variable performance of bacteria, AM fungi, and the fungi in lichen, and consistently impaired performance in corals and EM fungi (Fig. 2D; Table 1).

In our weighted analysis, phototroph responses to N-enrichment were nearly identical (Fig. 2 vs. Fig. S1). For heterotrophs, fungi in lichen showed only a 5\% decline in performance in the weighted analysis versus a $12 \%$ decline in the unweighted model $(\operatorname{Pr}(\operatorname{RR}<0)=0.74$ vs. $\operatorname{Pr}(R R<0)=0.96$ respectively). Surprisingly, EM fungi performance improved by $50 \%$ under $N$ enrichment in our unweighted analysis (Fig. $2 \mathrm{~B} ; \operatorname{Pr}(\mathrm{RR})>0=0.98$ ), but showed no response to $\mathrm{N}$ in the weighted analysis (Fig S1B; $\operatorname{Pr}(R R)>0=0.34)$, likely due to low replication $(n=2)$. For both $\mathrm{P}$ and $\mathrm{N}+\mathrm{P}$ enrichments, the responses of both phototroph and heterotrophs were nearly identical between the models for all mutualism types except Plant-EM Fungi. EM fungi were impaired under P-enrichment in the unweighted model (Fig. 2C) but not in the weighted model (Fig. S1C), while N+P enrichment impaired EM in the weighted model (Fig. S1D) but not the unweighted model (Fig. 2D).

We found evidence of linear trade-offs between the performance of heterotrophs and phototrophs under nutrient-enrichment in every mutualism type except for Algae-Clam and the Plant-AM symbiosis (Fig. 3). For Algae-Clam mutualisms, the response was opposite our predictions, with a positive relationship between clam and phototroph performance (Fig. 3A). However, Algae-Coral, Algae/Cyanobacteria-Fungi, Plant-EM and Plant-Bacteria mutualisms all showed linear declines in heterotroph performance as phototroph performance improved (Fig. 3; Table S2). The weighted model showed similar results with minor differences as trade-offs were no longer detected in Algae/Cyanobacteria-Fungi or Plant-EM Fungi partnerships (Fig. S2). For Plant-EM interactions, the difference between models was largely due to a loss of over half the replicates in the weighted analysis. However, for Algae/Cyanobacteria-Fungi, replication was equal in both analyses and the different responses were entirely due to weighting.

Visual examination of the effects of enrichment magnitude and average daily enrichment on phototroph and heterotroph performance revealed few clear patterns (Fig. S3 \& S4). Rhizobia 
under $\mathrm{N}$ enrichment and $\mathrm{AM}$ fungi under $\mathrm{P}$ enrichment both declined in performance with increasing enrichment levels (Figs. S3 \& S4). However for all other groups no clear patterns emerged. Enrichment levels were similar for Algae-Clam and Algae-Coral mutualisms. In terrestrial systems, P enrichment levels were much lower for Plant-EM Fungi experiments than for Plant-AM Fungi and Plant-Bacteria experiments, potentially contributing to the dissimilar patterns observed between these groups. Unfortunately, not enough studies reported baseline nutrient levels to assess how background levels may have influenced the results. Although it is reasonable to suspect that the magnitude of enrichment could impact the effect of nutrients on phototrophs and heterotrophs, there are not sufficient data to robustly test this hypothesis.

The overall effect of nutrients on mycorrhizal fungi and rhizobia were similar in both field studies and lab-based manipulations (Table S3). In both cases enrichment also positively impacted plant performance $(\operatorname{Pr}(R R)>0=1.00$ for both mutualism types in both types of studies). Thus, it is unlikely that having a mix of field and lab-based studies in our analyses impacted our results.

\section{Discussion}

We show that anthropogenic nutrient pollution presents a potentially serious threat to nutrient exchange mutualisms, with phototrophs benefitting at the expense of their heterotrophic partners. This general response was consistent across most mutualism types in terrestrial and marine environments. These patterns support the hypothesis that nutrient loading disrupts nutritional mutualisms by reducing the net benefit that phototrophs derive from their heterotrophic partners, leading the phototrophs to reduce the amount of $C$ they reciprocate in return (Johnson et al. 1997). However, heterotroph identity, the enrichment type, and the interaction between the two appeared to mediate the specific impact of nutrient enrichment.

Nutrient loading should only alter the costs of resource trade if the enriched nutrient is limiting for the phototroph and of the same type as that provided by the heterotrophic partner (Johnson et al. 1997; 2015). In support of this, we found that the performance of rhizobia and 
corals, which primarily deliver N to phototrophs (Dennison 2000; Shantz \& Burkepile 2014), declined substantially under $\mathrm{N}$ enrichment but not $\mathrm{P}$ enrichment (Fig. 2). In contrast, mycorrhizal fungi can facilitate both $\mathrm{N}$ and $\mathrm{P}$ uptake depending on the fungal type (e.g. AM vs. EM), plant and fungal stoichiometry, and soil characteristics. However, due to the higher mobility of $\mathrm{N}$ versus $\mathrm{P}$ in soil, mycorrhizae often benefit plants most through P supplementation (Smith \& Read 1997; Johnson et al. 2015; van der Heijden et al. 2015). Accordingly, P enrichment impaired AM and EM fungi performance while $\mathrm{N}$ enrichment resulted in moderate declines in performance only in our weighted model (Figs. 2B, 2C \& S1).

When experiments co-enriched with $\mathrm{N}+\mathrm{P}$, the effects on heterotrophs were generally smaller and more variable than the declines observed under single nutrient enrichments (Fig. 2). This suggests that the ratio of $\mathrm{N}: \mathrm{P}$ provided plays a strong role in mediating the outcome of enrichment and that co-enrichment can still result in nutrient limitation, potentially maintaining phototroph demand for heterotroph-derived nutrients (Johnson et al. 2015). Thus, the identity of the heterotrophic partner and the nutrients they provide can reasonably predict how nutrient exchange mutualisms respond to different types of nutrient pollution.

The effect of nutrient enrichment on nutrient sharing mutualisms may also depend on the heterotrophs' dependence on phototroph-derived C. Heterotrophs that are less reliant on phototrophs for $\mathrm{C}$ should suffer less from $\mathrm{C}$-sanctions imposed by their phototrophic partners. We found that clams, which can obtain as much as $65 \%$ of their $\mathrm{C}$ by filter feeding (Klumpp et al. 1992) and digest up to $89 \%$ of newly formed algal symbionts (Maruyama \& Heslinga 1997), benefitted from enrichment. In contrast, root-colonizing rhizobia, AM fungi, and corals are typically more dependent on their phototrophic partners for C (Dennison 2000; Houlbréque \& FerrierPagés 2009; van der Heijden et al. 2015), and enrichment largely impaired the performance of these groups (Fig. 2). Interestingly, the responses of EM fungi to nutrient enrichment were more variable than the consistent declines we observed in AM fungi performance. This increased variability in EM fungi responses might be expected if EM fungi can scavenge $C$ from the environment via the decomposition of organic matter (Read et al. 2004), decoupling the 
performance of EM from their plant hosts. However, the ability of many EM to acquire biologically meaningful amounts of C through saprotrophy appears limited (Lindahl \& Tunlid 2015), and the factors that shape potential differences in the response of AM and EM fungi to nutrient loading will be a fruitful area for future research. Overall however, our data suggest that mutualisms in which heterotrophs are heavily dependent on photosynthetically-derived $C$ are particularly vulnerable to nutrient-induced decline.

Understanding whether resource trade is based on the direct exchange of nutrients for $\mathrm{C}$ or balanced among multiple currencies is essential to predict the effects of enrichment on nutrient exchange mutualisms. The linear relationships between the RR of heterotrophs and phototrophs in nearly all of the mutualisms we examined suggest that reciprocal trade of nutrients for $\mathrm{C}$ plays a strong role in maintaining most types of mutualisms An interesting exception to this pattern appears to occur in AM fungi, in which no evidence of linear trade-offs was observed (Fig. 3D). One potential explanation may be that the reciprocal reward system that mediates Plant-AM Fungi interactions provides more flexible responses to enrichment than the single-partner control thought to mediate the other mutualism types. Another potentially important difference between AM mutualisms relative to the other groups is that $\mathrm{AM}$ fungi can provision both $\mathrm{N}$ and $\mathrm{P}$ (van der Heijden et al. 215) and form common mycelia networks (CMNs) that allow interplant signaling (Johnson \& Gilbert 2015), something not documented in EM networks. These CMNs create more complex interactions by allowing mycorrhizal fungi to interact with multiple plant partners (Walder et al. 2012; van der Heijden et al. 2015) and transport signaling compounds that improve plant defenses against herbivory and infection among all of the network members (Song et al. 2010; Babikova et al. 2013). Thus, mutualisms between plants and AM fungi may be paid in multiple currencies and limit the direct negative tradeoffs between phototroph and heterotroph performance.

Understanding drivers the variation in the responses of different mutualism types to enrichment will require focused research on the physiological mechanisms that mediate individual mutualism types. However, continuing to identify general patterns in how nutrient exchange 
mutualisms respond to global change will provide more rapid and broadly applicable management and remediation strategies, as well as help guide future research efforts. In particular, exploring the importance of nutrient stoichiometry of both mutualist partners, the enrichment source, and the form of enrichment (e.g. nitrate versus ammonium) will likely be fruitful avenues of research (e.g. Johnson et al. 2010, 2015; Weidenmenn et al. 2012). For example, Shantz and Burkepile (2014) found that nitrate enrichment had no effect on the density of algal symbionts in corals but strongly suppressed coral growth while ammonium enrichment increased Symbiodinium density but had no effect on coral growth. Thus, different sources of the same nutrient may generate different tradeoffs in mutualisms and may reveal even more contextdependency in how these mutualisms are regulated. Finally, the diversity and identity of partners in these symbioses may modify responses to nutrient pollution. For example, the genetic diversity of algal symbionts in corals and of microbial communities in soils can mediate the responses of Algae-Coral and Plant-Fungi mutualisms, respectively, to different environmental conditions (Hoeksema et al. 2010; Lesser et al. 2013; Cunning \& Baker 2014). Future research examining the generalities that we identified in how mutualisms respond to nutrient pollution will help to better understand the context-dependent nature of these intricate symbioses.

Interestingly, the fundamentally different architecture of marine and terrestrial symbioses may play a strong role in dictating how systems respond to mutualism disruption. In marine systems such as coral reefs, the ecosystem engineers are often heterotrophic mutualists with endosymbiotic phototrophs. Thus, impaired heterotroph performance on reefs may negatively impact corals with cascading effects on the goods and services these systems provided (e.g. reef dependent fisheries, shoreline protection, land accretion, etc.). In contrast, the ecosystem engineering mutualists of terrestrial systems are typically phototrophs that house symbiotic heterotrophs. As a result, the effect of enrichment-induced changes in mutualism strength on the structure, goods, and services of terrestrial communities is harder to predict. For example, increased phototroph performance could provide greater above-ground carbon storage (Weider et al. 2015), but this may be offset by impaired mycorrhizal sequestration of $C$ in soils, which can 
account for as much as $70 \%$ of C storage in some ecosystems (Clemmensen et al. 2013). Similarly, increased productivity will benefit resource production but declining heterotroph performance could bear financial costs. Nitrogen fixation by rhizobia in agricultural systems provides at least 70 million metric tons of $\mathrm{N}$ per year (Kiers et al. 2002), or roughly $\$ 28.7-\$ 59.3$ billion worth of fertilizer application (Nehring 2013), that must otherwise be replaced to maintain productivity if the plant-rhizobia relationship is drastically altered. Similarly, enrichment-driven declines in mycorrhizae performance may jeopardize the non-nutritional benefits that fungi confer to plants, such as tolerance to water stress, pathogens, and soil toxins (van der Heijden et al. 2015). Accordingly, resolving the consequences and benefits of anthropogenic disruption of nutrient sharing mutualisms will be a critical aspect of understanding global change in the $21^{\text {st }}$ century.

\section{References}

Akçay, E. \& Simms, E.L. (2011). Negotiation, sanctions, and context dependency in the legumerhizobium mutualism. Am. Nat. 178, 1-14.

Babikova, Z., Gilbert, L., Bruce, T.J.A., Birkett, M., Caulfield, J.A., Woodcock, C., Pickett, J.A. \& Johnson, D. (2013). Underground signals carried through common mycelia networks warn neighboring plants of aphid attack. Ecol. Lett. 16, 835-843.

Bennett, E.M., Carpenter, S.R. \& Caraco, N.F. (2001). Human impacts on erodible phosphorus and eutrophication: a global perspective. Bioscience 51, 227-234.

Cardini, U., Bednarz, V.N., Foster, R.A. \& Wild, C. (2014). Benthic N-2 fixation in coral reefs and the potential effects of human-induced environmental change. Ecol. \& Evol. 4, 17061727.

Clemmensen, K.E., Bahr, A., Ovaskainen, O., Dahlberg, A., Ekblal, A., Wallander, H., et al. (2013). Roots and associated fungi drive long-term carbon sequestration in boreal forest. Science 339, 1615-1618

Cunning, R. \& Baker, A.C. (2014). Not just who, but how many: the importance of partner abundance in reef coral symbioses. Front Microbiol 5, doi: 10.3389/fmicb.2014.00400

Dennison, R.F. (2000). Legume sanctions and the evolution of symbiotic cooperation by rhizobia. Am. Nat. 156, 567-576.

Doebeli, M. \& Knowlton N. (1998). The evolution of interspecific mutualisms. Proc. Natl. Acad. Sci. USA 95, 8676-8680. 
Falkowski, P.G., Dubinsky, Z., Muscatine, L. \& Porter, J.W. (1984). Light and the bioenergetics of a symbiotic coral. Bioscience 34, 705-709.

Gurevitch, J. \& Hedges, L.V. (1999). Statistical issues in ecological meta-analyses. Ecology 80, 1142-1149.

Herre, E.A., Knowlton, N., Mueller, U.G. \& Rehnerm S.A. (1999). The evolution of mutualisms: exploring the paths between conflict and cooperation. Trends Ecol. Evol. 14, 49-53.

Hoeksema, J.D., Chaudhary, V.B., Gehring, C.A, Johnson, N.C., Karst, J., Koide, et al. (2010). A meta-analysis of context-dependency in plant response to inoculation with mycorrhizal fungi. Ecol. Lett. 13, 394-407.

Houlbréque, F. \& Ferrier-Pagés, C. (2009). Heterotrophy in tropical scleractinian corals. Biol. Rev. 84,1-17.

Johnson, D. \& Gilbert, L. (2015). Interplant signaling through hyphal networks. New Phytol. 205, 1448-1453.

Johnson, N.C. (1993). Can fertilization select less mutualistic mycorrhizae? Ecol. Appl. 3, 749757.

Johnson, N.C., Graham, J.H. \& Smith, F.A. (1997). Functioning of mycorrhizal associations along the mutualism-parasitism continuum. New Phytol. 135, 575-585.

Johnson, N.C. \& Graham, J.H. (2013). The continuum concept remains a useful framework for studying mycorrhizal functioning. Plant Soil 363, 411-419.

Johnson, N.C., Wilson, G.W.T., Wilson, J.A., Miller, R.M. \& Bowker, M.A. (2015). Mycorrhizal phenotypes and the law of the minimum. New Phytol. 205, 1473-1484.

Karst, J., Marczak, L., Jones, M.D. \& Turkington, R. (2008). The mutualism-parasitism continuum in ectomycorrhizas: a quantitative assessment using meta-analysis. Ecology 89, 10321042.

Kiers, E.T., West, S.A. \& Denison, R.F. (2002). Mediating mutualisms: farm management practices and evolutionary changes in symbiont co-operation. J. Appl. Ecol. 39, 745-754.

Kiers, E.T., Rousseau, R.A., West, S.A. \& Denison, R.F. (2003). Host sanctions and the legumerhizobium mutualism. Nature 425, 78-81.

Kiers, T.E. \& van der Heijden M.G.A. (2006). Mutualistic stability in the arbuscular mycorrhizal symbiosis: exploring hypotheses of evolutionary cooperation. Ecology 87, 1627-1636

Kiers, E.T., Duhamel, M., Beesetty, Y., Mensah, J.A., Franken, O., Verbruggen E., et al. (2011). Reciprocal rewards stabilize cooperation in the mycorrhizal symbiosis. Science $333,880-$ 882.

Klumpp, D.W., Bayne, B.L., Hawkins, A.J.S. (1992). Nutrition of the giant clam Tridacna gigas (L.) I. Contribution of filter feeding and photosynthates to respiration and growth. J. Exp. Mar. Biol. Ecol. 155, 105-122.

Lesser, M.P., Stat, M. \& Gates, R.D. (2013). The endosymbiotic dinoflagellates (Symbiodinium sp.) of corals are both parasites and mutualists. Coral Reefs 32, 603-611. 
Lindahl, B.D. \& Tunlid, A. (2015). Ectomycorrhizal fungi - potential organic matter decomposers, yet not saprotrophs. New Phytol. 205, 1443-1447.

Littman, R.A., Bourne, D.G. \& Willis, B.L. (2010). Responses of coral-associated bacterial communities to heat stress differ with Symbiodinium type on the same coral host. Molecular Ecol. 19, 1978-1990

Maruyama, T., Heslinga, G.A. (1997). Fecal discharge of zooxanthellae in the giant clam Tridacna derasa, with reference to their in situ growth rate. Mar. Biol.127, 473-477.

Muscatine, L. \& Porter, J.W. (1977). Reef corals, mutualistic symbioses adapted to nutrient-poor environments. Bioscience. 27, 454-460.

Nehring, R. (2013). USDA fertilizer use and price report www.ers.usda.gov/dataproducts/fertilizer-use-and-price.aspx\#26727

Neuhauser, C \& Fargione, J.E. (2004). A mutualism-parasitism continuum model and its application to plant-mycorrhizae interactions. Ecol Model 177, 337-352

Read, D.J., Leake, J.R. \& Perez-Moreno, J. (2004). Mycorrhizal fungi as drivers of ecosystem processes in heathland and boreal forest biomes. Canadian J. of Bot. 82, 1243-1263.

Sachs, J.L. \& Simms, E.L. (2006). Pathways to mutualism breakdown. Trends Ecol. Evol. 21, 585-592.

Shantz, A.A. \& Burkepile, D.E. (2014). Context-dependent effects of nutrient loading on the coralalgal mutualism. Ecology 95,1995-2005.

Smith, S.E. \& Read, D.J. (1997). Mycorrhizal Symbiosis, $2^{\text {nd }}$ edn. San Diego, CA, USA: Academic Press.

Song, Y.Y., Zeng, R.S., Xu, J.F., Li, J., Shen, X. \& Yihdego, W.G. (2010). Interplant communication of tomato plants through underground common mycorrhizal networks. Plos ONE 5, e13324

Stachowicz, J.J. (2001). Mutualism facilitation and the structure of ecological communities. Bioscience 51, 235-246.

Stewart, G. (2010). Meta-analysis in applied ecology. Biol. Lett. 6, 78-81.

Sutton, A.J. \& Abrams, K.R. (2001). Bayesian methods in meta-analysis and evidence synthesis. Stat. Methods Med. Res. 10, 277-303.

Treseder, K.K. (2004). A meta-analysis of mycorrhizal responses to nitrogen, phosphorus, and atmospheric $\mathrm{CO}_{2}$ in field studies. New Phytol. 164, 347-355.

Tummers, B. (2006). Data Thief III. http://datathief.org. (2006).

van der Heijden, M.G.A., Martin, F., Selosse, M-A. \& Sanders, I.R. (2015). Mycorrhizal ecology and evolution: the past, the present, and the future. New Phytol. 205, 1406-1423.

Vitousek, P.M., Mooney, H.A., Lubchenco, J. \& Melillo, J.M. (1997). Human domination of Earth's ecosystems. Science 277, 494-499. 
Walder, F., Niemann, H., Natarajan, M., Lehmann, M.F., Boller, T. \& Wiemken, A. (2012). Mycorrhizal networks: common goods of plants shared under unequal terms of trade. Plant Physiol. 159, 789-797.

Weidenmenn, J., D’Angelo, C., Smith, E.G., Hunt, A.N., Legiret, F-E., Postle, A.D. \& Achterberg, E.P. (2012). Nutrient enrichment can increase the susceptibility of reef corals to bleaching. Nat. Clim. Chang. 3, 160-164.

West, S.A., Kiers, T., Pen, I. \& Denison, R.F. (2002). Sanctions and mutualism stability: when should less beneficial mutualists be tolerated. J. Evol. Biol. 15, 830-837.

Wieder, W.R., Cleveland, C.C., Smith, W.K. \& Todd-Brown, K. (2015) Future productivity and carbon storage limited by terrestrial nutrient availability. Nat. Geosci. 8, 441-444

Wooldridge, S.A. (2010). Is the coral-algae symbiosis really 'mutually beneficial' for the partners? Bioessays 32, 615-625.

Wyatt, G.A.K, Kiers, E.T., Gardner A. \& West, S.A. (2014). A biological market analysis of the plant-mycorrhizal symbiosis. Evolution 38, 2603-2618. 
Table 6.1 - The mean log response ratio (RR) and upper and lower 95\% Bayesian credible intervals for phototroph and heterotroph partners from each mutualism type overall and to each enrichment type. Data are provided for both the unweighted and weighted models for comparison.

\begin{tabular}{|c|c|c|c|c|}
\hline & \multicolumn{4}{|c|}{ Mean RR and 95\% Bayesian Credible Interval } \\
\hline $\begin{array}{l}\text { Unweighted } \\
\text { Analysis }\end{array}$ & All Nutrients & $\mathbf{N}$ & $\mathbf{P}$ & $\mathbf{N}+\mathbf{P}$ \\
\hline $\begin{array}{l}\text { Algae-Clam } \\
\text { (Phototroph) }\end{array}$ & $\begin{array}{c}\mathrm{RR}=0.75 \\
\mathrm{Cl}_{95}=0.55,0.93\end{array}$ & $\begin{array}{c}\mathrm{RR}=0.54 \\
\mathrm{Cl}_{95}=0.20,0.85\end{array}$ & $\begin{array}{c}\mathrm{RR}=0.40 \\
\mathrm{Cl}_{95}=0.12,0.67\end{array}$ & $\begin{array}{c}\mathrm{RR}=0.99 \\
\mathrm{Cl}_{95}=0.68,1.29\end{array}$ \\
\hline $\begin{array}{l}\text { Algae-Clam } \\
\text { (Heterotroph) }\end{array}$ & $\begin{array}{c}\mathrm{RR}=0.61 \\
\mathrm{Cl}_{95}=0.45,0.76\end{array}$ & $\begin{array}{c}\mathrm{RR}=0.54 \\
\mathrm{Cl}_{95}=0.11,0.86\end{array}$ & $\begin{array}{c}\mathrm{RR}=0.29 \\
\mathrm{Cl}_{95}=-0.29,0.73\end{array}$ & $\begin{array}{c}\mathrm{RR}=0.67 \\
\mathrm{Cl}_{95}=0.29,0.94\end{array}$ \\
\hline $\begin{array}{l}\text { Algae-Coral } \\
\text { (Phototroph) }\end{array}$ & $\begin{array}{c}\mathrm{RR}=0.50 \\
\mathrm{Cl}_{95}=0.28,0.72\end{array}$ & $\begin{array}{c}\mathrm{RR}=0.37 \\
\mathrm{Cl}_{95}=0.17,0.59\end{array}$ & $\begin{array}{c}\mathrm{RR}=0.20 \\
\mathrm{Cl}_{95}=-0.15,0.64\end{array}$ & $\begin{array}{c}\mathrm{RR}=0.84 \\
\mathrm{Cl}_{95}=0.35,1.34\end{array}$ \\
\hline $\begin{array}{l}\text { Algae-Coral } \\
\text { (Heterotroph) }\end{array}$ & $\begin{array}{c}\mathrm{RR}=-0.37 \\
\mathrm{Cl}_{95}=-0.56,-0.18\end{array}$ & $\begin{array}{c}\mathrm{RR}=-0.38 \\
\mathrm{Cl}_{95}=-0.60,-0.16\end{array}$ & $\begin{array}{c}\mathrm{RR}=0.17 \\
\mathrm{Cl}_{95}=-0.24,0.42\end{array}$ & $\begin{array}{c}\mathrm{RR}=-0.49 \\
\mathrm{Cl}_{95}=-0.94,-0.01\end{array}$ \\
\hline $\begin{array}{l}\text { Algael } \\
\text { Cyano-Fungi } \\
\text { (Phototroph) }\end{array}$ & $\begin{array}{c}\mathrm{RR}=0.14 \\
\mathrm{Cl}_{95}=-0.06,0.36\end{array}$ & $\begin{array}{c}\mathrm{RR}=0.10 \\
\mathrm{Cl} 95=-0.13,0.33\end{array}$ & $\begin{array}{c}\mathrm{RR}=0.16 \\
\mathrm{Cl}_{95}=-0.27,0.68\end{array}$ & $\begin{array}{c}\mathrm{RR}=0.64 \\
\mathrm{Cl}_{95}=0.03,1.26\end{array}$ \\
\hline $\begin{array}{l}\text { Algael } \\
\text { Cyano-Fungi } \\
\text { (Heterotroph) }\end{array}$ & $\begin{array}{c}\mathrm{RR}=-0.15 \\
\mathrm{Cl}_{95}=-0.27,-0.02\end{array}$ & $\begin{array}{c}\mathrm{RR}=-0.13 \\
\mathrm{Cl}_{95}=-0.27,0.02\end{array}$ & $\begin{array}{c}\mathrm{RR}=-0.03 \\
\mathrm{Cl}_{95}=-0.59,0.55\end{array}$ & $\begin{array}{c}\mathrm{RR}=-0.26 \\
\mathrm{Cl}_{95}=-0.77,0.30\end{array}$ \\
\hline $\begin{array}{l}\text { Plant-AM } \\
\text { Fungi } \\
\text { (Phototroph) }\end{array}$ & $\begin{array}{c}\mathrm{RR}=0.52 \\
\mathrm{Cl}_{95}=0.39,0.66\end{array}$ & $\begin{array}{c}\mathrm{RR}=0.36 \\
\mathrm{Cl}_{95}=0.15,0.58\end{array}$ & $\begin{array}{c}\mathrm{RR}=0.57 \\
\mathrm{Cl}_{95}=0.37,0.77\end{array}$ & $\begin{array}{c}\mathrm{RR}=0.51 \\
\mathrm{Cl}_{95}=0.27,0.80\end{array}$ \\
\hline $\begin{array}{l}\text { Plant-AM } \\
\text { Fungi } \\
\text { (Heterotroph) }\end{array}$ & $\begin{array}{c}\mathrm{RR}=-0.28 \\
\mathrm{Cl}_{95}=-0.42,-0.14\end{array}$ & $\begin{array}{c}\mathrm{RR}=-0.20 \\
\mathrm{Cl}_{95}=-0.44,0.03\end{array}$ & $\begin{array}{c}\mathrm{RR}=-0.29 \\
\mathrm{Cl}_{95}=-0.48,- \\
0.10\end{array}$ & $\begin{array}{c}\mathrm{RR}=-0.24 \\
\mathrm{Cl}_{95}=-0.79,0.33\end{array}$ \\
\hline $\begin{array}{l}\text { Plant-EM } \\
\text { Fungi } \\
\text { (Phototroph) }\end{array}$ & $\begin{array}{c}\mathrm{RR}=0.72 \\
\mathrm{Cl}_{95}=0.49,0.95\end{array}$ & $\begin{array}{c}\mathrm{RR}=0.34 \\
\mathrm{Cl}_{95}=0.05,0.66\end{array}$ & $\begin{array}{c}\mathrm{RR}=0.58 \\
\mathrm{Cl}_{95}=0.22,0.98\end{array}$ & $\begin{array}{c}\mathrm{RR}=0.93 \\
\mathrm{Cl}_{95}=0.59,1.30\end{array}$ \\
\hline $\begin{array}{l}\text { Plant-EM } \\
\text { Fungi } \\
\text { (Heterotroph) }\end{array}$ & $\begin{array}{c}\mathrm{RR}=-0.08 \\
\mathrm{Cl}_{95}=-0.26,0.10\end{array}$ & $\begin{array}{c}\mathrm{RR}=0.41 \\
\mathrm{Cl}_{95}=0.03,0.75\end{array}$ & $\begin{array}{c}\mathrm{RR}=-0.27 \\
\mathrm{Cl}_{95}=-0.66,0.12\end{array}$ & $\begin{array}{c}\mathrm{RR}=-0.16 \\
\mathrm{Cl}_{95}=-0.33,0.01\end{array}$ \\
\hline $\begin{array}{l}\text { Plant- } \\
\text { Bacteria } \\
\text { (Phototroph) }\end{array}$ & $\begin{array}{c}\mathrm{RR}=0.36 \\
\mathrm{Cl}_{95}=0.26,0.46\end{array}$ & $\begin{array}{c}\mathrm{RR}=0.19 \\
\mathrm{Cl}_{95}=0.12,0.26\end{array}$ & $\begin{array}{c}\mathrm{RR}=0.36 \\
\mathrm{Cl}_{95}=0.22,0.49\end{array}$ & $\begin{array}{c}\mathrm{RR}=1.0 \\
\mathrm{Cl}_{95}=0.51,1.57\end{array}$ \\
\hline $\begin{array}{l}\text { Plant- } \\
\text { Bacteria } \\
\text { (Heterotroph) }\end{array}$ & $\begin{array}{c}\mathrm{RR}=-0.36 \\
\mathrm{Cl}_{95}=-0.53,-0.18\end{array}$ & $\begin{array}{c}\mathrm{RR}=-0.56 \\
\mathrm{Cl}_{95}=-0.75,-0.36\end{array}$ & $\begin{array}{c}\mathrm{RR}=-0.01 \\
\mathrm{Cl}_{95}=-0.26,0.26\end{array}$ & $\begin{array}{c}\mathrm{RR}=-0.48 \\
\mathrm{Cl}_{95}=-1.25,0.26\end{array}$ \\
\hline $\begin{array}{l}\text { Overall } \\
\text { (Phototroph) }\end{array}$ & $\begin{array}{c}\mathrm{RR}=0.50 \\
\mathrm{Cl}_{95}=0.42,0.58\end{array}$ & $\begin{array}{c}\mathrm{RR}=0.32 \\
\mathrm{Cl}_{95}=0.20,0.43\end{array}$ & $\begin{array}{c}\mathrm{RR}=0.38 \\
\mathrm{Cl}_{95}=0.24,0.54\end{array}$ & $\begin{array}{c}\mathrm{RR}=0.82 \\
\mathrm{Cl}_{95}=0.62,1.03\end{array}$ \\
\hline $\begin{array}{l}\text { Overall } \\
\text { (Heterotroph) }\end{array}$ & $\begin{array}{c}\mathrm{RR}=-0.10 \\
\mathrm{Cl}_{95}=-0.17,-0.04\end{array}$ & $\begin{array}{c}\mathrm{RR}=-0.05 \\
\mathrm{Cl}_{95}=-0.17,0.05\end{array}$ & $\begin{array}{c}\mathrm{RR}=-0.02 \\
\mathrm{Cl}_{95}=-0.22,0.15\end{array}$ & $\begin{array}{c}\mathrm{RR}=-0.16 \\
\mathrm{Cl}_{95}=-0.38,0.06\end{array}$ \\
\hline $\begin{array}{l}\text { Weighted } \\
\text { Analysis } \\
\end{array}$ & Overall & $\mathbf{N}$ & $\mathbf{P}$ & $\mathbf{N + P}$ \\
\hline $\begin{array}{l}\text { Algae-Clam } \\
\text { (Phototroph) }\end{array}$ & $\begin{array}{c}\mathrm{RR}=0.76 \\
\mathrm{Cl}_{95}=0.56,0.95\end{array}$ & $\begin{array}{c}\mathrm{RR}=0.52 \\
\mathrm{Cl}_{95}=0.20,0.85\end{array}$ & $\begin{array}{c}\mathrm{RR}=0.35 \\
\mathrm{Cl}_{95}=0.03,0.62\end{array}$ & $\begin{array}{c}\mathrm{RR}=1.04 \\
\mathrm{Cl}_{95}=0.73,1.35\end{array}$ \\
\hline $\begin{array}{l}\text { Algae-Clam } \\
\text { (Heterotroph) }\end{array}$ & $\begin{array}{c}\mathrm{RR}=0.56 \\
\mathrm{Cl}_{95}=0.40,0.73\end{array}$ & $\begin{array}{c}\mathrm{RR}=0.43 \\
\mathrm{Cl}_{95}=-0.16,0.78\end{array}$ & $\begin{array}{c}\mathrm{RR}=0.20 \\
\mathrm{Cl}_{95}=-0.25,0.65\end{array}$ & $\begin{array}{c}\mathrm{RR}=0.64 \\
\mathrm{Cl}_{95}=0.27,0.94\end{array}$ \\
\hline $\begin{array}{l}\text { Algae-Coral } \\
\text { (Phototroph) }\end{array}$ & $\begin{array}{c}\mathrm{RR}=0.44 \\
\mathrm{Cl}_{95}=0.25,0.64\end{array}$ & $\begin{array}{c}\mathrm{RR}=0.33 \\
\mathrm{Cl}_{95}=0.16,0.52\end{array}$ & $\begin{array}{c}\mathrm{RR}=0.12 \\
\mathrm{Cl}_{95}=-0.14,0.45\end{array}$ & $\begin{array}{c}\mathrm{RR}=0.92 \\
\mathrm{Cl}_{95}=0.29,1.54\end{array}$ \\
\hline $\begin{array}{l}\text { Algae-Coral } \\
\text { (Heterotroph) }\end{array}$ & $\begin{array}{c}\mathrm{RR}=-0.41 \\
\mathrm{Cl}_{95}=-0.59,-0.22\end{array}$ & $\begin{array}{c}\mathrm{RR}=-0.41 \\
\mathrm{Cl}_{95}=-0.61,-0.20\end{array}$ & $\begin{array}{c}\mathrm{RR}=0.11 \\
\mathrm{Cl}_{95}=-0.29,0.46\end{array}$ & $\begin{array}{c}\mathrm{RR}=-0.59 \\
\mathrm{Cl}_{95}=-1.04,-0.05\end{array}$ \\
\hline $\begin{array}{l}\text { Algael } \\
\text { Cyano-Fungi } \\
\text { (Phototroph) }\end{array}$ & $\begin{array}{c}\mathrm{RR}=0.17 \\
\mathrm{Cl}_{95}=-0.02,0.37\end{array}$ & $\begin{array}{c}\mathrm{RR}=0.16 \\
\mathrm{Cl}_{95}=-0.05,0.35\end{array}$ & $\begin{array}{c}\mathrm{RR}=0.08 \\
\mathrm{Cl}_{95}=-0.34,0.48\end{array}$ & $\begin{array}{c}\mathrm{RR}=0.62 \\
\mathrm{Cl}_{95}=-0.13,1.48\end{array}$ \\
\hline Algael & $\mathrm{RR}=-0.05$ & $\mathrm{RR}=-0.05$ & $\mathrm{RR}=0.0$ & $\mathrm{RR}=-0.13$ \\
\hline
\end{tabular}




\begin{tabular}{|c|c|c|c|c|}
\hline $\begin{array}{l}\text { Cyano-Fungi } \\
\text { (Heterotroph) }\end{array}$ & $\mathrm{Cl}_{95}=-0.15,0.03$ & $\mathrm{Cl}_{95}=-0.16,0.05$ & $\mathrm{Cl}_{95}=-0.50,0.51$ & $\mathrm{Cl}_{95}=-0.81,0.48$ \\
\hline $\begin{array}{l}\text { Plant-AM } \\
\text { Fungi } \\
\text { (Phototroph) }\end{array}$ & $\begin{array}{c}\mathrm{RR}=0.39 \\
\mathrm{Cl}_{95}=0.31,0.49\end{array}$ & $\begin{array}{c}\mathrm{RR}=0.31 \\
\mathrm{Cl}_{95}=0.19,0.44\end{array}$ & $\begin{array}{c}\mathrm{RR}=0.42 \\
\mathrm{Cl}_{95}=0.28,0.57\end{array}$ & $\begin{array}{c}\mathrm{RR}=0.41 \\
\mathrm{Cl}_{95}=0.27,0.60\end{array}$ \\
\hline $\begin{array}{l}\text { Plant-AM } \\
\text { Fungi } \\
\text { (Heterotroph) }\end{array}$ & $\begin{array}{c}\mathrm{RR}=-0.25 \\
\mathrm{Cl} 95=-0.37,-0.14\end{array}$ & $\begin{array}{c}\mathrm{RR}=-0.19 \\
\mathrm{Cl} 95=-0.39,-0.01\end{array}$ & $\begin{array}{c}\mathrm{RR}=-0.22 \\
\mathrm{Cl}_{95}=-0.37,- \\
0.03\end{array}$ & $\begin{array}{c}\mathrm{RR}=-0.30 \\
\mathrm{Cl} 95=-0.77,0.20\end{array}$ \\
\hline $\begin{array}{l}\text { Plant-EM } \\
\text { Fungi } \\
\text { (Phototroph) }\end{array}$ & $\begin{array}{c}\mathrm{RR}=0.90 \\
\mathrm{Cl}_{95}=0.48,1.33\end{array}$ & $\begin{array}{c}\mathrm{RR}=0.38 \\
\mathrm{Cl}_{95}=-0.18,1.06\end{array}$ & $\begin{array}{c}\mathrm{RR}=0.15 \\
\mathrm{Cl}_{95}=-0.07,0.46\end{array}$ & $\begin{array}{c}\mathrm{RR}=1.36 \\
\mathrm{Cl}_{95}=0.85,1.83\end{array}$ \\
\hline $\begin{array}{l}\text { Plant-EM } \\
\text { Fungi } \\
\text { (Heterotroph) }\end{array}$ & $\begin{array}{c}\mathrm{RR}=-0.16 \\
\mathrm{Cl} 95=-0.27,-0.06\end{array}$ & $\begin{array}{c}\mathrm{RR}=-0.08 \\
\mathrm{Cl} 95=-0.73,0.53\end{array}$ & $\begin{array}{c}\mathrm{RR}=-0.06 \\
\mathrm{Cl} 95=-0.28,0.21\end{array}$ & $\begin{array}{c}\mathrm{RR}=-0.23 \\
\mathrm{Cl} 95=-0.42,-0.07\end{array}$ \\
\hline $\begin{array}{l}\text { Plant- } \\
\text { Bacteria } \\
\text { (Phototroph) }\end{array}$ & $\begin{array}{c}\mathrm{RR}=0.66 \\
\mathrm{Cl}_{95}=0.39,0.94\end{array}$ & $\begin{array}{c}\mathrm{RR}=0.29 \\
\mathrm{Cl}_{95}=0.12,0.46\end{array}$ & $\begin{array}{c}\mathrm{RR}=0.22 \\
\mathrm{Cl}_{95}=0.10,0.37\end{array}$ & $\begin{array}{c}\mathrm{RR}=1.57 \\
\mathrm{Cl}_{95}=0.90,2.16\end{array}$ \\
\hline $\begin{array}{l}\text { Plant- } \\
\text { Bacteria } \\
\text { (Heterotroph) }\end{array}$ & $\begin{array}{c}\mathrm{RR}=-0.32 \\
\mathrm{Cl} 95=-0.61,-0.05\end{array}$ & $\begin{array}{c}\mathrm{RR}=-0.30 \\
\mathrm{Cl}_{95}=-0.65,0.04\end{array}$ & $\begin{array}{c}\mathrm{RR}=0.00 \\
\mathrm{Cl} 95=-0.20,0.20\end{array}$ & $\begin{array}{c}\mathrm{RR}=-0.56 \\
\mathrm{Cl}_{95}=-1.56,0.36\end{array}$ \\
\hline $\begin{array}{l}\text { Overall } \\
\text { (Phototroph) }\end{array}$ & $\begin{array}{c}\mathrm{RR}=0.55 \\
\mathrm{Cl}_{95}=0.45,0.66\end{array}$ & $\begin{array}{c}\mathrm{RR}=0.33 \\
\mathrm{Cl}_{95}=0.20,0.48\end{array}$ & $\begin{array}{c}\mathrm{RR}=0.22 \\
\mathrm{Cl}_{95}=0.11,0.36\end{array}$ & $\begin{array}{c}\mathrm{RR}=0.99 \\
\mathrm{Cl}_{95}=0.76,1.23\end{array}$ \\
\hline $\begin{array}{l}\text { Overall } \\
\text { (Heterotroph) }\end{array}$ & $\begin{array}{c}\mathrm{RR}=-0.11 \\
\mathrm{Cl} 95=-0.17,-0.04\end{array}$ & $\begin{array}{c}\mathrm{RR}=-0.10 \\
\mathrm{Cl}_{95}=-0.26,0.04\end{array}$ & $\begin{array}{c}\mathrm{RR}=0.01 \\
\mathrm{Cl} 95=-0.17,0.18\end{array}$ & $\begin{array}{c}\mathrm{RR}=-0.20 \\
\mathrm{Cl}_{95}=-0.45,0.05\end{array}$ \\
\hline
\end{tabular}


Figure 6.1 - Map of the locations and countries where marine (blue dots) and terrestrial (green shading) experiments used in our analyses were conducted.

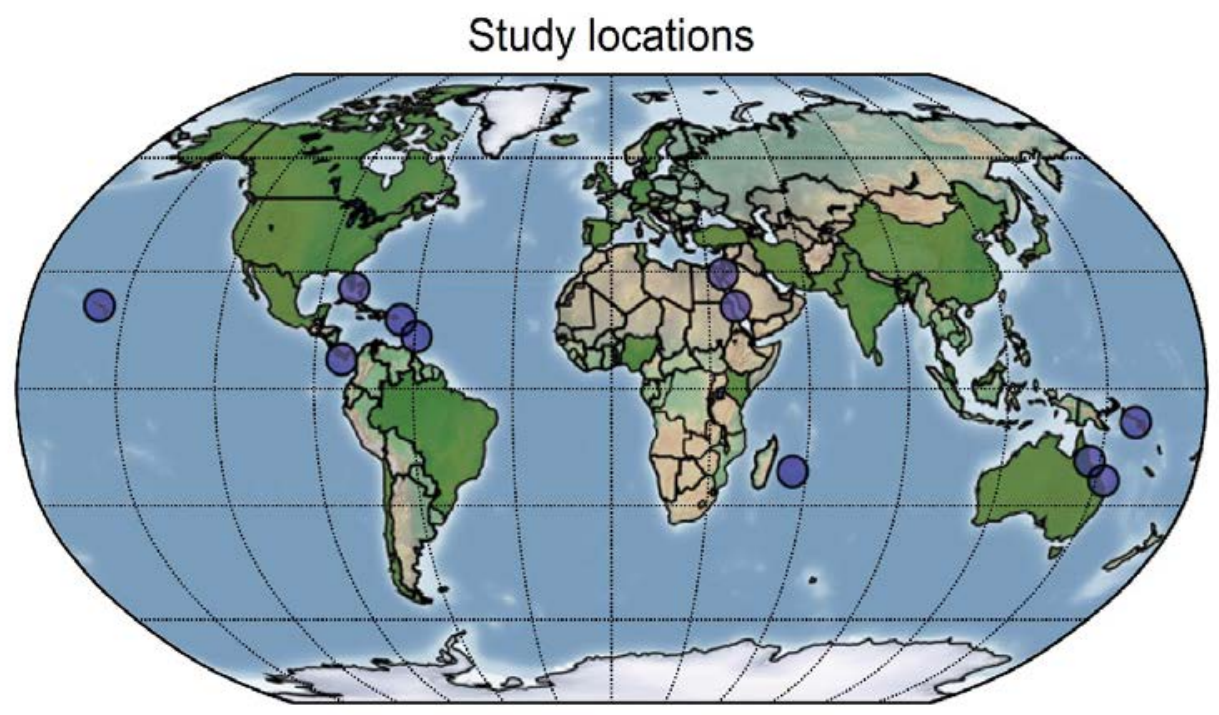


Figure 6.2 - Estimated effect sizes based on log response ratios for phototrophs and heterotrophs from each mutualism type (blue=marine, green=terrestrial) and overall median response across all studies from the unweighted model as (A) pooled across all nutrients or under (B) nitrogen, (C) phosphorus, or (D) nitrogen+phosphorus enrichment. Thin and thick lines depict the $95 \%$ and $80 \%$ Bayesian credible intervals respectively. Numbers in parentheses denote the number of experiments used in each calculation.
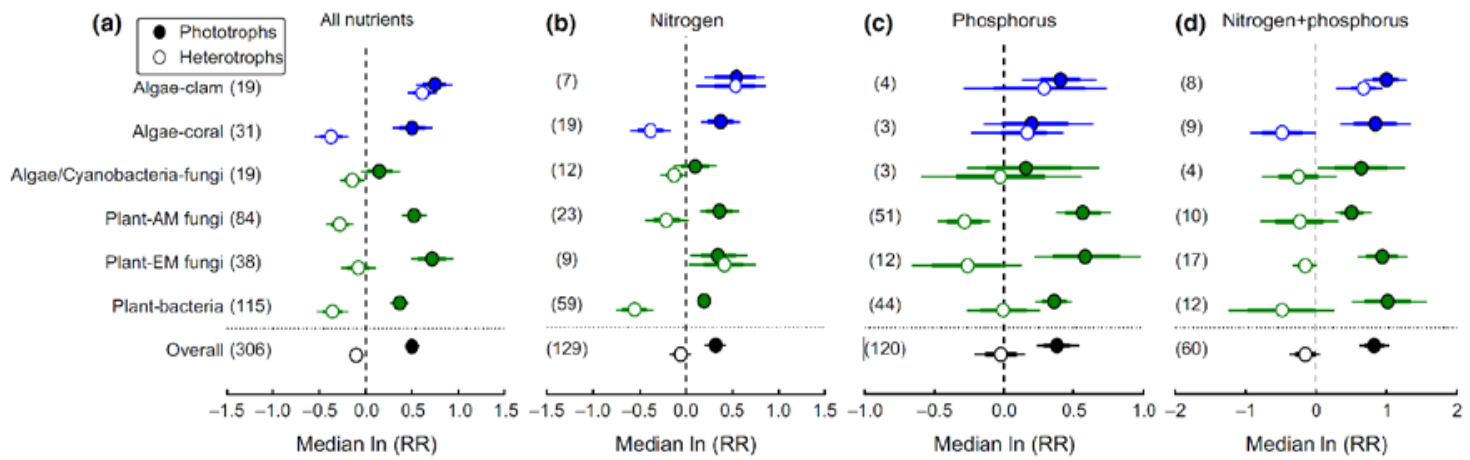
Figure 6.3 - Results of Bayesian Type II regression of heterotroph log response ratios against phototroph log response ratios for the different mutualism types: (A) Algae-Clam, (B) AlgaeCoral, (C) Algae/Cyanobacteria-Fungi, (D) Plant-AM Fungi, (E) Plant-EM Fungi, and (F) PlantBacteria. Shaded area represents the $95 \%$ Bayesian credible interval of the regression.
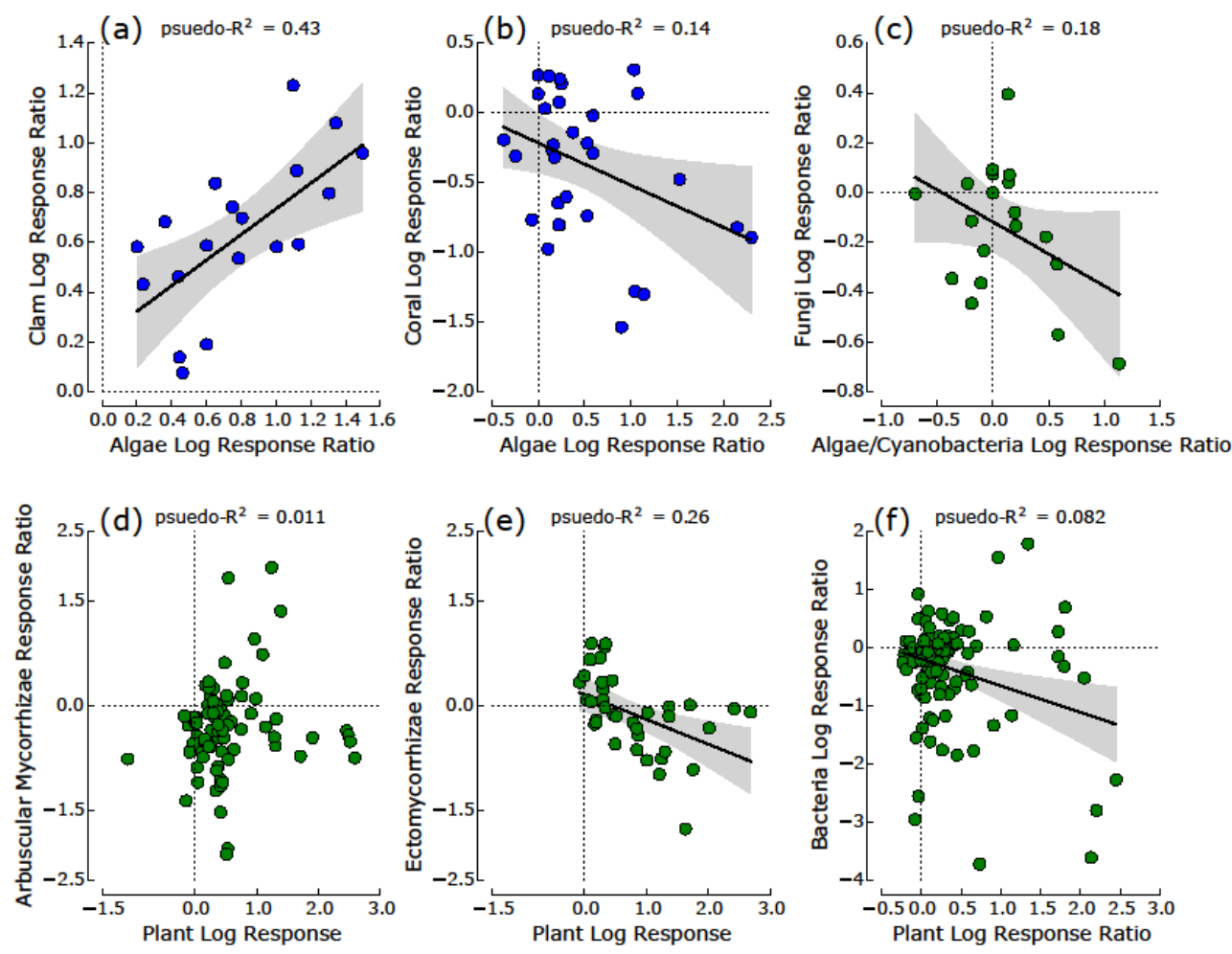
CHAPTER VII

CONCLUSIONS 
Nutrient pollution presents a severe threat to coastal marine ecosystems. On coral reefs, excess nutrients can cause coral diseases, increase coral susceptibility to bleaching, and contribute to shifts from coral to algae dominated reefs (Lapointe 1997; Littler et al. 2006; Weidenmann et al. 2012; Vega Thurber et al. 2014). Yet nutrient enrichment on coral reefs has largely been considered to be less important than herbivory (e.g., Bellwood et al. 2004; Burkepile and Hay 2006; Jackson et al. 2014). Furthermore, although the primary nutrients in coastal pollution, $\mathrm{N}$ and $\mathrm{P}$, each affect plants and animals differently, the majority of studies examining pollution on coral reefs have focused on the simultaneous addition of the two (e.g., Fabricius 2005; Burkepile and Hay 2009; Rasher et al. 2012; Vega Thurber et al. 2014). This singular focus is problematic, as the relative amounts of $\mathrm{N}$ and $\mathrm{P}$ delivered to coastal waters vary by source, and unique remediation strategies exist for each. As a result, isolating the individual effects of $\mathrm{N}$ and $\mathrm{P}$ is important for understanding how nutrient pollution impacts reefs and developing appropriate management and restoration strategies. Chapter II establishes general patterns to create a consensus regarding how $\mathrm{N}$ and $\mathrm{P}$ affect coral growth and photobiology. I found that over a wide range of concentrations, $\mathrm{N}$ reduced coral calcification by $11 \%$ on average but enhanced metrics of coral photobiology, such as photosynthetic rates. In contrast, P enrichment increased average calcification rates by $9 \%$, likely through direct impacts on the calcification process, but minimally impacted coral photobiology.

Various mechanisms may explain the different impacts of nutrient enrichment on corals. For example, P-induced increases in coral growth could be due to the incorporation of calcium phosphate into the coral skeleton (Dunn et al. 2012). Similarly, the increased photosynthesis that occurs under $\mathrm{N}$-enrichment is hypothesized to monopolize dissolved inorganic carbon and make this resource limiting for calcification (Muscatine et al. 1998). However, I found that only $\mathrm{NO}_{3}$ regularly impaired coral growth, despite $\mathrm{NH}_{4}{ }^{+}$consistently benefitting Symbiodinium populations. Similarly, Ezzat et al. (2015) reported that $\mathrm{NH}_{4}{ }^{+}$enrichment increases photosynthesis in the coral Stylophora pistillata but found that $\mathrm{NO}_{3}{ }^{-}$enrichment depressed photosynthesis. Thus, while there has been considerable progress resolving the complexity of coral-nutrient interactions, substantial 
gaps in our understanding still remain. Chapter III fills a portion of these gaps by exploring the effects of different nutrients on photobiological machinery that feeds corals. In this chapter, I propose a novel mechanism through which nutrients may impair coral growth by mediating the levels of photodamage to PSII. Due to an energetically expensive conversion, $\mathrm{NH}_{4}{ }^{+}$is a more efficient nitrogen source for dinoflagellates than $\mathrm{NO}_{3}{ }^{-}$(Raven et al. 1992). As a result, Symbiodinium enriched with $\mathrm{NH}_{4}{ }^{+}$tend to have more protein and lipid reserves than those enriched with $\mathrm{NO}_{3}{ }^{-}$(Ezzat et al 2015). Because harmful reactive oxygen species are a natural byproduct of oxygenic photosynthesis, Symbiodinium must be able to effectively repair damaged proteins in PSII to carry out photosynthesis and produce $\mathrm{C}$ to transfer to their coral hosts. I demonstrate that for some coral species, $\mathrm{NO}_{3}$ - based enrichments increase the levels of energetically costly photodamage to PSII whereas $\mathrm{NH}_{4}{ }^{+}$does not. Furthermore, metrics of photobiology in these corals that are closely associated with photodamage correlate well with reductions in coral growth rates that I recorded.

In chapter IV I expand my focus from individual organisms to important processes. Nutrients may contribute to algal blooms on coral reefs, but herbivores all well known to consume algae that competes with corals (Bellwood et al. 2004; Hughes et al. 2007). This process is particularly important for reef health, as algae can poison coral tissue (Rasher and Hay 2010), reduce coral growth rates (Vega Thurber et al. 2012), vector coral diseases (Smith et al. 2006), and impede the settlement and survival of coral larvae (Vermeij et al. 2009). Thus, herbivory is vital for promoting the resistance and resilience of coral reef ecosystems (Adam et al. 2011; 2015). Chapter IV shows that $\mathrm{N}$ and P-enrichment can increase the nutrient content of algal tissue, in turn altering feeding patterns of herbivorous fishes and the process of herbivory that is so important in structuring coral reefs. I show that grazing rates of initial, but not terminal phase, Sparisomid parrotfishes increased with algal N-content. Similarly, grazing rates of juvenile, but not adult, surgeonfishes increased with algal P-content The differences in nutrient selection between size and age classes of herbivorous fishes I document in this chapter suggest that fish from different size and age classes may be functionally distinct. Because herbivore functional 
diversity is vital for maintaining coral health (Bellwood 2003; Burkepile and Hay 2008; Adam et al. 2015) and driving recovery after disturbances (Bellwood et al. 2006), my data suggests that partitioning of resources along nutritional axes may be an important means of niche diversification on coral reefs. Furthermore, by targeting enriched resources on the reef, my data suggest that the effects of nutrient enrichment on coral-algal dynamics are likely to be dependent on the special scale of enrichment.

Chapter V utilizes the information from Chapters II-IV to explore the cumulative effects of nutrient-complexity on community development. I show that the effects of $\mathrm{N}$ and $\mathrm{P}$ on corals and herbivory interact with the spatial distribution of enrichment to structure a coral reef community. I show that fish excretion of $\mathrm{NH}_{4}{ }^{+}$and $\mathrm{P}$ at locations where schools of fishes regularly shelter significantly enriches shelter sites with these beneficial nutrients. When compared to structurally similar sites that lack sheltering fishes, I show that coral growth rates are higher and herbivore grazing is increased at localized fish-derived nutrient hotspots. In turn, these sites possess distinctly different benthic communities than the rest of the reef. Thus, this chapter revealed an important, yet previously unrecognized, role of fish-derived nutrients in shaping coral reef communities. Furthermore, I present the implications for how such natural processes could be utilized to foster coral reef restoration. Thus, this chapter ties together information from the previous chapters to demonstrate the complexity and previously overlooked importance of nutrients in structuring coral reef communities.

Finally, in Chapter VI I attempt to determine if the patterns I observed on coral reefs provide general rules applicable to other ecosystems. Reef building corals survive through a nutrient-exchange mutualism in which the heterotrophic coral provides limiting nutrients, such as $\mathrm{N}$ and $\mathrm{P}$, to a phototroph partner in exchange for $\mathrm{C}$. I previously show that changes in abiotic conditions (i.e. $\mathrm{N}$ and $\mathrm{P}$ loading) can destabilize these partnerships. As a result, $\mathrm{N}$ and $\mathrm{P}$ enrichment may jeopardize the performance and stability of nutrient-exchange mutualisms (Johnson 1993; Johnson et al. 1997; Akçay and Simms 2011). Chapter VI assembles data from 306 experiments across terrestrial and marine environments to reveal the effects of $\mathrm{N}$ and $\mathrm{P}$ - 
enrichment on ecologically and economically important nutrient-exchange mutualisms. I show that nutrient loading alters the costs and benefits that mutualists receive from interacting, benefiting phototrophs at the expense of their heterotrophic partners. The destabilization of these mutualisms reported in this chapter represent a potentially serious threat to nutrient-exchange mutualisms that could not only alter the ecology of natural systems but presents a pressing concern for ecosystem goods and services. For example, $\mathrm{N}$-fixation by rhizobia in agricultural systems provides at least 70 million metric tons of $\mathrm{N}$ per year (Kiers et al. 2002), or roughly \$28.7-\$59.3 billion worth of fertilizer application (USDA 2011). Enrichment-driven declines in mycorrhizae performance may jeopardize the non-nutritional benefits that fungi confer to plants, such as tolerance to droughts, diseases, and soil toxins (Siddiqui et al. 2008). Such lost services ultimately increase the risk of crop failure from drought and disease. Similarly, the nutrientinduced decline of reef building corals threatens populations of fishes that provide the principal protein source for nearly one billion people worldwide (UNEP 2004). As such, the potential for anthropogenic nutrient loading to disrupt nutrient-sharing mutualisms and their positive impacts on ecosystems, biodiversity, and human wellbeing may be one of the emerging threats of global change in the $21^{\text {st }}$ century.

In summary, this dissertation provides a physiological perspective on the potential effects of $\mathrm{N}$ and $\mathrm{P}$ enrichment to explore how changes in the delivery of these nutrients will impact animals and their environments. By first examining coral and herbivore physiology and then testing the observed patterns in natural settings, this dissertation provides a mechanistic understanding of the effects of changing nutrient regimes on natural and managed ecosystems. Thus, this work considerably advances our knowledge with respect to the effects of global nutrient loading on the natural world.

\section{References}

Adam TC, Schmitt RJ, Holbrook SJ, Brooks AJ, Edmunds PJ, Carpenter RC, Bernardi G (2011) Herbivory, connectivity, and ecosystem resilience: response of a coral reef to a largescale perturbation. PLoS ONE 6: e23717. Doi:10.1371/journal.pone.0023717 
Adam TC, Kelley M, Ruttenberg BI, Burkepile DE (2015) Resource partitioning along multiple niche axes drives functional diversity in parrotfishes on Caribbean coral reefs. Oecologia 179:1173-1185

Akçay E, Simms EL (2011) Negotiation, sanctions, and context dependency in the legumerhizobium mutualism. Am Nat 178:1-14

Bellwood DR (2003). Origins and escalation of herbivory in fishes: a functional perspective. Paleobiol 29:71-83

Bellwood DR, Hughes TP, Folke C, Nyström M (2004) Confronting the coral reef crisis. Nature 429:827-833

Bellwood DR, Wainwright CJ, Fulton CJ, Hoey AS (2006) Functional versatility supports coral reef biodiversity. Proc R Soc B 273: DOI: 10.1098/rspb.2005.3276

Burkepile DE, Hay ME (2006) Herbivore vs. nutrient control of primary producers: Contextdependent effects. Ecology 87:3128-3139

Burkepile DE, Hay ME (2008) Herbivore species richness and feeding complementarity affect community structure and function on a coral reef. Proc Natl Acad Sci 105:16201-6

Dunn JG, Sammarco PW, LaFleur G (2012) Effects of phosphate on growth and skeletal density in the scleractinian coral Acropora muricata: A controlled experimental approach. J Exp Mar Bio Ecol 411:34-44

Ezzat L, Maguer J-F, Grover R, Ferrier-Pagès C (2015) New insights into carbon acquisition and exchanges within the coral-dinoflagellate symbiosis under $\mathrm{NH}_{4}{ }^{+}$and $\mathrm{NO}_{3}{ }^{-}$supply. Proc $\mathrm{R}$ Soc B 282: DOI:20150610

Fabricius KE (2005) Effects of terrestrial runoff on the ecology of corals and coral reefs: Review and synthesis. Mar Pollut Bull 50:125-146

Hughes TP, Rodrigues MJ, Bellwood DR, Ceccarelli D, Hoegh-Guldberg O, McCook L, Moltschaniwskyj N, Pratchett MS, Steneck RS, Willis B (2007) Phase shifts, herbivory, and the resilience of coral reefs to climate change. Current Biol 17:360-365

Jackson JBC, Donovan M, Cramer K, Lam V (eds) (2014) Status and trends of Caribbean coral reefs 1970-2012. Global Coral Reef Monitoring Network, International Union for the Conservation of Nature Global Marine and Polar Program, Washington, DC

Johnson NC (1993) Can fertilization select less mutualistic mycorrhizae? Ecol Appl 3:749-757

Johnson NC, Graham JH, Smith FA (1997) Functioning of mycorrhizal associations along the mutualism-parasitism continuum. New Phytol 135:575-585

Kiers ET, West SA, Denison RF (2002) Mediating mutualisms: farm management practices and evolutionary changes in symbiont co-operation. J Appl Ecol 39:745-754

Lapointe BE (1997) Nutrient thresholds for bottom-up control of macroalgal blooms on coral reefs in Jamaica and Southeast Florida. Limnol. Oceanogr. 42:1119-1131

Littler MM, Littler DS, Brooks BL (2006) Harmful algae on tropical coral reefs: bottom-up eutrophication and top-down herbivory. Harmful Algae 5:565-585 
Muscatine L, Ferrier-Pagès C, Blackburn A, Gates RD, Baghdasarian G, Allemand D (1998) Cellspecific density of symbiotic dinoflagellates in tropical anthozoans. Coral Reefs 17:329337

Rasher DB, Hay ME (2010) Chemically rich seaweeds poison corals when not controlled by herbivores. Proc. Natl Acad Sci. 107:9683-9688

Rasher DB, Engel S, Bonito V, Fraser GJ, Montoya JP, Hay ME (2012) Effects of herbivory, nutrients, and reef protection on algal proliferation and coral growth on a tropical reef. Oecologia 169:187-198

Raven JA, Wollenweber B, Handley LL (1992) A comparison of ammonium and nitrate as nitrogen sources for photolithotrophs. New Phytol. 121:19-32

Siddiqui ZA, Akhtar MS, Futai K, Eds. Mycorrhizae: Sustainable agriculture and forestry. Springer Science+Business Media, Dordrecht, NL, 2008.

Smith JE, Shaw M, Edwards RA, Obura D, Pantos O, Sala E, Sandin SA, Smriga S, Hatay M, Rohwer FL, (2006) Indirect effects of algae on coral: algae-mediated, microbe-induced coral mortality. Ecol Lett 9:835-45

UNEP: People and reefs. UNEP Regional Seas Reports and Studies No. 176. UNEP 2004

USDA fertilizer use and price report www.ers.usda.gov/data-products/fertilizer-use-andprice.aspx\#26727

Vega Thurber R, Burkepile DE, Correa AMS, Thurber AR, Shantz AA, Welsh R, Pritchard C, Rosales S (2012) Macroalgae decrease growth and alter microbial community structure of the reef-building coral, Porites astreoides. PLoS ONE 7: e44246.

Doi:10.1371/journal.pone.0044246

Vega Thurber RL, Burkepile DE, Fuchs C, Shantz AA, McMinds R, Zaneveld JR (2014). Chronic nutrient enrichment increases the prevalence and severity of coral disease and bleaching. Glob Chang Biol 20:544-554

Vermeij MJA, Smith JE, Smith CM, Vega Thurber R, Sandin SA (2009) Survival and settlement success of coral planulae: independent and synergistic effects of macroalgae and microbes. Oecologia 159:325-336

Wiedenmann J, D'angelo C, Smith EG, Hunt AN, Legiret F-E, Postle AD, Achterberg EP (2012) Nutrient enrichment can increase the susceptibility of reef corals to bleaching. Nat Clim Chang 3:160-164 
Appendix A: Supplementary tables and figures for Chapter II.

Table A1 - Summary of studies used for analyses of the effects of nutrients on coral growth. Categories are as follows:

Study: the author(s) and year published of each study used. Letters in superscript listed after studies, when present, indicate additional notes provided below.

Species: list of coral species used in each study.

Metric: Growth metric used in our analyses. Cal $=$ Calcification rate, Den $=$ Skeletal Density, Ext $=$ Extension Rate. Multiple metrics listed under a single study indicates use in each analysis.

Nutrient: Type of enrichment used in the study. $\mathrm{N}=$ mixed/unspecified nitrogen, $\mathrm{NH}_{4}=$ ammonium, $\mathrm{NO}_{3}=$ Nitrate, $\mathrm{P}=$ Phosphate. Nutrients separated by ',' indicate separate enrichments with each, nutrients separated by ' + ' indicate joint enrichment.

Source: Nutrient source used in each study. ANTH=enrichment resulted from anthropogenic pollution, MAN=enrichment resulted from manipulative nutrient additions, $\mathrm{FISH}=e n r i c h m e n t$ resulted from fish excretion.

Control N/P: Background level or range of levels for nitrogen $(N)$ and phosphorus $(P)$ in micromoles recorded in control treatments.

Enriched N/P: The level or range of levels for nitrogen $(N)$ and phosphorus $(P)$ in micromoles recorded in enriched treatments.

\begin{tabular}{|c|c|c|c|c|c|c|}
\hline Study & Species & Metric & Nutrient & Source & $\begin{array}{l}\text { Control } \\
\text { N/P }\end{array}$ & $\begin{array}{l}\text { Enriched } \\
\text { N/P }\end{array}$ \\
\hline $\begin{array}{l}\text { L. Bongiorni et al. } 2003 . \\
\text { Marine Ecology Progress } \\
\text { Series, 253, pp. 137-144. }\end{array}$ & $\begin{array}{l}\text { Acropora } \\
\text { eurystoma, } \\
\text { Stylophora } \\
\text { pistillata }\end{array}$ & $\begin{array}{l}\text { Cal. \& } \\
\text { Ext. }\end{array}$ & $\mathrm{NH}_{4}+\mathrm{P}$ & ANTH & $0.32 / 0.04$ & $1.4 / 0.12$ \\
\hline $\begin{array}{l}\text { D.J. Bucher. The Effects of } \\
\text { Experimentally elevate nutrient } \\
\text { concentrations on growth rate, } \\
\text { skeletal architecture and soft } \\
\text { tissue morphology of Acroporid } \\
\text { corals. Southern Cross } \\
\text { University, New South Whales, } \\
\text { Australia. } 2000\end{array}$ & $\begin{array}{c}\text { A. } \\
\text { longicyathus, } \\
\text { A. aspera, } \\
\text { Porites porites }\end{array}$ & $\begin{array}{l}\text { Cal., } \\
\text { Den. \& } \\
\text { Ext. }\end{array}$ & $\begin{array}{l}\mathrm{NH}_{4}, \mathrm{P}, \\
\mathrm{NH}_{4}+\mathrm{P}\end{array}$ & MAN & $\begin{array}{l}0.51- \\
3.85 / 0.01 \\
-0.16\end{array}$ & $10-20 / 2-4$ \\
\hline $\begin{array}{l}\text { K. Koop et al. 2001. Marine } \\
\text { Pollution Bulletin, 42, pp. 91- } \\
120 .\end{array}$ & A. longicyathus & Ext. & $\begin{array}{l}\mathrm{NH}_{4}, \mathrm{P}, \\
\mathrm{NH}_{4}+\mathrm{P}\end{array}$ & MAN & $3.85 / 0.16$ & $10-20 / 2-4$ \\
\hline $\begin{array}{l}\text { P.S. Davies, 1990. Marine } \\
\text { Pollution Bulletin, 21, pp. 346- } \\
348 .\end{array}$ & P. porites & Cal. & $\mathrm{N}+\mathrm{P}$ & ANTH & $0.45 / 0.06$ & $0.65 / 0.11$ \\
\hline $\begin{array}{l}\text { R.E. Dodge \& G.W. Brass, } \\
\text { 1984. Bulletin of Marine } \\
\text { Science, 34, pp. 288-307. }{ }^{\text {a }}\end{array}$ & $\begin{array}{c}\text { Montastraea } \\
\text { annularis }\end{array}$ & $\begin{array}{l}\text { Cal., } \\
\text { Den. \& } \\
\text { Ext. }\end{array}$ & $\mathrm{N}+\mathrm{P}$ & ANTH & NA & NA \\
\hline $\begin{array}{l}\text { J.G. Dunn et al. 2012. Journal of } \\
\text { Experimental Marine Biology } \\
\text { and Ecology, 411, pp. 34-44. }\end{array}$ & A. muricata & $\begin{array}{l}\text { Cal., } \\
\text { Den. \& } \\
\text { Ext. }\end{array}$ & $\mathrm{P}$ & MAN & $0.13 / 0.09$ & $0 / 0.2$ \\
\hline $\begin{array}{l}\text { E.N. Edinger et al 2000. Marine } \\
\text { Pollution Bulletin, 40, pp. 404- } \\
\text { 425. }\end{array}$ & P. lobata & Ext. & $\mathrm{P}, \mathrm{N}+\mathrm{P}$ & ANTH & $0.34 / 0.18$ & $\begin{array}{c}0.50- \\
0.63 / 0.3- \\
0.38\end{array}$ \\
\hline $\begin{array}{l}\text { E.M. Elizalde-Rendon et al. } \\
\text { 2010. Coral Reefs, 29, pp. 607- } \\
\text { 614. }\end{array}$ & P. astreoides & $\begin{array}{l}\text { Cal., } \\
\text { Den. \& } \\
\text { Ext. }\end{array}$ & $\mathrm{N}+\mathrm{P}$ & ANTH & $5.76 / 1.1$ & $14.65 / 2.8$ \\
\hline $\begin{array}{l}\text { C. Ferrier-Pages et al. } 2000 . \\
\text { Coral Reefs, } 19 \text {, pp. } 103-113 .{ }^{c}\end{array}$ & S. pistillata & Cal. & $\begin{array}{l}\mathrm{NH}_{4}^{+}, \mathrm{P}, \\
\mathrm{NH}_{4}+\mathrm{P} \\
\end{array}$ & MAN & $1.39 / 0.19$ & $14.75 / 2.6$ \\
\hline $\begin{array}{l}\text { C. Ferrier-Pages et al. } 2001 . \\
\text { Journal of Experimental Marine }\end{array}$ & S. pistillata & Cal. & $\mathrm{NO}_{3}$ & MAN & $1.39 / \mathrm{NA}$ & 2.13/NA \\
\hline
\end{tabular}




\begin{tabular}{|c|c|c|c|c|c|c|}
\hline $\begin{array}{l}\text { Biology and Ecology, 259, pp. } \\
\text { 249-261. }\end{array}$ & & & & & & \\
\hline $\begin{array}{l}\text { C. Godinot et al. 2011. Journal } \\
\text { of Experimental Marine Biology } \\
\text { and Ecology, 409, pp. 200-207. }\end{array}$ & S. pistillata & Cal. & $\mathrm{P}$ & MAN & NA/0.04 & NA/0.5 \\
\hline $\begin{array}{l}\text { S.J. Holbrook et al. } 2008 . \\
\text { Marine Biology, 155, pp. 521- } \\
530 .\end{array}$ & $\begin{array}{c}\text { Pocillopora } \\
\text { eydouxi }\end{array}$ & Cal. & $\mathrm{NH}_{4}+\mathrm{P}$ & FISH & NA/NA & $0.35 / \mathrm{NA}$ \\
\hline $\begin{array}{l}\text { S.J. Holbrook et al. 2011. } \\
\text { Oecologia, 166, pp. 739-749. }\end{array}$ & Po. eydouxi & Cal. & $\mathrm{NH}_{4}+\mathrm{P}$ & FISH & NA/NA & NA/NA \\
\hline $\begin{array}{l}\text { J. Jompa \& L.J. McCook } 2002 . \\
\text { Limnology and Oceanography, } \\
\text { 47, pp. 527-534. }\end{array}$ & P. cylindrical & Ext. & $\mathrm{NH}_{4}+\mathrm{P}$ & MAN & $1 / 0.08$ & $\begin{array}{c}5-10 / 0.5- \\
1.0\end{array}$ \\
\hline $\begin{array}{l}\text { T. Liberman et al. 1995. Marine } \\
\text { Biology, 121, pp. 741-746. }\end{array}$ & S. pistillata & $\begin{array}{l}\text { Cal. \& } \\
\text { Ext. }\end{array}$ & $\mathrm{NH}_{4}+\mathrm{P}$ & FISH & NA/NA & NA/NA \\
\hline $\begin{array}{l}\text { F. Marubini \& M.J. Atkinson } \\
\text { 1999. Marine Ecology Progress } \\
\text { Series, 188, pp. 117-121. }\end{array}$ & P. compressa & Cal. & $\mathrm{NO}_{3}$ & MAN & $0.42 / \mathrm{NA}$ & $\begin{array}{c}0.91- \\
5.66 / \mathrm{NA}\end{array}$ \\
\hline $\begin{array}{l}\text { F. Marubini \& P.S. Davies } 1996 . \\
\text { Marine Biology, 127, pp. 319- } \\
328\end{array}$ & P. porites & Cal. & $\mathrm{NO}_{3}$ & MAN & $0.2 / 0.05$ & $1-20 / 0$ \\
\hline $\begin{array}{l}\text { F. Marubini \& B. Thake } 1999 . \\
\text { Limnology and Oceanography, } \\
\text { 44, pp. } 716-720 .\end{array}$ & $P$. porites & $\begin{array}{l}\text { Cal. \& } \\
\text { Ext. }\end{array}$ & $\begin{array}{r}\mathrm{NH}_{4} \\
\mathrm{NO}_{3}\end{array}$ & MAN & $0.2 / 0.05$ & $20 / 0$ \\
\hline $\begin{array}{l}\text { J.L. Mate 1997. Proceedings of } \\
\text { the } 8^{\text {th }} \text { International Coral Reef } \\
\text { Symposium, 1, pp. 515-520. }\end{array}$ & $\begin{array}{c}\text { Po. } \\
\text { damicornis, } \\
\text { Psammacora } \\
\text { stellata } \\
\end{array}$ & Ext. & $\mathrm{NO}_{3}+\mathrm{P}$ & MAN & $0.5 / 0.5$ & $26 / 26$ \\
\hline $\begin{array}{l}\text { J.L. Meyer et al. } 1982 . \text { Science, } \\
220 \text {, pp. } 1047-1049 .\end{array}$ & P. furcata & Cal. & $\mathrm{NH}_{4}+\mathrm{P}$ & FISH & 2.8/NA & $3.0 / \mathrm{NA}$ \\
\hline $\begin{array}{l}\text { M.P. McGuire \& A.M. Szmant } \\
\text { 1997. Proceedings of the } 8^{\text {th }} \\
\text { International Coral Reef } \\
\text { Symposium, 1, pp. 909-914. }\end{array}$ & P. astreoides & Cal. & $\mathrm{NH}_{4}+\mathrm{P}$ & MAN & $0.5 / 0.2$ & $10 / 0$ \\
\hline $\begin{array}{l}\text { J.L. Meyer \& E.T. Schultz } 1985 . \\
\text { Limnology and Oceanography, } \\
\text { 30, pp. 157-166. }\end{array}$ & P. furcata & $\begin{array}{l}\text { Cal., } \\
\text { Den. \& } \\
\text { Ext. }\end{array}$ & $\mathrm{NH}_{4}+\mathrm{P}$ & FISH & 3.71/NA & $3.90 / \mathrm{NA}$ \\
\hline $\begin{array}{l}\text { D.A. Renegar \& B.M. Riegl } \\
\text { 2005. Marine Ecology Progress } \\
\text { Series, 293, pp. 69-76. }{ }^{c}\end{array}$ & A. cervicornis & Cal. & $\begin{array}{l}\mathrm{NO}_{3}, \mathrm{P} \\
\mathrm{NO}_{3}+\mathrm{P}\end{array}$ & MAN & $0.5 / 0.08$ & 7.5/3.15 \\
\hline $\begin{array}{l}\text { N. Stambler et al. 1991. Pacific } \\
\text { Science, 45, 299-307. }\end{array}$ & Po. damicornis & Ext. & $\begin{array}{c}\mathrm{NH}_{4} \\
\mathrm{NH}_{4}+\mathrm{P}\end{array}$ & MAN & $2.0 / 0.1$ & $15-20 / .5-2$ \\
\hline $\begin{array}{l}\text { A.D. Broadbent, } 1997 . \\
\text { Proceedings of the } 8^{\text {th }} \\
\text { International Coral Reef } \\
\text { Symposium, 1, pp. 867-872. }\end{array}$ & A. palifera & Cal. & $\begin{array}{l}\mathrm{NH}_{4}, \mathrm{P}, \\
\mathrm{NH}_{4}+\mathrm{P}\end{array}$ & MAN & $3.85 / 0.16$ & $20 / 4$ \\
\hline $\begin{array}{l}\text { T. Tomascik \& F. Sander } 1985 . \\
\text { Marine Biology, } 87, \text { pp. } 143- \\
155 .\end{array}$ & M. annularis & Ext. & $\mathrm{N}, \mathrm{N}+\mathrm{P}$ & ANTH & $\begin{array}{c}0.36- \\
0.45 / 0.06\end{array}$ & $\begin{array}{c}0.55- \\
4.4 / .11- \\
.21\end{array}$ \\
\hline
\end{tabular}

a TBF site near sewage outfall considered pristine, CHF considered enriched.

${ }^{b}$ Measurements included only for sites where nutrient and turbidity data were provided.

${ }^{c}$ Measurements were averaged from a time series of results. 
Table A2 - Summary of studies used for analyses of the effects of nutrients on coral photobiology. Categories are:

Study: the author(s) and year published of each study used. Letters in superscript listed after studies, when present, indicate additional notes provided below.

Species: list of coral species used in each study.

Metric: Photobiology metric used in our analyses. Chl.a = Chlorophyll a concentration obtained from an area of coral tissue, Chl. per Symbio = Chlorophyll a within individual Symbiodinium, SymDensity = Density of Symbiodinium within an area of coral tissue, Photosynth = Gross photosynthetic rate. Multiple metrics listed under a single study indicates use in each analysis. Nutrient: Type of enrichment used in the study. $\mathrm{NH}_{4}=$ ammonium, $\mathrm{NO}_{3}=$ Nitrate, $\mathrm{P}=\mathrm{Phosphorus}$. Nutrients separated by ', indicate separate enrichments with each, nutrients separated by ' + ' indicate joint enrichment.

Source: Nutrient source used in each study. ANTH=enrichment resulted from anthropogenic pollution, MAN=enrichment resulted from manipulative nutrient additions, $\mathrm{FISH}=e n r i c h m e n t$ resulted from fish excretion.

N Level/P Level: The level or range of levels provided for $\mathrm{N}$ (nitrogen) and $\mathrm{P}$ (phosphorus).

\begin{tabular}{|c|c|c|c|c|c|c|}
\hline Study & Species & Metric & Nutrient & Source & $\begin{array}{l}\text { Control } \\
\mathrm{N} / \mathrm{P}\end{array}$ & $\begin{array}{l}\text { Enriched } \\
\text { N/P }\end{array}$ \\
\hline $\begin{array}{l}\text { C. Ferrier-Pages et al. } \\
\text { 2000. Coral Reefs, 19, } \\
\text { pp. 103-113. }\end{array}$ & S. pistillata & Photosynth & $\mathrm{NH}_{4}+\mathrm{P}$ & MAN & $<1.5 / 0.2$ & $\begin{array}{l}18.5- \\
19.5 / 2.4- \\
2.8\end{array}$ \\
\hline $\begin{array}{l}\text { C. Ferrier-Pages et al. } \\
\text { 2001. Journal of } \\
\text { Experimental Marine } \\
\text { Biology and Ecology, } \\
\text { 259, pp. 249-261. }\end{array}$ & S. pistillata & $\begin{array}{l}\text { Chl.a, } \\
\text { SymDensity, } \\
\text { Photosynth }\end{array}$ & $\mathrm{NO}_{3}$ & MAN & $<1.5 / 0.2$ & 2.5/NA \\
\hline $\begin{array}{l}\text { C. Godinot et al. } 2011 . \\
\text { Journal of Experimental } \\
\text { Marine Biology and } \\
\text { Ecology, 409, pp. 200- } \\
207^{\mathrm{a}}\end{array}$ & S. pistillata & $\begin{array}{l}\text { Chl. per } \\
\text { Symbio, } \\
\text { SymDensity, } \\
\text { Photosynth }\end{array}$ & $\mathrm{P}$ & MAN & NA/0.04 & NA/.5-2.5 \\
\hline $\begin{array}{l}\text { F. Marubini \& P.S. } \\
\text { Davies 1996. Marine } \\
\text { Biology, 127, pp. 319- } \\
328\end{array}$ & $\begin{array}{l}\text { P. porites, } M \text {. } \\
\text { annularis }\end{array}$ & $\begin{array}{l}\text { Chl. per } \\
\text { Symbio, } \\
\text { SymDensity, } \\
\text { Photosynth }\end{array}$ & $\mathrm{NO}_{3}$ & MAN & $0.2 / 0.05$ & $1-20 / 0$ \\
\hline $\begin{array}{l}\text { F. Marubini \& B. Thake } \\
\text { 1999. Limnology and } \\
\text { Oceanography, 44, pp. } \\
\text { 716-720. }\end{array}$ & P. porites & Chl.a & $\begin{array}{l}\mathrm{NH}_{4}, \\
\mathrm{NO}_{3}\end{array}$ & MAN & $0.2 / 0.05$ & $20 / 0$ \\
\hline $\begin{array}{l}\text { M.P. McGuire \& A.M. } \\
\text { Szmant } 1997 . \\
\text { Proceedings of the } 8^{\text {th }} \\
\text { International Coral Reef } \\
\text { Symposium, 1, pp. 909- } \\
\text { 914. }\end{array}$ & P. astreoides & $\begin{array}{l}\text { Chl. per } \\
\text { Symbio, } \\
\text { SymDensity }\end{array}$ & $\mathrm{NH}_{4}$ & MAN & $0.5 / 0.2$ & $10 / 0$ \\
\hline $\begin{array}{l}\text { J.L. Meyer \& E.T. } \\
\text { Schultz 1985. Limnology } \\
\text { and Oceanography, 30, } \\
\text { pp. 157-166. }\end{array}$ & P. furcata & SymDensity & $\mathrm{NH}_{4}+\mathrm{P}$ & FISH & $3.71 / \mathrm{NA}$ & $3.90 / \mathrm{NA}$ \\
\hline $\begin{array}{l}\text { A. Chauvin et al. } 2011 . \\
\text { Coral Reefs, } 30 \text { pp. 911- } \\
\text { 923. }\end{array}$ & A. muricata & $\begin{array}{l}\text { Chl.a, } \\
\text { SymDensity }\end{array}$ & $\mathrm{NO}_{3}$ & ANTH & $0.61 / 0.12$ & $5 / .14$ \\
\hline $\begin{array}{l}\text { C. Godinot et al. } 2009 . \\
\text { Limnology and } \\
\text { Oceanography, 54, 1627- } \\
1633 .\end{array}$ & S. pistillata & SymDensity & $\mathrm{P}$ & MAN & $\begin{array}{l}\text { NA } /<0.0 \\
5\end{array}$ & NA/2.5 \\
\hline
\end{tabular}




\begin{tabular}{|c|c|c|c|c|c|c|}
\hline $\begin{array}{l}\text { Y. Tanaka et al. } 2007 . \\
\text { Limnology and } \\
\text { Oceanography, } 52 \text { pp. } \\
\text { 1139-1146. }\end{array}$ & A. pulchra & Chl.a & $\mathrm{NO}_{3}+\mathrm{P}$ & MAN & $1.5 / 0.08$ & $5 / 0.3$ \\
\hline $\begin{array}{l}\text { Y. Tanaka et al. } 2010 . \\
\text { Coral Reefs, } 29 \text { pp. } 675- \\
682 .\end{array}$ & $\begin{array}{l}\text { Montipora } \\
\text { digitata }\end{array}$ & Chl.a & $\mathrm{NO}_{3}+\mathrm{P}$ & MAN & $0.22 / 0.06$ & $10 / 0.5$ \\
\hline $\begin{array}{l}\text { L. Muscatine et al. } 1989 . \\
\text { Proceedings of the Royal } \\
\text { Society, Biology, 236, } \\
\text { 311-324. }\end{array}$ & S. pistillata & $\begin{array}{l}\text { Chl.a, } \\
\text { SymDensity }\end{array}$ & $\begin{array}{l}\mathrm{NH}_{4}, \mathrm{P} \\
\mathrm{NH}_{4}+\mathrm{P}\end{array}$ & MAN & $\begin{array}{l}\text { Below } \\
\text { detection }\end{array}$ & $20 / 2$ \\
\hline $\begin{array}{l}\text { Snivdongs and Kinzie } \\
1994\end{array}$ & $\begin{array}{l}\text { Po. } \\
\text { damicornis }\end{array}$ & Chl. per Symbio & $\begin{array}{l}\mathrm{NH}_{4}, \mathrm{P}, \\
\mathrm{NH}_{4}+\mathrm{P}\end{array}$ & MAN & $0.7 / 0.2$ & $15 / 1.2$ \\
\hline $\begin{array}{l}\text { Stambler et al. } 1994 . \\
\text { Pacific Science, 48, pp. } \\
\text { 284-290. }\end{array}$ & $\begin{array}{l}\text { M. verrucosa, } \\
\text { Po. } \\
\text { damicornis }\end{array}$ & $\begin{array}{l}\text { Chl. per } \\
\text { Symbio, Chl.a, } \\
\text { SymDensity }\end{array}$ & $\mathrm{NH}_{4}$ & MAN & $<2.0 / \mathrm{NA}$ & $2-50 / 0$ \\
\hline $\begin{array}{l}\text { N. Stambler et al. } 1991 . \\
\text { Pacific Science, 45, pp. } \\
\text { 299-307. }\end{array}$ & $\begin{array}{l}\text { Po. } \\
\text { damicornis }\end{array}$ & $\begin{array}{l}\text { Chl. per } \\
\text { Symbio, Chl.a, } \\
\text { SymDensity } \\
\end{array}$ & $\begin{array}{l}\mathrm{NH}_{4}, \mathrm{P}, \\
\mathrm{NH}_{4}+\mathrm{P}\end{array}$ & MAN & $2.0 / 0.1$ & $15 / 0.5-2$ \\
\hline $\begin{array}{l}\text { A.D. Broadbent } 1997 . \\
\text { Proceedings of the } 8^{\text {th }} \\
\text { International Coral Reef } \\
\text { Symposium, 1, pp. } 867- \\
872 .\end{array}$ & A. palifera & $\begin{array}{l}\text { Chl. per } \\
\text { Symbio, } \\
\text { SymDensity }\end{array}$ & $\begin{array}{l}\mathrm{NH}_{4}, \mathrm{P}, \\
\mathrm{NH}_{4}+\mathrm{P}\end{array}$ & MAN & $3.85 / 0.16$ & $20 / 4$ \\
\hline $\begin{array}{l}\text { J. Stimson \& R.A. Kinzie } \\
\text { 1991. Journal of } \\
\text { Experimental Marine } \\
\text { Biology and Ecology, } \\
\text { 153, pp. 63-74. }\end{array}$ & $\begin{array}{l}\text { Po. } \\
\text { damicornis }\end{array}$ & SymDensity & $\mathrm{NH}_{4}$ & MAN & $0.6 / \mathrm{NA}$ & $17 / \mathrm{NA}$ \\
\hline $\begin{array}{l}\text { D.J. Bucher \& P.L. } \\
\text { Harrison } 2002 . \\
\text { Proceedings of the } 9^{\text {th }} \\
\text { International Coral Reef } \\
\text { Symposium pp. 23-27. }\end{array}$ & $\begin{array}{l}\text { A. } \\
\text { longicyanthus }\end{array}$ & Chl.a & $\begin{array}{l}\mathrm{NH}_{4}, \mathrm{P}, \\
\mathrm{NH}_{4}+\mathrm{P}\end{array}$ & MAN & $3.85 / 0.16$ & $20 / 4$ \\
\hline $\begin{array}{l}\text { O. Hoegh-Guldberg \& } \\
\text { G.J. Smith 1989. Marine } \\
\text { Ecology Progress Series, } \\
\text { 57, pp. 173-186. }\end{array}$ & $\begin{array}{l}\text { S. hystrix, } S \text {. } \\
\text { pistillata }\end{array}$ & $\begin{array}{l}\text { Chl.a, } \\
\text { SymDensity, } \\
\text { Photosynth }\end{array}$ & $\mathrm{NH}_{4}$ & MAN & NA/NA & $10.0 / \mathrm{NA}$ \\
\hline $\begin{array}{l}\text { G. Muller-Parker et al. } \\
\text { 1994. Pacific Science, } 48 \\
\text { pp. 273-283. }\end{array}$ & $\begin{array}{l}\text { Po. } \\
\text { damicornis }\end{array}$ & $\begin{array}{l}\text { Chl.a, } \\
\text { SymDensity }\end{array}$ & $\mathrm{NH}_{4}$ & MAN & NA/NA & 20-50/NA \\
\hline $\begin{array}{l}\text { E. Titlyanov et al. } 2000 . \\
\text { Marine Biology, } 137 \text { pp. } \\
\text { 463-472. }\end{array}$ & S. pistillata & $\begin{array}{l}\text { Chl. per } \\
\text { Symbio, } \\
\text { SymDensity, } \\
\text { Photosynth }\end{array}$ & $\mathrm{NH}_{4}$ & MAN & $2.25 / 0.25$ & $10 / 0$ \\
\hline
\end{tabular}

a Measurements averaged from two time periods.

${ }^{b}$ Measurements only taken from highest irradiance levels which were closest to irradiance levels recorded at collection sites. 
Table A3 - Results of linear regression analysis examining the relationship between effect sizes and the background nitrogen $(\mathrm{N})$ and phosphorus $(\mathrm{P})$ levels for each metric of coral growth and photobiology under $\mathrm{N}, \mathrm{P}$ and $\mathrm{N}+\mathrm{P}$ enrichment.

\begin{tabular}{|c|c|c|c|c|}
\hline Metric & d.f. & $\mathbf{F}$ & $\mathbf{p}$ & $\mathbf{R}^{2}$ \\
\hline \multicolumn{5}{|l|}{ Calcification } \\
\hline $\mathrm{N}$ & 3,13 & 1.409 & 0.285 & 0.071 \\
\hline $\mathrm{P}$ & 3,7 & 29.32 & 0.001 & 0.895 \\
\hline $\mathrm{N}+\mathrm{P}$ & 3,13 & 1.451 & 0.274 & 0.078 \\
\hline \multicolumn{5}{|l|}{ Extension } \\
\hline $\mathrm{N}$ & 3,4 & 1.727 & 0.299 & 0.238 \\
\hline $\mathrm{P}$ & 1,2 & 1.778 & 0.314 & 0.206 \\
\hline $\mathrm{N}+\mathrm{P}$ & 3,15 & 1.559 & 0.241 & 0.085 \\
\hline \multicolumn{5}{|l|}{ Density } \\
\hline $\mathrm{N}$ & NA & NA & NA & NA \\
\hline $\mathrm{P}$ & 1,4 & 2.098 & 0.221 & 0.18 \\
\hline $\mathrm{N}+\mathrm{P}$ & 3,3 & 2.292 & 0.257 & 0.392 \\
\hline \multicolumn{5}{|l|}{$\begin{array}{l}\text { Chl. a per } \\
\text { Symbiodinium }\end{array}$} \\
\hline $\mathrm{N}$ & 3,9 & 0.413 & 0.748 & 0.172 \\
\hline $\mathrm{P}$ & 2,1 & 0.233 & 0.826 & 1.046 \\
\hline $\mathrm{N}+\mathrm{P}$ & 2,1 & 45.71 & 0.104 & 0.968 \\
\hline \multicolumn{5}{|c|}{$\begin{array}{l}\text { Symbiodinium } \\
\text { density in coral }\end{array}$} \\
\hline $\mathrm{N}$ & 3,18 & 0.520 & 0.674 & 0.074 \\
\hline $\mathrm{P}$ & 2,1 & 3.062 & 0.375 & 0.579 \\
\hline $\mathrm{N}+\mathrm{P}$ & 3,1 & 45.49 & 0.109 & 0.971 \\
\hline \multicolumn{5}{|c|}{$\begin{array}{l}\text { Chl. a per coral } \\
\text { area }\end{array}$} \\
\hline $\mathrm{N}$ & 3,10 & 1.52 & 0.269 & 0.107 \\
\hline $\mathrm{P}$ & 2,1 & 12.04 & 0.200 & 0.880 \\
\hline $\mathrm{N}+\mathrm{P}$ & 3,3 & 0.793 & 0.573 & 0.115 \\
\hline \multicolumn{5}{|c|}{$\begin{array}{l}\text { Gross } \\
\text { photosynthesis }\end{array}$} \\
\hline $\mathrm{N}$ & 2,5 & 5.484 & 0.055 & 0.562 \\
\hline $\mathrm{P}$ & NA & NA & NA & NA \\
\hline $\mathrm{N}+\mathrm{P}$ & NA & NA & NA & NA \\
\hline
\end{tabular}


Table A4 - Results from model selection for linear or quadratic models and the corresponding regression analysis for the relationship between effect sizes and enrichment level for calcification and each metric of photobiology. Best fit was determined via Akaike Information Criteria corrected for small sample sizes (AICC). For each metric, the best model type is listed along with the AICc score, the AICc difference between the two model types, and the regression statistics. NA = not sufficient data to conduct the analysis.

\begin{tabular}{|c|c|c|c|c|c|c|c|c|}
\hline Metric & $\begin{array}{l}\text { Best } \\
\text { Model }\end{array}$ & $\begin{array}{l}\text { AIC } \\
\text { c }\end{array}$ & $\begin{array}{l}\Delta \mathrm{AIC} \\
\mathrm{c}\end{array}$ & d.f. & Slope & $\mathbf{F}$ & $\mathbf{p}$ & $\mathbf{R}^{2}$ \\
\hline \multicolumn{9}{|l|}{ Calcification } \\
\hline Ammonium & Linear & $\begin{array}{c}14.2 \\
6\end{array}$ & 29.98 & 1,4 & 0.024 & $\begin{array}{c}1.0 \\
4\end{array}$ & 0.37 & 0.008 \\
\hline Nitrate & Linear & $\begin{array}{c}12.5 \\
2\end{array}$ & 3.18 & 1,10 & $\begin{array}{c}- \\
0.006\end{array}$ & $\begin{array}{c}0.2 \\
9\end{array}$ & 0.60 & 0.069 \\
\hline Phosphate & Linear & $\begin{array}{c}23.2 \\
2\end{array}$ & 4.21 & 1,7 & $\begin{array}{c}\overline{-} \\
0.207\end{array}$ & $\begin{array}{c}2.9 \\
1\end{array}$ & 0.13 & 0.193 \\
\hline \multicolumn{9}{|l|}{$\begin{array}{l}\text { Chl. a per } \\
\text { Symbiodiniu } \\
m\end{array}$} \\
\hline Ammonium & Linear & $\begin{array}{c}13.0 \\
4\end{array}$ & 4.48 & 1,8 & 0.008 & $\begin{array}{c}1.6 \\
3 \\
\end{array}$ & 0.24 & 0.066 \\
\hline Nitrate & Linear & $\begin{array}{c}11.6 \\
4\end{array}$ & 23.27 & 1,4 & 0.014 & $\begin{array}{c}2.5 \\
4\end{array}$ & 0.19 & 0.235 \\
\hline Phosphate & NA & NA & NA & NA & NA & NA & NA & NA \\
\hline \multicolumn{9}{|l|}{$\begin{array}{l}\text { Symbiodiniu } \\
m \text { density in } \\
\text { coral }\end{array}$} \\
\hline Ammonium & Linear & $\begin{array}{c}33.2 \\
9\end{array}$ & 2.61 & 1,13 & 0.003 & $\begin{array}{c}0.0 \\
9\end{array}$ & 0.76 & 0.069 \\
\hline Nitrate & Linear & 1.16 & 5.48 & 1,6 & $\begin{array}{c}- \\
0.015\end{array}$ & $\begin{array}{c}4.8 \\
8\end{array}$ & 0.07 & 0.357 \\
\hline Phosphate & NA & NA & NA & NA & NA & NA & NA & NA \\
\hline \multicolumn{9}{|l|}{$\begin{array}{l}\text { Chl. } a \text { per } \\
\text { coral area }\end{array}$} \\
\hline Ammonium & Linear & $\begin{array}{c}32.3 \\
6\end{array}$ & 4.68 & 1,10 & 0.011 & $\begin{array}{c}0.8 \\
1\end{array}$ & 0.39 & 0.018 \\
\hline Nitrate & NA & NA & NA & NA & NA & NA & NA & NA \\
\hline Phosphorus & NA & NA & NA & NA & NA & NA & NA & NA \\
\hline
\end{tabular}




\begin{tabular}{|c|c|c|c|c|c|c|c|c|}
\hline $\begin{array}{l}\text { Gross } \\
\text { photosynthes } \\
\text { is }\end{array}$ & & & & & & & & \\
\hline Ammonium & NA & NA & NA & NA & NA & NA & NA & NA \\
\hline Nitrate & Linear & 2.54 & 9.06 & 1,5 & 0.015 & $\begin{array}{c}5.7 \\
8\end{array}$ & 0.06 & 0.444 \\
\hline Phosphate & NA & NA & NA & NA & NA & NA & NA & NA \\
\hline
\end{tabular}

Table A5 - Results from model selection using Akaike Information Criteria corrected for small sample sizes (AICc) to select between linear and quadratic models of the effect of N:P ratio of different metrics of coral growth. For each metric, the best model type is listed along with the corresponding fit, AICc score and difference between the two model types.

\begin{tabular}{|l|l|l|l|l|}
\hline & Best Model & $\mathrm{r}^{2}$ & AICc & AAICc \\
\hline Calcification & Quadratic & 0.395 & 15.658 & 2.294 \\
\hline Extension & Quadratic & 0.508 & 30.159 & 2.866 \\
\hline Density & Linear & 0.291 & 0.504 & 28.007 \\
\hline
\end{tabular}


Figure A1 - Cumulative effect sizes for (a) skeletal extension rates for all corals and (b) skeletal density for all corals, in response to enrichment with $N, P$, or N+P. Data are means \pm $95 \%$ confidence intervals. Numbers in parenthesis indicate the number of experiments used to calculate effect sizes. 


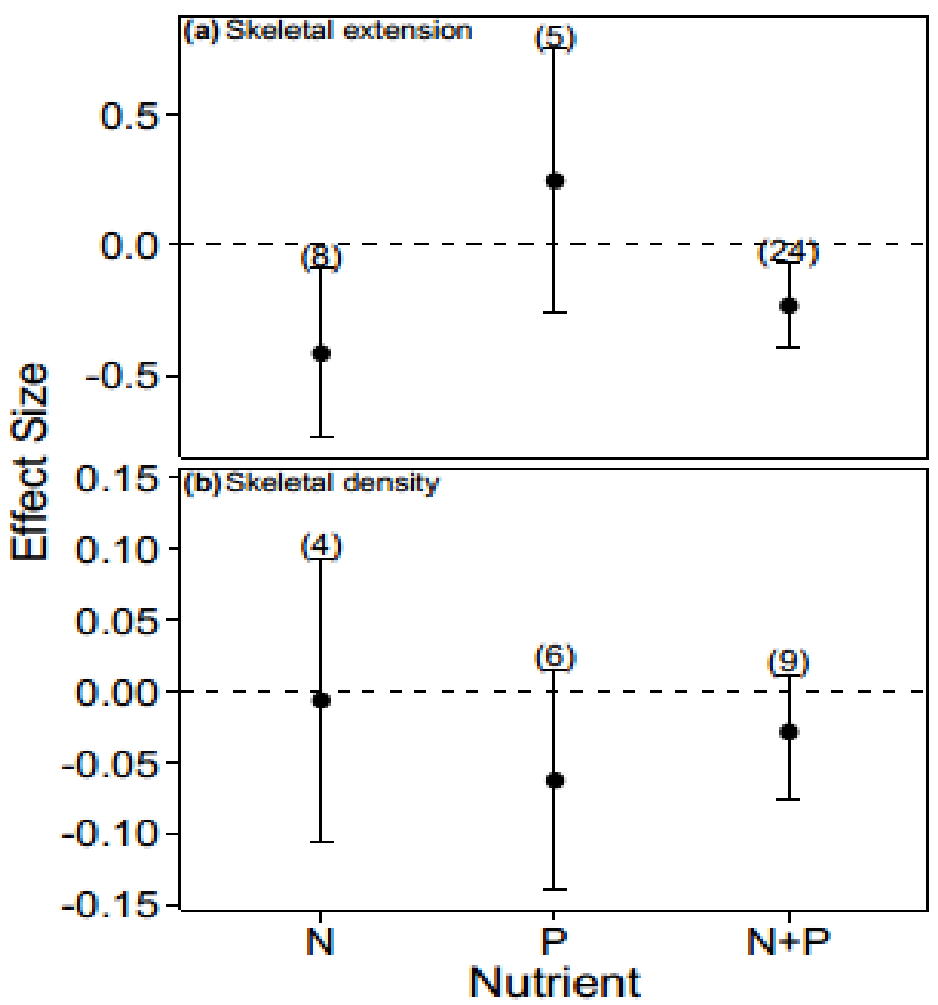


Figure A2 - Regression analysis using best fitting quadratic models of the effect of N:P ratio on effect sizes for coral calcification (left), and skeletal extension rates (right).

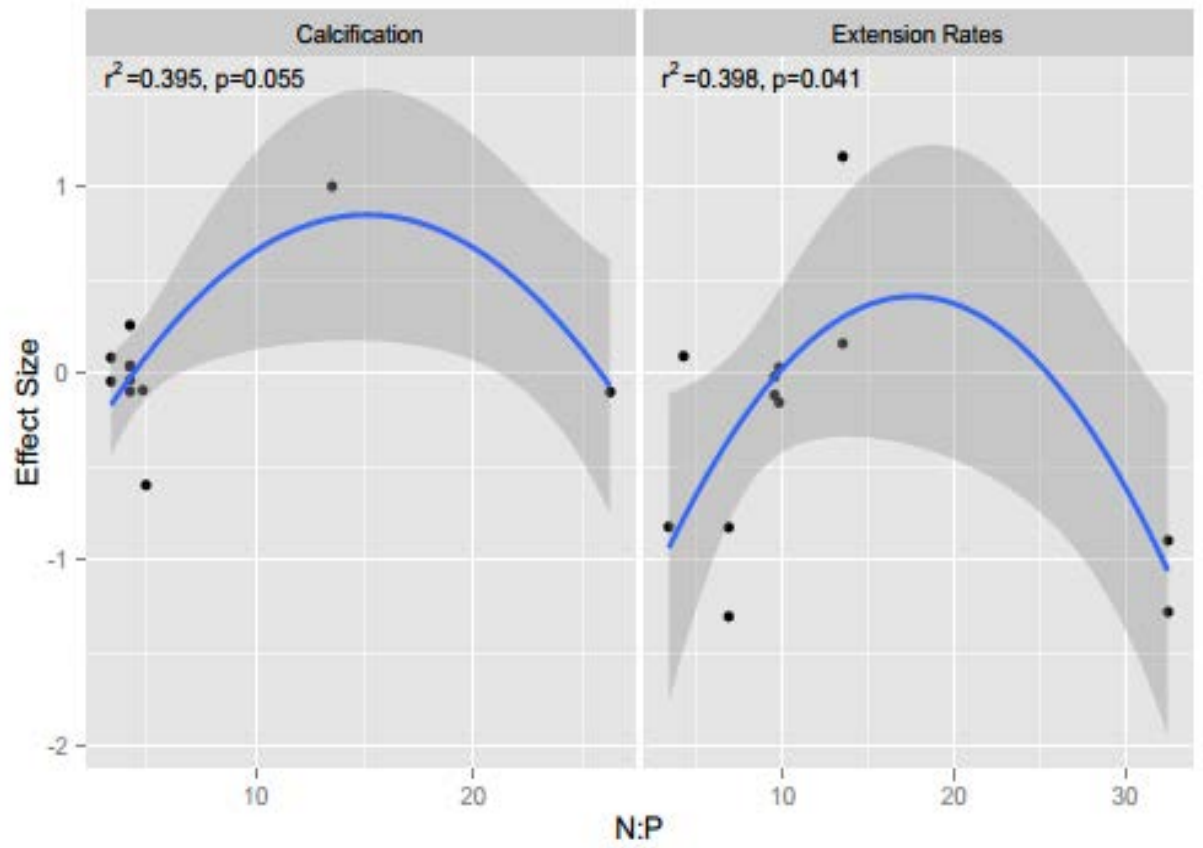


Appendix B: Supplemental tables and figures from Chapter V.

Table B1 - Results of repeated measures ANOVA to assess the biomass of grunts sheltering around study colonies throughout the duration of the study.

\begin{tabular}{|l|l|l|l|l|}
\hline & Numerator DF & $\begin{array}{c}\text { Denominator } \\
\text { DF }\end{array}$ & F-value & p-value \\
\hline Intercept & 1 & 180 & 1861.07 & $<.0001$ \\
\hline $\begin{array}{l}\text { Biomass } \\
\text { Status }\end{array}$ & 1 & 18 & 87.54 & $<.0001$ \\
\hline Time & 10 & 180 & 4.07 & $<.0001$ \\
\hline $\begin{array}{l}\text { Biomass } \\
\text { Status x Time }\end{array}$ & 10 & 180 & 3.65 & $<.0001$ \\
\hline
\end{tabular}


Table B2 - Results from SIMPER analysis for the contribution of dissimilarity between High Biomass vs. Low Biomass sites for each benthic group. Contribution is the mean percent dissimilarity contribution from each benthic category. Cumulative contribution represents the total dissimilarity contribution from multiple groups.

\begin{tabular}{|l|l|l|l|}
\hline Benthic Group & Contribution (\%) & S.D. & $\begin{array}{l}\text { Cumulative } \\
\text { Contribution }\end{array}$ \\
\hline TAS & 26.75 & 18.27 & 26.75 \\
\hline CCA & 24.51 & 14.17 & 51.26 \\
\hline $\begin{array}{l}\text { Brown } \\
\text { Macroalgae }\end{array}$ & 23.97 & 15.75 & 75.23 \\
\hline Turf & 14.46 & 10.72 & 89.69 \\
\hline Red Macroalgae & 3.77 & 2.59 & 93.46 \\
\hline Green Macroalgae & 3.34 & 4.16 & 96.8 \\
\hline Cyanobacteria & 3.2 & 4.91 & 100.00 \\
\hline
\end{tabular}


Figure B1 - Google Earth image of the study location. Numbers indicate location of each of the 20 study colonies, as determined by a diver towing a GPS attached to a dive float. Red numbers are High Biomass sites and white numbers are Low Biomass sites.

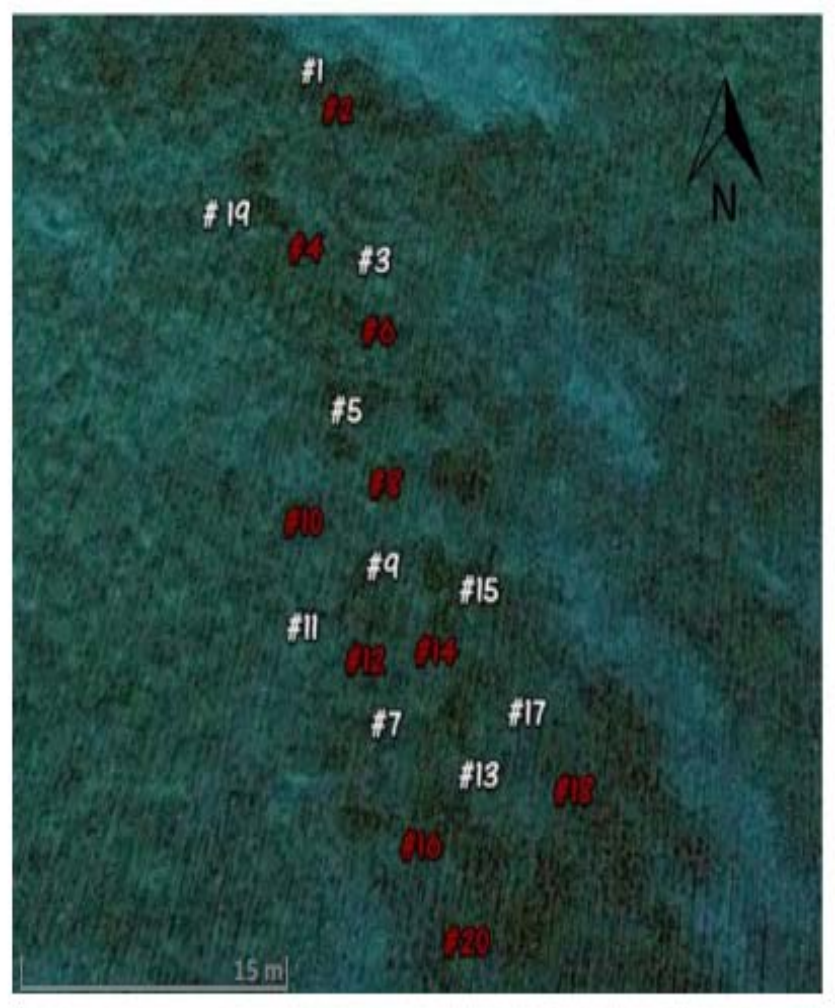


Appendix C: Supplemental tables and figures from Chapter VI.

Table C1 - List of studies used in our analyses. "Type" indicates the mutualism group. "Site" denotes whether the study was conducted in an outdoor field setting (Field) or in a lab or glasshouse (Lab). "Location" provides the country or ocean region where the study took place. "Treat" denotes the type of nutrients provided with multiple nutrients listed if a study contained independent treatments of different nutrients. "N" provides the enrichment level and units for N-enrichments while "P" provides the enrichment level and units for $\mathrm{P}$ enrichments. "Duration" provides the length of the study in days. "Metric $(\mathrm{P} / \mathrm{H})$ " indicates the response metric used to measure the performance for the phototroph partner / the heterotroph partner. "Wtd. Anl." Provides a Yes/No indication of whether or not the study was included in our weighted analysis.

\begin{tabular}{|c|c|c|c|c|c|c|c|c|c|}
\hline Study & Type & Site & Location & Treat & $\mathrm{N}$ & $\mathrm{P}$ & Days & Metric $(\mathrm{P} / \mathrm{H})$ & $\begin{array}{l}\text { Wtd. } \\
\text { Anl. }\end{array}$ \\
\hline Beraud et al. 2013 & Algae-Coral & Lab & Red Sea & $\mathrm{N}$ & $3.4 \mathrm{uM}$ & & 7 & $\begin{array}{l}\text { Cells } \mathrm{cm}^{-2} / \\
\text { Growth } \\
\left(\mu \mathrm{MCaCO}_{3} \mathrm{~cm}^{-2} \mathrm{~h}^{-}\right. \\
\left.{ }^{1}\right)\end{array}$ & $\mathrm{Y}$ \\
\hline Chauvin et al. 2011 & Algae-Coral & Field & La Réunion & $\mathrm{N}$ & $4.86 \mathrm{uM}$ & & 1 & $\begin{array}{l}\text { Cells } \mathrm{cm}^{-2} / \\
\text { Growth (g) }\end{array}$ & $\mathrm{Y}$ \\
\hline $\begin{array}{l}\text { Ferrier-Pages et al. } \\
2001\end{array}$ & Algae-Coral & Lab & Jordan & $\mathrm{N}$ & $2.25 \mathrm{uM}$ & & 63 & $\begin{array}{l}\text { Cells } \mathrm{cm}^{-2} / \\
\text { Growth }\left(\% \mathrm{~d}^{-1}\right)\end{array}$ & $\mathrm{Y}$ \\
\hline Godinot et al. 2011 & Algae-Coral & Lab & Red Sea & $P$ & & $0.5-2.5$ uM & 77 & $\begin{array}{l}\text { Cells } \mathrm{cm}^{-2} / \\
\text { Growth } \\
\left(\mu \mathrm{MCaCO}_{3} \mathrm{~cm}^{-2} \mathrm{~h}^{-}\right. \\
\left.{ }^{1}\right)\end{array}$ & $\mathrm{Y}$ \\
\hline $\begin{array}{l}\text { Langdon and Atkinson } \\
2005\end{array}$ & Algae-Coral & Lab & USA & NP & 109 uM & $13 \mathrm{uM}$ & 4 & $\begin{array}{l}\text { Cells } \mathrm{cm}^{-2} / \\
\left(\mu \mathrm{MCaCO}_{3} \mathrm{~cm}^{-2} \mathrm{~h}^{-}\right. \\
\left.{ }^{1}\right)\end{array}$ & $\mathrm{Y}$ \\
\hline Marubini \& Davies 1996 & Algae-Coral & Lab & Barbados & $\mathrm{N}$ & $1-20 \mathrm{uM}$ & & $30-40$ & $\begin{array}{l}\text { Cells } \mathrm{cm}^{-2} / \\
\text { Growth (mg cm- } \\
{ }^{2} \mathrm{~d}^{-1} \text { ) }\end{array}$ & $\mathrm{Y}$ \\
\hline Marubini \& Thake 1999 & Algae-Coral & Lab & Barbados & $\mathrm{N}$ & $20 \mathrm{uM}$ & & $9-23$ & $\begin{array}{l}\mu \mathrm{g} \text { Chl. a cm} \mathrm{cm}^{-2} / \\
\text { Growth (mg cm } \\
\left.{ }^{2} \mathrm{~d}^{-1}\right)\end{array}$ & $\mathrm{Y}$ \\
\hline
\end{tabular}




\begin{tabular}{|c|c|c|c|c|c|c|c|c|c|}
\hline Mate 1997 & Algae-Coral & Lab & Panama & NP & $4.2 \mathrm{uM}$ & 18.6 uM & & $\begin{array}{l}\text { Cells } \mathrm{cm}^{-2} / \\
\text { Growth }\left(\mathrm{mm} \mathrm{m}^{-1}\right)\end{array}$ & Y \\
\hline $\begin{array}{l}\text { McGuire \& Szmant } \\
1997\end{array}$ & Algae-Coral & Lab & USA & $\mathrm{N}$ & $10 \mathrm{uM}$ & & 28 & $\begin{array}{l}\text { Cells } \mathrm{cm}^{-2} / \mathrm{mg} \mathrm{cm}^{-} \\
\text {- }\end{array}$ & Y \\
\hline Meyer and Schultz 1985 & Algae-Coral & Field & St. Croix & NP & 3.9 uM & & 60 & $\begin{array}{l}\text { Cells } \mathrm{cm}^{-2} / \\
\text { Growth }\left(\mathrm{g} \mathrm{m}^{-1}\right)\end{array}$ & $\mathrm{Y}$ \\
\hline $\begin{array}{l}\text { Muller-Parker et al. } \\
1994\end{array}$ & Algae-Coral & Lab & USA & $\mathrm{N}$ & $20-50$ uM & & 49 & $\begin{array}{l}\text { Cells } \mathrm{cm}^{-2} / \\
\text { Biomass }\left(\mathrm{mg} \mathrm{cm}^{-2}\right)\end{array}$ & Y \\
\hline $\begin{array}{l}\text { Steven and Broadbent } \\
1997\end{array}$ & Algae-Coral & Field & Australia & $\begin{array}{l}N, P \\
N P\end{array}$ & $20 \mu \mathrm{M}$ & $4 \mu \mathrm{M}$ & 365 & $\begin{array}{l}\text { Cells } \mathrm{cm}^{-2} / \\
\text { Growth }\left(\% \mathrm{~d}^{-1}\right)\end{array}$ & Y \\
\hline Stambler et al. 1991 & Algae-Coral & Lab & USA & $N, N P$ & 15 uM & $0.5-2 \mathrm{uM}$ & 28 & $\begin{array}{l}\text { Cells } \mathrm{cm}^{-2} / \\
\text { Growth }\left(\mathrm{mm} \mathrm{d}^{-1}\right)\end{array}$ & Y \\
\hline $\begin{array}{l}\text { Ambariyanto and } \\
\text { Hoegh-Guldberg } 1997\end{array}$ & Algae-Clam & Field & Australia & $\begin{array}{l}N, P \\
N P\end{array}$ & $10 \mathrm{uM}$ & $2 \mathrm{uM}$ & 365 & $\begin{array}{l}\text { Cells } \mathrm{Clam}^{-1} / \\
\left.\text { Biomass } \% \mathrm{~d}^{-1}\right)\end{array}$ & Y \\
\hline Belda et al. 1993 & Algae-Clam & Lab & Australia & $\begin{array}{l}N, P, \\
N P\end{array}$ & 5-10 uM & $2-10$ uM & 90 & $\begin{array}{l}\text { Cells } g^{-1} \text { tissue/ } \\
\text { Growth }(\Delta \mathrm{g})\end{array}$ & Y \\
\hline Braley et al. 1992 & Algae-Clam & Lab & Australia & NP & $20-40$ uM & $2.3 \mathrm{uM}$ & 91 & $\begin{array}{l}\text { Cells } \mathrm{g}^{-1} \text { tissue/ } \mathrm{g} \\
\mathrm{mm}^{-1} \text { shell }\end{array}$ & Y \\
\hline Grice and Bell 1997 & Algae-Clam & Lab & $\begin{array}{l}\text { Solomon } \\
\text { Islands }\end{array}$ & $\mathrm{N}$ & $40 \mu \mathrm{M}$ & & 45 & $\begin{array}{l}\text { Cells } g^{-1} \text { tissue/ } \\
\text { Biomass }(\Delta g)\end{array}$ & $Y$ \\
\hline Grice and Bell 1999 & Algae-Clam & Lab & $\begin{array}{l}\text { Solomon } \\
\text { Islands }\end{array}$ & $\mathrm{N}$ & $35-80$ uM & & 25 & $\begin{array}{l}\text { Cells Clam }{ }^{-1} / \\
\text { Biomass }\left(\mathrm{mg} \mathrm{d}^{-1}\right)\end{array}$ & Y \\
\hline Dahlman et al. 2002 & $\begin{array}{l}\text { Algae/ } \\
\text { Cyano- } \\
\text { Fungi }\end{array}$ & Field & Sweden & $N, N P$ & $\begin{array}{l}20 \mathrm{mg} \mathrm{m}^{-} \\
{ }^{2} \text { twice }^{-1} \text { week }^{-1}\end{array}$ & NA & 90 & $\begin{array}{l}\text { Chl.a }\left(\mathrm{mg} \mathrm{cm}^{-2}\right) / \\
\text { Chitin }\left(\mathrm{mg} \mathrm{cm}^{2}\right)\end{array}$ & Y \\
\hline Gaio-Oliveira et al. 2004 & $\begin{array}{l}\text { Algae/ } \\
\text { Cyano- } \\
\text { Fungi }\end{array}$ & Field & Portugal & $\mathrm{N}$ & $\begin{array}{l}0.6-9.6 \mathrm{~g} \mathrm{~m}^{-} \\
{ }^{2} \text { week }^{-1}\end{array}$ & & 308 & $\begin{array}{l}\text { Chl. a }\left(\mathrm{mg} \mathrm{cm}^{-2}\right) / \\
\text { Chitin }\left(\mathrm{mg} \mathrm{cm}^{2}\right)\end{array}$ & Y \\
\hline Johannsson et al. 2011 & $\begin{array}{l}\text { Algae/ } \\
\text { Cyano- } \\
\text { Fungi }\end{array}$ & Field & Sweden & $\begin{array}{l}N, P \\
N P\end{array}$ & $\begin{array}{l}2.5 \mathrm{mM} \text { in } 1.6 \\
\text { I day }\end{array}$ & $\begin{array}{l}0.037 \mathrm{mM}^{\mathrm{m}} \\
1.6 \mathrm{Iday}^{-1}\end{array}$ & 62 & $\begin{array}{l}\text { Growth (mg dry } \\
\text { weight)/ Growth } \\
\text { (mg dry weight) }\end{array}$ & Y \\
\hline $\begin{array}{l}\text { Aggangan and Moon } \\
2013\end{array}$ & $\begin{array}{l}\text { Plant-AM } \\
\text { Fungi }\end{array}$ & Lab & Korea & $\mathrm{P}$ & & $\begin{array}{l}0.03-0.27 \mathrm{mg} \\
\mathrm{kg}^{-1}\end{array}$ & 120 & $\begin{array}{l}\text { Biomass }(\mathrm{g}) / \% \\
\text { Root Col. }\end{array}$ & Y \\
\hline
\end{tabular}




\begin{tabular}{|c|c|c|c|c|c|c|c|c|c|}
\hline $\begin{array}{l}\text { Anderson and Liberta } \\
1992\end{array}$ & $\begin{array}{l}\text { Plant-AM } \\
\text { Fungi }\end{array}$ & Field & USA & $N, P$ & $165 \mathrm{ml} \mathrm{m}^{-2}$ & $165 \mathrm{ml} \mathrm{m}^{-2}$ & 469 & $\begin{array}{l}\text { Biomass }(\mathrm{g}) / \% \\
\text { Root Col. }\end{array}$ & $\mathrm{Y}$ \\
\hline Baon et al. 1993 & $\begin{array}{l}\text { Plant-AM } \\
\text { Fungi }\end{array}$ & Lab & Australia & $P$ & & $10-20 \mathrm{mg} \mathrm{kg}^{-1}$ & 42 & $\begin{array}{l}\text { Biomass }(\mathrm{g}) / \% \\
\text { Root Col. }\end{array}$ & $\mathrm{Y}$ \\
\hline Bi et al. 2003 & $\begin{array}{l}\text { Plant-AM } \\
\text { Fungi }\end{array}$ & Lab & Ireland & $P$ & & $100 \mathrm{mg} \mathrm{kg}-1$ & 40 & $\begin{array}{l}\text { Biomass }(\mathrm{g}) / \% \\
\text { Root Col. }\end{array}$ & $\mathrm{N}$ \\
\hline Blanke et al. 2011 & $\begin{array}{l}\text { Plant-AM } \\
\text { Fungi }\end{array}$ & Field & Germany & $\mathrm{N}$ & $8.5 \mathrm{~g} \mathrm{~m}^{-2} \mathrm{y}^{-1}$ & & 1460 & $\begin{array}{l}\text { Biomass (g)/ \% } \\
\text { Root Col. }\end{array}$ & $\mathrm{Y}$ \\
\hline Borowicz 1997 & $\begin{array}{l}\text { Plant-AM } \\
\text { Fungi }\end{array}$ & Lab & USA & $P$ & & $0.4 \mathrm{mM}$ & 84 & $\begin{array}{l}\text { Biomass }(\mathrm{g}) / \% \\
\text { Root Col. }\end{array}$ & $\mathrm{Y}$ \\
\hline Grogan \& Chapin & $\begin{array}{l}\text { Plant-AM } \\
\text { Fungi }\end{array}$ & Field & USA & $\begin{array}{l}N, P \\
N P\end{array}$ & $20 \mathrm{~g} \mathrm{~m}^{-2}$ & $20 \mathrm{~g} \mathrm{~m}^{-2}$ & 56 & $\begin{array}{l}\text { Biomass }(\mathrm{g}) / \% \\
\text { Root Col. }\end{array}$ & $\mathrm{Y}$ \\
\hline Hartwig et al. 2002 & $\begin{array}{l}\text { Plant-AM } \\
\text { Fungi }\end{array}$ & Lab & Switzerland & $\mathrm{N}$ & $4.5 \mathrm{mM}$ & & $42-60$ & $\begin{array}{l}\text { Biomass }(\mathrm{g}) / \% \\
\text { Root Col. }\end{array}$ & $\mathrm{N}$ \\
\hline Jeyanny et al. 2011 & $\begin{array}{l}\text { Plant-AM } \\
\text { Fungi }\end{array}$ & Lab & Malaysia & NP & $100 \mathrm{mg} \mathrm{kg}^{-1}$ & $100 \mathrm{mg} \mathrm{kg}^{-1}$ & 90 & $\begin{array}{l}\text { Biomass (g)/ \% } \\
\text { Root Col. }\end{array}$ & $\mathrm{Y}$ \\
\hline Johnson et al. 2015 & $\begin{array}{l}\text { Plant-AM } \\
\text { Fungi }\end{array}$ & Lab & USA & $\begin{array}{l}N, P \\
N P\end{array}$ & $\begin{array}{l}2.3-8.6 \mu g^{-} \\
1\end{array}$ & $55 \mu \mathrm{g} \mathrm{g}^{-1}$ & 98 & $\begin{array}{l}\text { Biomass (g)/ } \\
\text { HyphMass (m g- } \\
{ }^{1} \text { soil) }\end{array}$ & $\mathrm{Y}$ \\
\hline Karaca et al. 2013 & $\begin{array}{l}\text { Plant-AM } \\
\text { Fungi }\end{array}$ & Lab & Turkey & $P$ & & 100 mg kg-1 & 45 & $\begin{array}{l}\text { Biomass (g)/ \% } \\
\text { Root Col. }\end{array}$ & $\mathrm{Y}$ \\
\hline Lagrange et al. 2013 & $\begin{array}{l}\text { Plant-AM } \\
\text { Fungi }\end{array}$ & Field & $\begin{array}{l}\text { New } \\
\text { Caledonia }\end{array}$ & $\begin{array}{l}N, P, \\
N P\end{array}$ & $500 \mathrm{~kg} \mathrm{ha}^{-1}$ & $200 \mathrm{~kg} \mathrm{ha}^{-1}$ & 730 & $\begin{array}{l}\text { Biomass }(\mathrm{g}) / \% \\
\text { Root Col. }\end{array}$ & $\mathrm{Y}$ \\
\hline LeCroy et al. 2013 & $\begin{array}{l}\text { Plant-AM } \\
\text { Fungi }\end{array}$ & Lab & USA & $\mathrm{N}$ & $\begin{array}{l}34 \text { kg ha- }^{-} \\
{ }^{1} \text { week }^{-1}\end{array}$ & & 28 & $\begin{array}{l}\text { Biomass }(\mathrm{g}) / \% \\
\text { Root Col. }\end{array}$ & $\mathrm{Y}$ \\
\hline Li et al. 2012 & $\begin{array}{l}\text { Plant-AM } \\
\text { Fungi }\end{array}$ & Field & China & $P$ & & $175 \mathrm{mg} \mathrm{kg}^{-1}$ & & $\begin{array}{l}\text { Biomass (g) } \\
\text { /HyphMass (g m- } \\
\text { 1) }\end{array}$ & $\mathrm{Y}$ \\
\hline Liu et al. 2012 & $\begin{array}{l}\text { Plant-AM } \\
\text { Fungi }\end{array}$ & Field & China & NP & $\begin{array}{l}6.4-25.4 \mathrm{~g} \mathrm{~m}^{-} \\
{ }^{2} \mathrm{y}^{-1}\end{array}$ & $7-28.2 \mathrm{~g} \mathrm{~m}^{-2} \mathrm{y}^{-1}$ & 2900 & $\begin{array}{l}\text { Growth (kg m } \\
\left.{ }^{2}\right) / \text { HyphMass (g } \\
\mathrm{m}^{-1} \text { ) }\end{array}$ & $\mathrm{Y}$ \\
\hline Montalba et al. 2010 & $\begin{array}{l}\text { Plant-AM } \\
\text { Fungi }\end{array}$ & Lab & Chile & $\mathrm{N}$ & $60 \mathrm{~kg} \mathrm{ha}^{-1} \mathrm{y}^{-1}$ & & 100 & $\begin{array}{l}\text { Biomass (g)/ \% } \\
\text { Root Col. }\end{array}$ & $\mathrm{Y}$ \\
\hline
\end{tabular}




\begin{tabular}{|c|c|c|c|c|c|c|c|c|c|}
\hline $\begin{array}{l}\text { Ochoa-Hueso et al. } \\
2013\end{array}$ & $\begin{array}{l}\text { Plant-AM } \\
\text { Fungi }\end{array}$ & Field & Spain & $\mathrm{N}$ & $\begin{array}{l}10-50 \mathrm{~kg} \mathrm{ha} \\
{ }^{1} \mathrm{y}^{-1}\end{array}$ & & 540 & $\begin{array}{l}\text { Biomass }(\mathrm{g}) / \% \\
\text { Root Col. }\end{array}$ & $Y$ \\
\hline Ortas 2012 & $\begin{array}{l}\text { Plant-AM } \\
\text { Fungi }\end{array}$ & Lab & Turkey & $P$ & & $25-125 \mathrm{mg} \mathrm{kg}^{-1}$ & 51 & $\begin{array}{l}\text { Biomass }(\mathrm{g}) / \% \\
\text { Root Col. }\end{array}$ & $\mathrm{Y}$ \\
\hline $\begin{array}{l}\text { Sangabriel-Conde et al. } \\
2014\end{array}$ & $\begin{array}{l}\text { Plant-AM } \\
\text { Fungi }\end{array}$ & Lab & Mexico & $P$ & & $65 \mathrm{mg} \mathrm{kg}^{-1}$ & 120 & $\begin{array}{l}\text { Biomass }(\mathrm{g}) / \% \\
\text { Root Col. }\end{array}$ & $\mathrm{Y}$ \\
\hline $\begin{array}{l}\text { Schroeder-Moreno et } \\
\text { al. } 2012\end{array}$ & $\begin{array}{l}\text { Plant-AM } \\
\text { Fungi }\end{array}$ & Lab & USA & $\mathrm{N}$ & $\begin{array}{l}8-100 \mathrm{~kg} \mathrm{ha}^{-} \\
{ }^{1} \mathrm{y}^{-1}\end{array}$ & & 84 & $\begin{array}{l}\text { Biomass }(\mathrm{g}) / \% \\
\text { Root Col. }\end{array}$ & $Y$ \\
\hline Tawaraya et al. 2012 & $\begin{array}{l}\text { Plant-AM } \\
\text { Fungi }\end{array}$ & Lab & Japan & $P$ & & $\begin{array}{l}300-1500 \mathrm{mg} \\
\mathrm{kg}^{-1}\end{array}$ & 167 & $\begin{array}{l}\text { Growth }(\mathrm{g}) / \% \\
\text { Root Col. }\end{array}$ & $\mathrm{Y}$ \\
\hline Waceke et al. 2002 & $\begin{array}{l}\text { Plant-AM } \\
\text { Fungi }\end{array}$ & Lab & Kenya & $P$ & & $\begin{array}{l}150-300 \mathrm{mg} \mathrm{m}^{-} \\
\end{array}$ & 150 & $\begin{array}{l}\text { Biomass (g)/ \% } \\
\text { Root Col. }\end{array}$ & $\mathrm{N}$ \\
\hline $\begin{array}{l}\text { Watts-Williams et al. } \\
2013\end{array}$ & $\begin{array}{l}\text { Plant-AM } \\
\text { Fungi }\end{array}$ & Lab & Australia & $P$ & & $20-100 \mathrm{mg} \mathrm{kg}^{-1}$ & 63 & $\begin{array}{l}\text { Biomass }(\mathrm{g}) / \% \\
\text { Root Col. }\end{array}$ & $Y$ \\
\hline Allen et al. 2010 & $\begin{array}{l}\text { Plant- } \\
\text { AM/EM } \\
\text { Fungi }\end{array}$ & Field & USA & $\mathrm{N}$ & $10 \mathrm{~g} \mathrm{~m}^{-2} \mathrm{y}^{-1}$ & & 2190 & $\begin{array}{l}\text { Growth (g)/ } \\
\text { Myco. Root tips }\end{array}$ & $\mathrm{N}$ \\
\hline Bougher et al. 1990 & $\begin{array}{l}\text { Plant-EM } \\
\text { Fungi }\end{array}$ & Lab & Australia & $P$ & & $\begin{array}{l}0.17-0.23 \mathrm{mg} \\
\mathrm{kg}^{-1} \text { day }^{-1}\end{array}$ & 120 & $\begin{array}{l}\text { Biomass (mg)/ EM } \\
\text { Roots }\end{array}$ & $\mathrm{N}$ \\
\hline Mason et al. 2000 & $\begin{array}{l}\text { Plant-EM } \\
\text { Fungi }\end{array}$ & Lab & Chile & $\begin{array}{l}N, P \\
N P\end{array}$ & $35-71 \mathrm{mg} \mathrm{l}^{-1}$ & $\begin{array}{l}7 \mathrm{mg} \mathrm{l}^{-1}, 4 \\
\text { times week }^{-1}\end{array}$ & 84 & $\begin{array}{l}\text { Biomass }(\mathrm{g}) / \% \\
\text { Root Col. }\end{array}$ & $\mathrm{N}$ \\
\hline $\begin{array}{l}\text { Oskarsson \& } \\
\text { Halldorsson } 2008\end{array}$ & $\begin{array}{l}\text { Plant-EM } \\
\text { Fungi }\end{array}$ & Field & Iceland & $\begin{array}{l}N, P \\
N P\end{array}$ & $\begin{array}{l}1.5-24.2 \mathrm{~g} \\
\text { seedling }^{-1}\end{array}$ & $\begin{array}{l}11.1-55.6 \mathrm{~g} \\
\text { seedling }^{-1}\end{array}$ & 1095 & $\begin{array}{l}\text { Biomass }(\mathrm{g}) / \% \\
\text { Root Col. }\end{array}$ & $Y$ \\
\hline Pampolina et al. 2002 & $\begin{array}{l}\text { Plant - EM } \\
\text { Fungi }\end{array}$ & Field & Australia & $P$ & & $\begin{array}{l}100-1000 \mathrm{~kg} \\
\mathrm{ha}^{-1}\end{array}$ & 365 & $\begin{array}{l}\text { Biomass (g)/ } \\
\text { HyphMass (mg g- } \\
{ }^{1} \text { soil) }\end{array}$ & $\mathrm{Y}$ \\
\hline Shaw et al. 1987 & $\begin{array}{l}\text { Plant-EM } \\
\text { Fungi }\end{array}$ & Lab & Great Britain & NP & $360 \mathrm{~g} \mathrm{~m}^{-3}$ & $210 \mathrm{~g} \mathrm{~m}^{-3}$ & 98 & $\begin{array}{l}\text { Biomass (g)/ \% } \\
\text { Root Col. }\end{array}$ & $\mathrm{N}$ \\
\hline Abbasi et al. 2010 & $\begin{array}{l}\text { Plant- } \\
\text { Bacteria }\end{array}$ & Lab & Pakistan & $P$ & & & & $\begin{array}{l}\text { Biomass (g plant } \\
\left.{ }^{1}\right) / \text { Nod.Mass (g }^{-} \\
\text {plant }^{-1} \text { ) }\end{array}$ & $\mathrm{N}$ \\
\hline Batterman et al. 2013 & $\begin{array}{l}\text { Plant- } \\
\text { Bacteria }\end{array}$ & Lab & Panama & $P, N P$ & & $\begin{array}{l}24.71-219.78 \\
\mathrm{mg} \mathrm{m}^{-2}\end{array}$ & 182 & $\begin{array}{l}\text { Biomass }(\mathrm{g}) / \\
\text { Nod.Mass (mg g- } \\
{ }^{1} \text { plant) }\end{array}$ & $\mathrm{Y}$ \\
\hline
\end{tabular}




\begin{tabular}{|c|c|c|c|c|c|c|c|c|c|}
\hline Dumroese et al. 2009 & $\begin{array}{l}\text { Plant- } \\
\text { Bacteria }\end{array}$ & Lab & USA & NP & $\begin{array}{l}0.35-1.79 \mathrm{~kg} \\
\mathrm{~m}^{-3}\end{array}$ & $0.2-1.07 \mathrm{~kg} \mathrm{~m}^{-3}$ & 84 & $\begin{array}{l}\text { Biomass (g plant } \\
\left.{ }^{1}\right) / \text { Nod.Mass (mg }^{-} \\
\text {plant }^{-1} \text { ) }\end{array}$ & $Y$ \\
\hline Erman et al. 2009 & $\begin{array}{l}\text { Plant- } \\
\text { Bacteria }\end{array}$ & Field & Turkey & $\mathrm{P}$ & & $30-90 \mathrm{~kg} \mathrm{ha}^{-1}$ & 250 & $\begin{array}{l}\text { Biomass (g plant } \\
\left.{ }^{1}\right) / \text { Nod. Plant }^{-1}\end{array}$ & Y \\
\hline Eskew et al. 1989 & $\begin{array}{l}\text { Plant- } \\
\text { Bacteria }\end{array}$ & Lab & Austria & $\mathrm{N}$ & $7.5-450 \mathrm{mg}$ & & 82 & $\begin{array}{l}\text { Biomass (g plant } \\
\left.{ }^{1}\right) / \text { Nod.Mass (mg }^{-} \\
\text {plant }^{-1} \text { ) }\end{array}$ & $\mathrm{N}$ \\
\hline $\begin{array}{l}\text { Gibson and Harper } \\
1985\end{array}$ & $\begin{array}{l}\text { Plant- } \\
\text { Bacteria }\end{array}$ & Lab & Australia & $\mathrm{N}$ & $0.5-1 \mathrm{mM}$ & & 10 & $\begin{array}{l}\text { Biomass (g plant } \\
\left.{ }^{1}\right) / \text { Nod. Plant }^{-1}\end{array}$ & $\mathrm{~N}$ \\
\hline Hungria et al. 2006 & $\begin{array}{l}\text { Plant- } \\
\text { Bacteria }\end{array}$ & Field & Brazil & $\mathrm{N}, \mathrm{P}$ & & & & $\begin{array}{l}\text { Biomass (g plant } \\
\left.{ }^{1}\right) / \text { Nod.Mass (mg }^{-} \\
\text {plant }^{-1} \text { ) }\end{array}$ & $\mathrm{N}$ \\
\hline Laberge et al. 2005 & $\begin{array}{l}\text { Plant- } \\
\text { Bacteria }\end{array}$ & Lab & Canada & $\mathrm{N}$ & & & 70 & $\begin{array}{l}\text { Biomass (mg } \\
\text { plant }^{-1} \text { )/ Nod. \# }\end{array}$ & $\mathrm{N}$ \\
\hline Malik et al. 2014 & $\begin{array}{l}\text { Plant- } \\
\text { Bacteria }\end{array}$ & Field & Pakistan & $\mathrm{N}$ & & & & $\begin{array}{l}\text { Biomass (g plant } \\
\left.{ }^{1}\right) / \text { Nod.Mass (mg }^{-} \\
\text {plant }^{-1} \text { ) }\end{array}$ & $\mathrm{N}$ \\
\hline Milton et al. 2000 & $\begin{array}{l}\text { Plant- } \\
\text { Bacteria }\end{array}$ & Field & Brazil & $\mathrm{N}$ & $\begin{array}{l}50.1-300 \mathrm{mg} \\
\mathrm{m}^{-2}\end{array}$ & & $20-35$ & $\begin{array}{l}\text { Biomass (g plant } \\
\left.{ }^{1}\right) / \text { Nod.Mass (mg }^{-} \\
\text {plant }^{-1} \text { ) }\end{array}$ & $\mathrm{N}$ \\
\hline Namvar et al. 2011 & $\begin{array}{l}\text { Plant- } \\
\text { Bacteria }\end{array}$ & Field & Iran & $\mathrm{N}$ & $\begin{array}{l}50-100 \mathrm{~kg} \mathrm{ha}^{-} \\
1\end{array}$ & & & $\begin{array}{l}\text { Biomass }\left(\mathrm{kg} \mathrm{ha}^{-1}\right) / \\
\text { Nod.Mass }(\mathrm{mg} \\
\left.\text { plant }^{-1}\right)\end{array}$ & $Y$ \\
\hline Nelson 1987 & $\begin{array}{l}\text { Plant- } \\
\text { Bacteria }\end{array}$ & Lab & Canada & $\mathrm{N}$ & $2-5 \mathrm{mM}$ & & $104-106$ & $\begin{array}{l}\text { Biomass (g plant } \\
\left.{ }^{1}\right) / \text { Nod. Plant }^{-1}\end{array}$ & $Y$ \\
\hline Ouertatanit et al. 2011 & $\begin{array}{l}\text { Plant- } \\
\text { Bacteria }\end{array}$ & Lab & Tunisia & $\mathrm{P}$ & & & & $\begin{array}{l}\text { Biomass (g plant } \\
\left.{ }^{1}\right) / \text { Nod.Mass (g }^{-} \\
\text {plant }^{-1} \text { ) }\end{array}$ & $\mathrm{N}$ \\
\hline Park and Buttery 1989 & $\begin{array}{l}\text { Plant- } \\
\text { Bacteria }\end{array}$ & Lab & Canada & $\mathrm{N}$ & $3.5-10.5 \mathrm{mM}$ & & 40 & $\begin{array}{l}\text { Biomass (g plant } \\
\left.{ }^{1}\right) / \text { Nod.Mass (mg }^{-} \\
\text {plant }^{-1} \text { ) }\end{array}$ & $Y$ \\
\hline
\end{tabular}




\begin{tabular}{|c|c|c|c|c|c|c|c|c|c|}
\hline Sanginga et al. 1996 & $\begin{array}{l}\text { Plant - } \\
\text { Bacteria }\end{array}$ & Lab & Nigeria & $P$ & & $7 \mathrm{~kg} \mathrm{ha}^{-1}$ & 98 & $\begin{array}{l}\text { Biomass (g plant } \\
\left.{ }^{1}\right) / \text { Nod.Mass (mg }^{-} \\
\text {plant }^{-1} \text { ) }\end{array}$ & $\mathrm{N}$ \\
\hline Seneviratne et al. 2000 & $\begin{array}{l}\text { Plant- } \\
\text { Bacteria }\end{array}$ & Field & Sri Lanka & NP & & & & $\begin{array}{l}\text { Biomass (g plant } \\
\left.{ }^{1}\right) / \text { Nod.Mass (g }^{-} \\
\text {plant }^{-1} \text { ) }\end{array}$ & Y \\
\hline Shahzad et al. 2014 & $\begin{array}{l}\text { Plant- } \\
\text { Bacteria }\end{array}$ & Field & Pakistan & $P$ & & $100 \mathrm{~g} \mathrm{~kg}^{-1}$ & & $\begin{array}{l}\text { Biomass }\left(\mathrm{t} \mathrm{ha}^{-1}\right) / \\
\text { Nod.Mass (g } \\
\text { plant }^{-1} \text { ) }\end{array}$ & Y \\
\hline Sheoran et al. 1997 & $\begin{array}{l}\text { Plant- } \\
\text { Bacteria }\end{array}$ & Field & India & $\mathrm{N}$ & $100 \mathrm{~kg} \mathrm{ha}^{-1}$ & & 60 & $\begin{array}{l}\text { Biomass }\left(\mathrm{kg} \mathrm{ha}^{-1}\right) / \\
\text { Nod.Mass }(\mathrm{mg} \\
\left.\text { plant }^{-1}\right)\end{array}$ & $\mathrm{N}$ \\
\hline Singleton et al. 1985 & $\begin{array}{l}\text { Plant- } \\
\text { Bacteria }\end{array}$ & Lab & USA & $P$ & & $50-400 \mathrm{mg} \mathrm{kg}^{-1}$ & 33 & $\begin{array}{l}\text { Biomass (g plant } \\
\left.{ }^{1}\right) / \text { Nod.Mass (mg }^{-} \\
\text {plant }^{-1} \text { ) }\end{array}$ & $\mathrm{N}$ \\
\hline Tahir et al. 2009 & $\begin{array}{l}\text { Plant- } \\
\text { Bacteria }\end{array}$ & Field & Pakistan & $\begin{array}{l}N, P, \\
N P\end{array}$ & $25-50 \mathrm{~kg} \mathrm{ha}^{-1}$ & $90 \mathrm{~kg} \mathrm{ha}^{-1}$ & 150 & $\begin{array}{l}\text { Biomass (g plant } \\
\left.{ }^{1}\right) / \text { Nod.Mass (g }^{-} \\
\text {plant }^{-1} \text { ) }\end{array}$ & $\mathrm{N}$ \\
\hline Temperton et al. 2003 & $\begin{array}{l}\text { Plant- } \\
\text { Bacteria }\end{array}$ & Field & Scotland & $\mathrm{N}$ & & $24.71 \mathrm{mg} \mathrm{m}^{-2}$ & 850 & $\begin{array}{l}\text { Growth (mg g- } \\
{ }^{1} \text { day)/ Nod.Mass } \\
\text { ( } \mathrm{g} \mathrm{g}^{-1} \text { root) }\end{array}$ & Y \\
\hline Thies et al 1995 & $\begin{array}{l}\text { Plant- } \\
\text { Bacteria }\end{array}$ & Field & USA & $\mathrm{N}$ & $900 \mathrm{~kg} \mathrm{ha}^{-1}$ & & 40 & $\begin{array}{l}\text { Biomass }\left(\mathrm{kg} \mathrm{ha}^{-1}\right) / \\
\text { Nod.Mass }\left(\mathrm{mg}^{-}\right. \\
\left.\text {plant }^{-1}\right)\end{array}$ & $\mathrm{N}$ \\
\hline Thomas et al. 2000 & $\begin{array}{l}\text { Plant- } \\
\text { Bacteria }\end{array}$ & Lab & Costa Rica & $\mathrm{N}$ & & & 100 & $\begin{array}{l}\text { Biomass (g plant } \\
\left.{ }^{1}\right) / \text { Nod.Mass (g }^{-} \\
\text {plant }^{-1} \text { ) }\end{array}$ & Y \\
\hline Valladares et al. 2002 & $\begin{array}{l}\text { Plant- } \\
\text { Bacteria }\end{array}$ & Lab & Spain & $\mathrm{N}$ & & & 95 & $\begin{array}{l}\text { Biomass (g)/ } \\
\text { Nod.Mass (g } \\
\text { plant }^{-1} \text { ) }\end{array}$ & Y \\
\hline Vankosky et al. 2011 & $\begin{array}{l}\text { Plant- } \\
\text { Bacteria }\end{array}$ & Field & Canada & $\mathrm{N}$ & $60 \mathrm{~kg} \mathrm{ha}^{-1}$ & & $\sim 60$ & $\begin{array}{l}\text { Biomass (g plant } \\
\left.{ }^{1}\right) / \text { Nod. Plant }^{-1}\end{array}$ & Y \\
\hline
\end{tabular}


Zaman-Allah et al. 2007

\begin{tabular}{l|l|l}
$\begin{array}{l}\text { Plant- } \\
\text { Bacteria }\end{array}$ & Lab & Tunisia \\
\hline
\end{tabular}

P

\begin{tabular}{l|l}
$\mathrm{P}$ \\
\end{tabular}

200 mg plant $^{-1}$

Biomass (g plant

$\left.{ }^{1}\right) /$ Nod.Mass (mg

plant $^{-1}$ ) 
Table C2 - Calculated slopes and the probability that slopes differ from zero for Bayesian Type II regressions of phototroph versus heterotroph response ratios for weighted and unweighted analyses. $\mathrm{N}$ indicates the number of experiments available for the regressions.

\begin{tabular}{|c|c|c|}
\hline Mutualism Type & Unweighted Analysis & Weighted Analysis \\
\hline Algae-Clam & $\begin{array}{c}\text { Slope }=0.51 \\
\text { Pr }(\text { Slope }>0)=0.99 \\
\text { Pseudo- } \mathrm{R}^{2}=0.43 \\
\mathrm{~N}=19\end{array}$ & $\begin{array}{c}\text { Slope }=0.48, \\
\text { Pr }(\text { Slope }>0)=0.96 \\
\text { Pseudo- } \mathrm{R}^{2}=0.28 \\
\mathrm{~N}=19\end{array}$ \\
\hline Algae-Coral & $\begin{array}{c}\text { Slope }=-0.32, \\
\text { Pr(Slope }<0)>0.99 \\
\text { Pseudo- } \mathrm{R}^{2}=0.14 \\
\mathrm{~N}=31\end{array}$ & $\begin{array}{c}\text { Slope }=-0.25, \\
\operatorname{Pr}(\text { Slope }<0)=0.98 \\
\text { Pseudo- } \mathrm{R}^{2}=0.14 \\
\mathrm{~N}=31\end{array}$ \\
\hline Algae/ Cyano-Fungi & $\begin{array}{c}\text { Slope }=-0.24 \\
\text { Pr(Slope }<0)=0.95 \\
\text { Pseudo- }{ }^{2}=0.18 \\
N=19\end{array}$ & $\begin{array}{c}\text { Slope }=0.04, \\
\operatorname{Pr}(\text { Slope }>0)=0.59 \\
\text { Pseudo- } \mathrm{R}^{2}=0.0 \\
\mathrm{~N}=19\end{array}$ \\
\hline Plant- AM Fungi & $\begin{array}{c}\text { Slope }=0.11, \\
\text { Pr(Slope }>0)=0.82 \\
\text { Pseudo- } \mathrm{R}^{2}=0.01 \\
\mathrm{~N}=84\end{array}$ & $\begin{array}{c}\text { Slope }=0.08, \\
\text { Pr(Slope }>0)=0.80 \\
\text { Pseudo- } \mathrm{R}^{2}=0.01 \\
\mathrm{~N}=76\end{array}$ \\
\hline Plant- EM Fungi & $\begin{array}{c}\text { Slope }=-0.40 \\
\operatorname{Pr}(\text { Slope }<0)>0.99 \\
\text { Pseudo- } \mathrm{R}^{2}=0.26 \\
\mathrm{~N}=38\end{array}$ & $\begin{array}{c}\text { Slope }=0.04, \\
\text { Pr }(\text { Slope }>0)=0.73 \\
\text { Pseudo- } \mathrm{R}^{2}=0.0 \\
\mathrm{~N}=16\end{array}$ \\
\hline Plant-Bacteria & $\begin{array}{c}\text { Slope }=-0.47 \\
\text { Pr(Slope }<0)>0.99 \\
\text { Pseudo- }{ }^{2}=0.08 \\
N=115\end{array}$ & $\begin{array}{c}\text { Slope }=-0.35 \\
\operatorname{Pr}(\text { Slope }<0)=0.98 \\
\text { Pseudo- } \mathrm{R}^{2}=0.22 \\
\mathrm{~N}=30\end{array}$ \\
\hline
\end{tabular}


Table C3 - The mean log response ration (RR) and upper and lower 95\% Bayesian credible intervals for phototroph and heterotroph partners in the Plant-Fungi and Plant-Bacteria mutualisms calculated from studies in natural field settings versus controlled lab or glass-house environments. $\mathrm{N}$ indicates the number of experiments available for the calculations.

\begin{tabular}{|c|c|c|}
\hline Mutualism type & Field Studies & $\begin{array}{c}\text { Glass-house/Lab } \\
\text { studies }\end{array}$ \\
\hline $\begin{array}{l}\text { Plant-Fungi } \\
\text { (Phototroph) }\end{array}$ & $\begin{array}{c}\mathrm{RR}=0.81 \\
\mathrm{Cl}_{95}=0.52,1.10 \\
\mathrm{~N}=38\end{array}$ & $\begin{array}{c}\mathrm{RR}=0.61 \\
\mathrm{Cl}_{95}=0.47,0.76 \\
\mathrm{~N}=84\end{array}$ \\
\hline $\begin{array}{l}\text { Plant-Fungi } \\
\text { (Heterotroph) }\end{array}$ & $\begin{array}{c}\mathrm{RR}=-0.20 \\
\mathrm{Cl}_{95}=-0.46,0.067 \\
\mathrm{~N}=38\end{array}$ & $\begin{array}{c}\mathrm{RR}=-0.23 \\
\mathrm{Cl}_{95}=-0.38,-0.07 \\
\mathrm{~N}=84\end{array}$ \\
\hline $\begin{array}{l}\text { Plant-Bacteria } \\
\text { (Phototroph) }\end{array}$ & $\begin{array}{c}\mathrm{RR}=0.61 \\
\mathrm{Cl}_{95}=0.41,0.81\end{array}$ & $\begin{array}{c}\mathrm{RR}=0.11 \\
\mathrm{Cl}_{95}=0.07,0.15 \\
\mathrm{~N}=57\end{array}$ \\
\hline $\begin{array}{l}\text { Plant-Bacteria } \\
\text { (Heterotroph) }\end{array}$ & $\begin{array}{c}\mathrm{RR}=-0.30 \\
\mathrm{Cl}_{95}=-0.45,-0.15 \\
\mathrm{~N}=59\end{array}$ & $\begin{array}{c}\mathrm{RR}=-0.40 \\
\mathrm{Cl}_{95}=-0.70,-0.10 \\
\mathrm{~N}=57\end{array}$ \\
\hline
\end{tabular}


Figure C1 - Estimated effect sizes based on log response ratios from the subset of data used in our weighted analysis for comparison with the unweighted analysis (Figure 2 in the main text).

The phototroph and heterotroph for each mutualism type (blue=marine, green=terrestrial) and the overall median response across all studies as (A) pooled across nutrients or under (B) nitrogen,

(C) phosphorus, or (D) nitrogen+phosphorus enrichment. Thin and thick lines depict the $95 \%$ and $80 \%$ Bayesian credible intervals respectively. Numbers in parentheses denote the number of experiments used in each calculation.
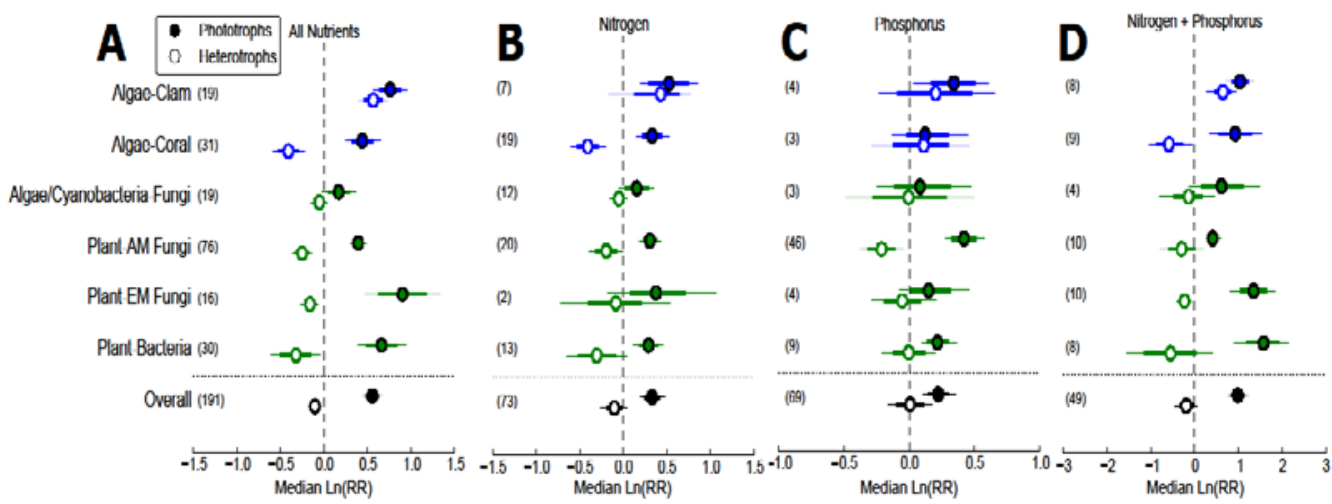
Figure C2 - Results from our weighted Bayesian Type II regression of heterotroph log response ratios against phototroph log response ratios for comparison with the unweighted model (Figure 3 in the main text). Panels are (A) Algae-Clams, (B) Algae-Coral, (C) Algae/Cyanobacteria-Fungi, (D) Plant-AM Fungi, (E) Plant-EM Fungi, and (F) Plant-Bacteria. Shaded area represents the 95\% Bayesian credible interval of the regression.
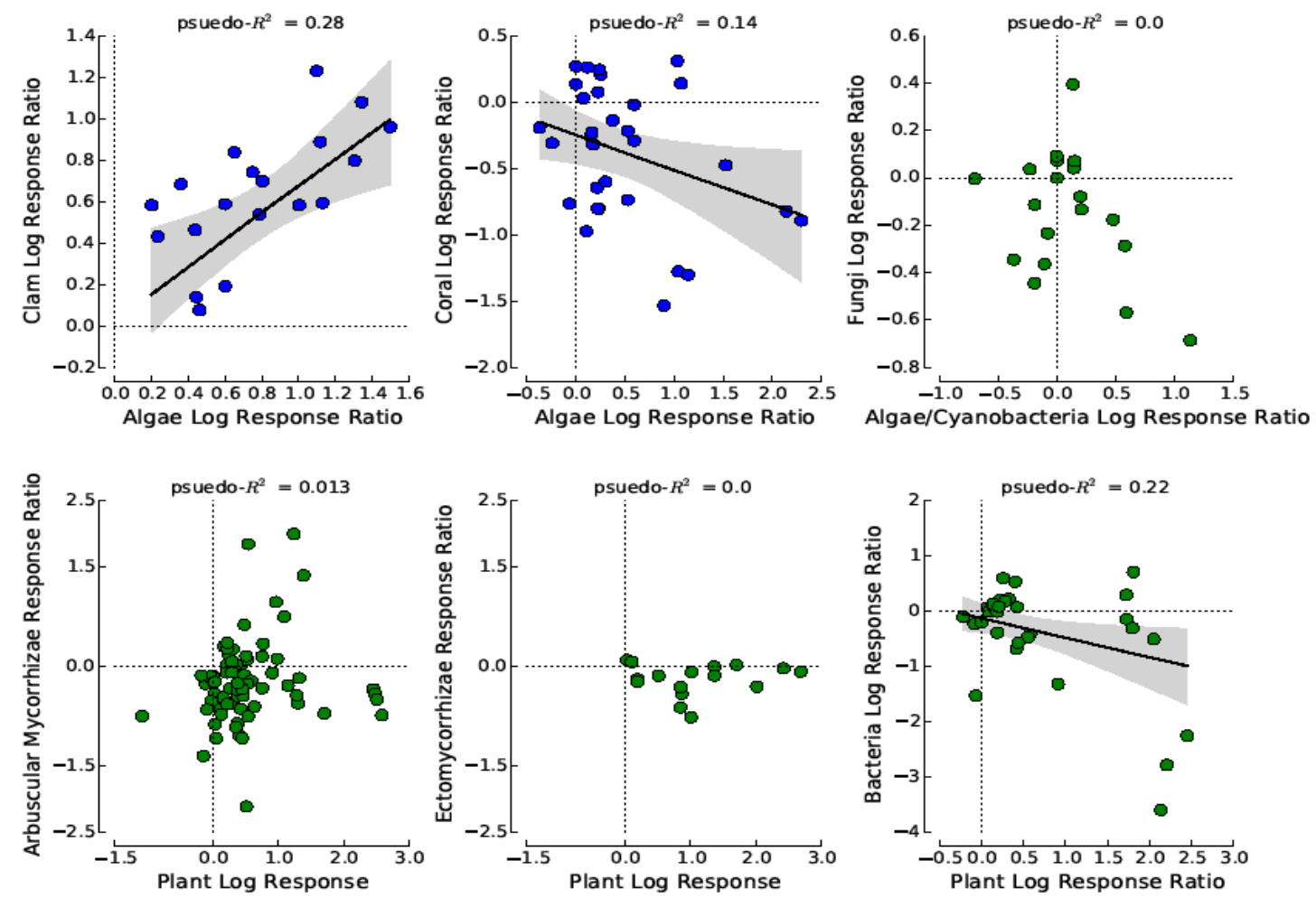
Figure C3 - Effect sizes plotted against total nitrogen and phosphorus enrichment magnitude. For each group, enrichment metrics are: (A) Algae-Clams: $\mu \mathrm{M}$; (B) Algae-Coral: $\mu \mathrm{M}$; (C)

Algae/Cyanobacteria-Fungi: $\mathrm{mg} \mathrm{m}^{-2}$; (D) Plant-AM Fungi: $\mathrm{mg} \mathrm{kg}^{-1}$; (E) Plant-EM Fungi: $\mathrm{mg} \mathrm{kg}^{-1}$ (F) Plant-Bacteria: $\mathrm{mg} \mathrm{m}^{-2}$. Note that no measurements were available to examine the effect of daily phosphorus enrichment on lichen.
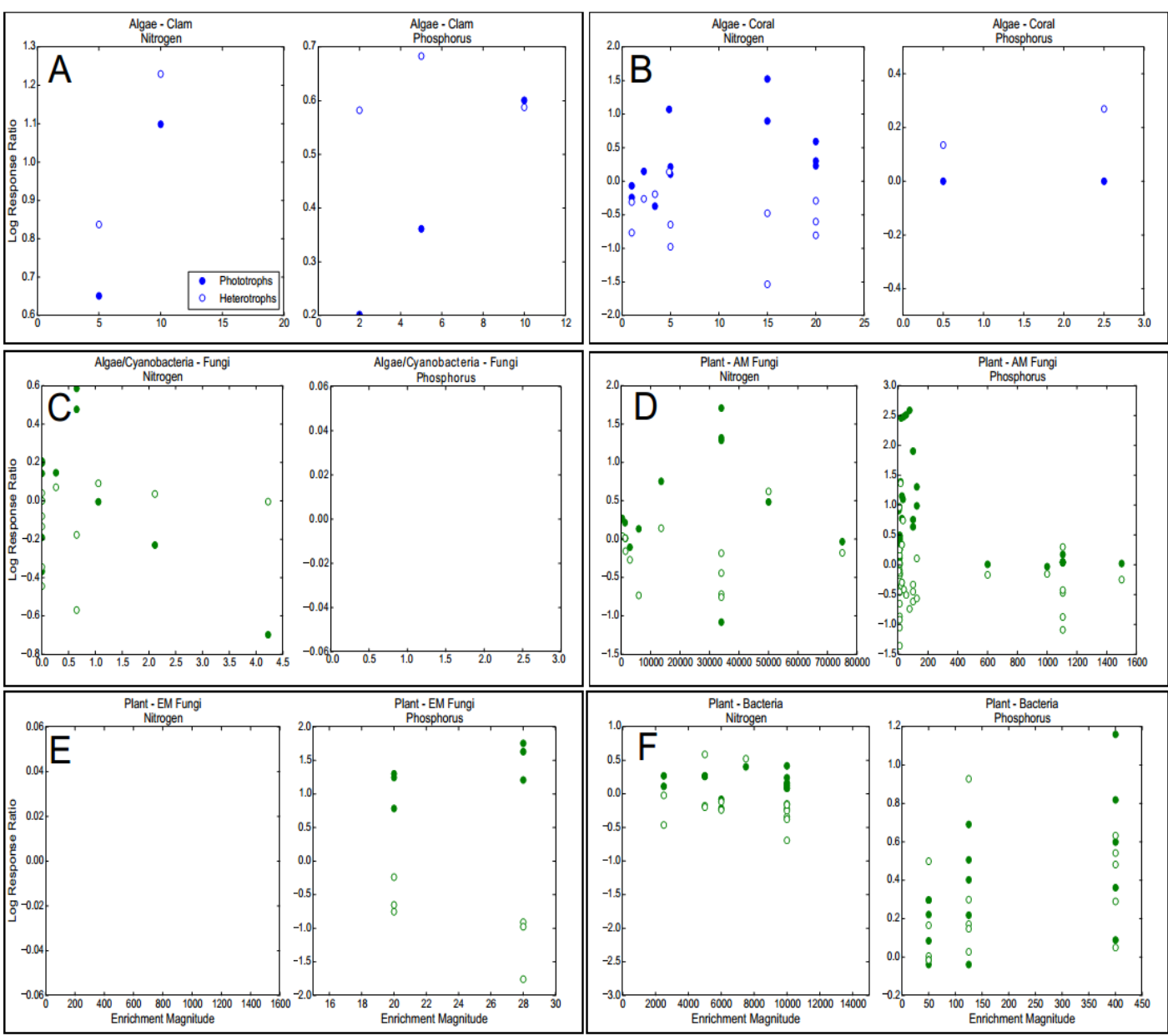
Figure C4 - Effect sizes plotted against total nitrogen and phosphorus enrichment magnitude. For each group, enrichment metrics are: (A) Algae-Clams: $\mu \mathrm{M}$; (B) Algae-Coral: $\mu \mathrm{M}$; (C)

Algae/Cyanobacteria-Fungi: $\mathrm{mg} \mathrm{m}^{-2}$; (D) Plant-AM Fungi: $\mathrm{mg} \mathrm{kg}^{-1}$; (E) Plant-EM Fungi: $\mathrm{mg} \mathrm{kg}^{-1}$ (F) Plant-Bacteria: $\mathrm{mg} \mathrm{m}^{-2}$. Note that no measurements were available to examine the effect of daily phosphorus enrichment on lichen.

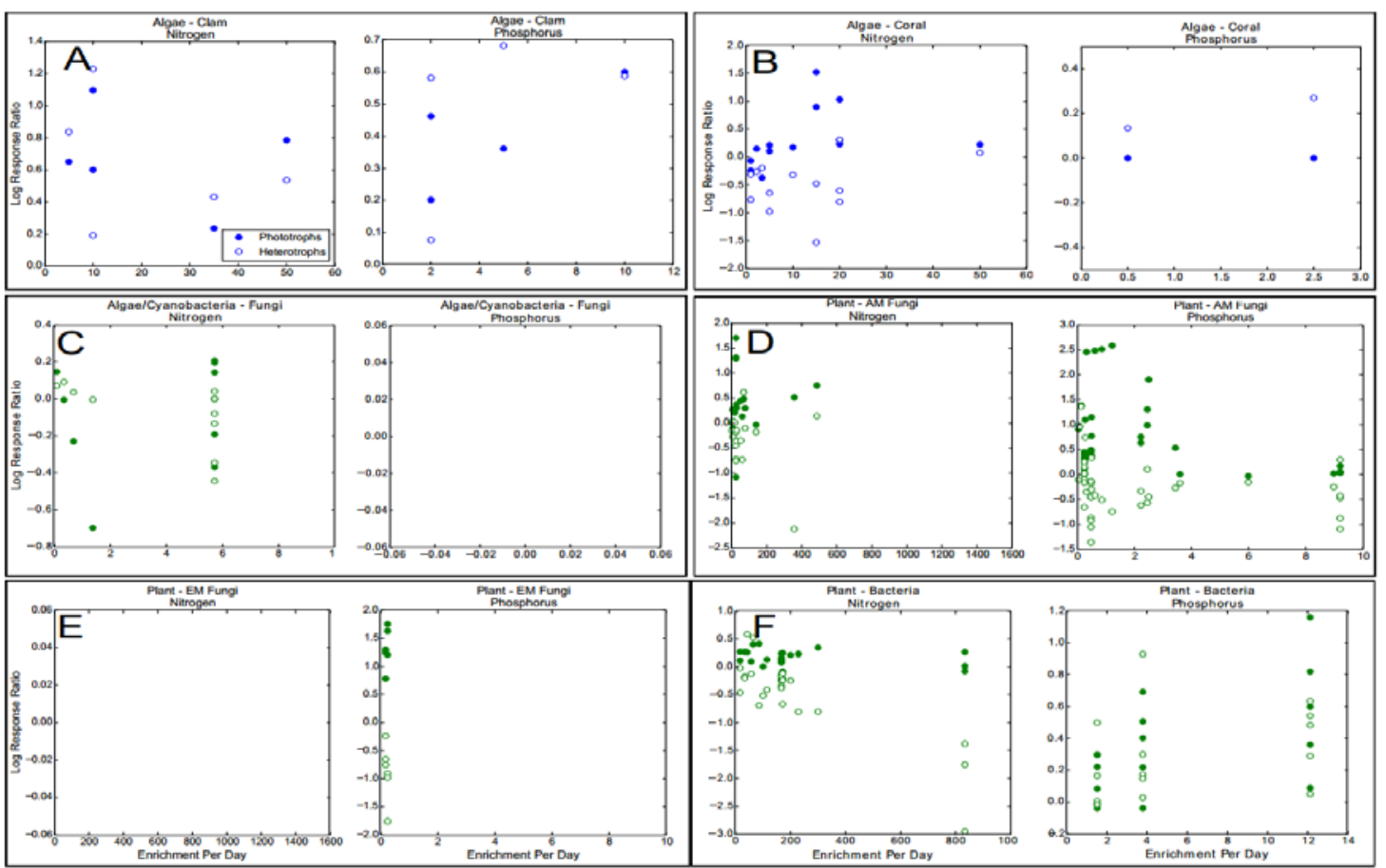


VITA

ANDREW A. SHANTZ

Born, Washington D.C,

2000-2005

B.A., Anthropology

University of Colorado, Boulder

Boulder, Colorado

2008-2010

M.S., Marine Sciences

Northeastern University

Boston, MA

2010-2016

Doctoral Candidate

Florida International University

Miami, Florida

\section{PUBLICATIONS}

Ladd, M.C., A.A. Shantz. In Press. Novel enemies or have we just been kept in the dark? Removing artificial shelters reveals a previously unknown predator of the bearded fireworm Hermodice carunculata. Frontiers in Ecology and Evolution.

Lemoine, N.P., A.A. Shantz. In Press. Warming induces nitrogen limitation of a generalist insect herbivore by increasing metabolic nitrogen demand. Ecological Entomology

Shantz, A.A., N.P. Lemoine, D.E. Burkepile (2016) Nutrient loading alters the performance of key nutrient exchange mutualisms. Ecology Letters 19:20-28

Shantz, A.A., M.C. Ladd, E. Schrack, D.E. Burkepile (2015) Fish-derived nutrient hotspots shape coral reef benthic communities. Ecological Applications 25:2142-2152

Stroud J.T., M.R. Bush, M.C. Ladd, R.J. Nowicki, A.A. Shantz, J. Sweatman (2015) Is a community still a community? Reviewing definitions of key terms in community ecology. Ecology and Evolution 5:4757-4765

Shantz, A.A., D.E. Burkepile (2014) Context-dependent effects of nutrient loading on the coralalgal mutualism. Ecology 95:1995-2005

Catano, L.B., A.A. Shantz, D.E. Burkepile (2014) Predation risk, competition, and territorial damselfishes as drivers of herbivore foraging on Caribbean coral reefs. Marine Ecology Progress Series 511:193-207.

Staaterman, E.R., A.A. Bhandiwad, P.M. Gravinese, P.M. Moeller, Z.C. Reichenbach, A.A. Shantz, D.S. Shiffman, L.T. Toth, A.M. Warneke, A.J. Gallagher (2014) Lights, camera, science: The utility and growing popularity of film festivals at scientific meetings. Ideas in Ecology and Evolution 7:11-16

Vega-Thurber, R., D.E. Burkepile, C. Fuchs, A.A. Shantz, R. McMinds \& J.R. Zaneveld (2014) Chronic nutrient enrichment increases prevalence and severity of coral disease and bleaching. Global Change Biology 20:544-554 
Burkepile, D.E., J.E. Allgeier, A.A. Shantz, C. Pritchard, N. Lemoine, L. Bhatti, C.A. Layman (2013) Nutrient supply from fishes facilitates macroalgae and suppresses corals in a Caribbean coral reef ecosystem. Scientific Reports, 3:1493, doi: 10.1038/srep01493

Vega-Thurber, R., D.E. Burkepile, A.M.S. Correa, A.A. Shantz, R.M. Welsh, C. Pritchard, S. Rosales (2012) Macroalgae decrease growth and alter microbial community structure of the reefbuilding coral Porites astreoides. PLOS ONE 7 doi:10.1371/journal.pone.0044246.

Shantz, A.A., A.C. Stier, J.A. Idjadi (2011) Coral density and predation affect growth of a reefbuilding coral. Coral Reefs 30:363-367 